\title{
ROBOTIC FLEXIBLE ENDOSCOPE
}

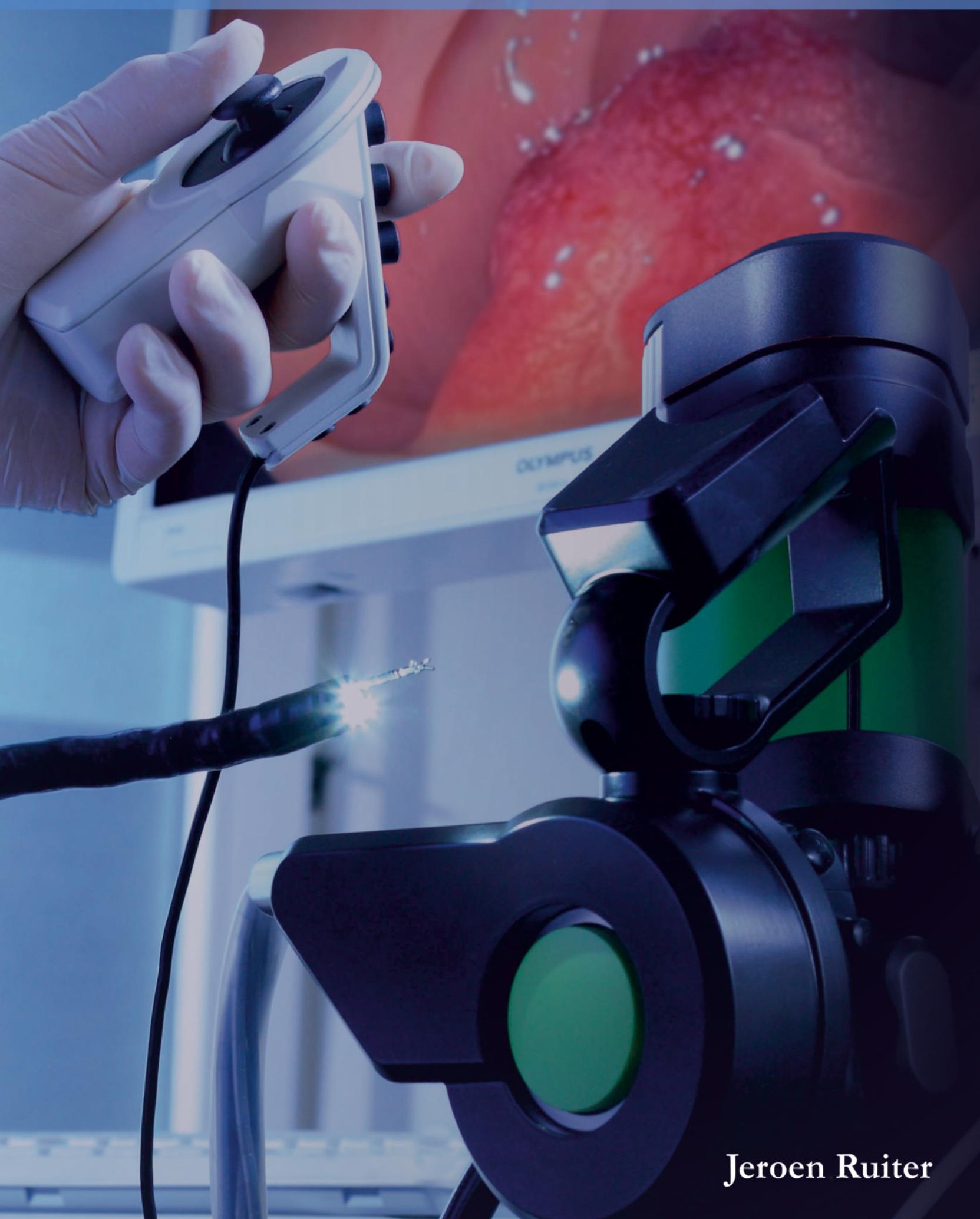




\title{
ROBOTIC FLEXIBLE ENDOSCOPE
}

\author{
Jeroen Ruiter
}


This research has been conducted within the TeleFLEX project at the Laboratory of Design, Production and Management, Department of Engineering Technology, University of Twente in strong collaboration with DEMCON, Enschede.

The research was funded by the Dutch Ministry of Economic Affairs and the Province of Overijssel, within the Pieken in de Delta (PIDON) initiative.

Flexible endoscopy equipment was provided by Olympus Corporation, Tokyo, Japan. The steerable instruments were provided by Karl Storz, Tuttlingen, Germany.

Cover photo and pictures clinical setting by Jan Schartman, Enschede Printed by Gildeprint, Enschede

ISBN 978-90-365-0291-7

DOI 10.3990/1.9789036502917

C2013 Jeroen Ruiter, Enschede, The Netherlands 


\title{
ROBOTIC FLEXIBLE ENDOSCOPE
}

\section{PROEFONTWERP}

\author{
ter verkrijging van \\ de graad van doctor aan de Universiteit Twente, \\ op gezag van de rector magnificus, \\ prof.dr. H. Brinksma, \\ volgens besluit van het College voor Promoties \\ in het openbaar te verdedigen \\ op vrijdag 6 september 2013 om 14.45 uur
}

door

Jeroen Gerard Ruiter

geboren op 24 november 1974

te Enschede 
Dit proefschrift is goedgekeurd door:

prof.dr.ir. F.J.A.M. van Houten, promotor prof.dr. I.A.M.J. Broeders, promotor dr.ir. M.C. van der Voort, assistent promotor dr.ir. G.M. Bonnema, assistent promotor 


\section{Dissertation committee}

\section{Chairman and Secretary}

prof.dr. F. Eising

University of Twente

\section{Promotors}

prof.dr.ir. F.J.A.M. van Houten

Design, Production, and Management University of Twente

prof.dr. I.A.M.J. Broeders

Minimal Invasive Surgery and Robotics University of Twente

\section{Assistant promotors}

dr.ir. M.C. van der Voort

Design, Production, and Management

University of Twente

dr.ir. G.M. Bonnema

Design, Production, and Management

University of Twente

\section{Opponents}

prof.dr.ir. R.H.M. Goossens

prof.dr. T. Tomiyama

prof.dr. B.L.A.M Weusten

prof.dr.ir. S. Stramigioli

prof.dr.ir. G.J. Verkerke

Applied Ergonomics and Design

Delft University of Technology

Life Cycle Engineering

Cranfield University

Innovative Gastrointestinal Endoscopy

University of Amsterdam

Robotics and Mechatronics

University of Twente

Biomedical Product Design

University of Twente 



\section{Voorwoord}

$\mathrm{Na}$ mijn studie Industrieel Ontwerpen in Delft heb ik nooit overwogen om te gaan promoveren. Sterker nog, promoveren was in mijn beleving een theoretische beschouwing met veel statistiek en weinig creativiteit. Terwijl mijn hart vooral bij praktische uitdagingen ligt. Toch ben ik er aan begonnen. De opdracht die me werd aangeboden bood juist veel ruimte voor creativiteit en moest resulteren in een werkend prototype. Ik heb het als een ongekende luxe ervaren om gedurende vier jaar en met een flink budget richting te mogen geven aan de ontwikkeling van een robotische flexibele endoscoop om een praktisch medisch probleem op te lossen. Onder andere het bijwonen van operaties, de brainstormsessies, het uitwerken van ontwerpen, het bouwen van prototypes en het testen met artsen heb ik als een leuke en leerzame tijd ervaren. Dat het laatste half jaar toch vooral in eenzame opsluiting is uitgevoerd, vergeet ik dan maar even.

Veel mensen hebben tijdens het traject een waardevolle rol gespeeld in het realiseren van de proefopstelling en het proefschrift. Allereerst wil ik het management van Demcon, Dennis en Peter, en de (voormalig) teamleiders Jan, Reinier en Chris bedanken voor het bieden van de mogelijkheid om in deeltijd te promoveren. De faciliteiten en vrijheid die me zijn geboden tijdens deze periode hebben zeker bijgedragen aan een soepel verloop.

Daarnaast wil ik de vakgroep Ontwerp, Productie en Management van de UT bedanken voor hun ondersteuning en de geboden faciliteiten. Mijn promotor Fred van Houten deelde gelukkig de visie dat de focus moest liggen op het fysieke eindproduct en minder op het boekje (al is het nog best dik geworden). Mascha van der Voort en Maarten Bonnema, mijn begeleiders, hebben een belangrijke bijdrage geleverd in de bewustwording dat wetenschap ook praktijkgericht kan zijn en tot een (wetenschappelijk verantwoord) product kan leiden. Ik waardeer het dat jullie zoveel tijd (ook vrije tijd) hebben vrijgemaakt voor het reviewen van mijn werk. Ik wil ook het secretariaat en Theo Krone bedanken voor hun belangrijke bijdrage.

Mijn andere promotor, Ivo Broeders, wil ik bedanken voor het delen van zijn medische visie, het mogen bijwonen van operaties en het in contact brengen met artsen en marktpartijen. Ik hoop dat de doorontwikkeling van het systeem succesvol is en dat we nog lang zullen samenwerken.

Gedurende een groot deel van mijn promotie heb ik onderdak gekregen bij de vakgroep Robotics and Mechatronics. Stefano bedankt voor de werkplek, de koffiekaart en je enthousiasme. Mijn kamergenoten Maarten, Michel en Rob bedankt voor de gezelligheid. Ook de ondersteuning van het secretariaat en de technici heb ik erg gewaardeerd.

Gedurende mijn promotie ben ik toch vooral Demcon werknemer gebleven. Naast de Demcon projecten die ik gedurende mijn promotie in deeltijd heb uitgevoerd, heb ik ook met veel medewerkers in dit project samengewerkt. Allereerst Leo bedankt voor je belangrijke rol in het realiseren van de prototypes en het creatief oplossen van de onvolkomenheden. Dat gaf veel rust in de toch altijd wat spannende realisatiefase. Daarnaast natuurlijk Tom, Han, Henri, Willem en Jeffrey bedankt voor jullie belangrijke bijdrage bij de prototyping. Ook heeft een grote groep engineers meegedacht over de ontwerpen en de uitwerking daarvan. Michel en Rob, onze samenwerking is begonnen als UT medewerkers en nu zijn jullie ook bij Demcon werkzaam. Jullie beheersen de disciplines waar ik weinig kaas van heb gegeten. Zonder jullie bijdrage op software- en elektrogebied zou het zeker geen werkend prototype zijn geworden. Michel ook bedankt voor het reviewen van dit proefschrift. Andere engineers die een belangrijke bijdrage hebben geleverd zijn Karel, Chris, Henk, Marco, Michiel, Jonathan, Martijn en Tonnie. Ik waardeer jullie inzet, 
flexibiliteit (en slechte endoscopie grappen). Anke en Henk bedankt voor het model staan tijdens de fotosessie. (Of heb ik nu verraden van wie die billen zijn?) Meerdere projectleiders zijn betrokken geweest bij het project. Bianca, Rini, Benno, Rik, Michiel en Job bedankt voor het stroomlijnen van het proces.

De studenten Kevin, Koen, Esther, Majorie, Gea, Ivor en Bart hebben een waardevolle bijdrage geleverd aan mijn onderzoek in de vorm van een stage of afstudeeropdracht. Kevin en Koen, leuk dat jullie nu ook bij Demcon werken. Esther, succes met de klinische evaluatie van het endoscopie project en ook wij zullen de komende jaren nog wel samenwerken.

Ook wil ik Olympus Nederland en Olympus Europa bedanken voor het beschikbaar stellen van endoscopie apparatuur en het delen van marktkennis. John van Wezel heeft daarin een belangrijke rol gespeeld. De firma Storz wil ik bedanken voor het beschikbaar stellen van de stuurbare instrumenten die in de opstelling zijn gebruikt.

Tijdens het onderzoek heb ik dankbaar gebruik gemaakt van de expertise van de artsen van het Meander Medisch Centrum, het UMCU, het AMC en van de artsen die deel uitmaakten van de gebruiksgroep van medisch experts. Bedankt voor jullie feedback. In het bijzonder wil ik Leon Moons bedanken voor zijn hulp bij het opzetten van de evaluatie van het systeem door medische experts in het UMCU.

Ook vrienden en familie hebben een belangrijke rol gehad in de voltooiing van dit promotieonderzoek. Vrienden, door het met mij vooral te hebben over fietsen, voetbal en andere belangrijke randzaken. Mijn familie door de getoonde interesse en de hulp in drukke tijden. Selma en Rob mooi dat jullie mijn paranimfen willen zijn. Ik ben benieuwd naar jullie technische kennis. Rob, bedankt voor de hulp bij de statistiek. Mijn ouders wil ik bedanken voor de interesse en ondersteuning gedurende het traject. Het doet me goed dat mijn vader voor zijn overlijden nog een groot deel van het uiteindelijke systeem heeft kunnen zien. Ma bedankt voor het bieden van een rustige werkplek gedurende het laatste half jaar en het in het gareel houden van Elise en Jesper. Papa zat dan wel wat veel naar zijn beeldscherm te turen, maar naar oma gaan maakte veel goed. Ook vonden de kinderen het wel interessant dat ik aan een echte robot werkte, maar ik betwijfel of ze net zo tevreden zijn over het eindresultaat als ik.

Tenslotte lieve Jojan, bedankt voor de steun en vrijheid die je me hebt gegeven tijdens mijn promotieonderzoek. De combinatie gezin, werk, sociaal leven en promotie is achteraf gezien best pittig geweest, maar samen hebben we het volbracht. 


\section{Samenvatting}

In flexibele endoscopie worden het spijsverteringskanaal, de voortplantingsorganen en de luchtwegen geïnspecteerd met behulp van een flexibele slang met een camera in de tip. De arts kijkt rond door met de linkerhand twee concentrisch geplaatste navigatiewielen op de flexibele endoscoop te roteren, zodat de tip van de endoscoop buigt. De slang wordt met de rechterhand ingebracht. Door de positie en de geometrie van de navigatiewielen wordt de bediening van de tip echter vaak met twee handen uitgevoerd en is een assistent nodig om de slang te manipuleren. De nadelen van deze workflow zijn dat de arts krachtterugkoppeling mist ten aanzien van weefsel en endoscoop interactie, communicatiefouten gemakkelijk optreden, en twee personen nodig zijn om een relatief eenvoudige diagnostische procedure uit te voeren.

Voor het uitvoeren van eenvoudige ingrepen, zoals de resectie van kleine poliepen, kan een instrument in de endoscoop worden gestoken. De beschikbare endoscopen en instrumenten hebben een beperkte bewegingsvrijheid om therapie uit te voeren. Moeilijke procedures, zoals de verwijdering van een grote tumor, worden alleen door zeer ervaren artsen uitgevoerd die assistentie krijgen bij het bedienen van de beschikbare vrijheidsgraden van de endoscoop en de instrumenten.

'Natural Orifice Surgery' (chirurgie via een natuurlijke opening) integreert de expertise van flexibele endoscopie met sleutelgatchirurgie. Uitwendige incisies kunnen worden voorkomen door het lichaam via een natuurlijke opening binnen te gaan. Chirurgie kan binnen het kanaal (endoluminaal) of in de buik-of borstholte worden uitgevoerd door het toegangskanaal te perforeren (transluminaal). De experimentele interventieplatformen die op dit moment worden gebruikt lijken op conventionele endoscopen. Meerdere werkkanalen zijn echter beschikbaar die geschikt zijn voor stuurbare instrumenten. Naast axiale translatie en rotatie bekend van conventionele instrumenten, kan de tip van stuurbare instrumenten buigen om bimanuele acties uit te voeren, zoals het gelijktijdig liften van weefsel en het wegsnijden van een tumor. Het bedienen van de huidige interventieplatformen vereist twee tot vier ervaren endoscopisten die nauw moeten samenwerken. Gebruik van de technologie is nog niet voldoende kosteneffectief, veilig en gebruiksvriendelijk en wordt alleen getest in experimentele settingen.

Naar verwachting zal het aantal flexibele endoscopische procedures voor zowel diagnose als therapie stijgen. Het succes van deze trend is afhankelijk van de beschikbaarheid van gebruiksvriendelijke instrumenten. Robottechnologie heeft de potentie om de vaardigheid van artsen te verbeteren in het bedienen van flexibele endoscopen en instrumenten. Een belangrijke reden is dat de user interface en de instrumenten mechanisch worden ontkoppeld en dat computerintelligentie wordt toegevoegd. Daardoor kunnen bijvoorbeeld intuitieve handbewegingen van de arts worden gekoppeld aan nauwkeurige bewegingen van de instrumenten.

Dit proefschrift beschrijft de ontwikkeling en evaluatie van een robotische flexibele endoscoop waarmee een arts op een intuïtieve en gebruiksvriendelijke manier diagnostische, bestaande therapeutische en experimentele therapeutische (Natural Orifice Surgery) procedures kan uitvoeren. Medische eisen zijn aan technische mogelijkheden gekoppeld om een systeem te ontwikkelen dat past bij zowel de huidige als de verwachte toekomstige klinische infrastructuur en werkwijzen. Met dit systeem kunnen artsen klinische procedures effectief, efficiënt en naar tevredenheid uitvoeren. De robot modules worden gekoppeld aan standaard apparatuur om hoge investeringskosten te voorkomen en om de huidige sterke 
eigenschappen van endoscopen te behouden. Door de modulaire setup kan het systeem aangepast worden aan de klinische eisen van een specifieke procedure.

Binnen het project werd een 'User-centred System Design' aanpak ontwikkeld om de voorkeuren en capaciteiten van eindgebruikers om te zetten in concepten voor een robotische flexibele endoscoop. Toepassing van deze aanpak resulteerde in de definitie van drie modules:

- Robotische stuurmodule voor diagnostische procedures (Figuur 1, links)

- Robotische slangmanipulatie module voor bestaande therapie (Figuur 1, midden)

- Robotische instrumentmanipulatie module voor experimentele therapie (Figuur 1, rechts)

In dit proefschrift wordt voor elk van deze modules ingegaan op de stand van de techniek, de huidige gebruiksproblemen, de ontwerpoverwegingen, de fysieke realisatie, en de gebruiksevaluaties.
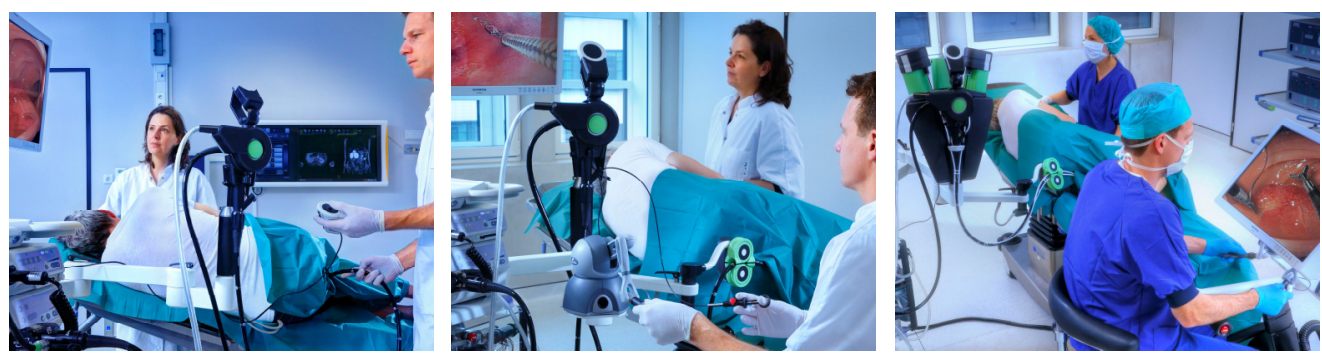

Figuur 1 Robotica voor diagnose (links), bestaande therapie (midden), en experimentele therapie (rechts)

\section{Robotische stuurmodule - diagnostische procedures}

De robotische stuurmodule verbetert de camerabesturing van traditionele endoscopen. Een compacte en lichte aandrijfunit is met behulp van een reinigbare interface unit gekoppeld aan de navigatiewielen. Een afstandsbediening wordt gebruikt om de camera van de endoscoop met één hand te besturen, terwijl de andere hand de slang manipuleert. De robotische endoscoop kan door de arts worden vastgehouden of op een zwenkarm worden geplaatst. Naast het sturen van de tip zijn alle andere functies van een traditionele endoscoop in de setup geïntegreerd en eenvoudig te bedienen.

Een experiment met beginners is uitgevoerd om de gebruiksvriendelijkheid (effectiviteit, efficiëntie en tevredenheid) van de robot setup in navigatietaken te beoordelen. De testresultaten lieten zien dat robotische besturing sneller, gemakkelijker, intuïtief, comfortabel en leuk is in vergelijking met conventionele besturing, terwijl de effectiviteit niet nadelig werd beïnvloed. Robotische besturing had de voorkeur van 23 van de 24 deelnemers.

\section{Robotische slang manipulatie module - bestaande therapeutische procedures}

De robotische slangmanipulatie module drijft de rotatie en translatie van de endoscoopslang aan. Het wordt gebruikt in combinatie met de robotische stuurmodule om alle stappen in de bestaande therapie te ondersteunen. Beide modules worden door één hand met een joystick bediend. De andere hand is beschikbaar om een instrument handmatig te bedienen. De belangrijkste ontwerpinspanning van de robotische slangmanipulatie module was gericht op de realisatie van een klein, betrouwbaar en gemakkelijk te reinigen aandrijfmechanisme, dat tevens geschikt is voor een snelle (ont)koppeling van de endoscoop tijdens de procedure. 
Uit gebruiksonderzoeken met beginners in gesimuleerde klinische therapie bleek dat robotische endoscoopbediening met één hand de efficiëntie en tevredenheid bij gebruikers verhoogt. Deelnemers waren ongeveer twee keer zo snel met de robot-opstelling dan met de conventionele endoscoopbediening. Tevens was de fysieke en mentale belasting significant lager. Alle 12 deelnemers gaven de voorkeur aan de robotische flexibele endoscoop. De intuitieve besturing, de nauwkeurigheid, het gevoel van controle en de eenpersoons setup werden zeer gewaardeerd.

Dezelfde testen zijn ook uitgevoerd met klinische experts. Gastro-enterologen waren ongeveer 2,5 keer sneller met de conventionele opstelling en ook de fysieke en mentale belasting was veel lager met de huidige werkwijze. Met uitzondering van één arts gaven de deelnemers de voorkeur aan de huidige manier van endoscoop tip en slang sturing, omdat zij het meest vertrouwd zijn met die methode. Ondanks de resultaten in het voordeel van de conventionele opstelling, waren artsen enthousiast over de potentiële toegevoegde waarde van robotische bediening in nauwkeurige en moeilijke taken. Bovendien schatten de artsen in dat het werken met de robotische setup zeer snel aangeleerd kan worden.

\section{Robotische instrument manipulatie module - experimentele therapeutische procedures}

De instrumentmanipulatie module is ontwikkeld om stuurbare instrumenten te bedienen. De grootste uitdaging was om een compacte aandrijfmodule te realiseren met 16 vrijheidsgraden, die dicht bij de patiënt kan worden gepositioneerd, die geschikt is voor steriel gebruik bij transluminale procedures en die eenvoudige uitwisseling van instrumenten mogelijk maakt. Wanneer de instrumentmanipulatie module wordt gecombineerd met de stuurmodule en de slangmanipulatie module, is een arts in staat om zelfstandig geavanceerde bimanuele handelingen uit te voeren. Vanwege het grote aantal vrijheidsgraden dat bediend moet worden, is een ergonomische bedieningsconsole met geoptimaliseerde oog-hand coördinatie ontwikkeld. Binnen deze console kunnen lichaamsondersteuningen, joysticks en de monitor worden ingesteld naar persoonlijke voorkeur.

De gebruiksvriendelijkheid van de volledige robotische flexibele endoscoop werd eerst getest met beginners. De uit te voeren taken vroegen om gecoördineerde manipulatie van de endoscoop en twee stuurbare instrumenten. De nauwkeurigheid en snelheid waarmee de stuurbare instrumenten bediend konden worden, werden door de meeste deelnemers als onvoldoende beoordeeld. Desondanks waren acht van de negen deelnemers in staat om zelfstandig de geavanceerde taken met succes te voltooien. Dit betekent dat de robotische flexibele endoscoop toegevoegde waarde heeft, aangezien met de huidige technologie deze taken niet kunnen worden uitgevoerd.

Experts (gastro-enterologen) hadden moeite met het bedienen van de robotische flexibele endoscoop met twee stuurbare instrumenten door bewegingsvertragingen, parasitaire bewegingen en de beschikbaarheid van stuurbare instrumenten met slechts één buigrichting. Ze verwachten echter dat hun behendigheid met het systeem door oefening snel zal toenemen. Volgens artsen zijn stuurbare instrumenten vooral van toegevoegde waarde bij moeilijke chirurgische taken waarbij één instrument het operatiegebied blootlegt, terwijl het andere instrument de interventie uitvoert; taken die niet uitvoerbaar zijn met bestaande flexibele instrumenten. Met de toepassing van op camerabeelden gebaseerde besturingsalgoritmes wordt verwacht dat de prestaties in de toekomst aanzienlijk zullen verbeteren.

De belangrijkste focus van het gepresenteerde onderzoek was gericht op de gebruiksvriendelijkheid van de aansturing van alle vrijheidsgraden van de endoscoop en de instrumenten. Uiteindelijk is een volledig functioneel systeem gerealiseerd dat is voorbereid 
op de klinische praktijk doordat rekening is gehouden met factoren als veiligheid, reiniging en gemakkelijke plaatsing dichtbij de patiënt. In het algemeen wordt de robotische flexibele endoscoop voor diagnostische, bestaande therapeutische en experimentele therapeutische procedures zeer gewaardeerd door deelnemers aan de experimenten. Beginners zijn enthousiast over het gemak waarmee de vrijheidsgraden kunnen worden bediend, terwijl experts de klinische mogelijkheden van robotische aansturing zien. Met het volledig functionele systeem wordt de intuitiviteit en gebruiksvriendelijkheid van de bediening van zowel bestaande endoscopieapparatuur als experimentele interventieplatformen met stuurbare instrumenten direct verbeterd voor beginners, maar moet het effect van de leercurve bij ervaren artsen verder onderzocht worden. Voor een goede evaluatie moeten de nauwkeurigheid en snelheid van instrumentbewegingen worden verbeterd en is verdere klinische validatie noodzakelijk. Geconcludeerd wordt dat het onderhavige werk een solide basis vormt voor toekomstige ontwikkelingen die zullen resulteren in een robotische flexibele endoscoop voor klinisch gebruik die de huidige praktijk verbetert en de klinische mogelijkheden van flexibele endoscopie uitbreidt. 


\section{Summary}

In flexible endoscopy the gastrointestinal, reproductive and respiratory tracts are diagnosed with a flexible shaft with a camera at the distal tip. To inspect the tracts the physician bends the tip by left-handed rotation of two concentric navigation wheels on the flexible endoscope. The right hand introduces the shaft into the patient. Because of the position and geometry of the navigation wheels the physician often uses both hands for tip steering and an assistant is required to manipulate the shaft. The drawbacks of this workflow are that the physician lacks force feedback on tissue and endoscope interaction, communication errors easily occur, and two persons are required to perform a relatively simple diagnostic procedure.

To perform simple interventions, such as resection of small polyps, an instrument can be inserted in the flexible endoscope. Current available endoscopes and instruments have limited capacity to execute therapy that requires advanced maneuverability. Difficult procedures, such as resection of a large tumor, are only performed by very skilled physicians who need assistance to control all degrees of freedom (movements) of the endoscope and the instrument(s).

Natural orifice surgery integrates the expertise of flexible endoscopy with laparoscopic surgery. External incisions can be prevented by using a natural orifice to enter the body. Surgery can be performed within the lumen (endoluminal procedures) or in the abdominal or thoracic cavity by perforating the lumen (transluminal procedures). The experimental endoscopic intervention platforms currently tested are comparable to traditional endoscopes. Multiple working channels are available that are suitable for steerable instruments. Besides axial translation and rotation known from conventional instruments, the tip of steerable instruments can bend to perform bimanual actions like simultaneous lifting tissue and dissecting a lesion. The operation of currently known endoscopic intervention platforms requires two up to four experienced endoscopists who have to cooperate closely. The technology is not ready yet for cost effective, safe, and user-friendly use and is only tested in experimental settings.

The number of flexible endoscopy procedures is expected to increase for both diagnosis and therapy. However, the success of this trend is dependent on the availability of userfriendly endoscopic equipment. Robotic technology has the potential to improve the dexterity of physicians in manipulating flexible endoscopes and instruments. A key factor is that user interface and tools are mechanically decoupled and computer intelligence is integrated, which for instance would allow the coupling of intuitive hand movements by the physician with the precise movements of the instruments.

This thesis describes the development and evaluation of a robotic flexible endoscope that allows a single physician to perform diagnosis, existing therapy, and experimental therapy (natural orifice surgery) in an intuitive and user-friendly way. Medical demands are linked to technical opportunities to create a system that fits the current as well as the anticipated future clinical infrastructure and workflow. This system allows users to perform clinical procedures in an effective, efficient, and satisfying way. The robotic modules interact with standard available equipment to prevent high investment costs and to preserve current endoscope qualities. The modular system setup enables customization to the clinical requirements of a specific procedure.

A user-centred system design approach is developed within this project to convert end user preferences and capabilities into robotic flexible endoscope concepts. Application of the approach resulted in the definition of three modules: 
- Robotic steering module for diagnostic procedures (Figure 1, left)

- Robotic shaft manipulation module for existing therapy (Figure 1, middle)

- Robotic instrument manipulation module for experimental therapy (Figure 1, right)

For each of these modules this thesis discusses the state of the art, current user interface problems, design considerations, the physical realization, and the usability tests.
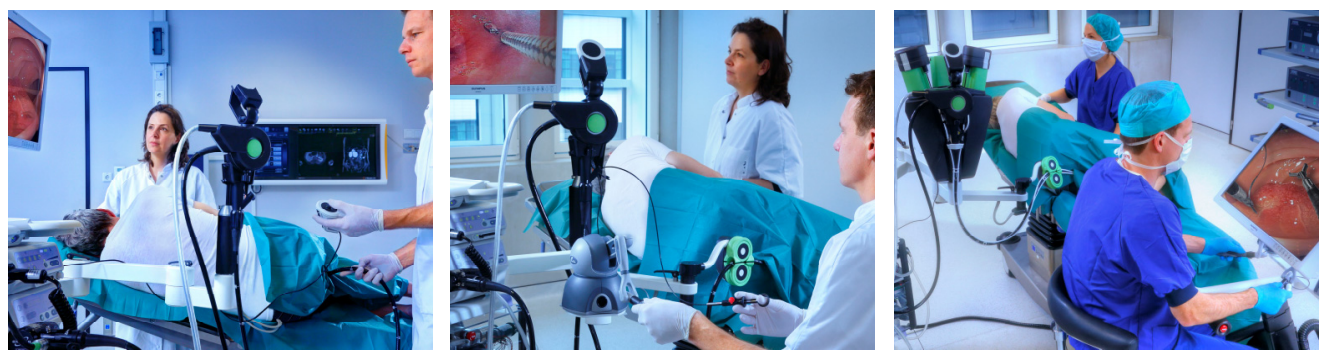

Figure 1 Robotics for diagnosis (left), existing therapy (middle), and experimental therapy (right)

\section{Robotic steering module - diagnostic procedures}

The robotic steering module improves camera steering of traditional endoscopes. A compact and lightweight drive unit is coupled to the navigation wheels by means of a disposable interface unit. A dedicated remote control is used to steer the tip of the endoscope with one hand, while the other hand manipulates the shaft. The robotic endoscope can be carried by the physician or positioned on a swivel arm. Besides steering, all other functions of a traditional endoscope are integrated.

An experiment with novices was conducted to judge the usability (effectiveness, efficiency, and satisfaction) of the robotic setup in navigational tasks. The test results showed that robotic steering is faster and more easy, intuitive, comfortable, and fun compared with conventional steering, while the effectiveness was not affected. Robotic as opposed to conventional steering was the preferred method for 23 out of 24 participants.

\section{Robotic shaft manipulation module - existing therapeutic procedures}

The robotic shaft manipulation module actuates shaft rotation and translation of the endoscope. The robotic shaft manipulation module is used in conjunction with the robotic steering module to assist in all steps of existing therapy. Both modules are operated singlehandedly with one multi-degree-of-freedom controller. This allows an instrument to be manually operated with the other hand. The main design effort of the robotic shaft manipulation module has been directed to the actuation mechanism that needs to be small, reliable, easy to clean, and which can be quickly (de)coupled to the endoscope during the procedure.

Usability tests with novices in simulated clinical therapy showed that single-handed robotic endoscope control increases efficiency and satisfaction. Participants were about twice as fast with the robotic setup compared to conventional control, and the physical and mental workload was significantly lower. All 12 participants preferred the robotic flexible endoscope. Its intuitiveness, its accuracy, the feeling of being in control, and the single person setup were highly appreciated.

The same tests were also conducted with clinical experts. Gastroenterologists were about 2.5 times faster with the conventional setup and its workload scoring was much lower. Except for one, all physicians preferred the current way of endoscope tip and shaft steering, because they are most familiar with that method. Despite the results in favour of the 
conventional setup, physicians were enthusiastic about the potential added value of robotic control in precise and difficult manipulation tasks. In addition, the physicians estimated that the learning curve of the robotic setup will be steep.

\section{Robotic instrument manipulation module - experimental therapeutic procedures}

The robotic instrument manipulation module is developed to control steerable instruments with multiple degrees of freedom. The major challenge was to create a compact module that actuates 16 degrees of freedom, that allows easy exchange of instruments, that can be positioned close to the patient, and that is suitable for sterile use in case of transluminal procedures. When the instrument manipulation module is combined with the steering and shaft manipulation modules, a single physician is able to perform advanced bimanual natural orifice surgery. Given the high number of degrees of freedom to operate, an ergonomic working console with optimized eye-hand coordination was developed. Body supports, input devices, and monitor can be set to personal preferences.

Usability of the complete robotic setup was first tested with novices. Tasks were performed that required coordinated manipulation of the endoscope and two steerable instruments. The accuracy and speed of controlling the steerable instruments were judged by most participants as being insufficient at this time. However, eight out of nine participants successfully completed the tasks. This indicates that the robotic flexible endoscope has added value, because with current technology these tasks cannot be executed.

Experts (gastroenterologists) had trouble in handling the robotic flexible endoscope with two steerable instruments, because of parasitic movements, response delays, and the limitation of only one bending direction of the steerable instruments. However, they expect that their dexterity with the robotic system will rapidly increase by practicing. Potential benefits of steerable instruments were identified by physicians for difficult surgical tasks in which one instrument exposes the operating field, while the other instrument performs the intervention; tasks that are not feasible with existing flexible tools. Future implementation of vision-based control algorithms can considerably improve performance.

The main focus of the research was directed to the usability of handling all degrees of freedom of the endoscope and the instruments. A fully functional system was realized that is prepared for clinical practice because of the integration of safety and cleanability aspects, and its easy positioning close to the patient. In general, feedback on the experimental setups indicate that the robotic flexible endoscope for diagnosis, existing therapy, as well as experimental therapy is highly appreciated by novice and expert participants. Novices are enthusiastic about the ease with which the degrees of freedom are operated, whereas experts value the clinical opportunities that robotic control provides. A system was realized that enhances for novices the intuitiveness and usability of handling both existing endoscopy equipment and experimental intervention platforms with steerable instruments, but the effect of the learning curve of experienced physicians needs to be further researched. For a good evaluation of the system the accuracy and speed of instrument movements need to be improved and further clinical validation is needed. It is concluded that the outcomes of the current project form a solid base for future developments that will result in a robotic flexible endoscope for clinical use that improves current practice and that expands the clinical capabilities of flexible endoscopy. 



\section{Glossary}

argon plasma coagulation

bariatric surgery

cecum

cholecystectomy

colonoscopy

degrees of freedom (DOF)

endoluminal

endoscopic mucosal resection (EMR)

endoscopic submucosal dissection (ESD)

endoscopic retrograde

cholangiopancreatography (ERCP)

gastroenterologist

gastroesophageal reflux disease (GERD)

gastrojejunostomy

haptic guidance

intuitive

laparoscopic surgery

mucosa

mucosectomy

myotomy non-contact electro-coagulation by ionised argon gas, mainly performed to stop bleeding

a variety of procedures performed on people who are obese, like reducing the size of the stomach with a gastric band

pouch at the beginning of the large intestine the surgical removal of the gallbladder visual inspection of the interior of the colon with a flexible shaft inserted through the rectum

independent displacements and/or rotations that specify the orientation of a body or system passing though the lumen (hollow tubular organ) the piecemeal dissection of large lesions in the gastrointestinal tract

the en bloc dissection of large lesions in the gastrointestinal tract

technique to treat problems of the bile and pancreatic ducts

physician that performs flexible endoscopy in the digestive tract

mucosal damage caused by stomach acid coming up from the stomach into the esophagus

a surgical procedure that directly connects the stomach to the jejunum to bypass the duodenum technique in which a haptic device guides the operator through a desired movement

familiar / use of readily transferred, existing skills a surgical technique in which operations in the abdomen are performed with rigid instruments through small incisions inner lining of body cavities and passages endoscopic removal of benign and early malignant lesions in the gastrointestinal tract

dissection of muscles 
natural orifice transluminal endoscopic surgery (NOTES)

proprioceptive feedback

polypectomy

splenectomy

telemanipulation

torque steering

transluminal

triangulation

tubal ligation

visual servoing an experimental surgical technique whereby abdominal and thoracic operations can be performed with a flexible endoscope passed through a natural orifice (mouth, anus, ureter, or vagina) then through an internal incision in the digestive tract, bladder, or vagina, thus avoiding any external incisions

sense of the relative position of neighbouring parts of the body and the strength of effort being employed in movement

the removal of a polyp

a surgical procedure that partially or completely removes the spleen

controlling a device through handles or switches, to perform manual operations while separated from the site of work

endoscope tip steering, in which the large navigation wheel is in use, the small wheel is locked in neutral position, and the endoscope shaft is torqued to compensate for the loss of motion of locking the small wheel

passing through an internal incision in the lumen

The instruments independently reach the operating field from two sides with vision in between. The angle between camera and instruments is approximately $30^{\circ}$ and their working axes coincide in one point. It improves depth perception and accessibility of tissue and organs.

a surgical procedure for sterilization in which a woman's fallopian tubes are occluded

vision-based robotic control 


\section{Contents}

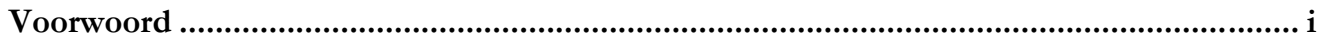

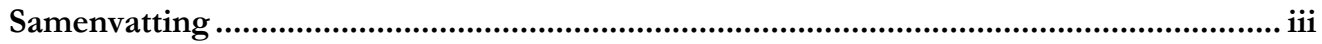

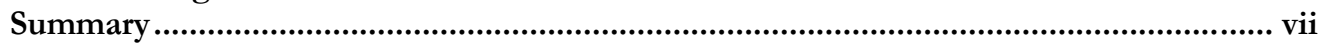

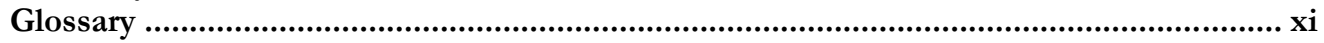

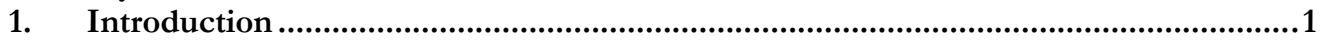

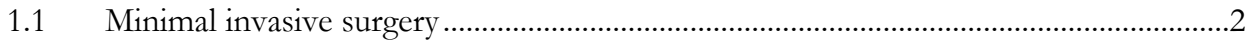

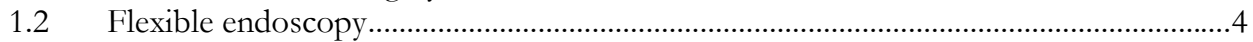

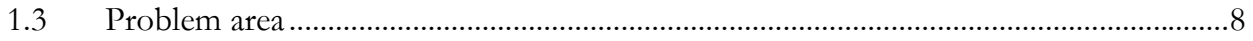

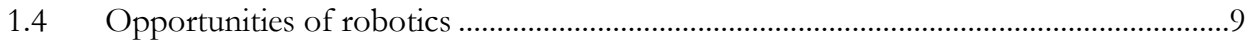

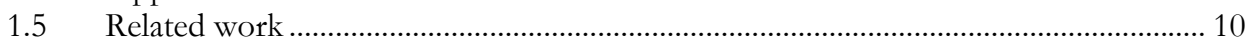

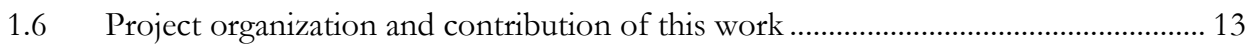

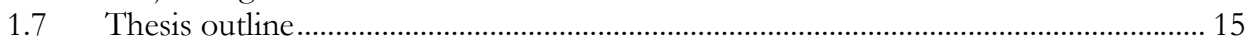

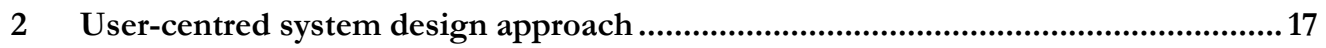

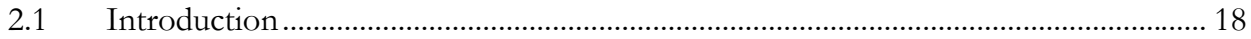

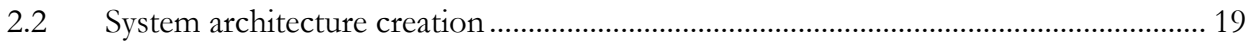

2.2.1 Step 1 - Focus development ..................................................................... 21

2.2.2 Step 2 - Create workflow of current system application................................ 21

2.2.3 Step 3 - Determine problem definition and design goal............................... 23

2.2.4 Step 4 - Create workflow of future system application................................. 23

2.2.5 Step 5 - Create functional overview................................................................ 24

2.2.6 Step 6 - Create physical overview …………..................................................... 26

2.2.7 Step 7 - Decompose physical overview into manageable modules .............. 28

2.2.8 Evaluation of the system architecture by stakeholders ................................ 30

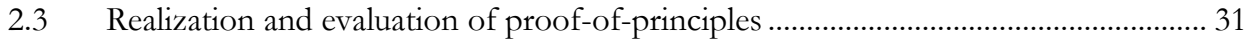

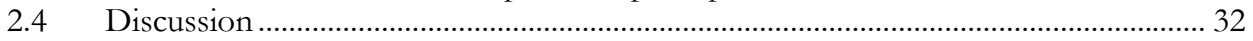

3 Robotic steering module - diagnostic procedures ..............................................33

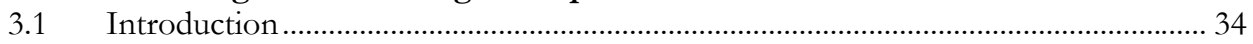

3.2 Related work ................................................................................................... 35

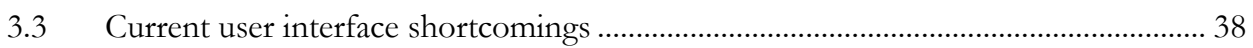

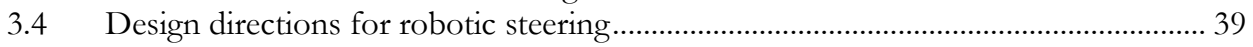

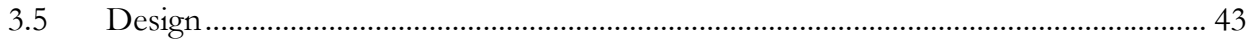

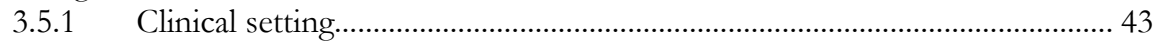

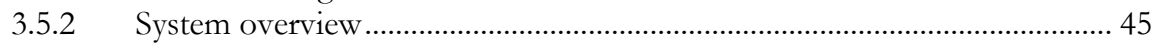

3.5.3 Drive system navigation wheels ……….......................................................... 46

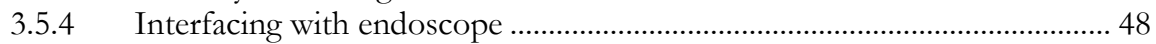

3.5.5 Suspension and positioning ........................................................................ 49

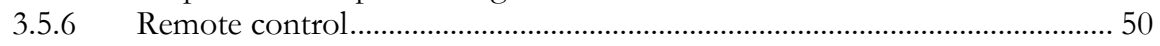

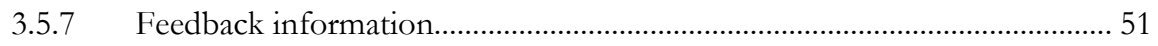

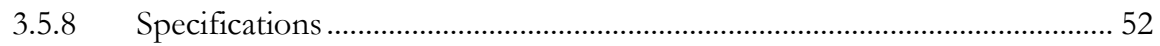

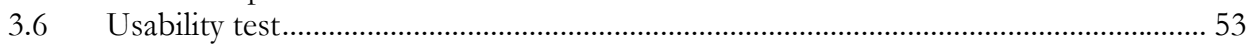

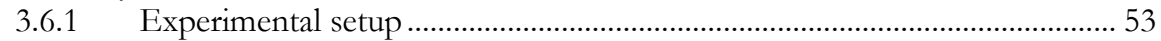

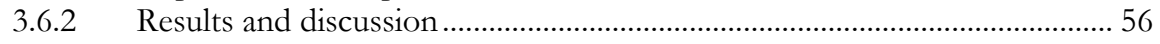

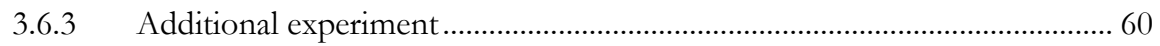

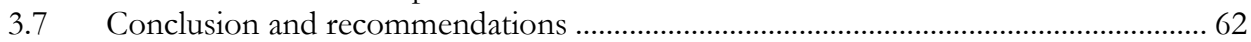

4 Robotic shaft manipulation module - existing therapeutic procedures ...................65

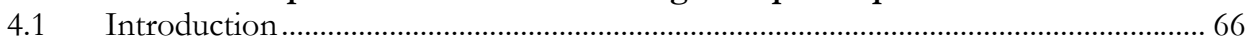

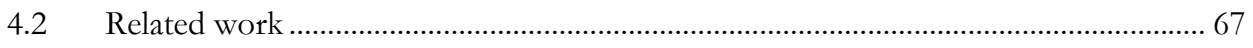

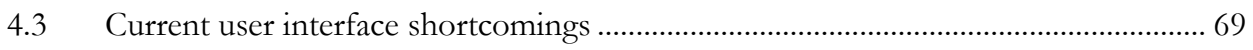


4.4 Design directions for robotic shaft manipulation.........................................................

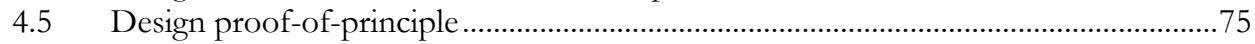

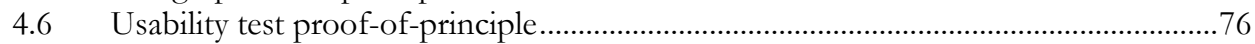

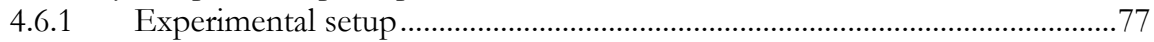

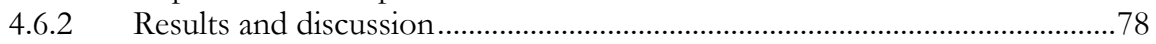

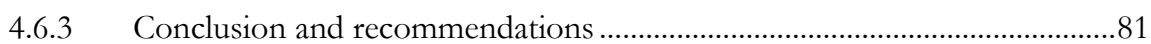

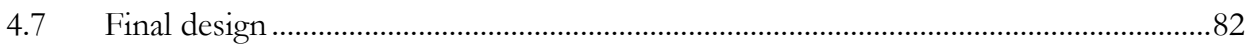

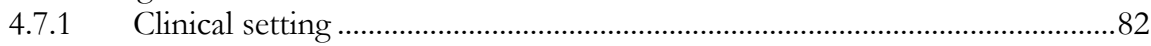

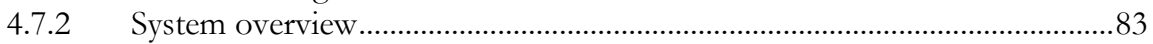

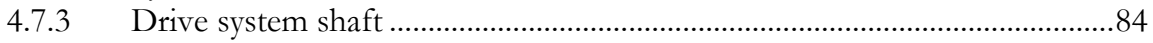

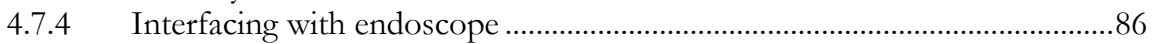

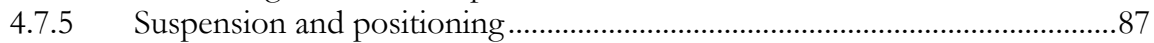

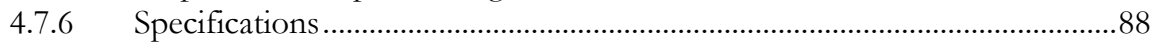

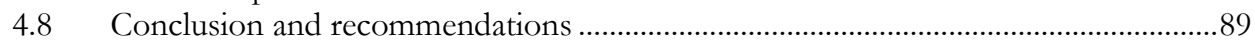

5 Robotic instrument manipulation module - experimental therapeutic procedures..91

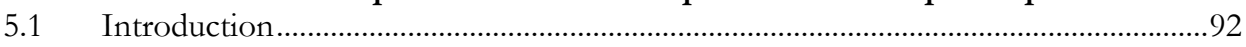

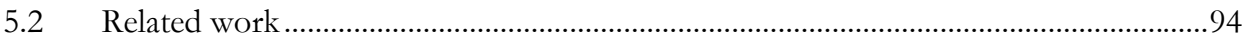

5.3 Current user interface shortcomings .......................................................................... 100

5.4 Design directions for robotic instrument manipulation ...............................................101

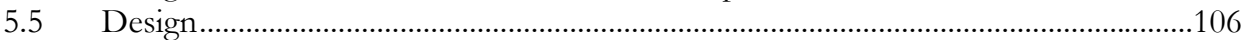

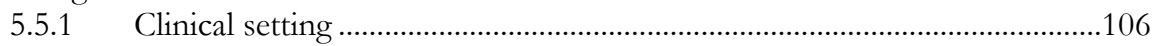

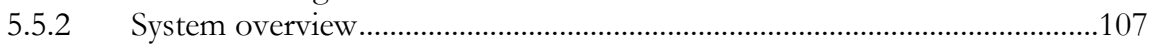

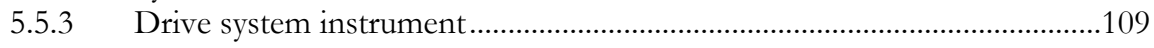

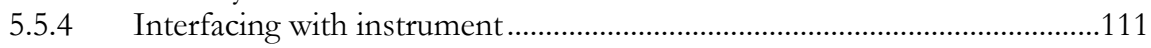

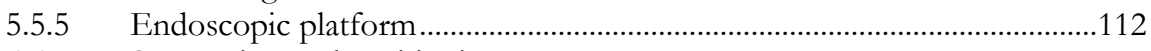

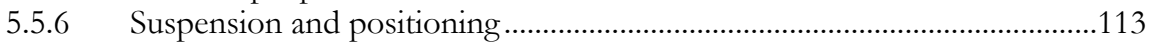

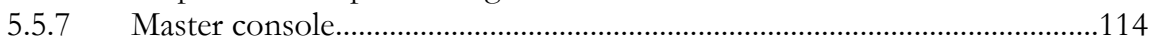

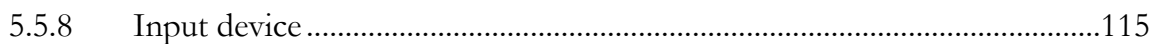

5.5.9 Electrical and software integration ..............................................................116

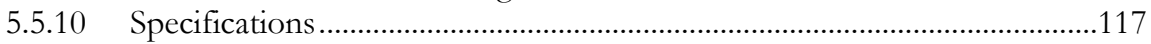

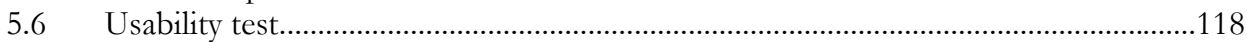

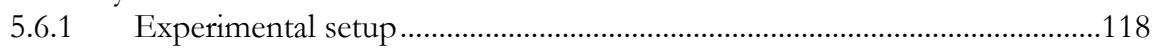

5.6.2 Results and discussion...........................................................................121

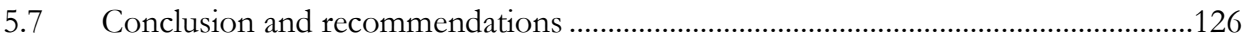

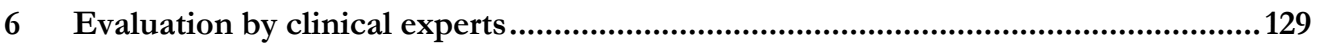

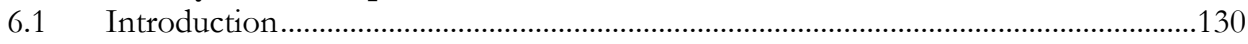

6.2 Evaluation robotic flexible endoscope for existing and experimental therapy.........130

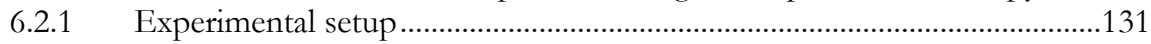

6.2.2 Results and discussion.............................................................................131

6.2.3 Conclusion and recommendations ............................................................137

6.3 Evaluation robotic steering for diagnostic procedures ..............................................139

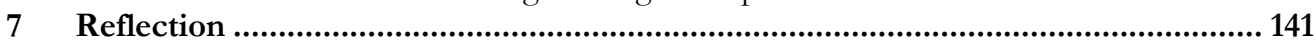

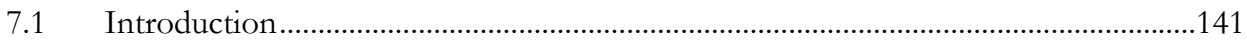

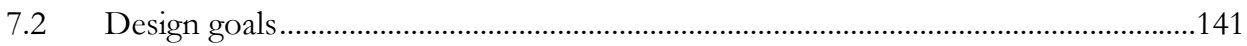

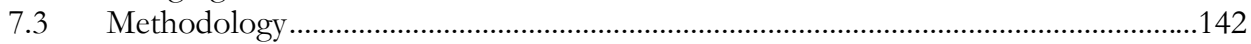

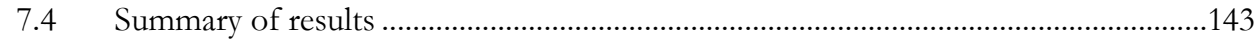

7.4.1 Robotic steering module - diagnostic procedures........................................145

7.4.2 Robotic shaft manipulation module - existing therapeutic procedures ....146

7.4.3 Robotic instrument manipulation module - experimental therapeutic

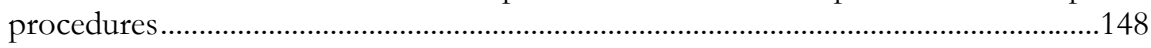

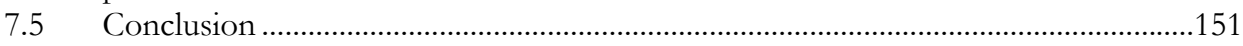


7.6 Directions for future work

Bibliography

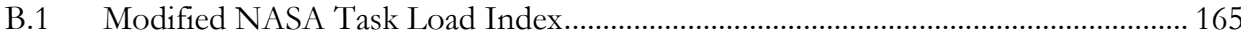

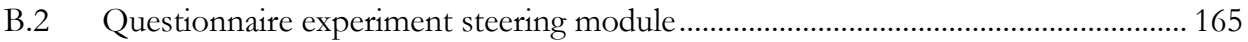

B.3 Questionnaire experiment instrument manipulation module - novices .................... 166

B.4 Questionnaire experiment instrument manipulation module - experts ................... 167

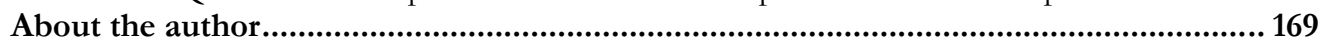



Technological improvements in surgery are focused on minimizing trauma to the patient. Using the natural orifices is a logical extension of this less invasive approach. Natural orifice surgery involves a shift from rigid to flexible instruments to be able to reach the operating area. Manual operation of these flexible instruments however requires a very skilled physician. The future of natural orifice surgery lies in the application of robotic technologies to support the physician in manipulating flexible instruments. This thesis describes the design and evaluation of a robotic flexible endoscope for diagnostic and therapeutic medical procedures. As an introduction, this chapter briefly discusses minimal invasive surgery, flexible endoscopy, the problems currently faced in natural orifice surgery, the potential of robotic surgery, and related work. 


\subsection{Minimal invasive surgery}

The development of surgical procedures and tools is focused on minimizing the size and number of incisions. During the last 25 years there has been a shift from open to minimal invasive surgery (also called keyhole surgery or endoscopic surgery) [Rosen and Ponsky, 2001]. It is a surgical technique in which operations are performed with rigid instruments through small incisions. A tubular video scope, inserted through one of the openings, transmits the image of the operating area to a monitor. Thanks to smaller incisions compared to open surgery, post-operative pain, recovery time and psychological impact are reduced [Cuschieri, 1995]. In Figure 1.1 a typical setting of minimal invasive surgery is depicted.

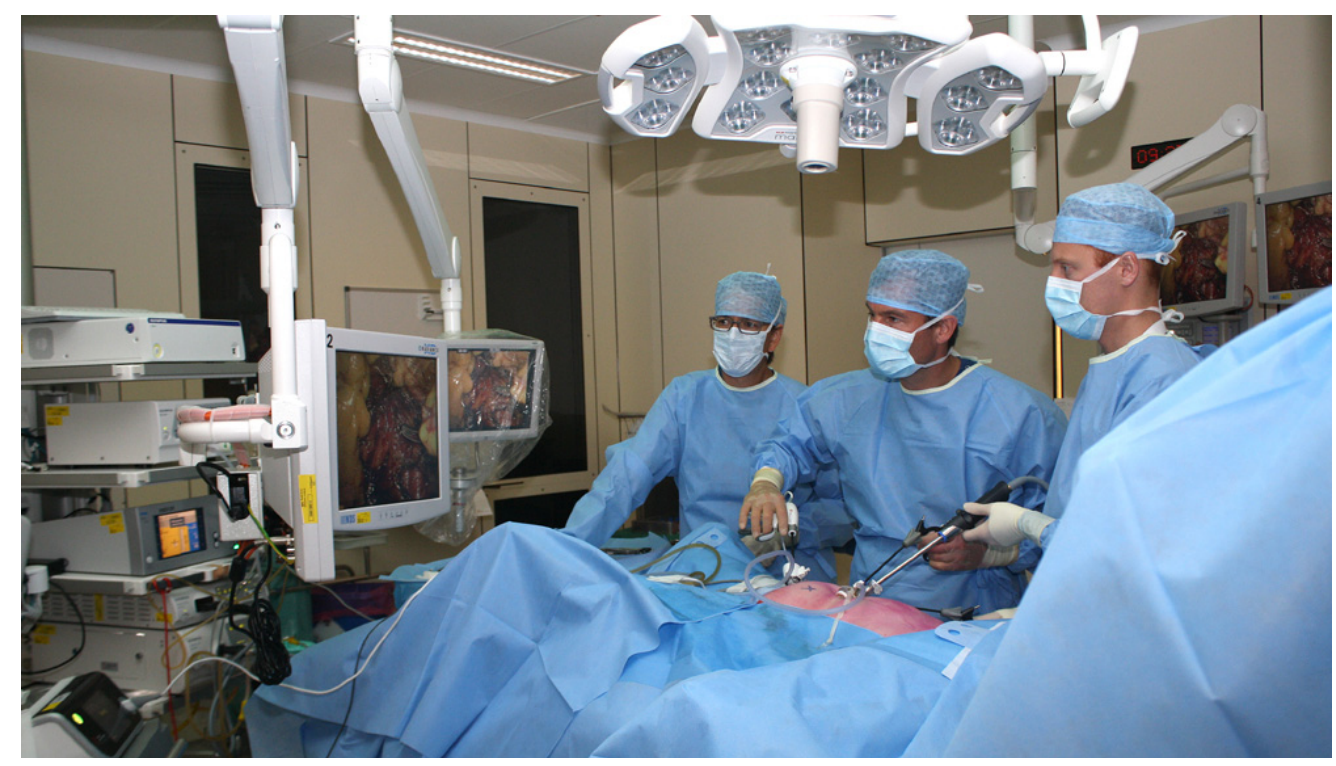

Figure 1.1 Minimal invasive surgery

Although there is 25 years of experience, surgeons are still confronted with problems related to the setup used in minimal invasive surgery. Physical problems arise due to bad ergonomics, and instruments are not able to provide the same intuitive (familiar) eye-hand coordination as in open surgery [Albayrak, 2008]. Surgical robots try to restore the ergonomics of open surgery by creating a user interface that provides a natural working posture and intuitive control of instruments. The da Vinci ${ }^{\circledR}$ surgical system (Intuitive Surgical, Mountain View, CA, USA), as shown in Figure 1.2, is clinically used and the most advanced system available today for minimal invasive robotic surgery with rigid instruments [Freschi et al., 2012]. 


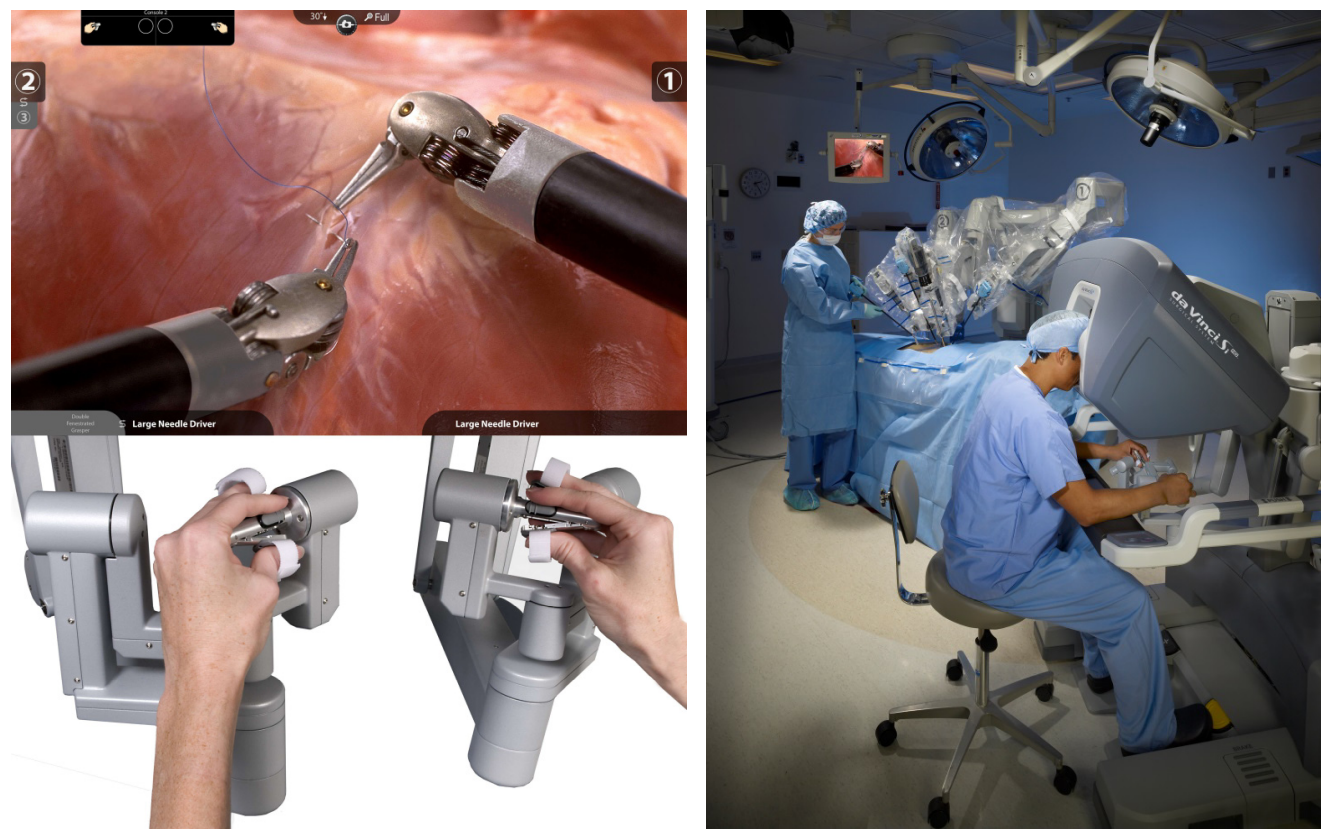

Figure 1.2 Da Vinci ${ }^{\circledR}$ Surgical System (C2012 Intuitive Surgical)

New techniques in minimal invasive surgery are now being developed that reduce the trauma to the patient even further by eliminating the external incisions and using natural orifices (mouth, anus, ureter or vagina) to enter the body. Natural orifice surgery involves a shift from rigid to flexible instruments to be able to reach the operating area. For that reason natural orifice surgery is closely linked to flexible endoscopy. Traditional flexible endoscopy is used to diagnose the interior surfaces of the gastrointestinal, reproductive and respiratory tracts. Natural orifice surgery integrates the expertise of flexible endoscopy with surgery and can replace more invasive procedures (e.g. performing a cholecystectomy [Marescaux et al., 2007]). Manual operation of flexible instruments however requires even more skills of the physician compared with rigid instruments and often requires a team to control all independent displacements and rotations (degrees of freedom or DOFs) [Thompson et al., 2009], as shown in Figure 1.3. These are the main reasons that surgery with flexible instruments is in its infancy and currently not generally adopted [Swanstrom, 6-2009].

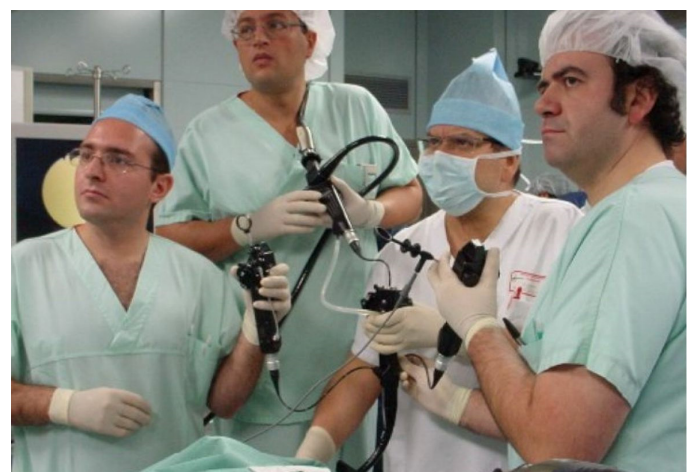

Figure 1.3 Therapeutic procedure with flexible instruments [Bardou et al., 2009] 
Robotic technology has the potential to enhance natural orifice surgery by supporting the physician in manipulating flexible instruments. As shown for robotizing rigid instruments, robotizing flexible instruments is the next logical step in improving patient's well-being, and physician's work comfort and capabilities [Marescaux et al., 2007; Canes et al., 2009; Santos and Hungness, 2011]. Prior to revealing the opportunities of robotics in natural orifice surgery, in the coming two sections the technology, the clinical procedures and the problems of flexible endoscopy are discussed in more detail.

\subsection{Flexible endoscopy}

In flexible endoscopy the physician uses a flexible shaft with a camera at the steerable distal tip that is introduced in the natural body openings. The high definition video image is depicted on a monitor to allow the physician to inspect the internal tubular organs (lumen) of the patient.

In the field of flexible endoscope handling, no revolutionary changes have occurred during the last five decades. The physician steers the distal tip by turning two navigation wheels on the control section for up/down and left/right motions. This is done with the left hand, while the right hand introduces the distal tip into the patient by applying axial force on the flexible shaft about $25-30 \mathrm{~cm}$ from the entry point of the patient. Figure 1.4 shows a diagnostic procedure, a colonoscopy, and the degrees of freedom of the endoscope that the physician needs to steer.
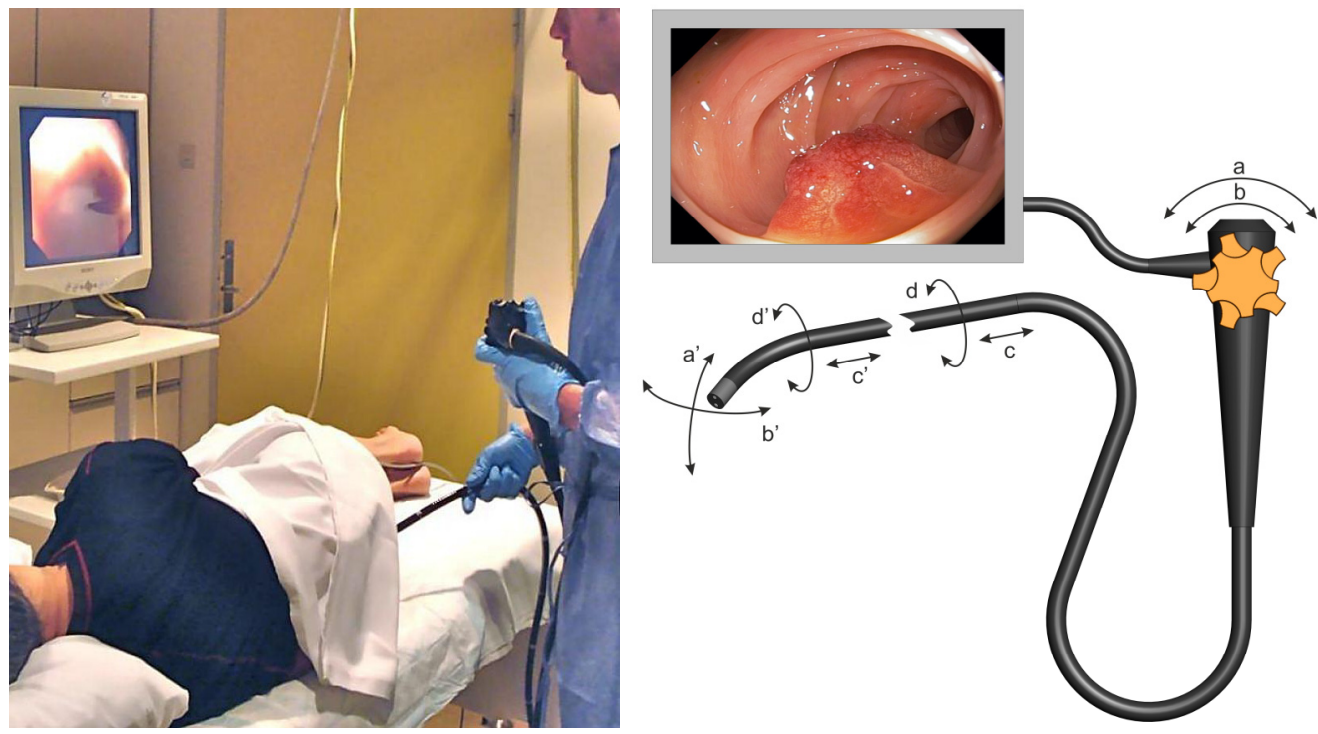

Figure 1.4 Flexible endoscope handling in diagnostic procedures (left). Manual operated degrees of freedom flexible endoscope (right): (a) Up-down, (b) Left-right, (c) In-out, (d) (Counter)clockwise rotation.

A colonoscopy is a demanding procedure and requires a lot of skills of the physician to introduce the flexible endoscope into the tortuous and elastic colon up to the point where the colon starts, the cecum. It is a delicate task that requires interpretation of force feedback information to limit excessive stretching of the intestinal wall, leading to increased patient discomfort [Williams, 2009].

In case of interventions a flexible instrument can be inserted in the endoscope. It protrudes from the tip and enables performing small interventions, like resecting a polyp or 
taking a biopsy. With the addition of an instrument in therapy even more independent translations and rotations of the tools need to be controlled, as shown in Figure 1.5.
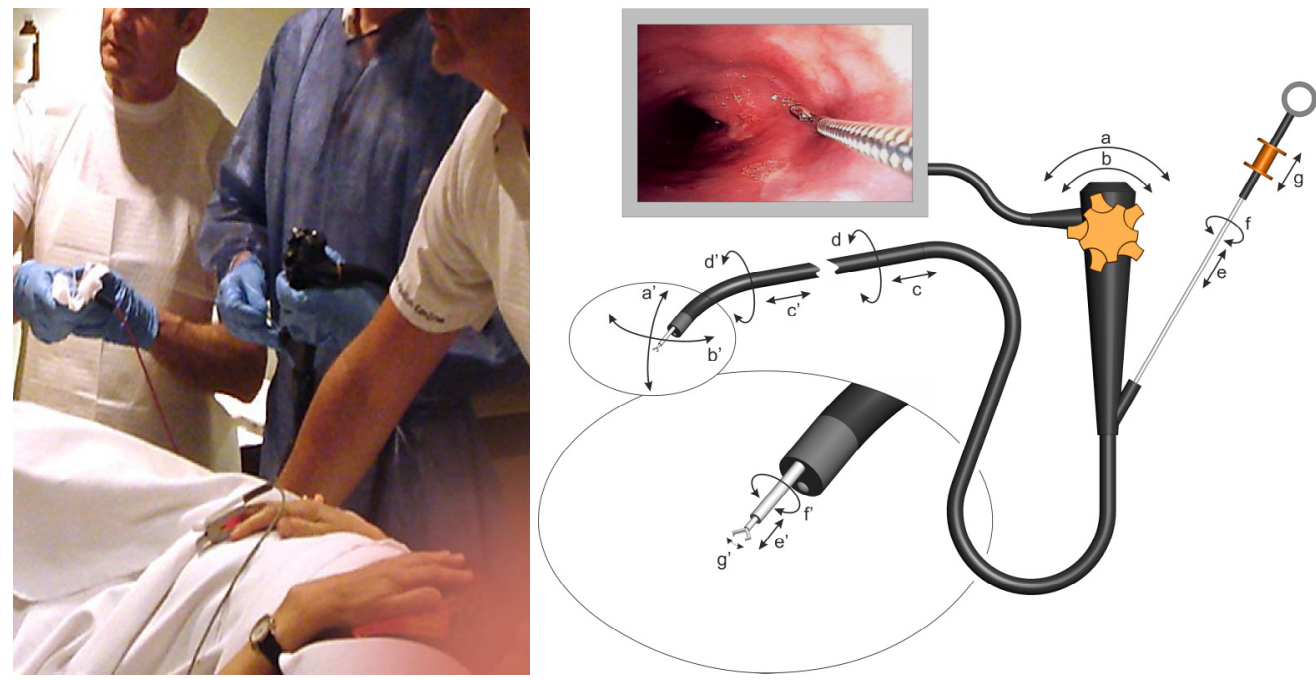

Figure 1.5 Flexible endoscope and instrument handling in existing therapeutic procedures (left). Manual operated degrees of freedom instrument in addition to endoscope handling (right): (a-d) Figure 1.4, (e) Inout, (f) (Counter)clockwise rotation, (g) Grasp.

Current commercial available flexible endoscopes and instruments have limited capacity to execute procedures that require advanced maneuverability. Technological improvements could enable a shift of more invasive surgical procedures that require external incisions to advanced endoluminal therapy in the gastrointestinal, reproductive and respiratory tracts that use the natural body openings (mouth, anus, ureter, or vagina) as access point, as shown in Figure 1.6 (left). As seen from open to keyhole surgery, endoluminal surgery further reduces post-operative pain, recovery time and psychological impact. Current applications for endoluminal surgery include endoscopic resection of large colonic, gastric and esophageal mucosal lesions (mucosectomy) as well as endoluminal therapies for gastroesophageal reflux disease (GERD), and bariatric surgery [Dunkin et al., 2009; Malik et al., 2006]. In these procedures physicians have to deal with the limitations of current available flexible endoscopes and instruments.

Since a decade several research groups focus on transluminal procedures in which the natural orifices provide the entry point as well, see Figure 1.6 (right).
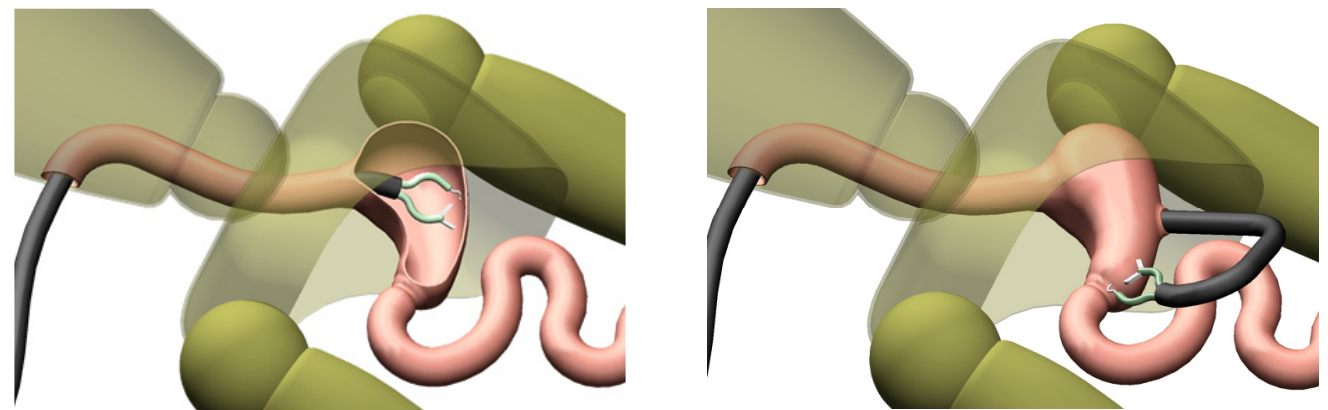

Figure 1.6 Flexible endoscopy: (left) endoluminal; (right) transluminal 
The internal membrane of the digestive tract or vagina is perforated to reach the abdominal or thoracic cavity, thereby avoiding external incisions. This surgical approach is also known as Natural Orifice Transluminal Endoscopic Surgery (NOTES) and performed in experimental interventions, like tubal ligation, cholecystectomy, gastrojejunostomy, splenectomy, and myotomy [Malik et al., 2006; Rattner and Kalloo, 2006; Makris et al., 2010].

Part of the research groups working on NOTES are focusing on clinical challenges as discussed in [Rattner and Kalloo, 2006] and they use commercial available endoscopes in their experiments [Auyang et al., 2011]. Others try to overcome current technological limitations, addressed in [Rattner and Kalloo, 2006], and focus on the development of advanced endoscopic intervention platforms [Swanstrom, 4-2011; Santos and Hungness, 2011]. The platforms developed are comparable to the flexible shaft of traditional flexible endoscopes and contain the same steering concepts for camera movement. Often two or three working channels are provided that are suitable for steerable instruments. Besides axial translation and rotation known from conventional instruments, the tip of steerable instruments can bend in at least one direction to allow movements in three-dimensional space. In Figure 1.7 a complete overview of available degrees of freedom of a typical advanced endoscopic intervention platform is depicted.

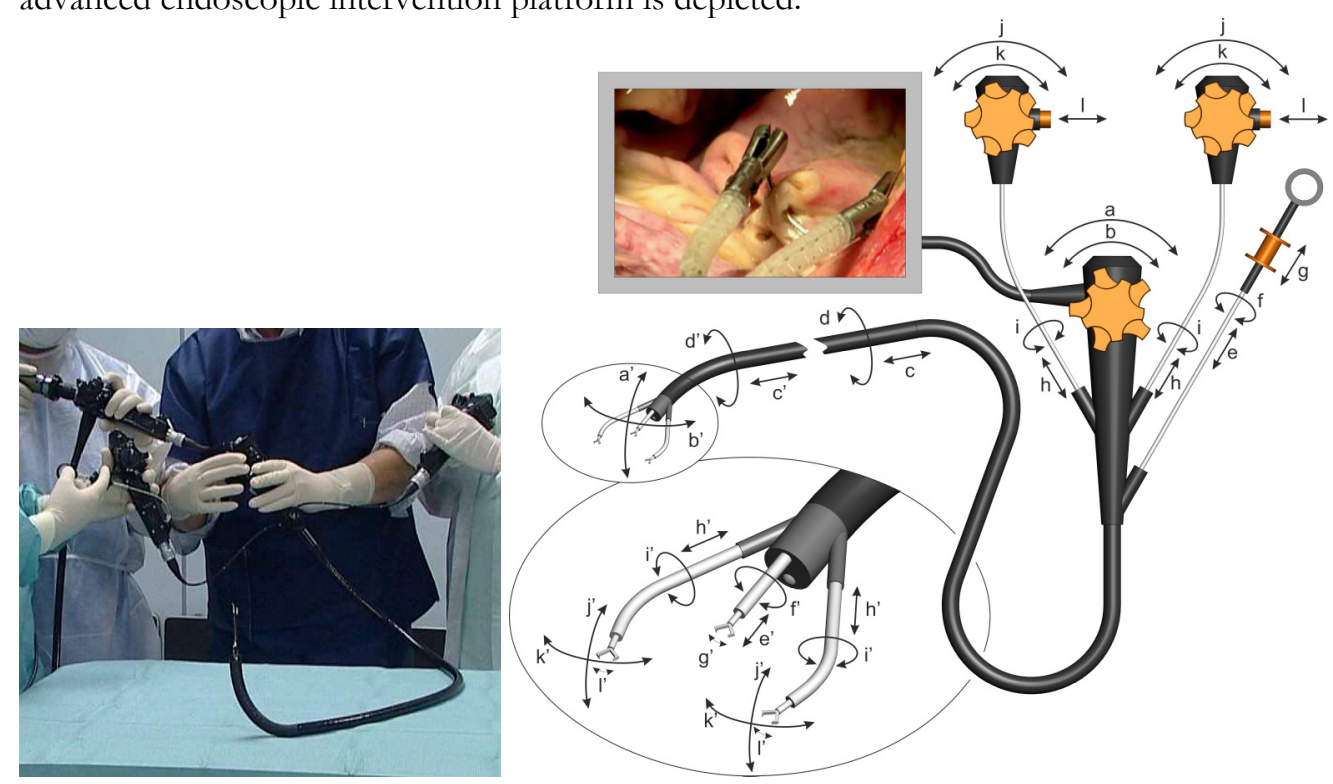

Figure 1.7 Handling of advanced endoscopic intervention platform with steerable instruments in experimental therapeutic procedures (left) [Bardou et al., 2009]. Manual operated degrees of freedom steerable instruments in addition to endoscope and conventional instrument handling (right): (a-g) Figure 1.4 and Figure 1.5, (h) In-out, (i) (Counter)clockwise rotation, (j) Up-down, (k) Left-right, (l) Grasp.

The added value of steerable instruments in surgery is that the physician can stabilize the distal tip of the endoscope at the operating area and concentrate on instrument manipulation. With a conventional endoscopic system more manipulation skills are required. Besides the instruments, the distal endoscope tip has to be manipulated as well to realize 3D movements. Additionally, steerable instruments are more suitable for bimanual tasks that require synergistic movements of 2 different instruments.

New mechanical user interfaces for steerable instruments are developed to control all degrees of freedom. An example of an experimental platform includes the ANUBIS 
NOTEScope ${ }^{\circledR}$ (Karl Storz, Tuttlingen, Germany) [Bardou et al., 2009], as depicted in Figure 1.8.
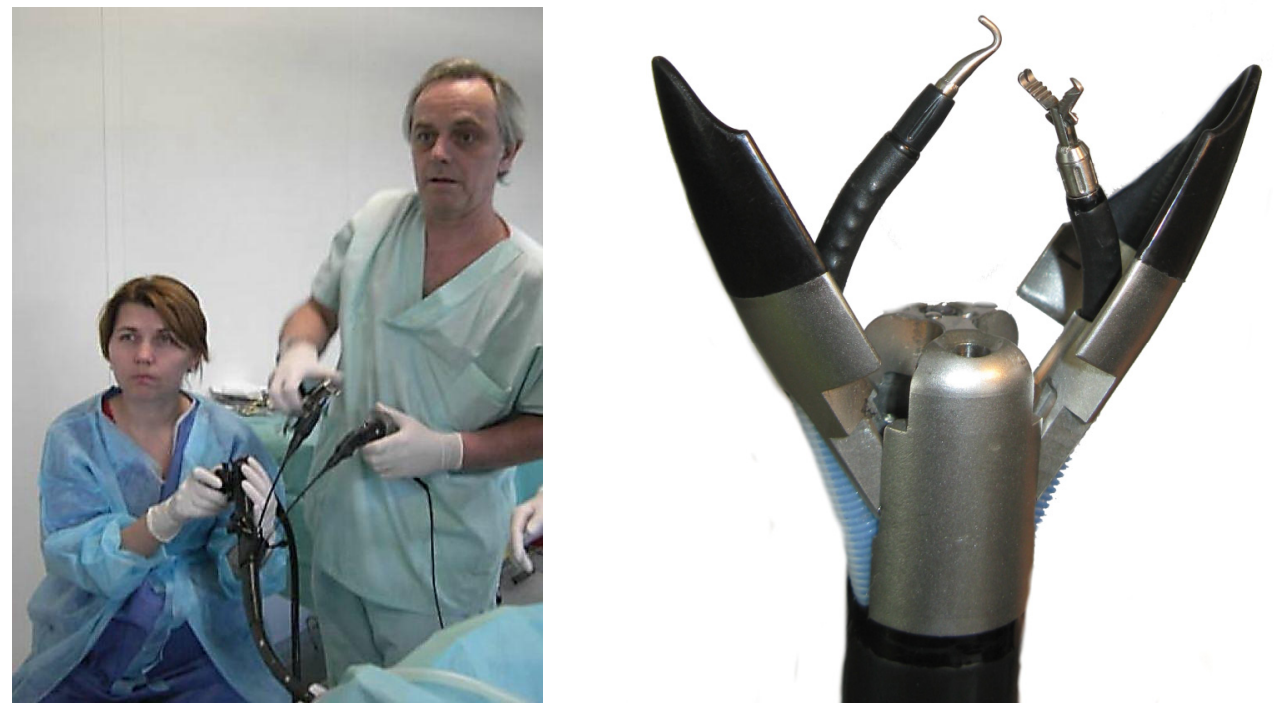

Figure 1.8 The ANUBIS NOTEScope ${ }^{\circledR}$ (CKarl Storz). The tip opens in the operating field to expose two instruments both with 4 degrees of freedom and controlled with pistol like handles [Bardou et al., 2009]

Designs such as that of the ANUBIS NOTEScope have the potential to be more applicable for complex endoluminal or transluminal procedures than current available endoscopes [Spaun et al., 4-2009]. However, some of the inherent deficiencies of traditional flexible endoscopes are still not solved [Wilhelm, 2012; Yeung and Gourlay, 2012], as discussed in Section 1.3.

In this section the different applications of flexible endoscopy were discussed. To summarize:

- Diagnostic procedures

Basic procedures where the endoscope is introduced into the lumen and the inner wall is inspected. Abnormalities can be further diagnosed by inserting instruments through one of the working channels.

- Existing therapeutic procedures

Advanced endoluminal procedures in which traditional endoscopes are being used as therapeutic devices. Basic three dimensional motion of inserted instruments is possible, often induced by motion of the endoscope tip itself. These procedures are currently only performed by very skilled clinical experts using conventional endoscopes.

- Experimental therapeutic procedures

A whole new range of advanced endoluminal as well as transluminal procedures could become possible with the introduction of advanced endoscopic intervention platforms. However, both the procedures and the tools are still highly experimental and not commercially available.

In the remainder of this thesis the phrase 'natural orifice surgery' is used to indicate endoluminal as well as transluminal procedures. If distinction between both procedures is needed, the terms endoluminal and transluminal are used. 


\subsection{Problem area}

The amount of flexible endoscopy procedures are expected to increase for diagnosis and therapy. However, the success of this trend hinges on the usability of flexible endoscopy equipment, as discussed in this section.

\section{Diagnosis}

High volume screening programs are being initiated in several countries to reduce the incidence and impact of colorectal cancer. The global incidence of colorectal cancer in 2008 was estimated at 1.2 million cases with a mortality of nearly $50 \%$, accounting for $8 \%$ of all cancer deaths, making it the fourth most common cause of death from cancer [Ferlay et al., 2012]. In the Netherlands colorectal cancer screening has started in 2013. Ultimately 2400 deaths can be prevented from this disease each year in the Netherlands because of the introduction of screening. The method of choice is the feces occult blood test once every two years for people aged 55-75. People with a positive test are referred for colonoscopy. It is estimated that 70.000 extra colonoscopies are required every year on top of the current number of 190.000 colonoscopies. Although capacity is growing to anticipate on introduction of screening programs, a large number of hospitals are currently having difficulty filling vacancies for gastroenterologists. The expectation of gastroenterologists is that shortage can be overcome by role reallocation (less complex procedures by endoscopy nurses), efficiency measures and increasing the intake to training programs [van VeldhuizenEshuis et al., 2012]. Improved usability of flexible endoscopes may help to implement these measures. According to [Tassios et al., 1999; Harewood, 2005] currently about 100 to 200 procedures are required to reach the level to perform a colonoscopy safely and within reasonable time. Main usability problems are related to the control section of the flexible endoscope at the proximal end. Because of the configuration of control elements the physician faces handling problems. Often physicians are using both hands for the control section, while an assistant manipulates the shaft according to spoken instructions. Drawback of this workflow is that the physician lacks valuable force feedback information on tissue interaction, communication errors easily occur, and at least two persons are required to perform the procedure. It is not expected that current shortage of colonoscopy capacity can be quickly resolved with current available technology.

\section{Existing therapy}

Current applications of endoluminal surgery reduce post-operative pain, recovery time and psychological impact when replacing more invasive open or laparoscopic procedures. Endoluminal surgery is currently only performed by very technical skilled clinical experts using traditional endoscopes. Endoscopic submucosal dissection (ESD), to dissect large lesions in the gastrointestinal tract, is for instance a highly technical and demanding procedure. Extensive training under the guidance of a skilled endoscopist is required to perform the procedure efficient, effectively, and safe [Matsui et al., 2012; Kim et al., 2012]. It is expected that ESD and other endoluminal surgical procedures are generally adopted by physicians if the enabling technology, that improves the dexterity of the physician, is available [Malik et al., 2006; Yeung and Gourlay, 2012].

\section{Experimental therapy}

The potential of natural orifice surgery is obvious [Malik et al., 2006; Yeung and Gourlay, 2012]. New endoluminal procedures can replace more invasive procedures. Whether transluminal access is able to replace conventional laparoscopic surgery is dependent on the 
ability to solve all clinical and technical challenges as stated in [Rattner and Kalloo, 2006; Chamberlain and Sakpal, 2009]. Based on some clinical studies comparing laparoscopic surgery and NOTES for performing a cholecystectomy, it might be concluded that with current available technology transluminal procedures will not be adopted in the clinic on a large scale [Chamberlain and Sakpal, 2009].

The clinical introduction of advanced endoscopic intervention platforms will allow physicians to perform complex therapeutic procedures. However, the technology is not ready yet for cost effective, safe, and user-friendly use in clinical practice and is up to now only tested in experimental interventions. Current flexible endoscopes and their instruments are already difficult to steer, but the advanced endoscopic intervention platforms that are currently developed contain additional degrees of freedom and require even more effort to control. They are not suitable for single person operation and require two up to four experienced endoscopists that cooperate closely (Figure 1.3). Additionally, in case of transluminal procedures a surgeon is required for specific knowledge on surgery [Rattner and Kalloo, 2006].

It can thus be concluded that, despite the expected increase of flexible endoscopy procedures, at this time no flexible endoscopy equipment is available that allows a single physician to perform diagnostic and therapeutic procedures in an intuitive and user-friendly way.

\subsection{Opportunities of robotics}

In the previous section manipulation of a flexible endoscope and its instruments is identified as being not user-friendly. However, no revolutionary changes have occurred in endoscope control since its introduction about 50 years ago. Deflection of the tip is still realized with Bowden cables that are manually operated by means of concentric navigation wheels. From a mechanical perspective this seems to be the only appropriate way, since all endoscope manufacturers are using this actuation principle. The downside of this concept, however, concerns the non-optimized usability. Exploration of alternative means of actuation and power transmission is required [Yeung and Gourlay, 2012].

Robotic technology has the potential to improve current practice. Robotic concepts are based on remote controlled electro-mechanical steering of the endoscope and its instruments. Key factor is that user interface and tools are mechanically decoupled and computer intelligence is integrated, as known from telemanipulation systems [Franken, 2011]. The physician uses a remote positioned master console (user interface) to control a slave robot (actuated tools) positioned near the patient. The slave device mimics the motions of the master device. The user interface is ergonomically optimized for the physician and the tools are mechanically optimized for the intervention. It allows for instance that the physician's hand movements are scaled, filtered and intuitively mapped to precise movements of instruments. Instrument manipulation is intuitive since it resembles familiar eye-hand coordination as used in direct manipulation of instruments. Teleoperated robotic systems could be the enabling technology for a single physician to easily perform diagnostic and therapeutic flexible endoscopy procedures.

Figure 1.9 shows a possible configuration for a master-slave setup for telemanipulated surgery with flexible instruments. A split system is not essential, master and slave can be integrated, but it could help to solve for instance space or sterility issues. 


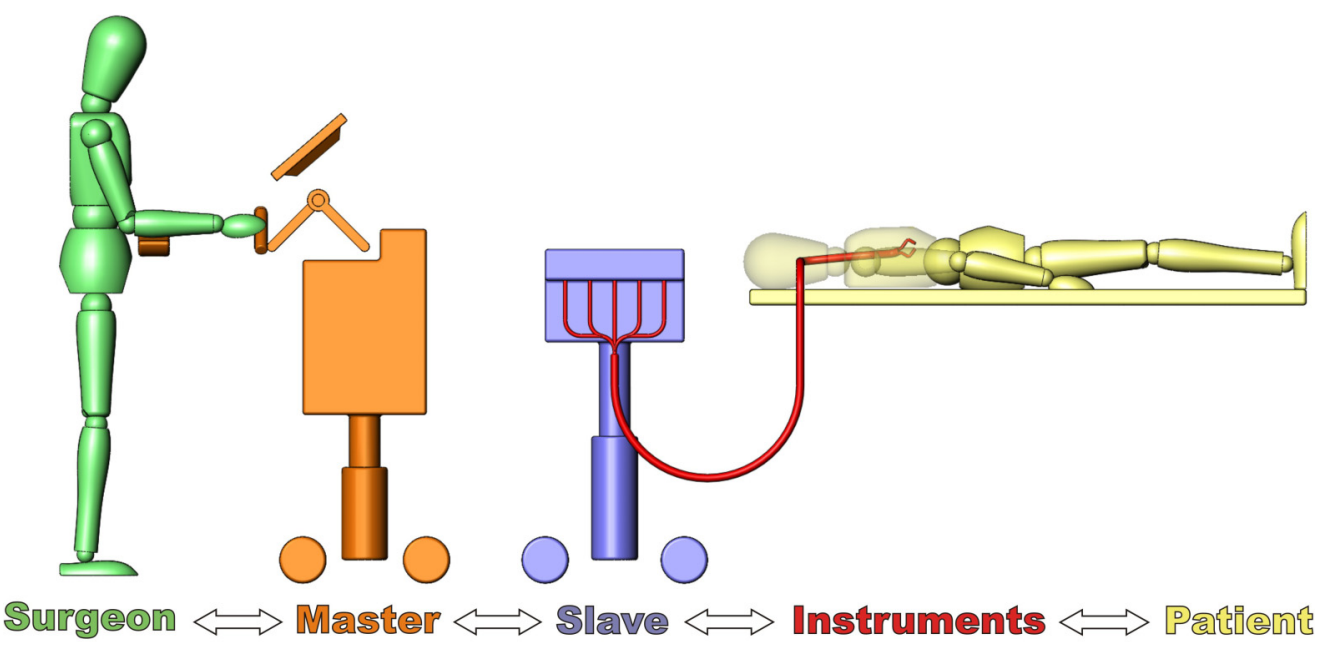

Figure 1.9 Possible master-slave setup for robotic flexible endoscopy

Generally a robot is seen as a machine that performs its tasks autonomously. Our work however focuses on enhancing the capabilities of physicians by introducing computer intelligence. The physician remains in control. However, the term robot is used because it is a generally accepted name in the medical community for the type of system described in this thesis [van den Bedem, 2010].

\subsection{Related work}

Most existing surgical robots for minimal invasive surgery are developed to control rigid instruments, as the Da Vinci shown in Figure 1.2. Their field of application is focused on neurosurgery, orthopedic surgery, laparoscopy, and thoracoscopy. An extensive overview of these setups is discussed in [Franken, 2011; van den Bedem, 2010]. Robotics for natural orifice surgery are less widespread. Highly experimental are the concepts in which robots are placed entirely inside the patient. Although these in vivo robots have shown to be useful in providing vision and task assistance, it is unlikely that these miniature devices could be used alone to perform advanced therapeutic procedures that require tissue manipulation [Rentschler et al., 2007].

The remainder of this section explores the availability of advanced endoscopic intervention platforms for endoluminal and transluminal surgery. Existing systems can be classified as either mechanical or robotic. Although in our work the opportunities of robotics are explored, first some mechanical concepts are presented to give a complete overview of solution directions.

The EndoSAMURAI ${ }^{\circledR}$ (Olympus Corporation, Tokyo, Japan, Figure 1.10) has a mechanical control console very similar to conventional laparoscopic instruments. The handles mechanically transmit the desired motion to two independent end-effectors, each with 5 degrees of freedom. A third working channel is available for conventional instruments. A steerable and lockable overtube provides a stable platform and excellent visualization [Spaun et al., 4-2009]. 

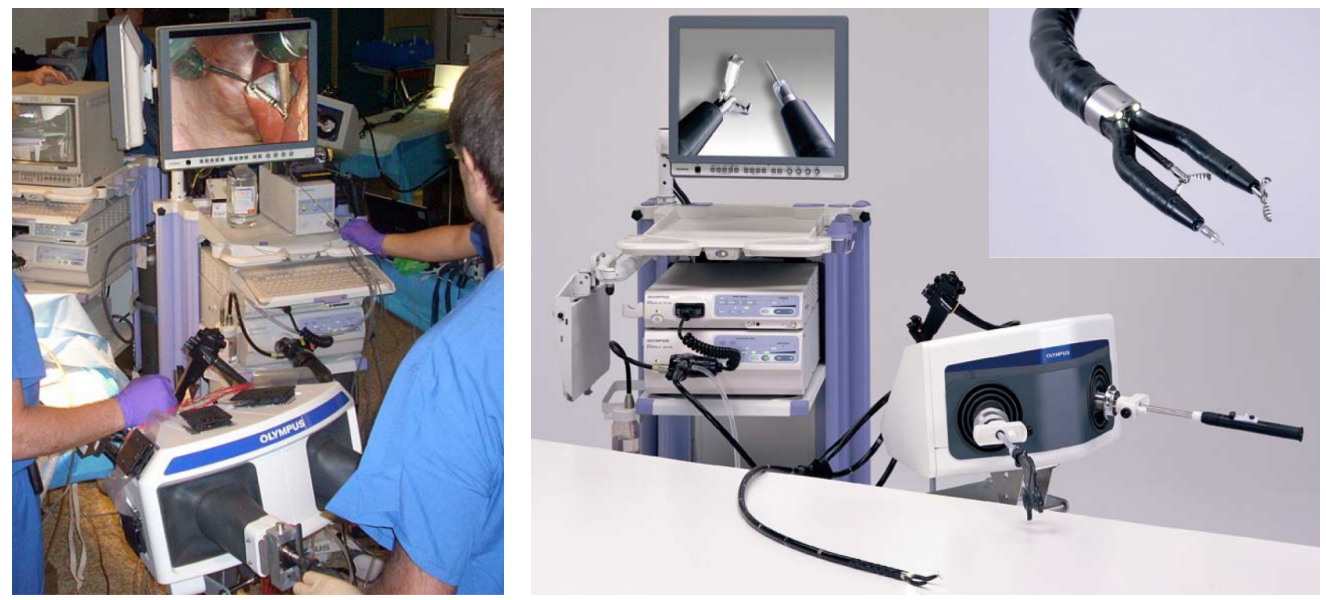

Figure 1.10 EndoSamurai ${ }^{\circledR}$ (COlympus Medical Systems Corporation) [Santos and Hungness, 2011; Spaun et al., 4-2009]

The Direct Drive Endoscopic System ${ }^{\circledR}$ (Boston Scientific Corporation, Natick, USA, Figure 1.11) has two instrument control handles that both steer 5 degrees of freedom end effectors. The control handles run on a rail platform that is adjustable for optimal ergonomic positioning [Thompson et al., 2009].
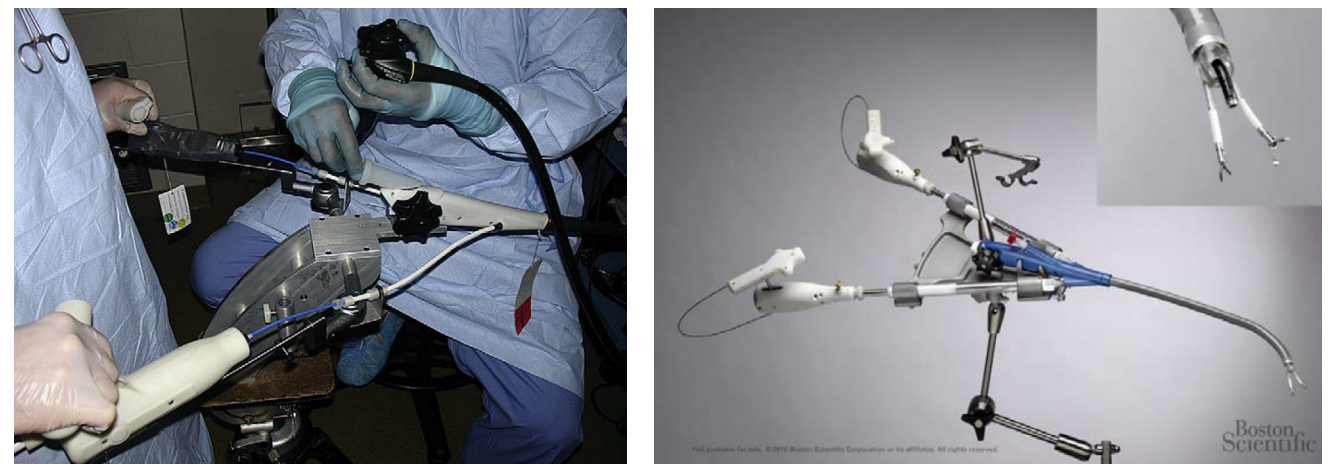

Figure 1.11 Direct Drive Endoscopic System ${ }^{\circledR}$ (CBoston Scientific Corporation) [Thompson et al., 2009; Santos and Hungness, 2011]

The EndoSamurai as well as the Direct Drive Endoscopic System introduce new mechanical user interfaces for instrument manipulation. The control handles are positioned as known from laparoscopy. To what extend the ergonomic problems faced in laparoscopy [Albayrak, 2008] are still faced in these setups is unknown. The steering concept for camera movement known from traditional endoscopes has been unchanged. Both setups are still in the prototype phase and not commercially available.

An overview of robotic concepts will be presented in the remainder of this section. This is not intended to be complete, but serves as a general introduction to robotic systems that have the same medical focus as this work. In a later stage when our designs are discussed a more in-depth review is discussed.

The ViaCath ${ }^{\circledR}$ (EndoVia Medical, Norwood, USA) is a teleoperated robot for endoluminal surgery that uses the existing master and slave of a robot for laparoscopic 
surgery, the Laprotek ${ }^{\circledR}$. Development has been focused on revising the mechanical drive mechanisms, the design of robotic instruments that run alongside a traditional flexible endoscope, and adaptation of the software kinematics to be applicable for endoluminal surgery. Experiments validated that the basic system architecture is functional [Abbott et al., 2007]. In 2005 EndoVia Medical was purchased by Hansen Medical (Mountain View, USA). The ViaCath is never commercialized, but Hansen Medical is successful with teleoperated robots for endovascular catheterization. Figure 1.12a shows the ViaCath of EndoVia Medical being the predecessor of the Magellan ${ }^{\circledR}$ of Hansen Medical as depicted in Figure $1.12 b$.
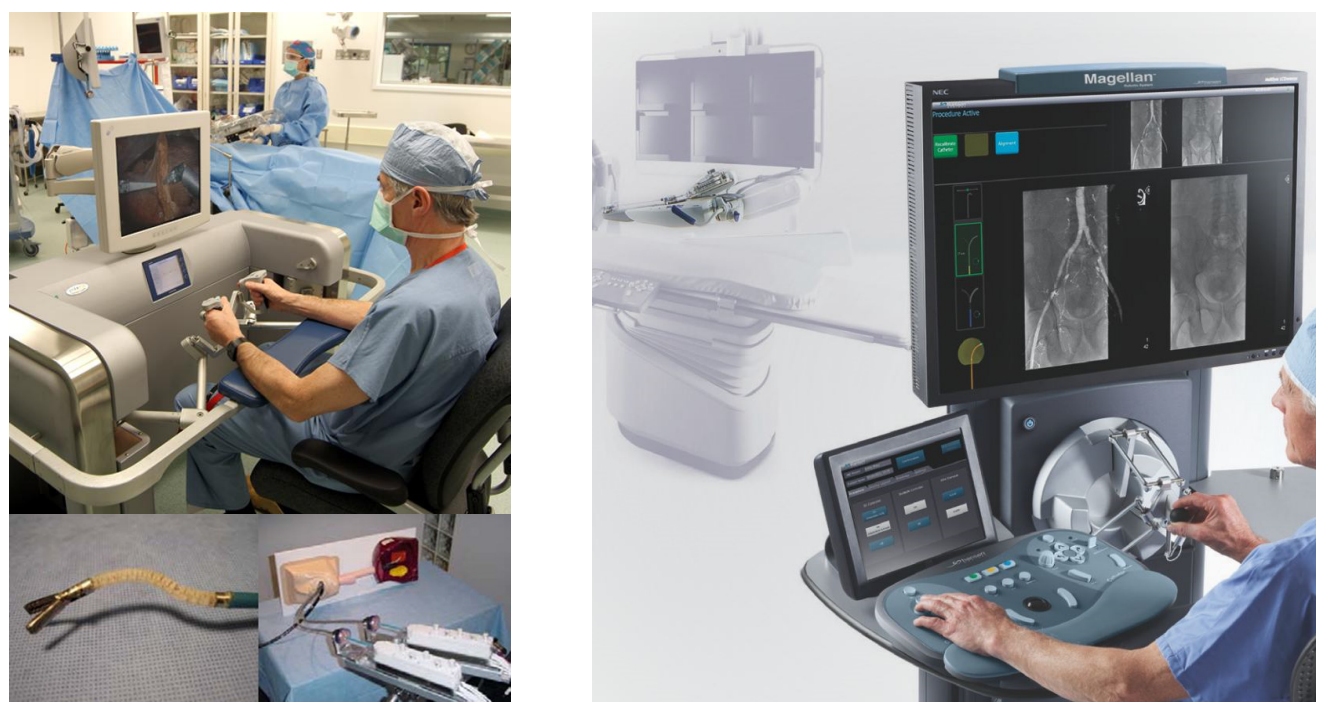

Figure 1.12 (a) ViaCath ${ }^{\circledR}$ robot (left) [Abbott et al., 2007]; (b) Magellan ${ }^{\circledR}$ robotic catheter (right, (C) Hansen Medical)

The Nanyang University (Singapore) endoscopic robot is also a master-slave system. An exoskeleton interface controls all degrees of freedom of the system, as depicted in Figure 1.13. The slave is a cable driven end effector that can be mounted on existing endoscopes [Phee et al, 2008].
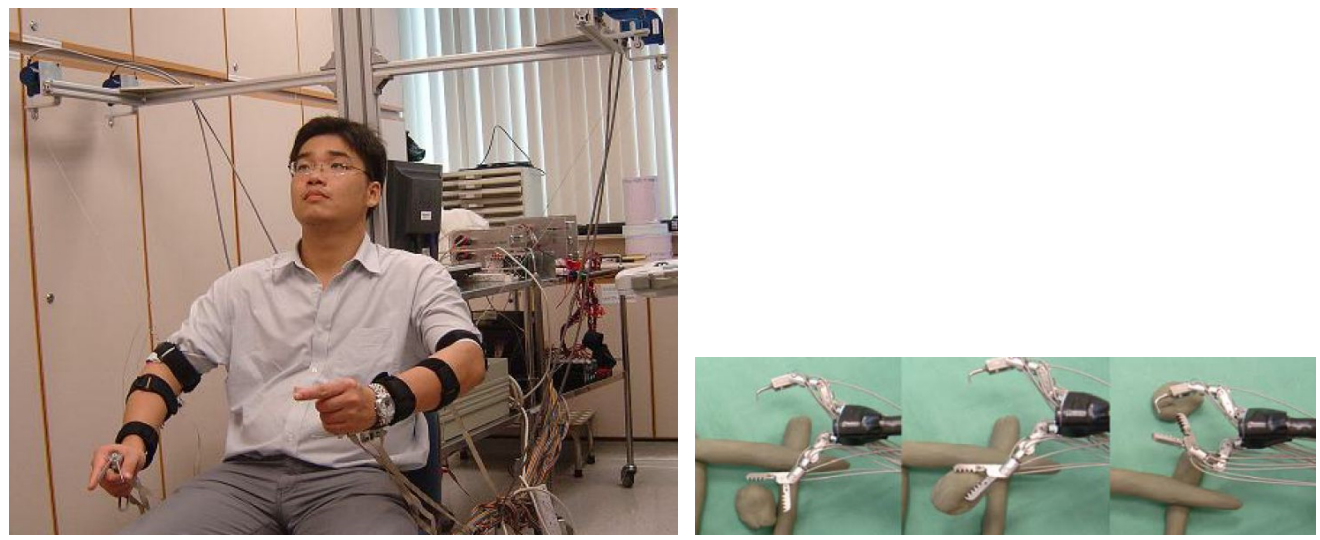

Figure 1.13 Robot Nanyang University [Phee et al., 2008] 
The Master and Slave Transluminal Endoscopic Robot (M.A.S.T.E.R.) presented in [Phee et al, 2009] of the Nanyang University uses the same (kind of) slave manipulator as the system discussed in [Phee et al., 2008]. The multi-degrees of freedom input devices link the movement of the user's hand to instrument movements. According to Phee [2009] the ergonomics of the M.A.S.T.E.R. (Figure 1.14) are improved compared with the exoskeleton interface (Figure 1.13).

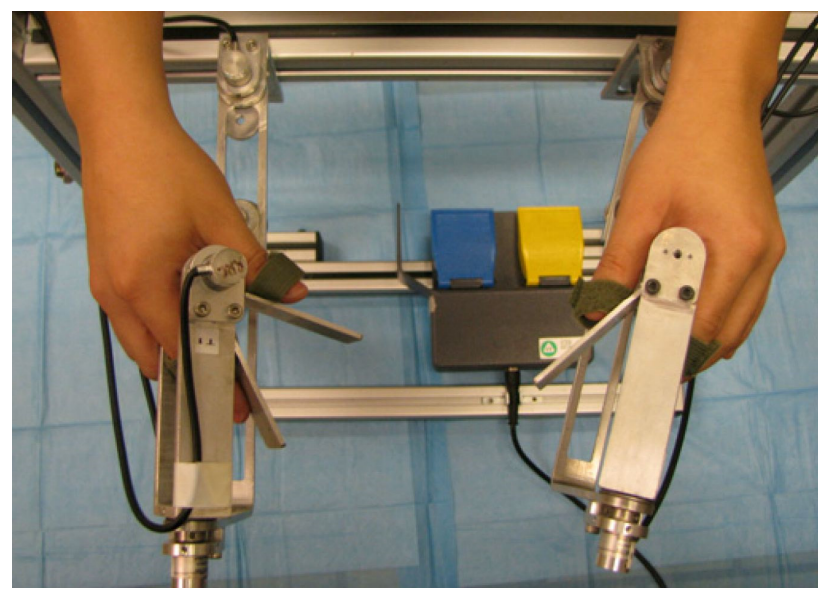

Figure 1.14 M.A.S.T.E.R. robot Nanyang University [Phee et al., 2009]

The IRCAD Institute and the University of Strasbourg are involved in the development of the ANUBIS NOTEScope of Karl Storz (Figure 1.8). Robotizing the manual operated ANUBIS NOTEScope is researched to allow a single physician to operate all degrees of freedom of the endoscope and its instruments by means of two master interfaces. Research has focused on mathematical modeling and autonomous tasks by vision-based robotic control (visual servoing). Requirements to fit the system in the current clinical workflow are not implemented. Some preliminary tests are executed, but no scientific data on performance is available yet. [Bardou et al, 2009; Ott et al., 2008]. The system is depicted in Figure 1.15.
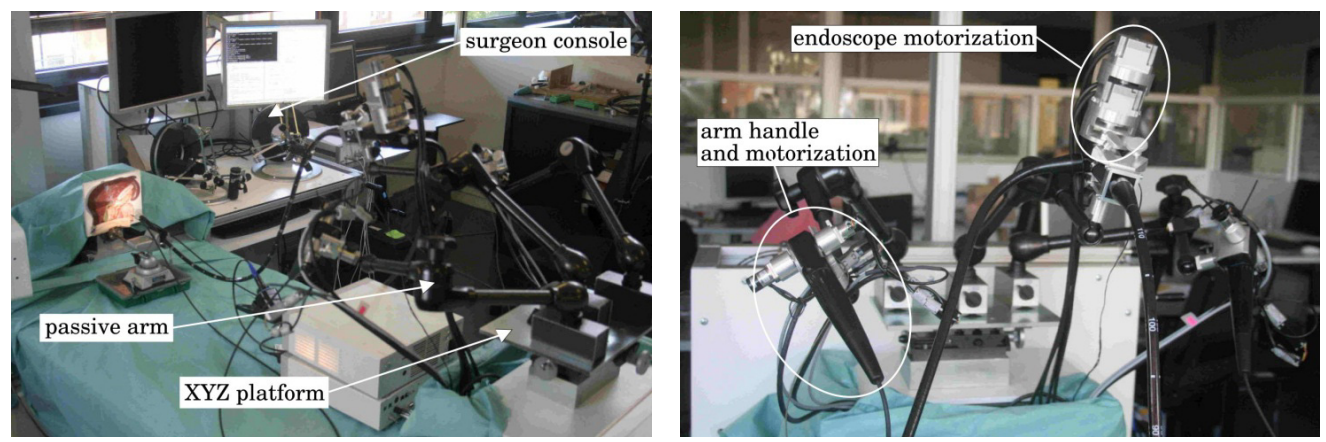

Figure 1.15 Robot IRCAD Institute and the University of Strasbourg [Bardou et al, 2009]

\subsection{Project organization and contribution of this work}

This research project is part of a trajectory that should ultimately result in a robotic flexible endoscope for clinical use. With the completion of this thesis the proof-of-principle 
phase, in which the feasibility of concepts are demonstrated, is finalized. The optimization (prototype phase) and realization (pre-production phase) are outside the scope of this work.

For the proof-of-principle phase a project team is composed that contains all required managing, development, and medical knowledge. Initially it consisted of three partners:

- DEMCON Advanced Mechatronics, Enschede

DEMCON is a high-end technology supplier of mechatronic products and systems. Focus areas are high-tech systems and medical devices. In this project DEMCON has been responsible for overall project management and it has supported in the development and realization of technology.

- University of Twente, Enschede

The University of Twente is a research university which focuses on the development of technology and its impact on people and society. PhD's and their supervisors from industrial design, mechatronics, control engineering, and technical medicine have been responsible for the scientific output.

- Meander Medical Centre (MMC), Amersfoort

The MMC is a general hospital. The departments of general surgery and gastroenterology have contributed in defining possible interventions and desired functionality for the robotic system. Additionally, they have supported the clinical evaluation of technology.

With the realization and demonstration of the first proof-of-principles, equipment manufacturers have shown their interest in commercializing our product ideas. Olympus Medical Systems (Tokyo, Japan), market leader in flexible endoscopy, shared their market and product knowledge, and their network of key opinion leaders. In addition, they provided us with standard equipment, like flexible endoscopes and imaging modules. Karl Storz (Tuttlingen, Germany), supplier of endoscopic equipment for the operating room, has made the ANUBIS NOTEScope available for our research.

The author of this thesis, senior industrial designer at DEMCON Advanced Mechatronics and $\mathrm{PhD}$ candidate at the Department of Design, Production and Management of the University of Twente, has been responsible for the overall definition, design and realization of the robotic demonstrators, with a special focus on industrial and mechanical design. Rob Reilink and Michel Franken, both formerly PhD candidate in this project at the Department of Robotics and Mechatronics of the University of Twente, and now respectively mechatronic system designer and business developer at DEMCON, have implemented the electronics and advanced motion algorithms of the system.

Special attention in the author's research and development project has been on incorporating human factors into the robotic flexible endoscope to optimize usability. Medical demands are linked to technical opportunities to create a safe system that is able to perform clinical procedures with effectiveness, efficiency, and satisfaction. In Chapter 2 a more in depth discussion of the approach is presented. A generic overview of tasks and responsibilities of the author is listed below.

- Definition of clinical procedures that can be enhanced by robotics

- Definition of the functional overview

- Definition of the system requirements document with clinical and technical demands

- Definition of the system architecture that defines the needed robotic modules and their interfaces 
- Conceptual system design

- Conceptual design of functions

- Lead engineer industrial and mechanical design with a special focus on styling, ergonomics, clinical implementation, manufacturability.

- Supervision on realization of demonstrators in workshop

- Technical testing of demonstrators

- Usability tests of demonstrators with novice users

- System integration

- Usability tests of integrated system with novice users

- Usability tests of integrated system with expert users and review of clinical value

These tasks are executed to realize: a robotic flexible endoscope that allows a single physician to perform diagnostic and therapeutic procedures in an intuitive and userfriendly way.

\subsection{Thesis outline}

The remainder of this thesis consists of three parts. In the remainder of the first part, in Chapter 2, the design methodology used in this work is presented. It discusses a new developed user-centred system design approach for requirements analysis and designing concepts for complex systems with critical use aspects. The main outcome of this chapter is a system architecture that defines the robotic modules constituting the system.

In the second part of this thesis the design and evaluation of all robotic modules is discussed. In Chapter 3 the steering module for diagnostic procedures is presented. Chapter 4 discusses the shaft manipulation module that assists in existing therapeutic procedures. In Chapter 5 the instrument manipulation module is discussed that controls the instruments of advanced endoscopic intervention platforms used in experimental therapeutic procedures. Each of these chapters will discuss the state of the art, current user interface problems, important design considerations, the physical realization, and finally the usability test of the robotic module.

The third part discusses the evaluation of our robotic system by clinical experts and reflects on this research project. In Chapter 6 the current status of the clinical evaluation of the robotic setups for diagnosis, existing therapy, and experimental therapy is discussed. Chapter 7 reflects on this research project by discussing to what extent the originally stated goals are achieved by using our design approach and realizing the integrated proof-ofprinciple setup. Finally some concluding remarks and directions for future work are provided. 



\section{User-centred system design approach}

Complex systems, like surgical robots, are developed by engineers. It is very difficult for them to determine the different needs and desires of all stakeholders. Especially when developed from scratch, end user input is essential in creating a system that has added value, is user friendly, and can be easily integrated into practice. For the development of the robotic flexible endoscope as presented in this work physicians, nurses, and equipment suppliers were involved in the development approach. Seven steps are executed to convert user preferences and capabilities into concepts:

1. Determine focus area of development.

2. Create the current workflow of system application to understand (the context of) use.

3. Determine problem definition and design goal.

4. Create the future workflow, in which current problems are eliminated and major system wishes are fulfilled.

5. Translate the future workflow into a functional overview that contains system functions.

6. Select and configure the appropriate construction elements into physical overviews, being preliminary concepts.

7. Decompose physical overview into manageable modules.

These views are evaluated by the major stakeholders and together form a system architecture. The system architecture belped us in defining the robotic modules required to fulfill all stakeholders' needs and desires. Demonstrators were built to evaluate critical concepts in clinical relevant experiments, as discussed in the chapters that follow. This chapter presents our approach to create an advanced robotic endoscopy system.

This chapter is a revised version of paper:

J.G. Ruiter, M.C. van der Voort, G.M. Bonnema, User-centred system development approach applied on a robotic flexible endoscope. In Proceedings of Conference on Systems Engineering Research, Volume 16, pp. 581-590, Atlanta, 2013. 


\subsection{Introduction}

Robots are characterized by the integration of mechanics, electronics, and software. Like for example aircrafts and medical imaging systems, robots are complex systems that are designed by multidisciplinary teams. Designing complex systems is a complex process. In this chapter our user-centred system design approach is discussed that has streamlined our development of a robotic flexible endoscope.

Torry-Smith et al. [2011] argue that most challenges in system development are primarily related to the way a system concept can be described and how information linked to the system concept can be shared across engineering disciplines. Central issue is how can engineers from different disciplines work together effectively, how can the problem of designing a large and complex system be divided into smaller, more manageable parts, and how can the fit between these parts that are designed by multidisciplinary teams be guaranteed. This is what system architecting is about [Bonnema, 2008]. However, in system development processes not only engineers but many more stakeholders are involved. Especially in systems with critical user interaction the intended end user should be part of the system development process to ensure that the system will function satisfactory in different use situations [van der Voort and Tideman, 2008]. A robotic flexible endoscope is a typical example of a complex system with critical use aspects.

\section{Product development methods}

Product development methods are often constrained to a specific discipline. In industrial design a wide variety of user-centred product development methods are available [Hoolhorst, 2012]. User-centred design is characterized by an extensive user involvement in the development process to realize a product that is user-friendly. The concept of usercentred design was originally introduced by Norman and Draper [1986] and applied on human-computer interaction design. Gulliksen et al. [2003] have composed an overview of 12 key principles to involve end-users in human-computer interaction development processes. Those principles are also very well applicable in hardware design.

\section{System development methods}

As mentioned in [Bonnema, 2008] the availability of system development methods is minimal. Well-known models include waterfall, V-model, spiral, and concurrent engineering process models, as reviewed by Pew and Mavor [2007]. They conclude that all of the models are taking human factors into account, but fall short with respect to incorporating stakeholders input during the development process. Maier and Rechtin [2000] also address needs, worries, and complications, originating from human and business aspects. They see the system designer as an 'agent of the client'. What is missing in their work is a stepwise approach in acquiring user information. Militello et al. [2010] discuss cognitive system engineering (CSE) methods that incorporate cognitive demands in systems that require dynamic human decision making activities (e.g. a warship). They conclude, based on three use cases, that in today's practice CSE is carried out independently from the other design activities carried out by the design team. Or even worse, sometimes cognitive engineering is seen as a natural byproduct of smart people using common sense. The central issue in the incremental commitment model (ICM) described in [Pew and Mavor, 2007] is risk management of system shortcomings like low usability, high rates of human error, low productivity, and safety problems. During the development process these risks are assessed by the stakeholders to estimate the feasibility of the system under design. In ICM humansystem integration methods (e.g. ethnography, personas) from the ISO standard on 
ergonomics of human-system interaction (ISO/PAS 18152, 2003) are picked to reduce risks and realize a system that meets stakeholders requirements.

Although used terminology and phase arrangement of existing product and system development methodologies might differ, most methods prescribe similar activities. The methods are developed to be generic and only give guidance with respect to the main process steps. It is up to the product development team to adapt the method to the specific project [Hoolhorst, 2012]. In this chapter our user-centred system design approach is discussed for requirements analysis and designing concepts for complex systems with critical use aspects. In our method we have taken a subset of existing activities for system architecting in system development processes and existing activities for incorporating human aspects in product development processes, as described in the following sections. To ensure that the physical outcome of our approach is user-centred 6 key principles from the ISO standard on human-centred design for interactive systems [ISO 9241-210, 2010] have been taken into account:

1. The design is based upon an explicit understanding of users, tasks and environments.

2. Users are involved throughout design and development.

3. The design is driven and refined by user-centred evaluation.

4. The process is iterative.

5. The design addresses the whole user experience.

6. The design team includes multidisciplinary skills and perspectives.

Until the UCD kick-off method introduced by Hoolhorst [2012] no methods were available to support system development teams in defining a univocal, effective and complete user-centred plan of approach. The approach presented in this work has been specified based on experience of the author and by consulting experts on user-centred design approaches and system architecting methods. There is no scientific way for verifying that our approach is best. Chapter 7 will reflect on the method by analyzing the process and the appreciation of the results of that process (conceptual and final results) by all stakeholders.

\subsection{System architecture creation}

A system architecture defines the parts constituting a system and allocates the system's functionality and performance over its parts, its user, its super system and the environment in order to meet system requirements [Bonnema, 2008]. Interviews, observations and a literature study are a good start to obtain relevant development information. Unfortunately, interpretation and translation into a list of requirements always leads to loss of information [van der Voort and Tideman, 2008]. Designers should not only rely on their own experience and common sense but have to verify requirements and ideas with end-users. For that reason recording development information into overviews, that together form a system architecture, helps to facilitate a joint understanding among all stakeholders in a development process. Good system architectures have several different overviews [TorrySmith, 2011; ISO/IEC/IEEE 42010, 2011], or shared representations as discussed in [Pew and Mavor, 2007]. Development information should be represented in an easily understandable format to include non-experts into the development process. Engineers should understand the (medical) context and physicians the technical opportunities (limitations). Verification of development information is a team process, therefore the system architecture should be easily accessible for stakeholders with different backgrounds. A common pitfall of architecture overviews is a high degree of too abstract and too 
academic statements [Muller, 2012]. The adage "a picture is worth a thousand words" should be kept in mind when creating a system architecture.

In Figure 2.1 an overview is shown of all steps involved in system architecting according to our method. Evaluation by stakeholders is essential in that process.

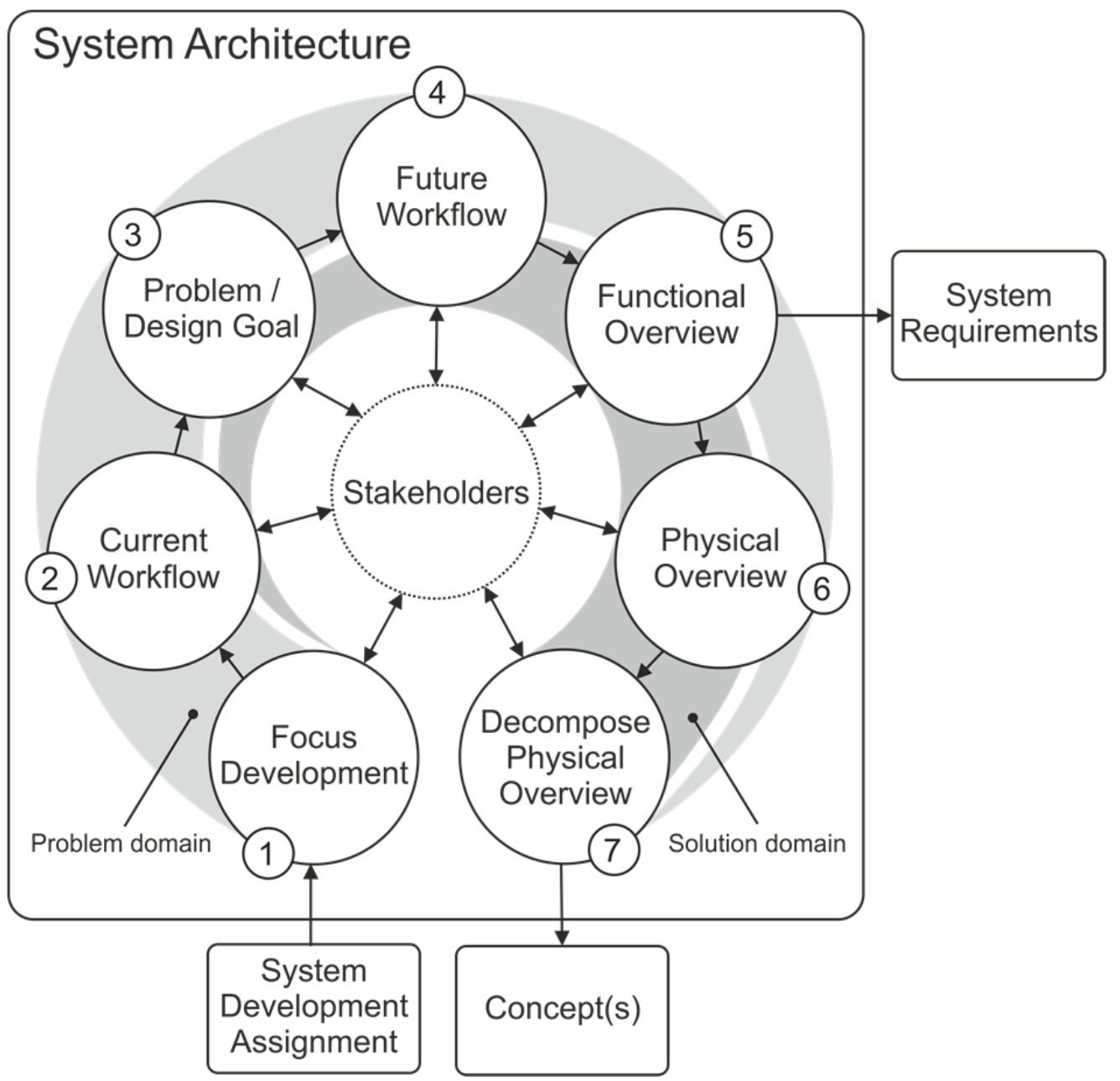

Figure 2.1 Overview of system architecture creation and evaluation

In our approach the problem domain and solution domain are closely coupled. By iteration through frequent hopping between the two domains, a problem can be investigated by a (conceptual) solution, and a solution can be evaluated by comparing it to the problem description and use scenario's. The first 5 steps are mainly focused on requirements finding, but from step 3 on the first concrete system ideas already appear. Actually, the solution domain is already entered by composing the system development assignment. It is not possible to formulate the assignment without referring to the solution [Hoolhorst, 2012]. Step 6 and 7 target the synthesis of system concepts (solutions). However, in this process system knowledge will evolve and requirements (and their related overviews in the problem domain) are updated. The next sections describe in more detail all steps that have been executed to create the system architecture of the robotic flexible endoscope. 


\subsubsection{Step 1 - Focus development}

Insufficient focus could result in a system that does not comply with stakeholders expectations and will not be adopted. Common mistakes are for instance that a system cannot be easily integrated into practice, is ahead of its time, or is too complex. Designers should verify if their interpretation of the initial assignment matches with end-users demands. At least end-users should be interviewed about what they expect from the system under development. The essence of the objectives of the customers can be captured in terms of key drivers. The key drivers provide direction to capture detailed requirements and to focus the development [Muller, 2004]. For the present research project a user group of medical specialists in general surgery, cardiothoracic surgery, urology, and gastrointestinal endoscopy is formed. From interviews and attending clinical interventions the design team composed the following key drivers:

- Intuitive and user friendly control.

- Single person control.

- Backwards compatibility with existing gastro- and colonoscopes.

The motivation for adding the first two key drivers is discussed in Section 1.3. The last key driver is added to prevent that hospitals are confronted with high costs related to replacement of endoscopic equipment. Additionally, in this way current endoscope qualities, like cleanability and good image quality, are maintained. Connection of the robotic system to the endoscope should not demand any adaptations of the endoscope.

The contact with the user group was also used to gain insight into the possible applications of the future system, and the associated functional and technical requirements from a medical perspective. A provisional list of in total 19 clinical procedures that could benefit from robotic control of a flexible endoscope has been composed. To get focus, the user group was asked to fill in a selection matrix that connects possible endoluminal and transluminal procedures to selection criteria that are formulated by the project team. The selection criteria incorporate medical as well as commercial values, like:

- Robotic surgery leads to less intra- and postoperative pain and/or scars.

- Number of hospitals that perform the procedure.

The scores of the selection matrix and the findings collected during the interviews and observations were discussed during a plenary meeting with the user group of medical experts, PhD's (industrial design, mechatronics, and control engineering) and their supervisors. In this meeting it was concluded that this project should focus on endoluminal interventions that require advanced manipulation in a limited space, like organ-sparing endoscopic removal of benign and early malignant lesions in the gastrointestinal tract (mucosectomy). However, it was also agreed to keep the door open to simpler (e.g. biopsy and polypectomy) as well as more complex transluminal (e.g. cholecystectomy) procedures. These last additions show that it is difficult to get focus in an early stage of a development process. During system development the picture of the intended design goal will become sharper and for that reason a system architecture should be a 'living' document that can be easily adapted to new insights that appear [Borches and Bonnema, 2008].

\subsubsection{Step 2 - Create workflow of current system application}

An accurate, comprehensive insight into how the current system is used in practice and the context in which system use takes place is essential for developing new systems that meet user expectations. To be able to identify problems related to current practice, the 
designer first summarizes obtained development information from interviews, observations and literature study into a workflow that describes the current way of working and the devices that are used.

In Figure 2.2 one of the workflows is shown that is composed. It contains the main steps for performing endoscopic submucosal dissection (ESD). ESD is one of the most demanding therapeutic endoluminal procedures performed in the clinic, as discussed in Section 1.3. The required functionality of the robotic flexible endoscope to perform this procedure is a good starting point for a more generic system to perform advanced endoluminal procedures, being our focus area of development. In Appendix A a workflow of performing a colonoscopy is depicted, as being representative for a diagnostic procedure.
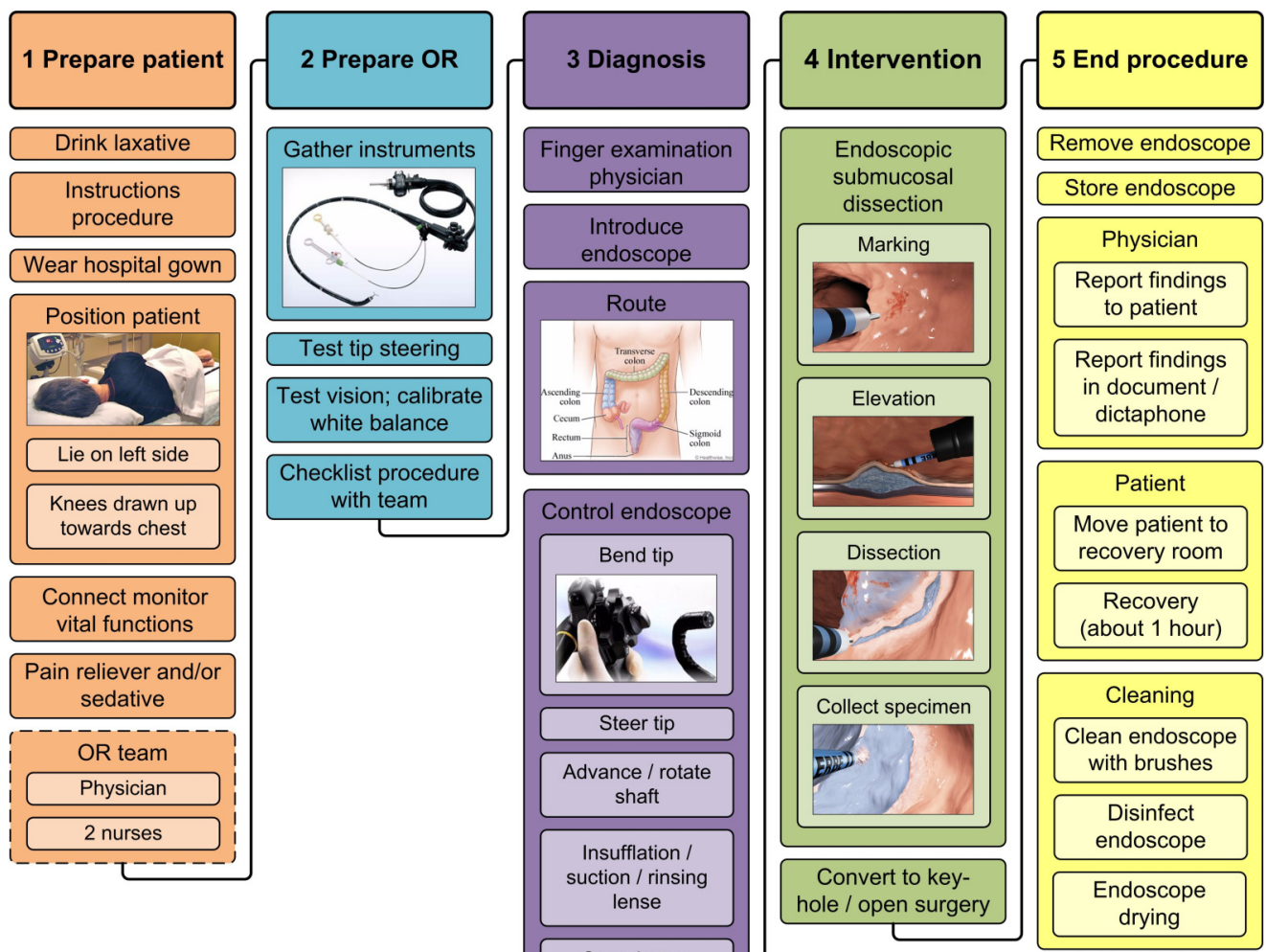

Figure 2.2 Main steps in the current workflow of endoscopic submucosal dissection 


\subsubsection{Step 3 - Determine problem definition and design goal}

Setting up the current workflow(s), as described in the previous section, helps to determine a problem definition and to set a common design goal for the system under development. Creating the workflow enforces the designers to critically look at all steps involved in the use of a system and to reveal problems.

What became clear from analyzing, documenting, and reviewing the current workflow in flexible endoscopy is that physicians are not completely in control while interacting with patients, as already discussed in Section 1.3. The main cause for reduced usability is related to the high number of degrees of freedom of the endoscope and the instruments and the way they are operated. In Chapter 1 the degrees of freedom in use for diagnostic procedures (Figure 1.4), existing therapeutic procedures (Figure 1.5), and experimental therapeutic procedures (Figure 1.7) have already been discussed. These are traced by composing the current workflows, like the one for an existing therapeutic ESD procedure (Figure 2.2) as presented in the previous section. In the following chapters a more in depth discussion will be presented with regard to handling problems and other problems of flexible endoscopy, that were revealed while composing the current workflows.

It can thus be concluded that at this time no flexible endoscopy equipment is available that allows a single physician to perform diagnostic and therapeutic procedures in an intuitive and user-friendly way. The goal of this project is to realize such equipment. Section 1.6 already described the specific tasks performed to realize this goal.

\subsubsection{Step 4 - Create workflow of future system application}

The next step is to translate the current workflow into the future workflow using the basic structure shown in Figure 2.2. In the future workflow current problems are eliminated and major product wishes are fulfilled. It is a high level description of personnel and procedural steps involved. The future workflow helps to understand the context of use and shows critical development aspects. Creation of the future workflow is a creative process that can be supported by creativity methods, like brainstorming [Roozenburg and Eekels, 1995]. Additionally, it is an iterative process that requires stakeholder's contribution and evaluation to come up with a viable overview.

Figure 2.3 shows a conceptual future workflow of endoluminal therapy using an advanced endoscopic intervention platform. Robotic modules are implemented, while taking account of the overall clinical workflow in the hospital. Some preliminary concepts already appear when creating the future workflows. These concepts already contain important project key drivers like single person control and backwards compatibility of the system with existing endoscopes. The future workflow is composed to identify conceptual solutions and to discuss them with stakeholders to assess the feasibility. 

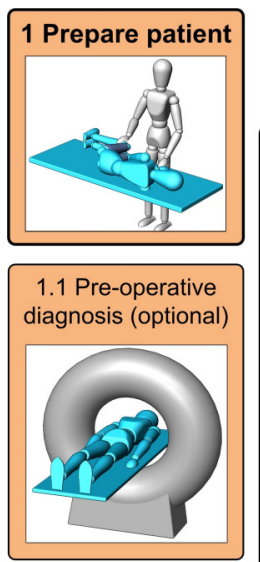

1.2 Position patient

1.3 Connect monitor vital functions
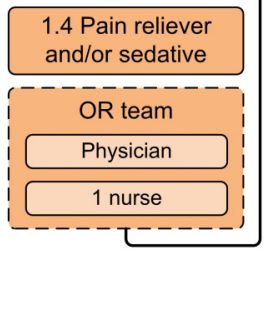

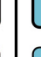

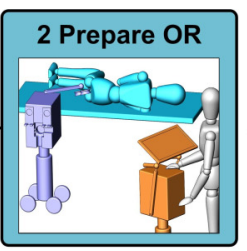

2.1 Position slave and master

2.2 Connect endoscopic platform
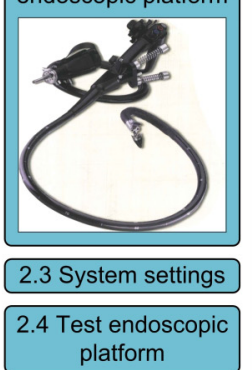
platform

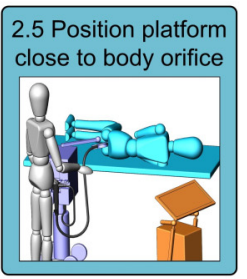

2.6 Checklist procedure with team
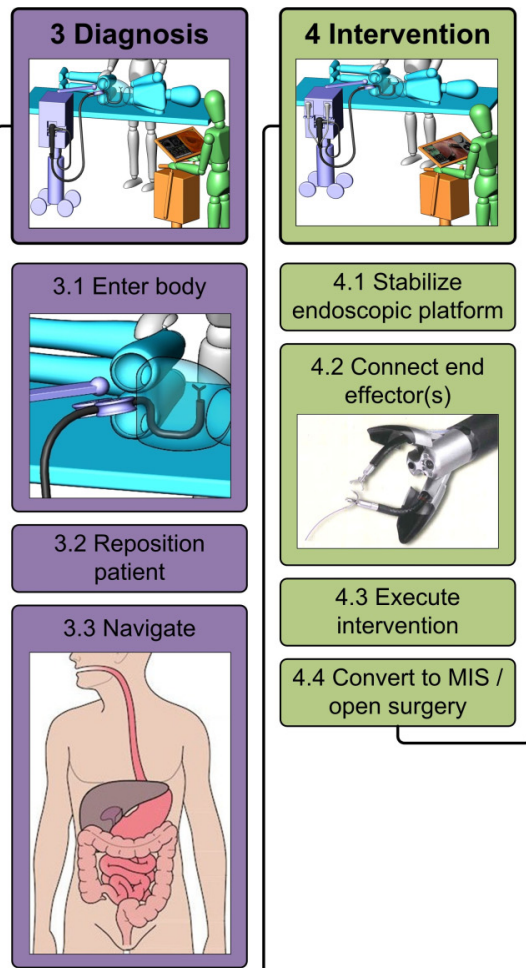

4.3 Execute intervention

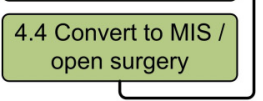

3.4 Diagnose lumen

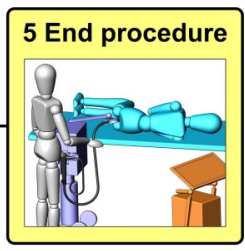

5.1 Retract platform and end effectors

5.2 Report findings 5.3 Turn off system

5.4 Detach endoscope from slave

5.5 Reposition slave and master

5.6 Move patient to recovery room

5.7 Clean / sterilize endoscope

5.8 Clean and maintain total system

Figure 2.3 Concept of the future workflow for endoluminal therapy

\subsubsection{Step 5 - Create functional overview}

A functional overview shows how the general goal of a system is achieved by the realization of functions. This decomposition into functions and sub functions is useful for managing complex systems. For building a functional overview the workflow of future system application (Figure 2.3) is a suitable starting point. Figure 2.4 shows a conceptual functional overview of endoluminal therapy using an advanced endoscopic intervention platform. 


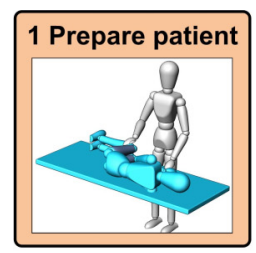

1.1 Pre-operative diagnosis (optional)
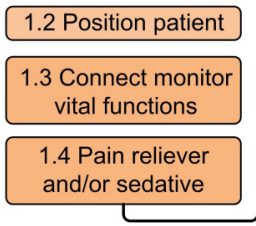

and/or sedative
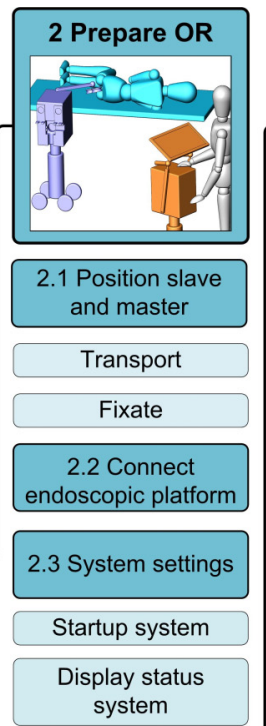

Settings graphical interface

\begin{tabular}{|c|}
\hline $\begin{array}{c}\text { Settings body } \\
\text { posture }\end{array}$ \\
\hline $\begin{array}{c}\text { Settings input } \\
\text { devices }\end{array}$ \\
\hline
\end{tabular}

Settings feedback
devices

\begin{tabular}{|c|}
\hline $\begin{array}{c}2.4 \text { Test endoscopic } \\
\text { platform }\end{array}$ \\
\hline Test irrigation \\
\hline Test suction \\
\hline Test air flow \\
\hline Display image \\
\hline $\begin{array}{c}\text { Calibrate white } \\
\text { balance }\end{array}$ \\
\hline
\end{tabular}

Adjust color balance, brightness, contrast of camera

Adjust light intensity

2.5 Position platform close to body orifice

Fixate platform noninvasive

\begin{tabular}{|c|}
\hline 2.6 Checklist \\
\hline Patient file \\
\hline Procedure \\
\hline
\end{tabular}

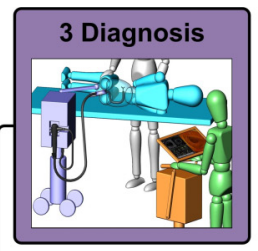

\subsection{Enter body}

Feed platform

Rotate platform

Steer tip platform

\section{Control air flow}

Irrigation

Suction

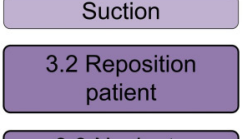

3.3 Navigate

Show shape platform

Guidance

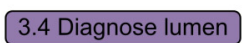

Display

intraoperative data

Real view,

Ultrasound

Spectroscopy

Clean lens

Zoom

Store image

Store video

Annotate image

Settings

Display vital functions patient

\section{Display preoperative} data

CT, MRI, etc.

Connect to databank

\section{Zoom}

Annotate image

Settings

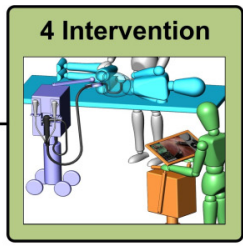

4.1 Stabilize endoscopic platform

Fixate platform invasive

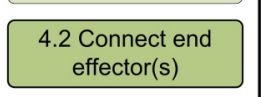

Feed end effector(s)

Connect to slave

4.3 Execute intervention

\section{Steer tip endoscopic platform \\ 5.7 Clean / sterilize endoscope}

Irrigation

Suction

Control air flow

Control end effectors

Cut / coagulate

Grasp

Suture / Glue

Needle biopsy

Exchange end effector(s)

Reposition platform

Collect removed structures

\subsection{Convert to MIS /} open surgery

Retract platform and end effectors

Reposition slave and master

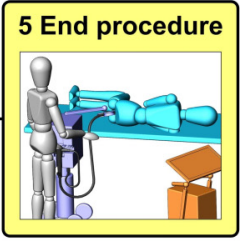

5.1 Retract platform and end effectors

5.2 Report findings

5.3 Turn off system

5.4 Detach

endoscope from slave

5.5 Reposition slave and master

5.6 Move patient to recovery room

5.8 Clean and maintain total system

Figure 2.4 Conceptual functional overview of endoluminal therapy 
Although the present research project is mainly focused on improving the usability of controlling all degrees of freedom of the endoscope and the instruments, all other functions that are in use in robotic endoluminal therapy need to be mapped too. Some of these functions may interact with the robotic flexible endoscope and require specific (software, electrical, or mechanical) interfaces. In Section 3.4, 4.4, and 5.4 critical functions are addressed and design directions are discussed.

The functional overview gives a high level description of the required functions. An additional system requirements document that contains detailed functional and technical requirements is needed for engineers to design the final system. The functional requirements provide detailed information about the context of use. A typical functional requirement for a user interface for telemanipulated surgery with flexible instruments is: "Input device is able to eliminate hand tremor". In the technical requirements the functional requirements are specified and quantified, for example: "Input device algorithm filters human hand tremor frequencies of 10 to $100 \mathrm{~Hz}$ with amplitudes of $0 \mathrm{~mm}$ to $2 \mathrm{~mm}$ ".

\subsubsection{Step 6 - Create physical overview}

In this section the transition of a functional overview into a physical overview is discussed. A physical overview (or scheme) is an outline solution to a design problem, carried to the point where the means of performing each major function has been fixed, as have the spatial and structural relationships of the principal components [Bonnema, 2008]. Several physical overviews could be created to visualize different thoughts of the envisioned system. These have to comply to the functional and technical requirements and should be evaluated with end-users. Four to six concepts are feasible; they can be made sufficiently different and they can be worked out far enough without wasting too much effort [Bonnema, 2008]. Like for creating the future workflows in Section 2.2.4, creativity methods [Roozenburg and Eekels, 1995] can be very helpful to create physical overviews.

In building physical overviews the focus was first directed to the components related to actuation of the degrees of freedom and the user interface(s) required to control them. A schematic overview of required components in the most advanced setup of the robotic flexible endoscope is depicted in Figure 2.5. It is derived from Figure 1.7 that showed the degrees of freedom of a manually controlled advanced endoscopic intervention platform with steerable instruments. In Chapter 5 the robotic setup will be discussed in detail. 


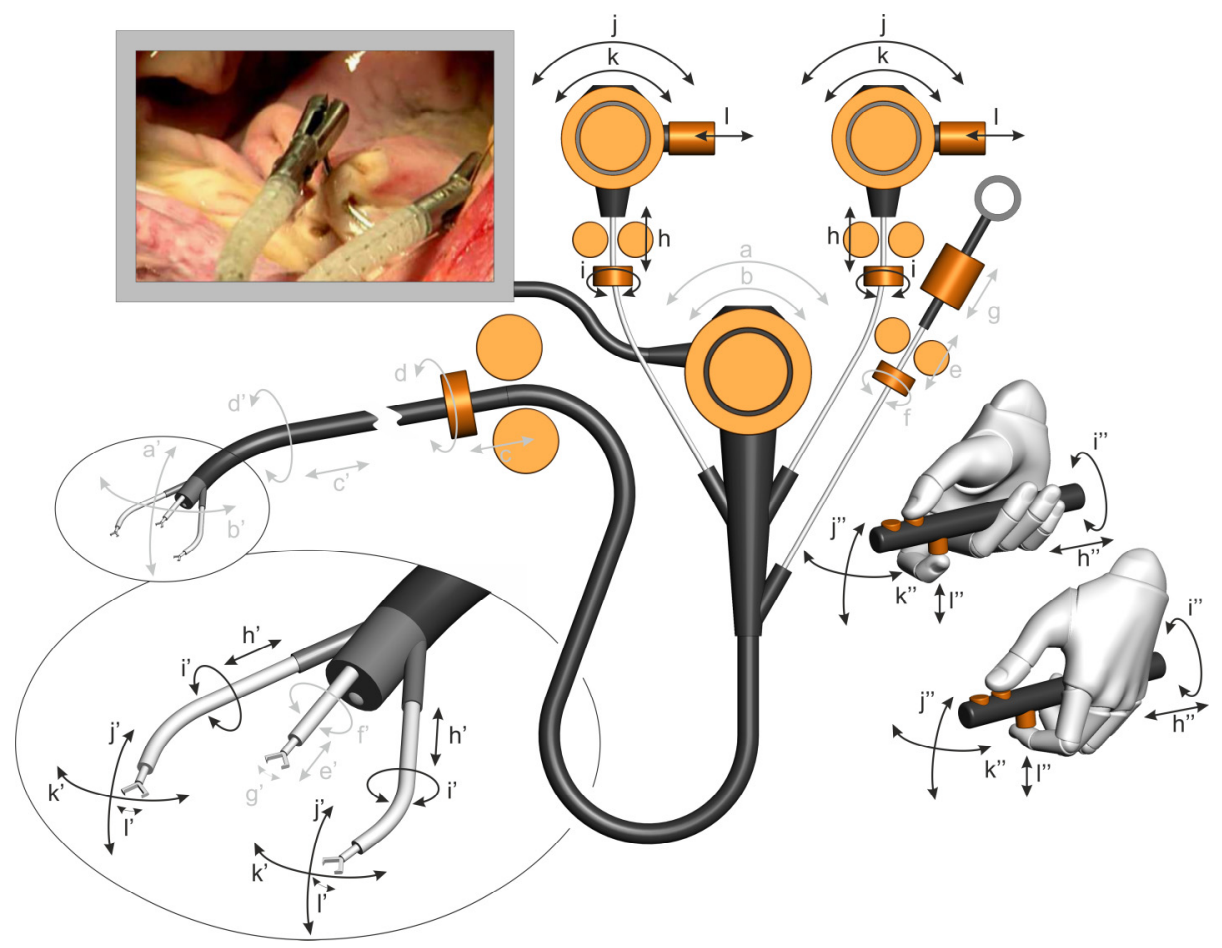

Figure 2.5 Schematic overview of degrees of freedom, actuators, and possible user interface devices of an robotic advanced endoscopic intervention platform

Subsequently, the spatial and structural relationship between the components has been captured in $3 \mathrm{D}$ visualizations. In this way the implementation of the robotic flexible endoscope in the clinical workflow and the usability consequences for personnel could be communicated with stakeholders. In addition, for internal documentation, concept choices are reported in a concept design description; a reference document that secures the argumentation for choosing specific physical components, their functions and their relations. In Figure 2.6a an example is given of a physical overview of the robotic flexible endoscope with steerable instruments.
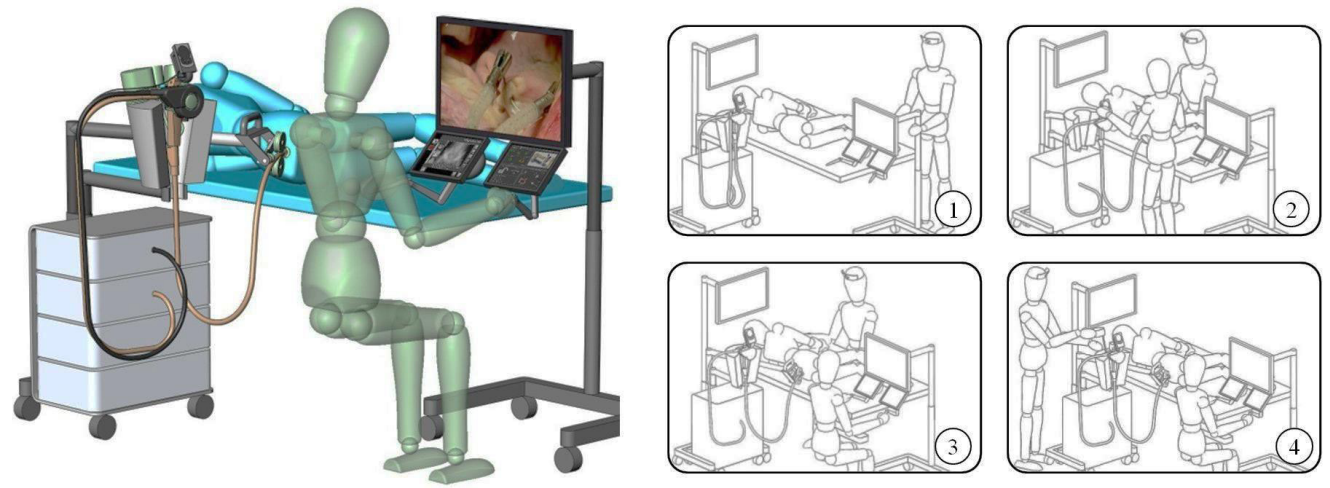

Figure 2.6 (a) Conceptual physical overview; (b) Updated conceptual future workflow 
During the development process knowledge of the system will evolve, and thus the components of the system architecture will evolve. The physical overviews can for instance be used to update the future workflow, as illustrated in Figure 2.6b. It is an opportunity to present stakeholders a sharper picture of the intended design goal. It is a good way to verify if the development process is still on the right track.

\subsubsection{Step 7 - Decompose physical overview into manageable modules}

$\mathrm{Up}$ to now the system is considered as being an integrated solution. There are an enormous number of issues to consider. The only way to create these systems is to divide and conquer. The determination of the division-lines is what system architecting is about. However, how the decomposition from system level to subsystem level is created is difficult [Bonnema, 2008]. In this project modular decomposition is used to divide the complete system in functional modules that operate apart from each other and can be tested separately. In this way technical and usability tests of modules could be conducted in an early phase and the risk of being confronted with major issues in the integration step was limited.

Besides the described benefits for development, decomposition of the system into largely self-contained parts is also beneficial for the end user. Modularity of our system allows endusers to customize the robotic endoscope to their clinical requirements. For diagnostic procedures it suffices to only use a steering module that improves the usability of navigating the endoscope through the digestive tract. For (experimental) therapeutic procedures additional modules can be integrated that allows a single user to control advanced endoscopic intervention platforms. In total three robotic modules are defined that support physicians in performing diagnostics, existing therapy, and experimental therapy.

\section{Robotic steering module - diagnostic procedures}

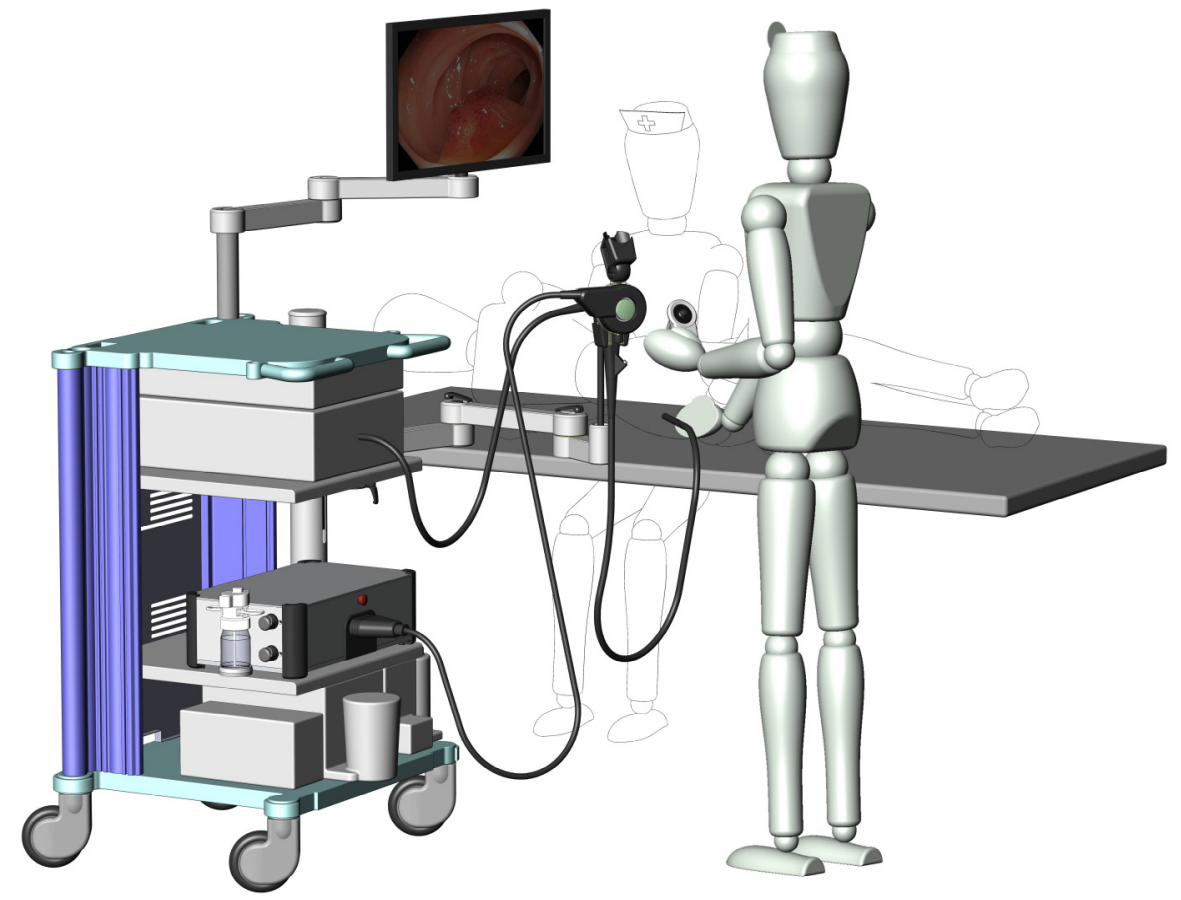

Figure 2.7 Robotic steering for diagnostic procedures 
The control section of a traditional endoscope is not ergonomic, user friendly and intuitive in use, as discussed before. In the robotic setup the controls (navigation wheels and buttons) are actuated by motors combined in a drive unit. With a dedicated remote control the deflection of the tip, insufflation, rinsing, suction and the programmable switches (e.g. photo, video, narrow band imaging) are controlled by the physician with one hand, while the other hand manipulates the shaft of the endoscope, as shown in Figure 2.7.

\section{Robotic shaft manipulation module - existing therapeutic procedures}

With the addition of instruments in therapy, single person control can only be obtained if the flexible endoscope can be operated with one hand and instruments with the other. The robotic steering module is combined with a robotic module that actuates the shaft of the flexible endoscope. The physician uses one multi-degree-of-freedom (multi-DOF) input device to steer, advance, rotate, and maintain the position of the motorized flexible endoscope, while the other hand is able to manipulate instruments, as shown in Figure 2.8.

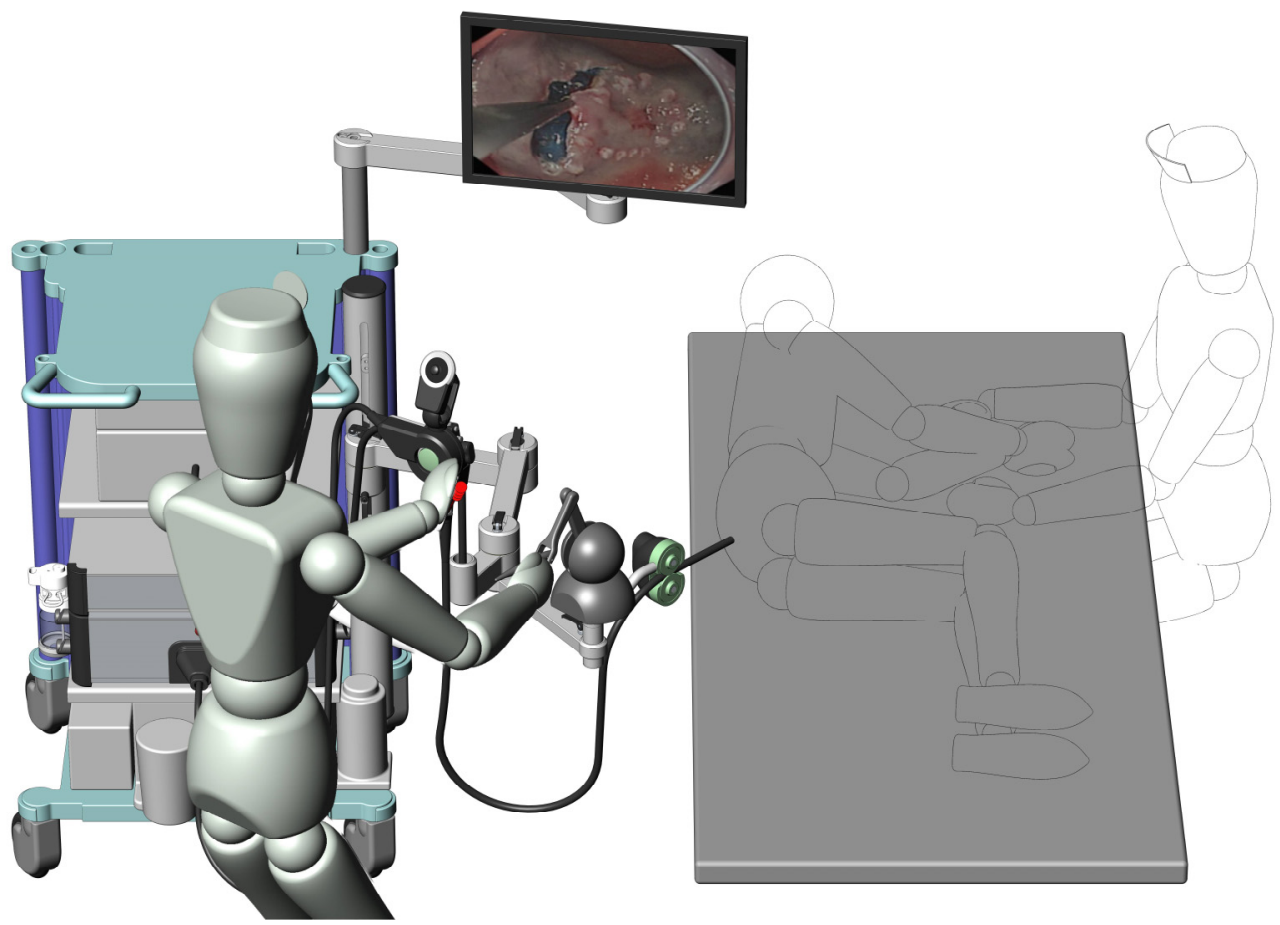

Figure 2.8 Robotic shaft manipulation for existing therapeutic procedures

\section{Robotic instrument manipulation module - experimental therapeutic procedures}

The instrument manipulation module is used to control the motions of advanced endoscopic instruments with multiple degrees of freedom. These instruments are designed to allow complex actions like suturing to be performed. It is noted that such instruments are not commercially available yet and as such this module is the most experimental. Given the high number of degrees of freedom the physician has to manage, an optimized working console needs to be developed providing a comfortable working posture, structured data presentation, and dexterous input devices. The complete setup is shown in Figure 2.9. 


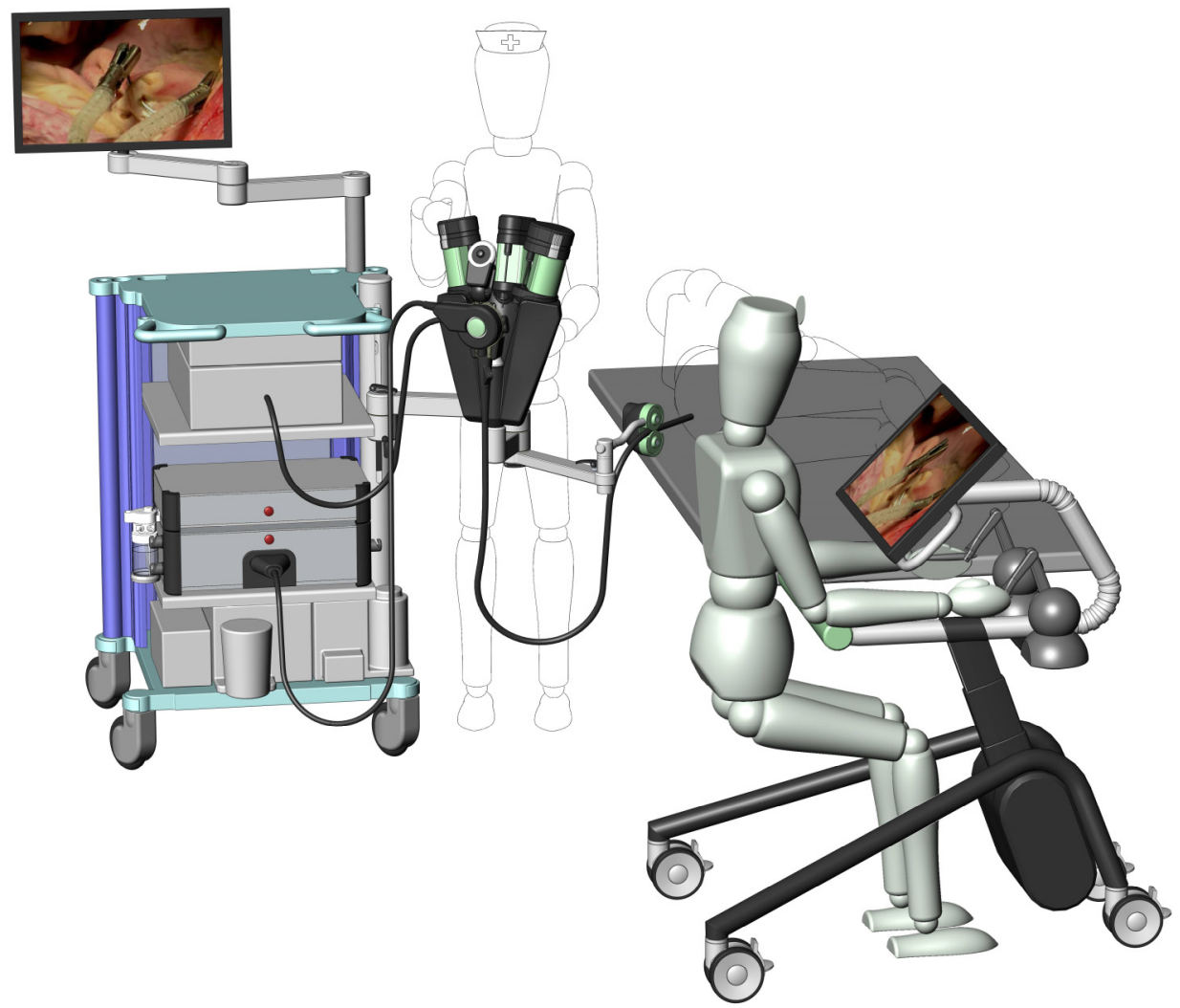

Figure 2.9 Robotic instrument manipulation for experimental therapeutic procedures

The robotic steering module (Figure 2.7) is discussed in Chapter 3, the robotic shaft manipulation module (Figure 2.8) in Chapter 4, and the robotic instrument module (Figure 2.9) in Chapter 5. The fit between the separate modules, both in geometry and functionality is checked constantly during the development process.

\subsubsection{Evaluation of the system architecture by stakeholders}

The overviews created in the previous seven steps form together the system architecture of our robotic flexible endoscope. A lot of knowledge has been retrieved from literature. It contributed significantly to the realization of the system architecture. However, since in this work new knowledge and new technology is created, additional research methods were required. As stated before stakeholders have contributed to this process. The system architecture has been evaluated during its creation by stakeholders. From the start clinical personnel were involved in verifying our ideas about how a robotic flexible endoscope should be fitted into clinical practice. In a later stage, when the ideas became more concrete and were visualized into concepts, system manufacturers were also asked to judge its feasibility. Because the concepts were presented in an easily understandable format, mostly rendered 3D views, the added value of our robotic flexible endoscope could be shown to commercial partners already in an early stage. They became partners in our project and provided valuable feedback. 
Regular contact with the stakeholders has been very helpful in giving the project the right direction. Concrete steps that have been taken to incorporate knowledge about the use and user during the creation and evaluation of the architecture overviews are:

- The user group of medical experts has been interviewed one-on-one by means of a questionnaire

- Clinical personnel is observed and interviewed during interventions.

- The user group of medical experts has filled out a survey on possible clinical interventions

- A plenary meeting with the user group of medical experts, PhD's, and their supervisors has been organized. In this meeting the focus interventions, the most important concluding remarks from the interviews, and the future workflow of system use were discussed.

- Brainstorm sessions have been organized with medical experts, PhD's, supervisors, and engineers.

- Physical overviews have been discussed with several experts in general surgery and gastroenterology from hospitals in Almelo, Amersfoort, Enschede, Hengelo, and Utrecht.

- Progress has been evaluated in plenary project team meetings, scientific team meetings, technical team meetings, and $\mathrm{PhD}$-supervisor(s) meetings.

The results of these activities are in part already presented in the previous sections and will be further addressed in the remainder of this thesis.

\subsection{Realization and evaluation of proof-of-principles}

The complete proof-of-principle phase, the focus of the present research, is subdivided into four steps: definition, concept design, realization, and evaluation. In the first two steps our user-centred system design approach is used, as discussed in the previous sections. To ensure a structured as well as user-centred approach in the realization and evaluation steps as well, the $\mathrm{V}$-model has been adopted to structure the complete user-centred design process. The V-model shows the relationships between each phase of the development process and its associated phase of testing [Blanchard and Farbrycky, 2008]. In the V-model the different evaluation moments are clearly depicted. The four steps of the proof-of-principle phase can be projected on the V-model, as shown in Figure 2.10. 


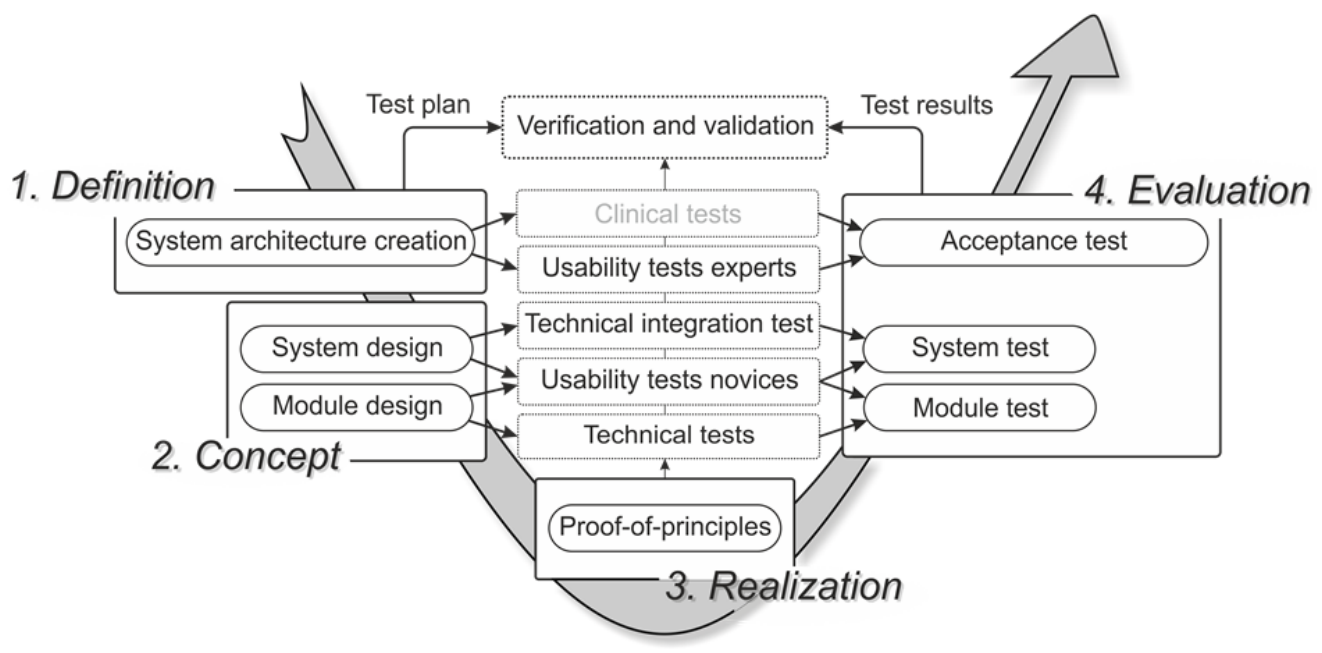

Figure 2.10 V-model of proof-of-principle development steps

\subsection{Discussion}

In this chapter an user-centred system design approach has been presented that supports composing a system architecture. The system architecture consists of detailed overviews such as schemes, flow charts, documents, and 3D rendered views that were obtained by executing the seven steps of the method. The main goal of system architecting was to acquire knowledge about the use and user of the system in a structured way. By composing the overviews and discussing them with stakeholders the author was able to define the robotic modules (Section 2.2.7) required to fulfill all stakeholders' needs and desires, being the most important result.

As stated in the introduction of this chapter the user-centred system design approach was created for this project and was not a goal in itself. There is no scientific way for verifying that this approach has been the most appropriate one for the present problem. Chapter 7 will reflect on the method in relation to the final system and its appreciation by important stakeholders. Since physicians have very strong expectations about usability, this approach might also be useful when developing other (non-medical) complex systems in which user interaction is critical. The steps involved have been defined based on more than 10 years of industrial design experience of the author of this work and discussions with experts on usercentred design approaches and system architecting methods. The method is mainly based on visualizing ideas and verifying these overviews with stakeholders. This implicates that the design team should have the skills (and tools) to be able to clearly present ideas to stakeholders.

The methodology supports in translating an abstract system development assignment into a concrete concept proposal that meets stakeholder's requirements. However, stakeholders contribution should not stop with the completion of a system architecture. Ideas are still on paper and need validation in experiments. For that reason proof-of-principles of the robotic modules have been built and are tested in various experiments by stakeholders, as discussed in the following chapters. 


\section{3 \\ Robotic steering module - diagnostic procedures}

In diagnostic procedures the physician faces problems in manipulating the flexible endoscope. A lot of experience is required to master the procedure. This chapter describes the design and evaluation of the robotic module that improves camera steering of traditional endoscopes. Critical use aspects of traditional endoscopes are identified and addressed in the robotic setup. In our design the physician uses a remote control that steers a compact and light drive system that is coupled to the endoscope. An experiment is conducted to judge the usability of the system. Results show that robotic steering increases efficiency and satisfaction.

This chapter is a revised version of paper:

J.G. Ruiter, E.D. Rozeboom, M.C. van der Voort, G.M. Bonnema, I.A.M.J. Broeders, Design and Evaluation of Robotic Steering of a Flexible Endoscope. In Proceedings of International Conference on Biomedical Robotics and Biomechatronics, pp. 761-767, Rome, 2012. 


\subsection{Introduction}

Experience is necessary to master the procedure of inserting, steering, and executing small interventions with a flexible endoscope. Performing a colonoscopy to inspect the large intestine is one of the most demanding diagnostic endoluminal procedures performed in the clinic. It requires extensive training to perform the procedure safely and within reasonable time. According to [Tassios et al., 1999] and [Harewood, 2005] about 100 to 200 procedures are required. Figure 1.4 showed the setup for performing a colonoscopy.

No revolutionary changes have occurred in endoscope handling technology during the last five decades. The three major endoscope manufacturers Olympus, Pentax and Fujinon use similar concepts. At present there are no flexible endoscopes available that can be controlled in an intuitive and user-friendly way by one person. Main usability problems are related to the control section at the proximal end of the colonoscope [Niwa and Williams, 2009; Barlow, 2009; Williams, 2009]. The navigation wheels for camera steering and the ergonomics of the control section are identical to those of gastroscopes, designed half a century ago to be steered with two hands [Williams, 2009]. In current practice to obtain single person endoscope control, the left hand alone manages the control section, while the right hand manipulates the flexible shaft. Because of the configuration of control elements, physicians face handling problems. Often both hands are used for the control section, while an assistant manipulates the shaft according to spoken instructions [Liberman et al., 2005; Dykes, 2009]. This is undesirable since introducing the flexible endoscope into the tortuous and elastic colon is a delicate task that requires interpretation of force feedback information to support steering. Inefficient steering may lead to time loss and excessive stretching of the intestinal wall, leading to increased patient discomfort [Kim et al., 2000].

A long term solution is to redesign the control section. However, despite the limited usability, current flexible endoscopes are widely used systems with qualities like cleanability, maneuverability, and good image quality [Bardou et al., 2009]. An add-on robotic steering module positioned on a traditional endoscope is proposed. An ergonomic input device is used to steer up-down and left-right of the bendable tip with one hand, while the other hand is used to manipulate the shaft. Key factor is that tip steering and tip actuation are mechanically decoupled and computer intelligence is integrated to realize single person userfriendly control. In Figure 3.1 the motorized and manual operated degrees of freedom of the robotic flexible endoscope are indicated and how displacements of the input device are linked to endoscope movements. 


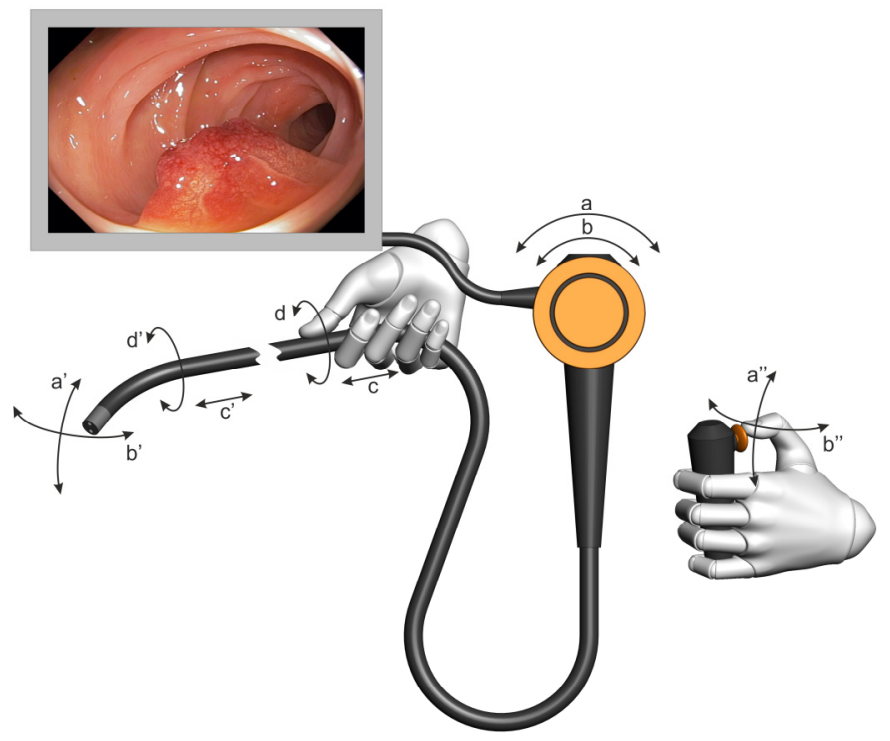

Figure 3.1 Degrees of freedom robotic flexible endoscope for diagnosis: (a) Robotic up-down, (b) Robotic left-right, (c) Manual in-out, (d) Manual (counter)clockwise rotation

Robotic steering of a traditional endoscope has the potential to improve usability, preserve current endoscope qualities, and prevent high costs related to replacement of endoscopic equipment. Acceptance is expected to be high, since the robotic setup fits the current workflow and infrastructure. The focus has been on the enabling technology to easily perform a colonoscopy. However, the interfaces of gastroscopes (for upper gastrointestinal endoscopy), duodenoscopes (for inspection of the duodenum and access to the bile and the pancreatic duct), and sigmoidoscopes (for sigmoid inspection) are similar, so the presented technology is expected to be also suitable for performing procedures with these endoscopes.

This chapter discusses the development and evaluation of the robotic steering module. Section 3.2 starts with the state of the art in robotic steering of flexible endoscopes. In Section 3.3 shortcomings of the current user interface are discussed. Section 3.4 describes the design considerations for our system. In Section 3.5 the design is specified and shown. Section 3.6 contains the results of the experiments that are conducted. Finally, Section 3.7 concludes and provides directions for future work.

\subsection{Related work}

Although the benefits are known of robotic steering, in current clinical practice all types of flexible endoscopes are operated manually. In literature (papers and patents) a lot of concepts for robotics in this field are discussed. This section discusses the most interesting concepts.

Patent research shows that Olympus, market leader in flexible endoscopy, has the majority of patents. However, none of the filed ideas regarding robotics are commercialized yet and the steering concepts of commercial flexible endoscopes have not changed for decades. All patents are based on integration of actuators in the flexible endoscope. Figure 3.2 shows a typical system setup from one of the patents of Olympus. The dedicated motorized flexible endoscope (no. 114) is mounted on a swivel arm and steered with a remote controller (no.12) [Adachi, 2008]. 


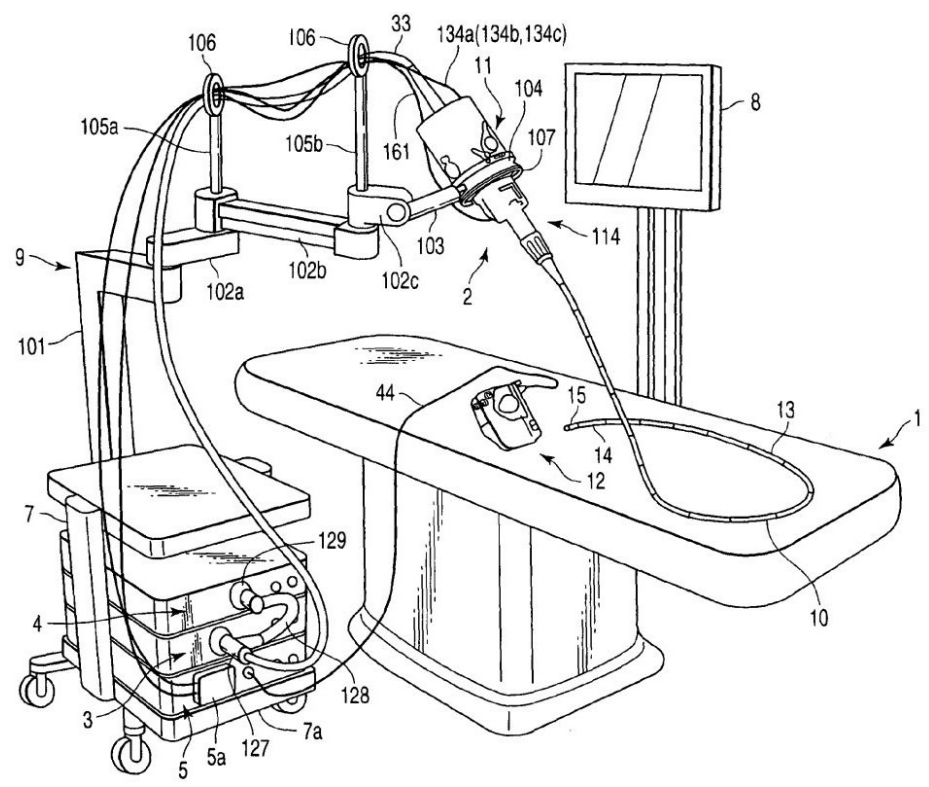

Figure 3.2 Patented robotic endoscope technology of Olympus [Adachi, 2008]

Besides patents several papers are published that describe systems that are designed to be less skill dependent compared with the user interface of conventional endoscopes. Bar-Meir [2009] and Gaglia et al. [2010] highlight technical innovations of these new endoscopic devices. None of them is commercially available and all of the described systems are based on a complete new design of the endoscope (e.g. segmented, disposable, and pneumatic driven endoscopes). One of the most promising systems and recently approved for clinical introduction, the Invendoscope ${ }^{\circledR}$ (Invendo Medical, Kissing, Germany), is shown in Figure 3.3. It is a motor-driven colonoscope, in which all endoscope functions including insertion and withdrawal, deflection of endoscope tip, rinsing, suction, insufflation and recording of images are controlled by a handheld remote control. It is not pushed or pulled, but driven in and out of the colon with an integrated inverted sleeve technology that allows the distal tip to advance in the lumen without movement of the shaft. This reduces patient discomfort. The system uses a dedicated colonoscope that is only suitable for single use [Groth et al., 2011].

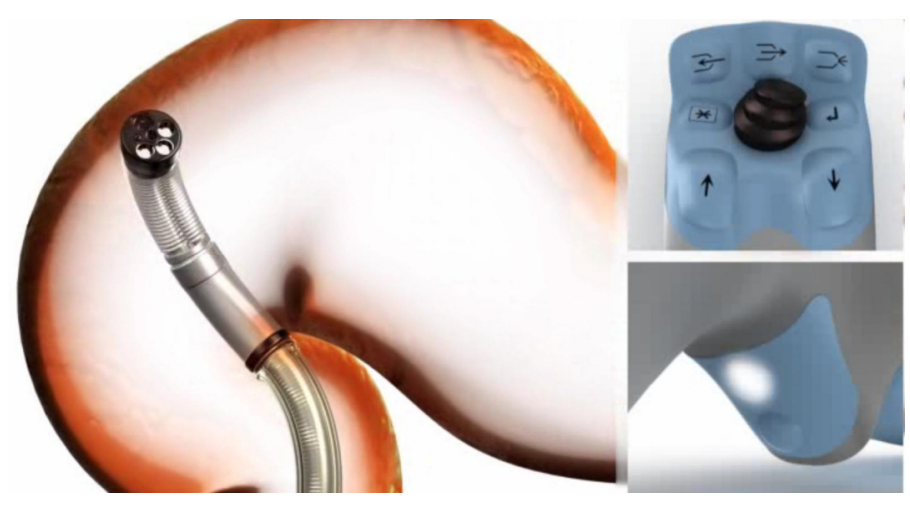

Figure 3.3 Invendoscope ${ }^{\circledR}$ (C2012 Invendo Medical) 
Some research groups have designed robotic systems that make use of standard flexible endoscopes. North et al. [2012] have worked on a remote controlled duodenoscope to perform endoscopic tasks within a MRI environment. The remote controller has the same geometry and position of control elements as the control section of the duodenoscope. Trained endoscopists were positive about the familiarity of the user interface. Loss of tactile feedback due to the remote actuation was appointed being a disadvantage. Performance of the robotic system in relation to manual operation was not tested. In the setup of Dupont et al. [2012] all degrees of freedom of a standard neuroendoscope as well as those of a simultaneously used instrument are controlled with a dual joystick master. No results are presented about the usability of the user interface. This is allocated as being future work. Allemann et al. [2009] have developed a system with a game joystick to control a motorized traditional gastroscope (Figure 3.4). In their evaluation both novices and experienced physicians needed significantly more time to complete a given task when using a joystick compared with conventional controls. They concluded that possibly the limited maneuverability of the endoscope positioned in the setup is responsible for the disappointing results.

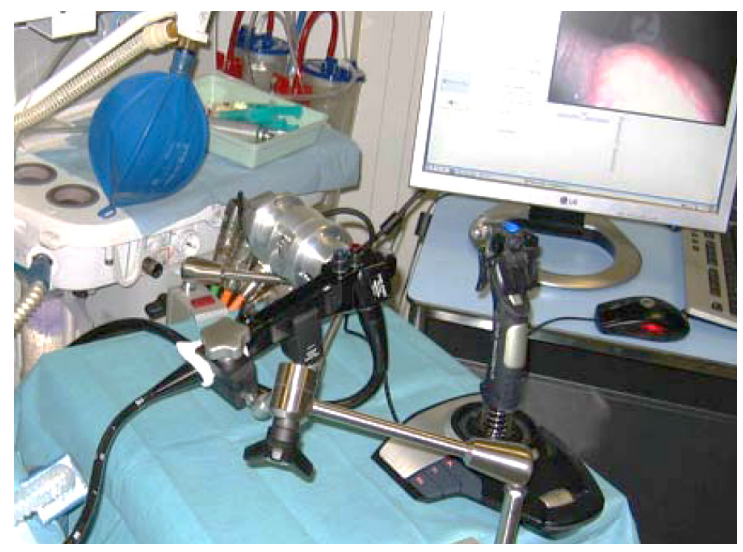

Figure 3.4 Experimental setup Allemann et al. [2009]

Zhang et al. [2002] performed a comparable experiment with a joystick controller and a fixed motorized endoscope. They concluded that the time required to finish the process relies on the degree of familiarity with the robot system. After 3-5 test runs an expert in flexible endoscopy performs equal in both techniques. Nevertheless, the lack of proprioceptive feedback was indicated to decrease the effectiveness of the system. Reilink et al. [2011] conducted an experiment with a six degrees of freedom haptic device coupled to a stationary motorized colonoscope. Experts were faster when using the conventional steering method compared with the motorized steering method. Students who had done flexible endoscopy training showed no significant differences.

Although traditional endoscopes are used in all above work, endoscope handling opportunities were inferior to the current manual steering concept. In literature only one robotic flexible endoscope is described that can be manipulated freely. In Figure 3.5 a motorized rhino endoscope is depicted that is designed by Fang et al. [2012] and that can be controlled by the physician with one hand while the other hand introduces the shaft. It is like our system designed to support the physician in navigating the lumen, but the endoscope's interface, its application, and its manipulation is totally different compared to colonoscopes. 


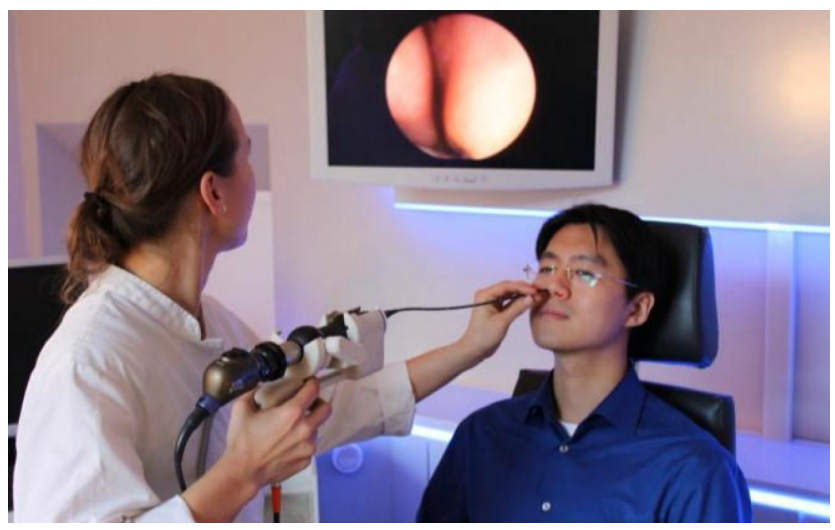

Figure 3.5 Motorized rhino endoscope [Fang et al., 2012]

To conclude, it appears that at this time no robotic flexible endoscopes are available that support in performing a colonoscopy, complies with user expectations, and can be easily fitted in clinical practice. The remainder of this chapter discusses the design and evaluation of such a robotic flexible endoscope for diagnosis. To start, in Section 3.3 shortcomings of the current user interface are discussed

\subsection{Current user interface shortcomings}

As discussed in the introduction main usability problems in flexible endoscopy are related to physician-instrument interaction. In the present setup the left hand steers the distal tip by turning two concentric navigation wheels on the control section (Figure 3.6).

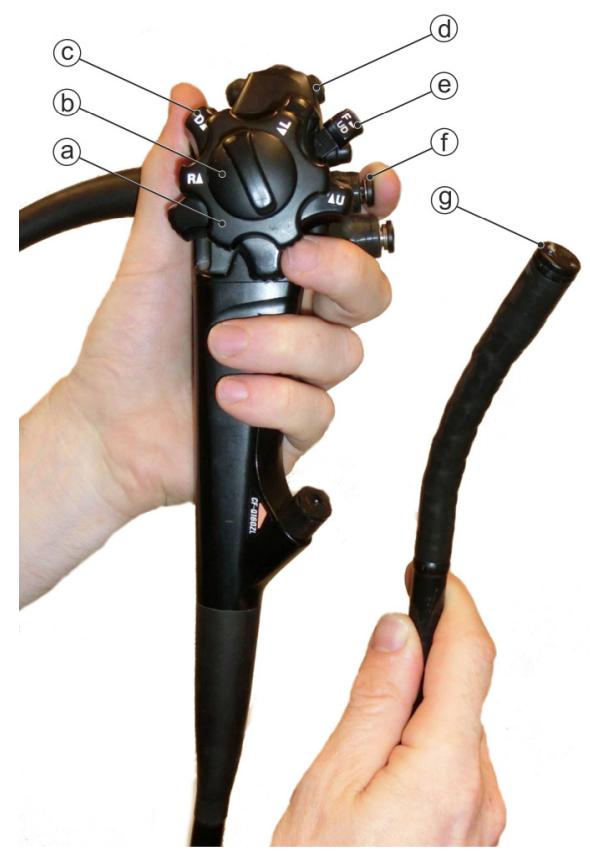

Figure 3.6 Control section endoscope: (a) Navigation wheel left-right, (b) Lock navigation wheel left-right, (c) Navigation wheel up-down, (d) Programmable switches, (e) Lock navigation wheel up-down, (f) Valves for insufflation, rinsing, and suction, (g) Steerable tip with camera 
The control of the tip orientation is not very intuitive because the navigation wheels are arranged in the same plane while the bendable portion will bend in two perpendicular directions. Single-handed operation of the wheels is difficult due to size, position and force requirements, especially with small hands. In a survey of U.S. gastroenterology fellows, 41\% of the respondents considered their hands too small for a standard endoscope's control section [Cohen et al., 2008]. Some endoscopists release the grip of the right hand on the shaft and use it to turn the smaller outer wheel. The shaft position is maintained by trapping it between the physician's thigh and the examination table [Williams, 2009]. Other physicians use torque steering as an alternative technique. They turn the large navigation wheel, while the small wheel is locked in neutral position, and additionally torque the shaft of the endoscope to compensate for the loss of motion of locking the small wheel [Shergill et al, 2009]. Drawback of this technique is that, because of the torsional stiffness of the shaft, the control section needs to be rotated too and cannot constantly be operated in a comfortable position.

The navigation wheels can both be locked in position. This is used in torque steering, as indicated in the previous paragraph, or to keep the endoscope tip in position. The drive system is not self-locking so the position of the tip moves back from an angulated to a neutral position due to internal cable tension. The angulation locks can be helpful, but the drawback is that the shaft of the endoscope has to be released momentarily to operate the locks.

The control section also contains manual operated valves to insufflate air or CO2 into the lumen, to rinse the camera lens, to suck fluids and gas out of the lumen, and some programmable switches for functions like taking a picture or switching to narrow band imaging. Operation of these controls complicates single-handed operation even further [Williams, 2009].

As a consequence of the current user interface, manipulation of flexible endoscopes is associated with awkward body rotations, bending of the knees, and a variety of arm movements. These movements are in the clinic sometimes referred to as the endoscopy dance and are especially performed during difficult parts of the procedure. The prevalence of musculoskeletal complaints has been shown to be higher for endoscopists than for other non procedure-oriented internal medicine specialists (74\% vs. 35\%) [Hansel et al., 2009]. Steering the navigation wheels and operating the control buttons of the control section requires repetitive, extreme and prolonged wrist and finger flexion or extension. Manipulation of the shaft of a flexible endoscope is associated with awkward wrist, shoulder, and neck postures. In a questionnaire under colonoscopists concerning work related injuries, 226 out of the 608 respondents reported physical complaints obtained by performing colonoscopy. Most injuries were related to torquing the shaft and turning the dials [Liberman et al., 2005].

It can thus be concluded that current endoscope handling is not ergonomic and user friendly. Physicians have learned to overcome the drawbacks, but at the expense of personal well-being.

\subsection{Design directions for robotic steering}

In this section opportunities and considerations are discussed for robotic steering. The human-machine interface of the robotic endoscope should allow the physician to operate cooperatively with the robot. Thus, ergonomics and integration into the clinical workflow are essential elements of a successful design [Hager, 2008].

Even in case of non-sterile endoluminal procedures the patient should be protected against cross contamination. Thanks to stringent guidelines on disinfection, transmission of 
infections as a result of flexible endoscopy is extremely rare. According to the 'Spaulding classification system' and approved by the Food and Drug Administration (FDA) three categories of medical devices and their levels of disinfection are identified [Banerjee et al., 2008]:

- Critical.

Items that enter sterile tissue or vascular spaces. These items include needles, surgical instruments, biopsy forceps, and flexible endoscopes when intended for use in sterile environments. Reuse of these items requires sterilization.

- Semi-critical.

Items that come in contact with the mucosa, like flexible endoscopes in the gastrointestinal tract. Reuse of these items requires at least high-level disinfection.

- Non-critical.

Items that come in contact with intact skin, such as endoscopy carts. These items may be cleaned by low-level disinfection.

These guidelines should also be applied to our robotic endoscope. All parts that can potentially be touched by the therapist or the patient should be clean. In the clinic the robotic steering module and the flexible endoscope are connected during preparation. The mechanical interfaces between the clean endoscope (semi-critical part), the drive unit (noncritical part), and the user interface (semi-critical part) should prevent cross contamination. After the procedure the robotic steering module will be dismantled and the flexible endoscope has to be cleaned or disinfected according to the current clinical workflow. The robotic module should be suitable for cleaning afterwards or protected against contamination during the procedure. Usage of a disposable interface that separates the clean form the contaminated world is a known method. In case the robotic steering module is used in interventions that require sterility, additional measures are required. Components that are close to the operating table and that can be easily touched by the therapist should be sterile, draped with sterile sheets, or enclosed with a sterile plastic sleeve.

Axial rotation of the shaft of an endoscope is a very effective way to pass difficult parts of the lumen [Williams, 2009]. The shaft can be rotated in four different ways: (1) by direct manipulation of the shaft, (2) by rotation of the control handle around its axis, (3) by swinging the control handle, (4) or by closely holding the control handle and turning around your own axis. As a consequence direct manipulation of the robotic endoscope may be required to perform shaft rotation. However, the robotic setup will probably be heavier than the conventional setup. A hybrid setup is proposed. In one configuration the endoscope including the add-on robotic module is positioned in a docking station and the physician holds the remote control in one hand and the shaft in the other hand. In the other configuration the physician carries the robotic endoscope with the remote control that is directly coupled to the control section of the endoscope, as shown in Figure 3.7. The former is easy to carry while the latter allows for extra maneuverability of the endoscope. If necessary during a procedure the setup can also be changed to conventional steering by taking the endoscope out of the robot within a few seconds. 

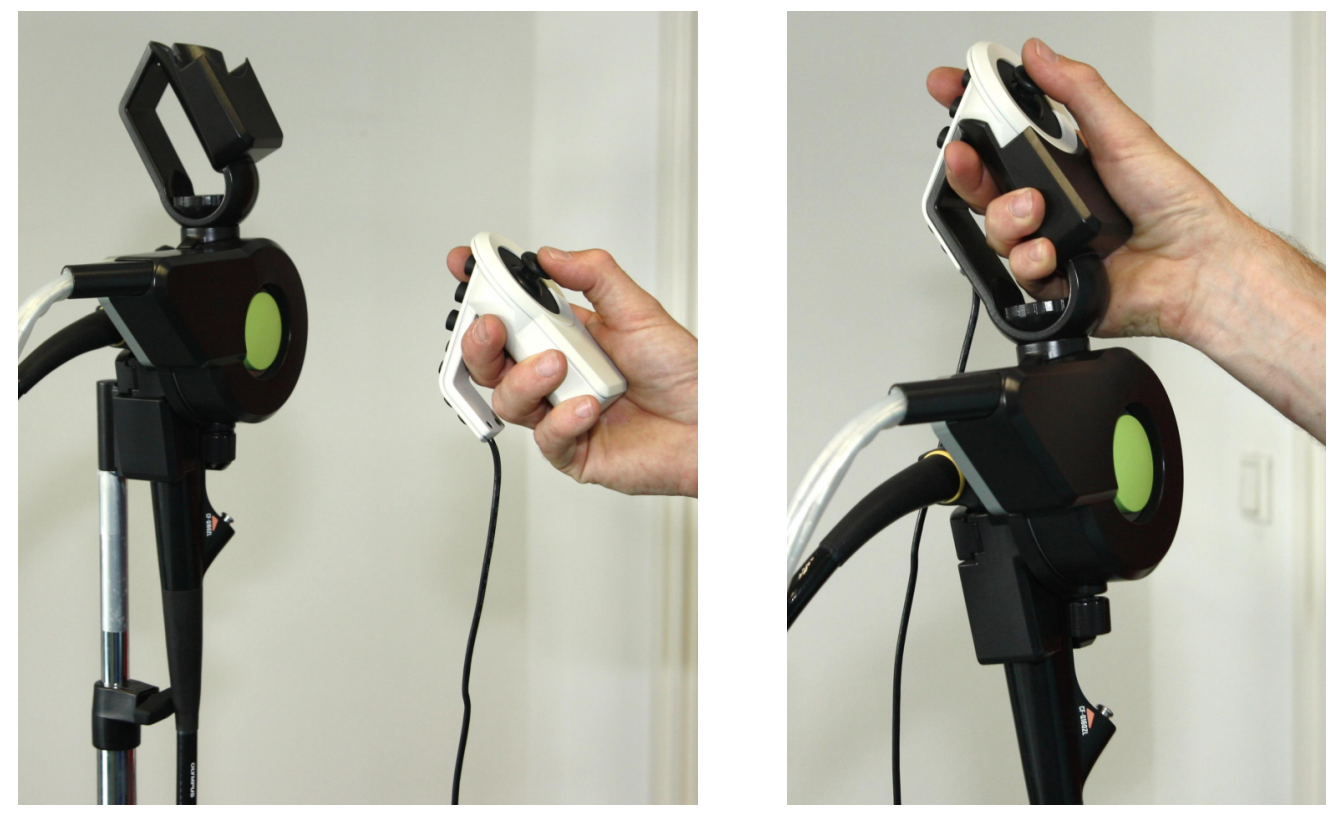

Figure 3.7 Stationary (left) versus portable use of the robotic endoscope

The remote control should be intuitive and suitable for single-handed use. It should prevent musculoskeletal complaints of the operator and will be operated close to the patient. All input controls of the control section of the current endoscope have to be included in the remote control. The physician should be able to actuate insufflation, suction and rinsing while steering the tip. In current practice the flow is controlled by repeatedly actuation of mechanical valves (pulse-width modulation). Robotic technology allows proportional flow control (analog input). In particular precise (limited) insufflation contributes to successful insertion [Roberts-Thomson and Teo, 2009] and minimal patient discomfort [Bretthauer et al., 2003]. Additionally, in motorized valve control advanced vision algorithms can be implemented that anticipate on changing conditions. For instance when during inspection the intestine is collapsing and vision is disturbed, air or CO2 can be automatically insufflated into the lumen.

The remote control has to be operated while wearing disposable gloves and should allow for left as well as right handed use. In that way the delicate task of shaft manipulation, that requires precise interpretation of force feedback information, is always possible with the dominant hand. In current practice the control section can only be operated with the left hand. For the about 10\% left handed physicians this means that the shaft needs to be manipulated with the non-dominant right hand [Hardyck and Petrinovich, 1977].

The input device that steers the tip is a critical component with regard to intuitive use, usability, and performance. It should be able to manipulate the tip from $-180^{\circ}$ to $+180^{\circ}$ in left-right, up-down and combined (diagonal) directions, equivalent to the current specifications of traditional endoscopes. The input device should allow for fast large movements, precise small movements and stabilization of the bendable tip in a preferred position. For instance during inspection of the lumen, the tip should follow a smooth circular path. Thereby providing images of the entire mucosal surface within reasonable time and allowing for precise camera positioning to inspect suspicious areas. Occasionally, an 
endoscope is used in retroflexion $\left(180^{\circ}\right.$ bent) to be able to inspect the rectum or the entrance of the stomach.

Some of the requirements of our setup, like portability and single-handed use, limit the number of suitable input devices to steer the tip. Different kind of input devices that are used for computer applications (e.g. mouse, joystick, haptic device) are used for clinical systems as well. New innovations are related to speech, gaze, and gesture control. The clinical application of these innovative techniques is limited, mainly because of safety issues, like limited accuracy and robustness. A thumb joystick as seen in gamepad controllers or a touchpad like in laptops are the most likely options to steer the tip.

Position and rate control are the two common transfer functions. In position control the input device indicates the desired position of the end effector, whereas in rate control the input device indicates the desired end effector velocity. Rate control is most suitable for exploration and searching tasks, whereas position control is better for manoeuvring tasks; tasks that are characterized by short-range and high-precision movements [Zhai, 1995]. As indicated before, the input device should allow for fast large movements and precise small movements so it is difficult to choose between these alternatives and both transfer functions are tested. In our setup a thumb joystick combines best with rate control. It allows the physician to use the full bending range of the tip of the endoscope. Additionally, rate control can freeze the tip in a preferred position when releasing the joystick. The joystick, with spring loaded return-to-centre functionality, returns to its initial position and sets the speed to zero. A touchpad can be best combined with incremental position control. Like in mouse navigation, clutching allows the physician to use the full manipulation range of the endoscope. Lifting the finger fixates the tip of the endoscope into position. A third alternative would be to use a hybrid position and rate control transfer function, that allows both incremental position control in tasks that require accurate manipulation as well as rate control in navigational tasks without the need to clutch. But without appropriate feedback, the transition between position and rate mode is difficult to distinguish and the rate is difficult to control. Research of Caziez et al. [2007] has shown that a hybrid transfer function has only a performance advantage over position control when the operator is faced with significant clutching. This is not expected in steering the endoscope tip and for that reason hybrid control is not implemented and tested. In the conducted usability test, as described in Section 3.6, rate control (joystick) and incremental position control (touchpad) are compared, to determine the best control option.

In current practice the physician estimates the shape of the tip and shaft inside the body by interpreting the forces required to turn the navigation wheels of a traditional endoscope. The navigation wheels transmit actuation forces to the tip by means of flexible Bowden cables. The force increases by friction in accordance with the degree of flexion of the endoscope. This helps the physician to estimate the flexion of the tip, interaction forces of the tip with tissue, and shaft loops that need to be straightened [Körner and Männer, 2003]. Force information from the navigation wheels need to be fed back to the physician in the robotic setup. Ideally this would be haptic feedback to achieve a sense of transparency but a haptic device with at least two degrees of freedom that can be integrated with a small remote control is not available. Vision could provide an appropriate sensory substitute in the robotic setup. Indication bars that represent force information should be shown on the monitor. It should be verified in the experiment if vision can adequately replace haptic information.

The drive system should be self-locking so the position of the tip of the endoscope (camera position) is maintained when the input device of the remote control is not actuated. In this way the manual operated angulation locks of a traditional endoscope do not have to be in use. However, it should be ensured that the navigation wheels are not locked when 
these are coupled to the drive system, since it would badly influence performance and possibly the endoscope is damaged. Drawback of a self-locking drive system is that, in case of system failure or power outage, the drive unit possibly needs to be decoupled from the endoscope. Otherwise it is not possible to retract a deflected endoscope tip from the patient. It first need to be straightened. For safety purposes a robotic system that can be decoupled in a few seconds is required.

The most important performance parameters and other important design requirements of tip steering are summarized in Table 3.1. Speed and accuracy have been estimated based on observations of clinical procedures, and have to be verified in experiments.

Table 3.1 Important requirements robotic tip steering

\begin{tabular}{ll}
\hline Decoupling drive unit & $<10$ sec. \\
\hline Degrees of freedom tip steering & 2 DOF: Up-down, left-right \\
\hline Input device / transfer function & $\begin{array}{l}(1) \text { Thumb joystick / rate control } \\
(2) \text { Touchpad / incr. position } \\
\text { control }\end{array}$ \\
\hline Up-down / Left-right (a' / b') range & $360^{\circ}$ (omnidirectional, retroflexion) \\
\hline Up-down / Left-right accuracy & $\pm 1^{\circ}$ \\
\hline Up-down / Left-right speed & $180^{\circ} / \mathrm{s}$ \\
\hline In-out (c') & Manual \\
\hline Counter)clockwise rotation (d') & Manual \\
\hline
\end{tabular}
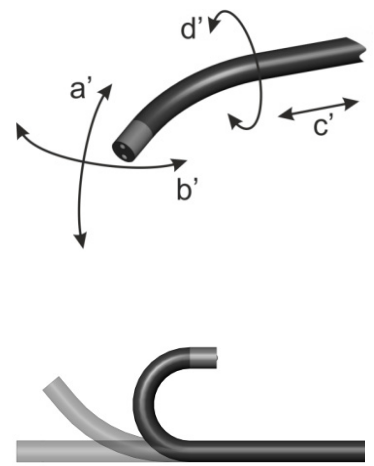

retroflexion

\subsection{Design}

In this section the integration of the system in a clinical setting, the available functionality, the technical embodiment and the specifications of the final design of the robotic flexible endoscope for diagnostic procedures are discussed.

\subsubsection{Clinical setting}

In Figure 3.8 the robotic flexible endoscope is depicted in its clinic setting. As discussed in the introduction our design aims at easy integration in the current clinical workflow and infrastructure. The robotic flexible endoscope is supported by a swivel arm that is directly mounted to a standard endoscopy cart. The physician steers and inserts the endoscope, while the endoscopy assistant monitors the patient. 


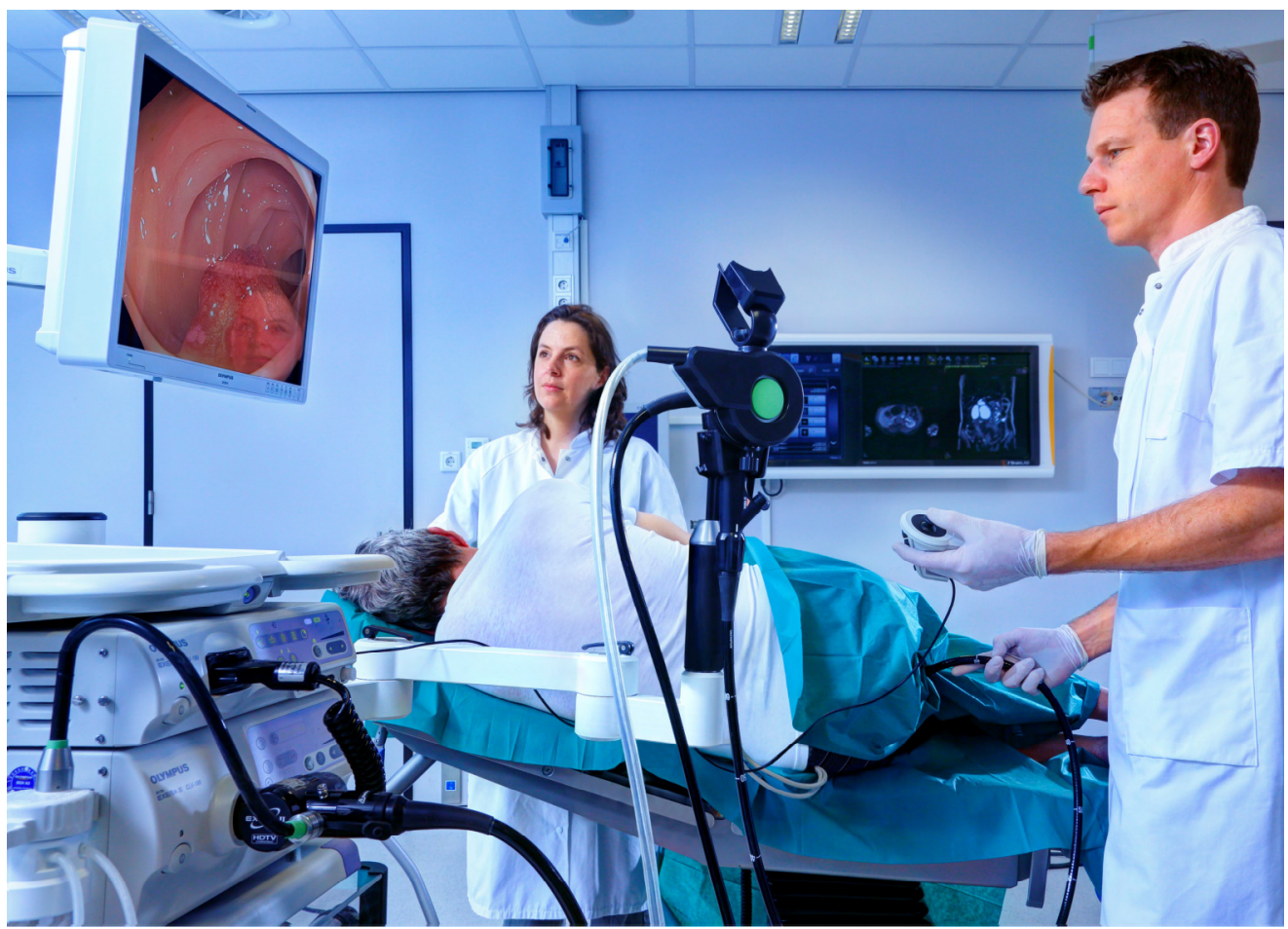

Figure 3.8 Clinical setup of a colonoscopy performed with the robotic steering module

Robotic diagnostic procedures are performed polyclinically in an endoscopy room. The endoscopy team consist of one endoscopy assistant and one gastroenterologist. The assistant is responsible for preparation of the room and patient well-being, while the physician operates all equipment during the procedure. The room is divided by the patient's bed in an assistant work zone, and a work zone for the physician. Occasionally the assistant needs to help the physician, for instance to unpack an instrument or to collect a biopsy specimen. It is expected that in the robotic setup one endoscopy assistant is sufficient, whereas currently often two assistants are required, of which one is assisting the physician in manipulating the endoscope. 


\subsubsection{System overview}

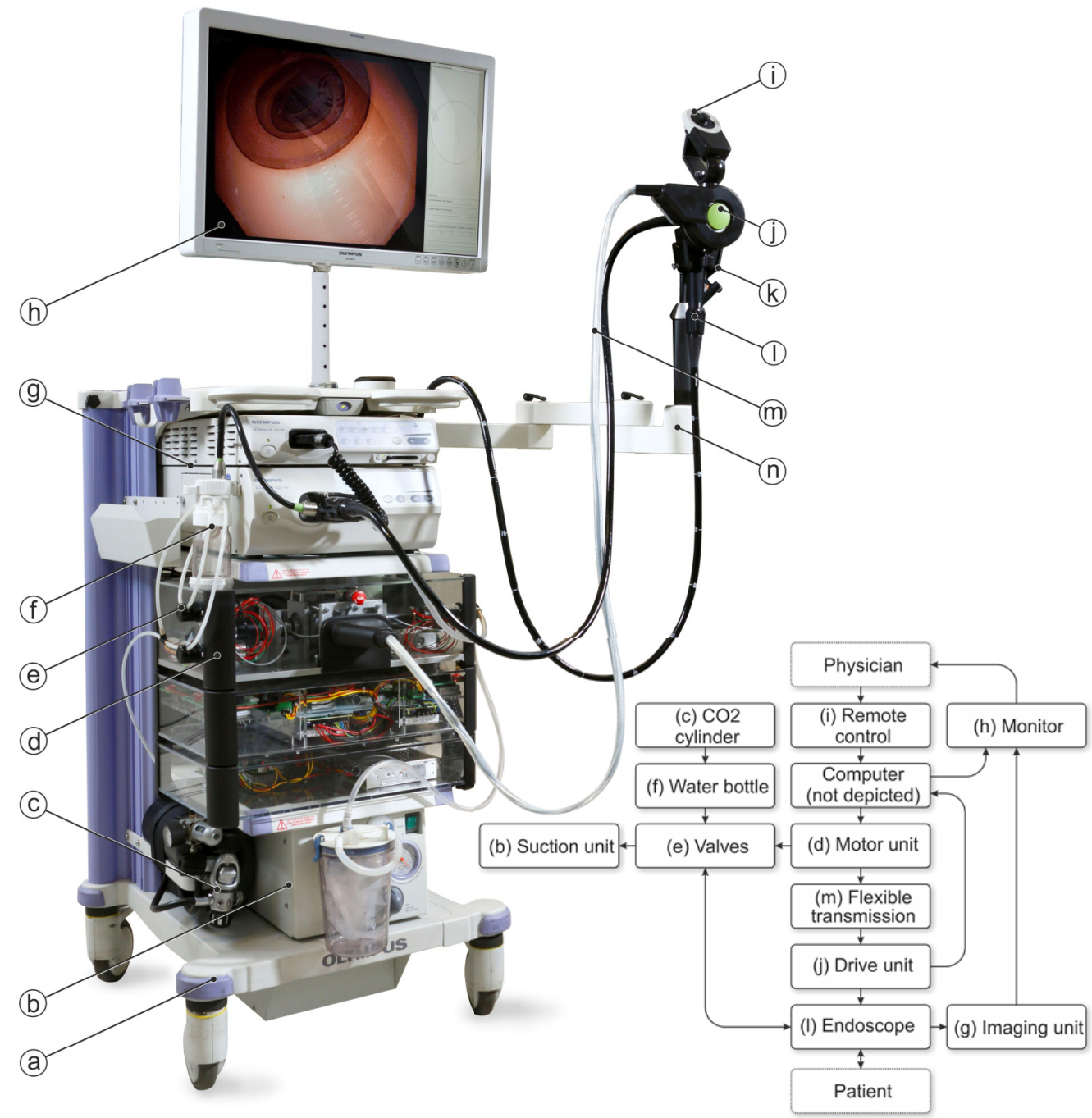

Figure 3.9 System setup robotic steering (standard equipment in grey): (a) Equipment cart, (b) Suction unit, (c) CO2 cylinder, (d) Motor unit (only top unit), (e) Valves for insufflation, rinsing, and suction, (f) Water bottle, (g) Imaging unit, (h) Monitor, (i) Remote control, (j) Portable drive unit, (k) Docking station, (l) Flexible endoscope, (m) Flexible transmission (n) Swivel arm

In Figure 3.9 an overview is shown of the setup for robotic steering in diagnostic procedures. The configuration of the setup is chosen to obtain a lightweight robotic endoscope. In certain circumstances it might be required to lift the robotic endoscope from the docking station (Section 3.4). For that reason all heavy components, in particular the motors, are placed in a stationary positioned motor unit that is connected through a flexible transmission to a compact and light portable drive unit (Section 3.5.3). The motor unit is positioned on the endoscopy cart and the generic portable drive unit connects with a dedicated interface unit (Section 3.5.4) to the navigation wheels of each individual type of endoscope. The interface unit of our setup is designed to fit with Olympus colonoscopes, 
gastroscopes, duodenoscopes, and sigmoidoscopes, that all have the same interfacing elements. The robotic flexible endoscope can be carried by a swivel arm (Section 3.5.5) that is directly mounted to the endoscopy cart. On top of the interface unit a holder is situated that allows docking of the remote control (Section 3.5.6). A monitor provides visual feedback of the camera image and shows some additional feedback information on system status (Section 3.5.7).

\subsubsection{Drive system navigation wheels}

The navigation wheels are actuated by antagonistic Bowden cables that run between a motor unit, that is placed on the endoscopy cart, and a portable drive unit, that is connected to the control section of the endoscope. Figure 3.10 shows the complete drive train for steering the camera.

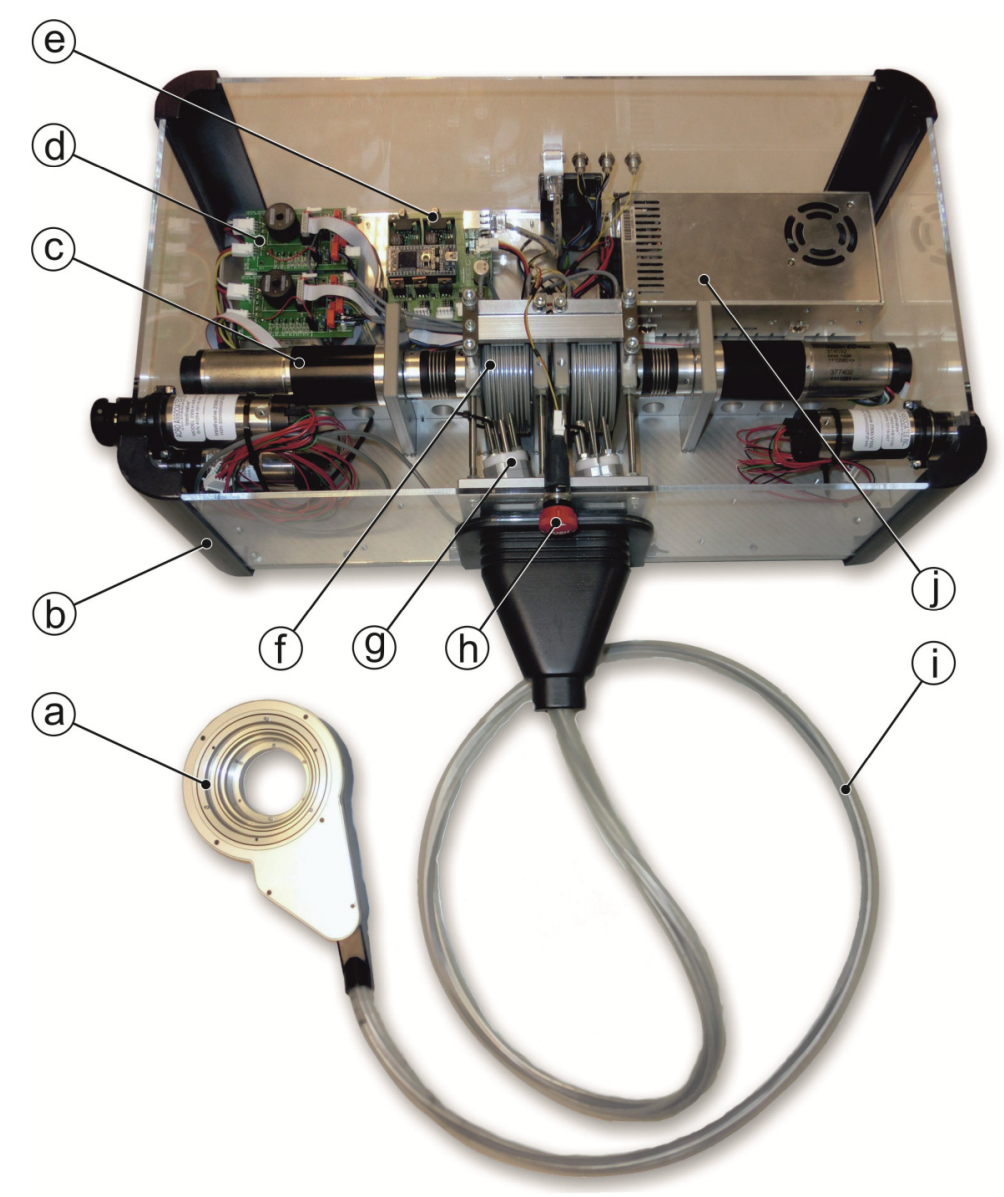

Figure 3.10 Drive system navigation wheels: (a) Portable drive unit, (b) Stationary unit, (c) Motors stationary unit, (d) Motor controllers, (e) Communication board, (f) Cable pulleys, (g) Pretension mechanism cables, (h) Emergency stop, (i) Bowden cables, (j) Power supply

The Nokon Bowden cables (Carl Stahl - Nokon, Süßen, Germany) of the linkage are highly flexible to allow free manipulation of the robotic flexible endoscope if required. Two pairs of in total four Bowden cables (2-DOF actuation) are bundled with a flexible hose and 
traverse form the stationary to the portable unit. The cables are pretensioned in the stationary unit to prevent backlash and delay in control. However, pre-tensioning the cables increases friction that worsens hysteresis phenomena. Since the effects of friction are difficult to predict in the drive system, cable tension is adaptable to be able to experiment with different settings. In addition, it allows to compensate for cable elongation in the course of time.

The drive system is backdrivable, but during system operation locked in position by software control. The tip of the endoscope (camera position) is kept in its current position when the input device of the remote control is not operated. Two DC servo motors (EC$\max$ 40-70W, Maxon, Sachseln, Switzerland) were selected for actuation. Incremental encoders provide position feedback. The two motors, the two motor controllers (Whistle, Elmo motion control, Petach-Tikva, Israel), the communication board, and the power supply are all integrated in the stationary motor unit. The main program is programmed in Python (Python Software Foundation) and runs on an external laptop computer (EliteBook 2.4GHz, Hewlett-Packard, Palo Alto, USA) with Windows XP (Microsoft, Redmond, USA) installed.

A homing procedure is required each time before the drive unit is coupled to the endoscope. The Bowden cable actuation principle only allows a limited range of motion, since the cables run only a few times around the pulleys at the stationary side and are then fixated. The cable pulleys need to be in a neutral position and the tip of the endoscope needs to be straight when the drive unit is connected to the navigation wheels. The range of motion of the drive unit is software limited and approximates the range of motion of the navigation wheels of the endoscope. Since the homing procedure is critical and the range of motion is slightly smaller in the robotic setup, future work might address the opportunity to remove the homing procedure and use the mechanical end stops of the endoscope to limit the range of motion, in this situation a current limiter could be used to prevent the motors from exerting excessive forces that might damage the endoscope.

The portable drive unit has to be light. The weight that is added to a standard flexible endoscope in the robotic setup is $0.92 \mathrm{~kg}$. If the two motors for navigation wheel actuation would be positioned in the portable drive unit it would be about $1.6 \mathrm{~kg}$, making the robotic endoscope less portable. In Figure 3.11 the mechanical and sensory system of the portable drive unit is shown.

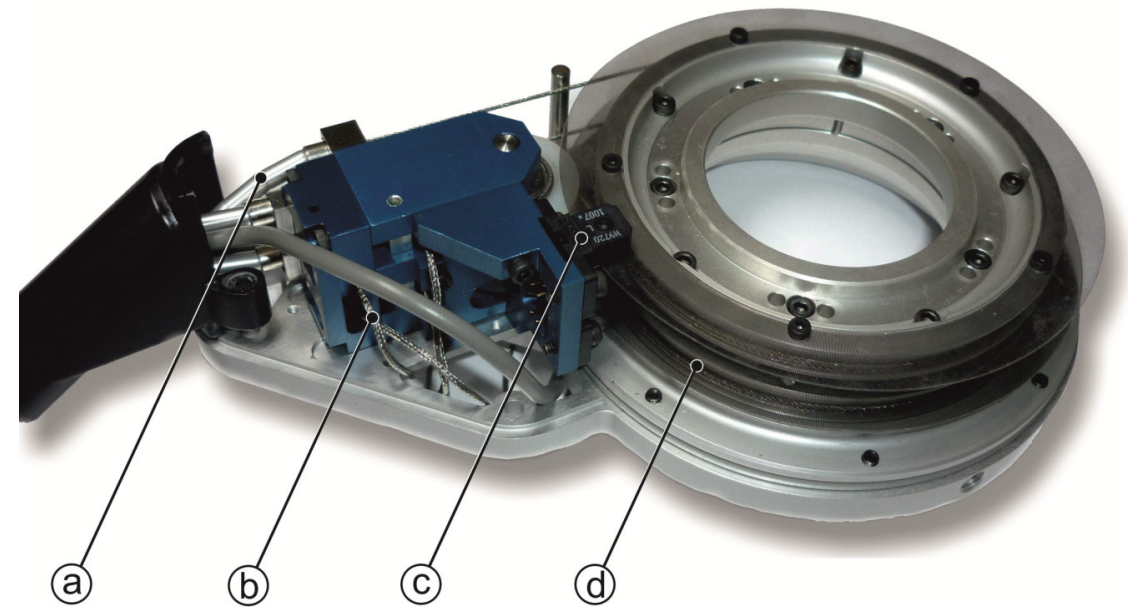

Figure 3.11 Portable drive unit: (a) Bowden cables, (b) Force sensors, (c) Optical disc encoders, (d) Cable pulleys 
The outer sheaths of the Bowden cables at the load side are supported by load cells (Model LLB130, FUTEK, Irvine, USA) to measure the applied torque on the navigation wheels. As discussed in Section 3.4, force information from the navigation wheels needs to be fed back to the physician in the robotic setup. Section 3.5.7 discusses the representation of this information.

Two optical encoders are added to the load side that can be used to improve position control of the navigation wheels. Because of the tight space and weight requirements, dedicated rotating disks are developed. Its pattern is read with an off-the-shelf light source and photo detector.

\subsubsection{Interfacing with endoscope}

The drive system cannot be sterilized or intensively cleaned. As shown in Figure 3.12 an interface unit couples the drive unit to the clean endoscope to prevent cross contamination. The interface unit separates the clean world (endoscope) from the possibly contaminated world (drive unit) and should for that reason be clean itself. Two options are open; either the interface unit is a disposable part or it can be sterilized after use. The current design consists of injected moulded parts and is suitable for both options. Logistic considerations and the business model for sale will be decisive in the final choice. To prepare the system for a sterile setting, the portable drive unit can be enclosed by a plastic sleeve. A trunk-like plastic sleeve is sealed to the interface unit and this assembly completely encapsulates the drive unit ((g) in Figure 3.12).

The disinfection requirements for the remote control are the same as for the endoscope. The remote control should be disinfected in an endoscope washing machine. Currently the remote control is not yet water tight. This is allocated as future work.
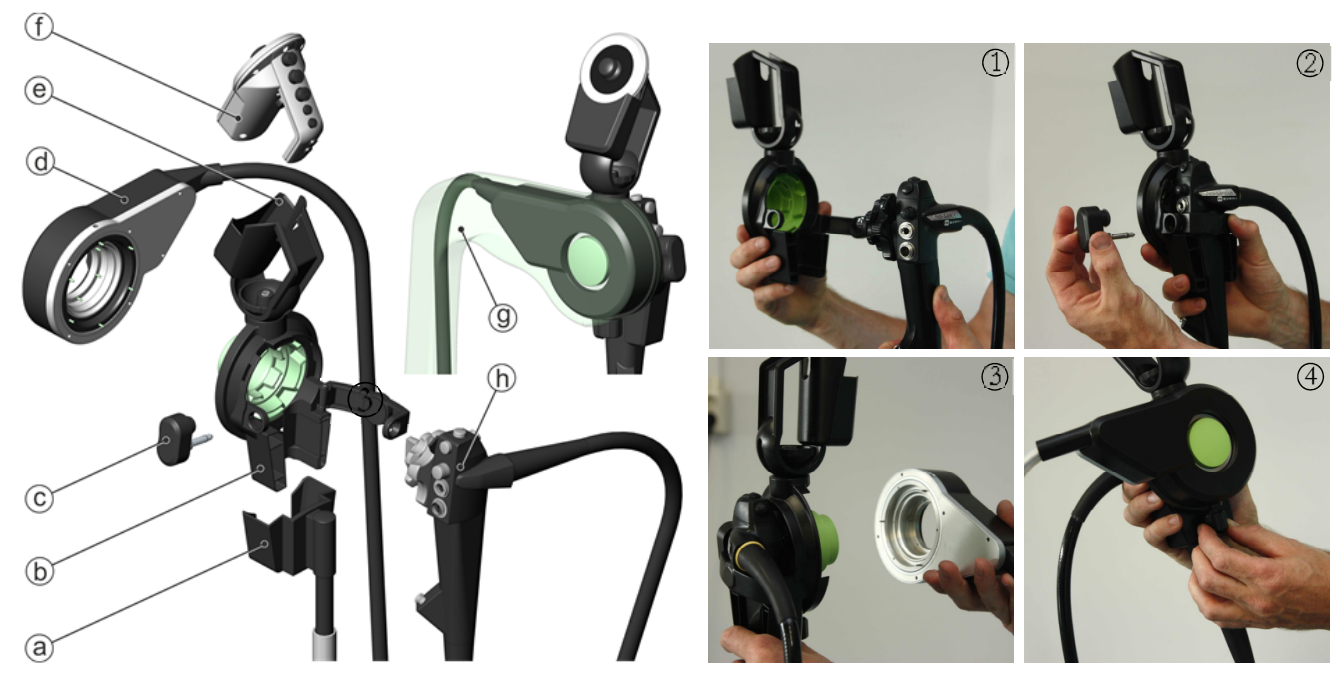

Figure 3.12 Exploded view and installation instruction of the robotic steering module: (a) Docking station,

(b) Interface unit, (c) Plug, (d) Drive unit, (e) Holder remote control, (f) Remote control, (g) Sterile sleeve,

(h) Endoscope, (1-4) Installation instruction

The interface unit is first connected to the endoscope (step 1). The navigation wheels are connected to custom designed transmission wheels that perfectly fit. The interface unit is locked by an endoscope specific plug (step 2) that bypasses the valves of insufflation, rinsing, and suction on the endoscope so these can be controlled with the remote control 
(Section 3.5.6). This assembly is subsequently connected with the portable drive unit by threaded knobs(step 3 and 4). Torque between drive unit and interface unit is transferred with a pin hole connection.

\subsubsection{Suspension and positioning}

A configurable holder for the remote control is integrated with the interface, as shown in Figure 3.12. The physician is able to position it to personal preferences to comfortably hold and carry the robotic endoscope. If preferred the robotic endoscope is positioned in the docking station on the swivel arm and the remote control can be detached from the holder (Figure 3.7).

The robotic flexible endoscope should not restrict personnel in their freedom of movement. As shown in Figure 3.13, the swivel arm has a large range of motion and can be positioned according to personal preferences. The height of the swivel arm is adaptable to position the docked remote control at a height between 100 and $145 \mathrm{~cm}$ from the floor level ((b) in Figure 3.13). All degrees of freedom can be locked by cam levers.

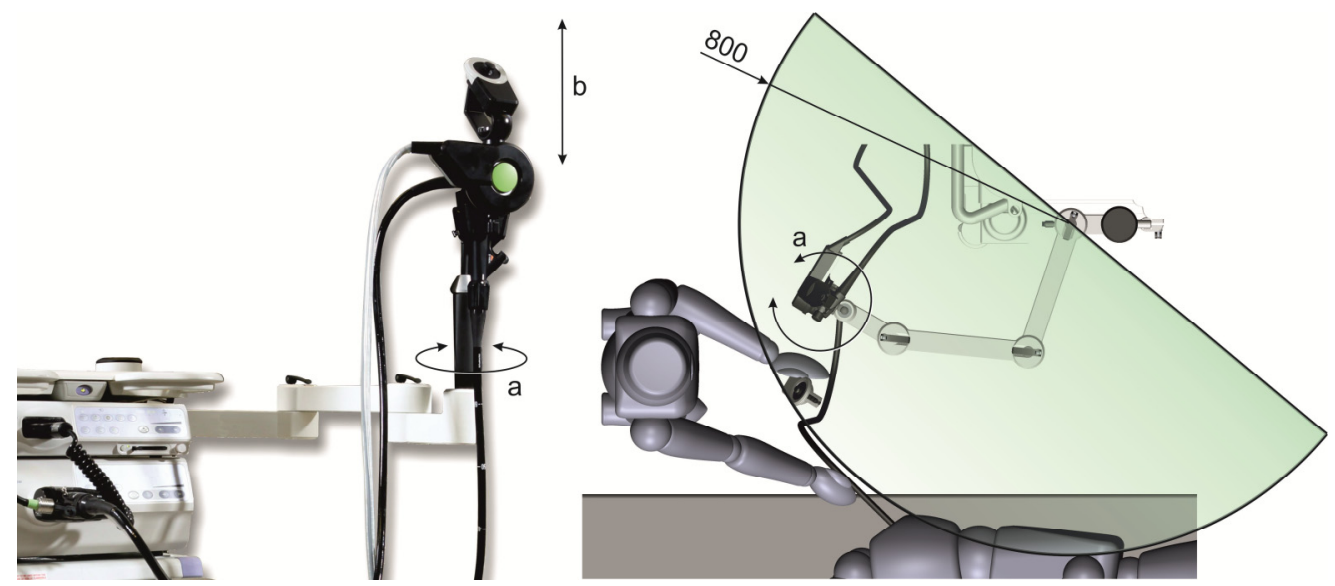

Figure 3.13 Range of motion swivel arm

The docking station should allow axial rotation ((a) in Figure 3.13) of the shaft of the endoscope that is induced by the physician. Rotating the flexible shaft is a known method to pass difficult parts of the lumen [Williams, 2009]. Since the shaft of a flexible endoscope is made to be torsional stiff, rotating the shaft not only affects the distal tip but also the proximal section that is positioned in the docking station. Rotation of the docked robotic endoscope should minimally affect endoscope-tissue force feedback experience of the physician. In the setup the suspension system is passive and rotation is induced by the therapist. 


\subsubsection{Remote control}

The remote control allows single-handed control of all available functionality of the control section of a traditional endoscope, as shown in Figure 3.14.
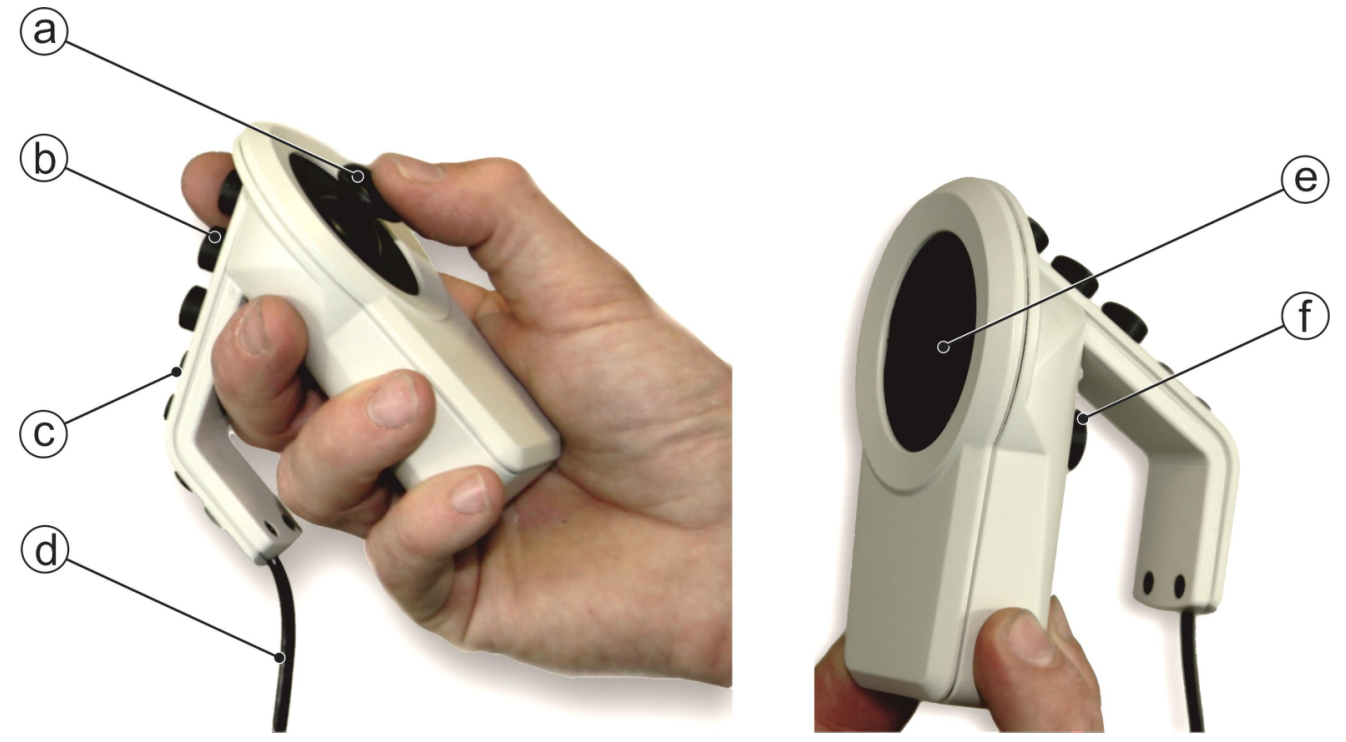

Figure 3.14 Joystick and touchpad remote controllers: (a) Thumb joystick, (b) Buttons for insufflation, rinsing, and suction, (c) Programmable switches, (d) USB cable to computer, (e) Touchpad, (f) Hold-to-run safety switch.

A thumb joystick (model 802, P3 America, San Diego, USA) as well as a touchpad (Ergonomic touchpad, UK) can be integrated as input device to steer the tip. As explained in Section 3.4 a joystick with rate control or a touchpad with incremental position control are the most suitable input device-transfer function combinations. In our evaluation, as described in Section 3.6, both alternatives are tested.

A hold-to-run safety switch needs to be pressed during operation of the robotic endoscope to prevent unintended actuation of input controls. Push buttons are arranged to operate all valves and switches of the control section of the current endoscope. Buttons for proportional insufflation, rinsing, and suction are pressure sensitive by means of an underlying force sensing resistor (FSR 400, Interlink Electronics, Camarillo, USA). Flow is controlled with solenoid pinch valves (Intelivalve 2300, Acro, Concord, USA) that are positioned in the stationary motor unit, as shown in Figure 3.15. An adapter is added to a standard water bottle of Olympus to bypass the existing air pump unit, that is positioned in the imaging unit, and to couple a CO2 cylinder. Flow of insufflation and rinsing is controlled by squeezing a silicon tube that passes through the pinch valves. The control of suction is achieved by passing the flexible tube, that runs between the pump unit and the endoscope, through one of the valves as well. 


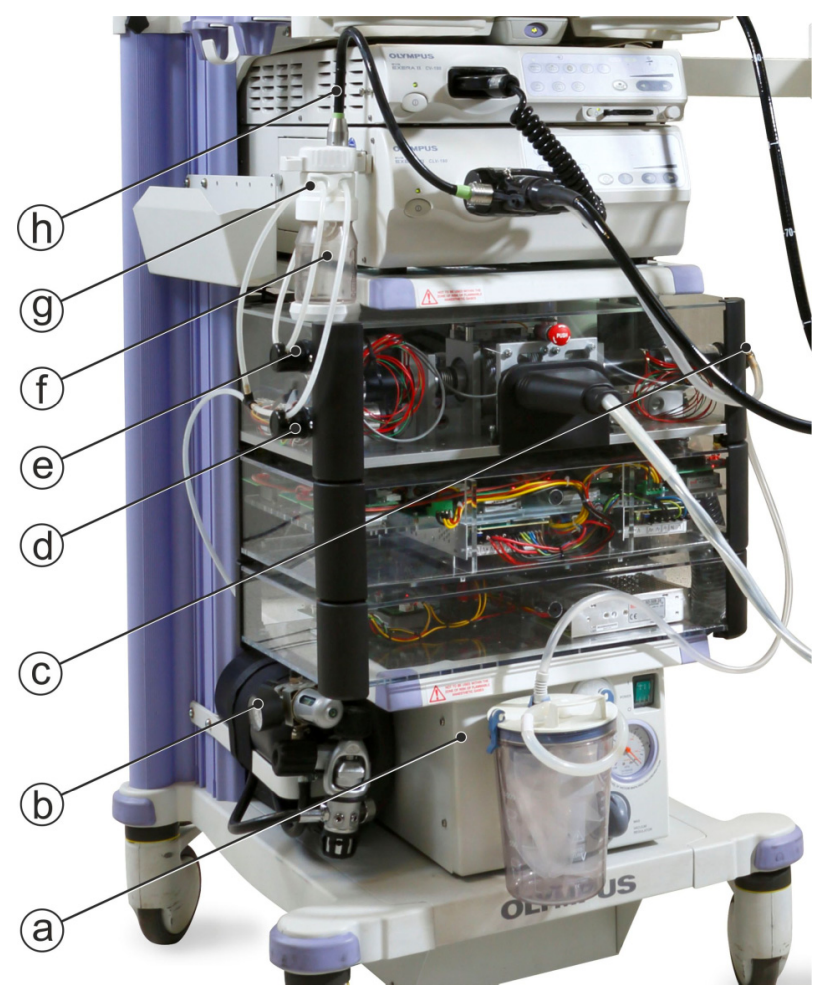

Figure 3.15 Components for insufflation, rinsing, and suction (standard equipment in grey): (a) Suction pump unit, (b) CO2 gas cylinder, (c) Solenoid valve suction, (d) Solenoid valve insufflation, (e) Solenoid valve rinsing, (f) Water container, (g) Adapter for solenoid bypass, (h) Water bottle tube

\subsubsection{Feedback information}

The operator is confronted with several sources of visual feedback to support control of the robotic endoscope. These are integrated in a single monitor (Figure 3.16).
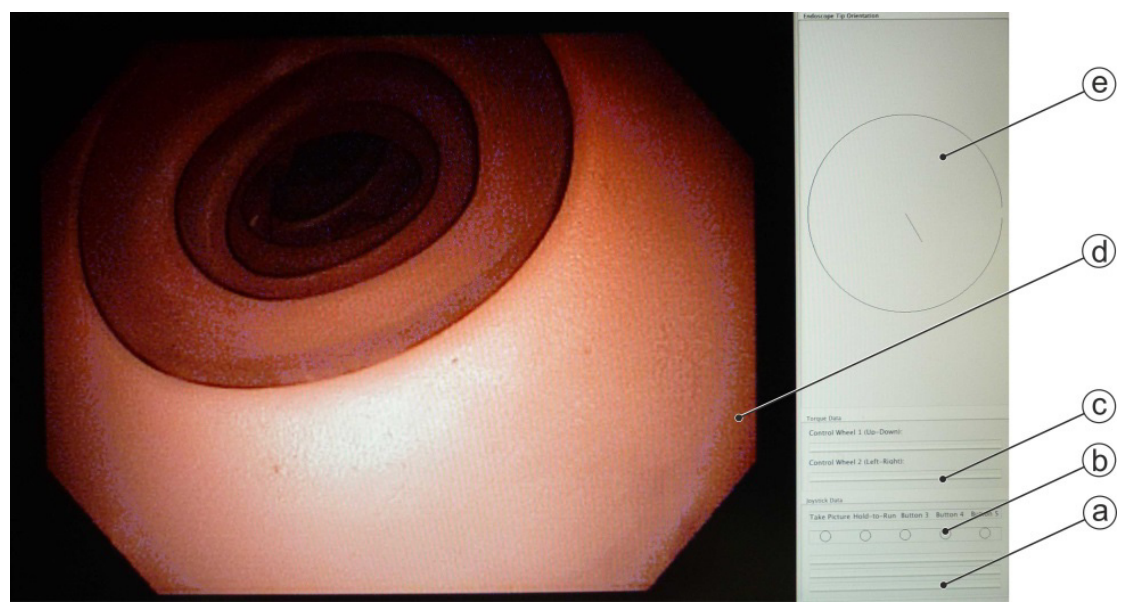

Figure 3.16 Graphical user interface robotic steering: (a) Bar indicators operation proportional valves (b) Light indicators operation programmable switches, (c) Bar indicators torque forces navigation wheels, (d) Diagnostic data, (e) Bending diagram on deflection tip endoscope. 
The endoscopic images that visualize patient tissue are most important and take up most surface of the monitor. The endoscope and its imaging unit determine the characteristics of these images. Nowadays high definition (1920 x 1080 pixels) is the standard.

One fourth of the monitor is reserved for additional feedback provided by the robotic system. The flexion of the endoscope tip is shown in a bending diagram. The diagram shows a line in a circle that extends from the centre into the direction that the tip is moving. The direction and length of the line are an indication of tip direction and flexion respectively and are calculated from the motor position of the drive unit.

Bar indicators provide information about the torque required to turn the navigation wheels. The forces are measured with the load cells that are positioned inside the portable drive unit (Figure 3.11). The length (and colour) relates to the shape of the shaft and interaction of the endoscope tip with tissue, as discussed in Section 3.4. Due to time constraints, within this work it was not possible to depict accurate data that could be easily interpreted. An algorithm needs to be developed to filter the measured data and to represent it in a meaningful way.

Information on the amount of insufflation, rinsing, and suction is also fed back by bar indicators. If the buttons on the remote control are pressed harder flow will increase and the indicator bars will lengthen. Actuation of the programmable switches is shown by light indicators.

\subsubsection{Specifications}

The most important performance requirements are estimated based on observations of procedures and on literature study. In Table 3.2 the original requirements as well as the achieved specifications of the robotic flexible endoscope are listed.

The accuracy of the robotic flexible endoscope is impeded by the presence of hysteresis due to friction and compliance in the mechanical drive train. Part of the problems are caused by the Bowden cable actuation of the endoscope itself, in addition the Bowden cable actuation principle of the robotic drive unit impedes control. For that reason the initially defined required accuracy is not achieved. However, since a human operator is in the control loop, the endoscope can be accurately positioned. In the next section the performance of the robotic setup is verified in usability tests, being the most reliable way of assessing the suitability and added value of the new robotic system. 
Table 3.2 Specifications robotic steering

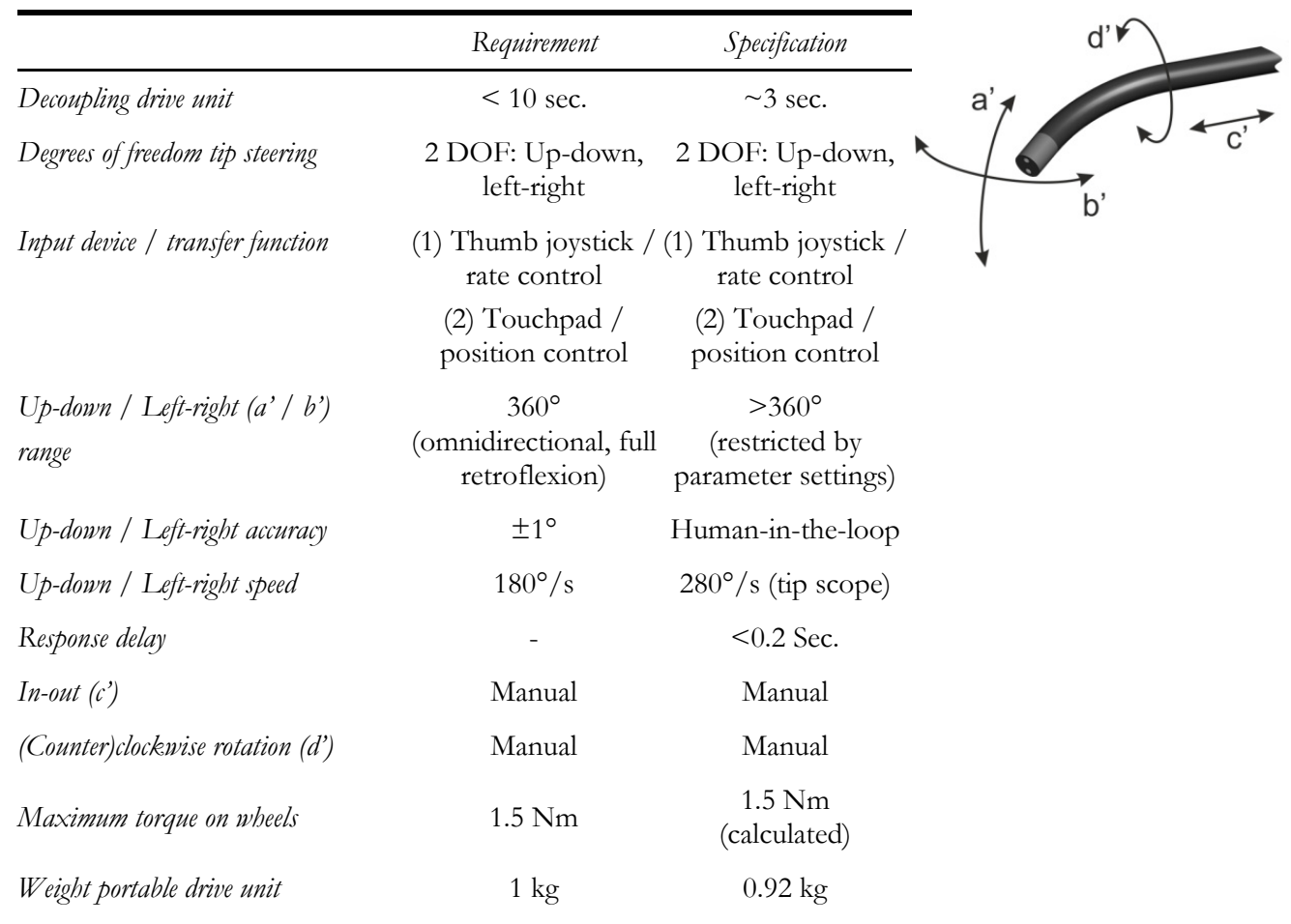

\subsection{Usability test}

This section describes the experiment conducted to determine the optimal settings of the robotic endoscope and to assess its intuitiveness and usability in steering the endoscope tip.

\subsubsection{Experimental setup}

In this experiment conventional steering of the tip is compared with robotic steering to obtain knowledge about the best input device and the required maneuverability of the endoscope. The tested setups were:

1. Conventional steering with navigation wheels. We used this method as a reference for the robotic setups.

2. Joystick steering with stationary endoscope. The endoscope including the drive unit is positioned in a docking station and the participant only holds the remote control, as shown in Figure 3.7.

3. Touchpad steering with stationary endoscope.

4. Joystick steering with portable endoscope. The participant carries the endoscope and the remote control, which is directly coupled to the control section of the endoscope, as shown in Figure 3.7 and Figure 3.17.

5. Touchpad steering with portable endoscope. 


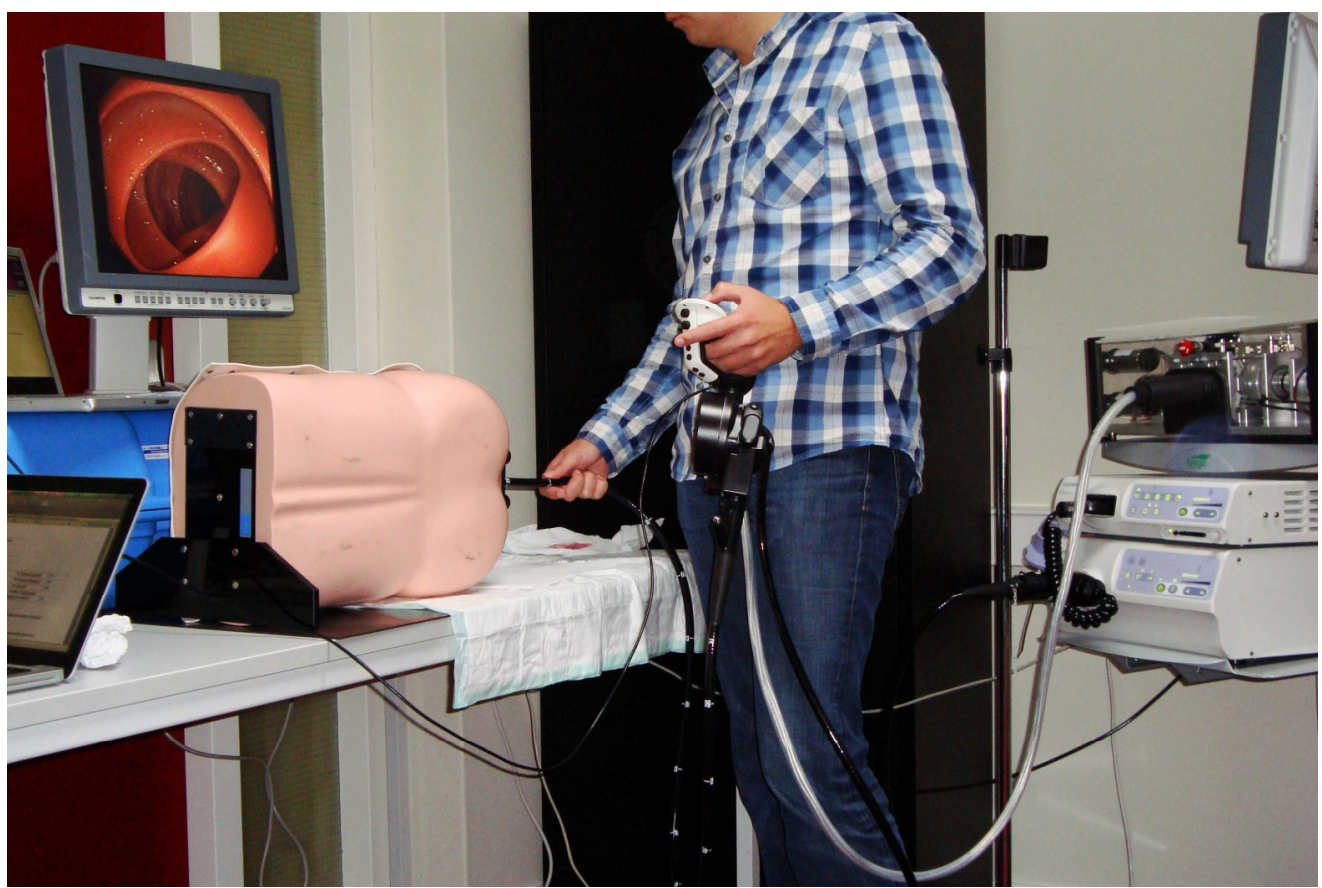

Figure 3.17 Experimental setup

Participants were engineers and supporting staff of DEMCON and the University of Twente. They had no medical background, no experience in endoscope handling, and no experience in controlling one of the robotic setups. The absence of experience enabled testing of intuitiveness, the ability to easily control the device without any prior training or reasoning process. It was too time consuming for the individual participants to test all setups. For that reason the population of 24 participants (aged 21-50 years, 7 women and 17 men) was divided over 2 groups. One group tested setup 1, 2 and 5. The other group tested setup 1, 3 and 4. This way, all participants tested both robotic input devices and both settings of endoscope handling. Each of the six possible orders of the three conditions was performed equally often to correct for learning effects and fatigue.

A standard flexible colonoscope (Evis Exera II CF-H180AL, Olympus, Tokyo, Japan) and imaging unit (Evis Exera II CLV-180, Olympus, Tokyo, Japan) were used for all experimental conditions. As shown in Figure 3.17, a cart was placed behind the participant, carrying the stationary drive unit and the imaging unit. A monitor that depicted the diagnostic data and the bending diagram (Section 3.5.7) was placed about 1 meter in front of the participant. Participants were asked to perform two colonoscopy tasks on an anatomical model (M40, Kyoto Kagaku, Kyoto, Japan) that was placed in left lateral position. First, participants had to advance and steer the endoscope up to the point where the colon starts, the cecum. An easy colon configuration was chosen in which all participants could complete the task. Second, the endoscope had to be retracted to the rectum while inspecting the mucosal surfaces for lesions, represented by 7 prepositioned red blocks sized 2x2x1 mm. The position of the colon as well as the type of target that participants had to detect are depicted in Figure 3.18. 

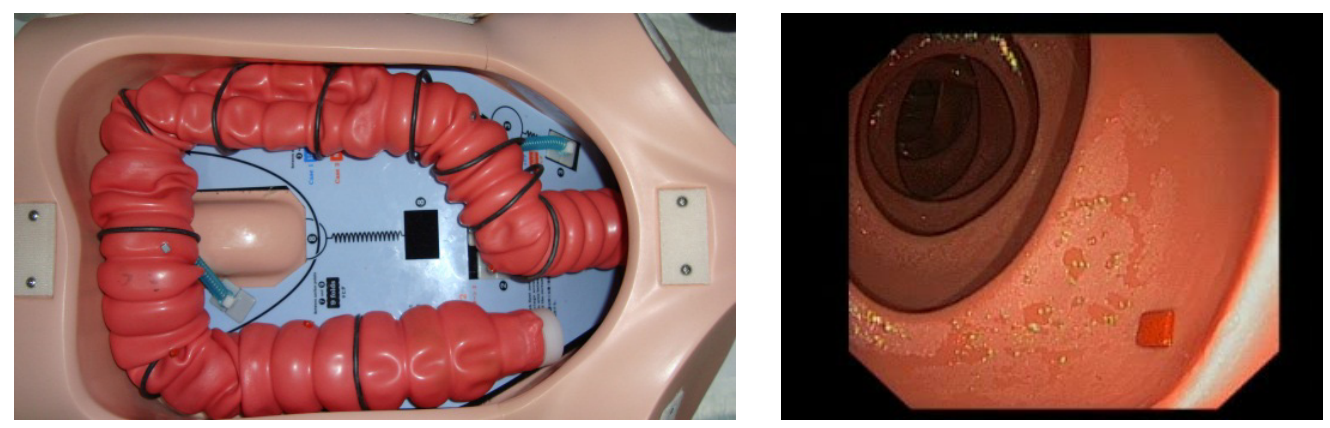

Figure 3.18 Anatomical model experiment: (left) Configuration of colon; (right) Lesion

Participants first had to read an instruction form with an introduction to performing a colonoscopy and the tasks that need to be performed. Next, each setup was introduced with a short demonstration of the steering module and some tips regarding the procedure, like:

- Try to keep the colonoscope shaft as straight as possible during insertion.

- In case of "red out" the camera is pressed against the wall. Pulling back and if necessary steering the tip to a centred position will re-establish vision.

- Rotate the insertion tube in case you cannot pass a corner with fully bended tip.

- Perform the tasks quickly without applying excessive forces to the patient.

For each experimental setup 5 minutes of practice time was available followed by the opportunity to ask for advice on usage.

The focus of this experiment was to test the usability of steering the endoscope. Usability is defined by the International Standardisation Organisation (ISO) as: "the extent to which a product can be used by specific users to achieve goals with effectiveness, efficiency, and satisfaction in a specified context of use". The three factors are widely accepted to concern distinct measures and were evaluated in the experiment. The effectiveness of an endoscopic procedure can be seen as the quality of the procedure as it is performed as well as the resulting (lack of) patient trauma. The efficiency of an endoscopic procedure can be seen as the amount of physical, cognitive and time resources that the therapist needs for completing the procedure. Satisfaction is based on perceived usefulness, perceived ease of use, and behavioral intention. Satisfaction is partly seen as a consequence of factors of effectiveness and efficiency. Because the relative importance of components of usability depends on the context of use and the purposes for which usability is being described, there is no general rule for how measures should be chosen or combined [ISO 9241-11:1998(E); Hornbæk, 2006]. In our experiment the following dependent variables were determined:

- Full insertion into the cecum (effectiveness)

- Detection rate of lesions (effectiveness)

- Insertion time (efficiency)

- Subjective workload analysis measuring mental and physical demand, performance, effort and frustration (efficiency). Based on a modified NASA Task Load Index [Hart and Staveland, 1988; NASA TLX, 2011], as shown in Appendix B.1.

- Rank interfaces according to preference (satisfaction).

- Questionnaire by interview related to intuitiveness, ease of use, and ergonomics (satisfaction), as indicated in Appendix B.2.

After testing of each condition the participant was interviewed and the scoring of the workload was documented. The experiment took approximately 1,5 hour per participant. 


\subsubsection{Results and discussion}

In general the participants of the experiment were enthusiastic about the robotic setups. That conclusion is supported by remarks like "it was fun", "it looks like a computer game", and "I did not expect that the system would work that easy". Additionally they could imagine that this system will eventually replace conventional steering in the hospital. Some of the comments that are consistent with that observation are: "If I compare it to conventional steering I see the potential of robotic steering for the hospital", "The robotic user interface is much more comfortable to hold, and steering is much easier in comparison with a standard endoscope", and "I think you can belp more patients per day with the robotic setup". Critical comments were related to technical characteristics that can be improved, like movements being too aggressive and components being heavy. These and other qualitative results are discussed in the remainder of this section. First the quantitative results of the experiment, that are depicted in Table 3.3, will be discussed.

Table 3.3 Quantitative results experiment

\begin{tabular}{|c|c|c|c|c|c|}
\hline Setup & $\begin{array}{l}\text { 1. Conventional } \\
\text { control } \\
(n=24)\end{array}$ & $\begin{array}{c}\text { 2. Joystick } \\
\text { Stationary scope } \\
\quad(n=12)\end{array}$ & $\begin{array}{l}\text { 3. Touchpad } \\
\text { Stationary scope } \\
\quad(n=12)\end{array}$ & $\begin{array}{l}\text { 4. Joystick } \\
\text { Portable scope } \\
(n=12)\end{array}$ & $\begin{array}{l}\text { 5. Touchpad } \\
\text { Portable scope } \\
\quad(n=12)\end{array}$ \\
\hline Insertion time $(s)^{*}$ & $178(88-350)$ & $145(77-212)$ & $188(85-420)$ & $150(70-298)$ & $108(50-289)$ \\
\hline Workload (1-5)* & $3.40(2-4.60)$ & $2.60(1.60-3.60)$ & $2.30(1.40-4)$ & $2.40(1.20-3.80)$ & $3(1.80-4)$ \\
\hline Detection rate $(\%)^{*}$ & $68(16)$ & $86(22)$ & $71(22)$ & $64(26)$ & $71(19)$ \\
\hline
\end{tabular}

Data resulting from the experiments is analyzed using several statistical models in SPSS Statistics. The low sample size $(n=12)$, the large variation in individual scores, and the absence of normal data distributions on these measures across the five set-ups made us decide to base the analyses on ranked data using non-parametric tests. Separate Friedman's ANOVA's were conducted to compare setup 1,2, and 5 and to compare 1,3, and 4, respectively, following the separation of the setups in two groups. In case of a significant overall effect, Wilcoxon signed-rank tests were conducted to compare the scores between two setups. A Bonferroni correction was applied to control for chance capitalization, resulting in a .0167 level of significance for the contrast analyses. Overall significance level was $p=.05$. The results are summarized in Table 3.4 and discussed afterwards. 
Table 3.4 Summary table statistical results $p$-values

\begin{tabular}{|c|c|c|c|c|c|}
\hline & \multicolumn{2}{|c|}{ Insertion time } & \multicolumn{2}{|c|}{ Workload } & Detection rate \\
\hline \multirow[t]{2}{*}{ Group 1} & \multicolumn{2}{|c|}{$\chi^{2}(\mathrm{~N}=12,2)=9.75, p=.005$} & \multicolumn{2}{|c|}{$\chi 2(\mathrm{~N}=12,2)=6.83, p=.029$} & $\chi 2(\mathrm{~N}=12,2)=0.84, p=.683$ \\
\hline & 1. Conv. & 2. J-stationary & 1. Conv. & 2. J-stationary & 2. J-stationary \\
\hline 1. Conv. & - & .006 & - & .011 & t's $>306$ \\
\hline 5. T-portable & .008 & .556 & .130 & .169 & $p s=-.000$ \\
\hline \multirow[t]{2}{*}{ Group 2} & \multicolumn{2}{|c|}{$\chi^{2}(\mathrm{~N}=12,2)=5.66, p=.060$} & \multicolumn{2}{|c|}{$\chi 2(\mathrm{~N}=12,2)=10.18, p=.004$} & $\chi 2(\mathrm{~N}=12,2)=1.11, p=.599$ \\
\hline & 1. Conv. & 3. T-stationary & 1. Conv. & 3. T-stationary & 1. Conv. 3. T-stationary \\
\hline 1. Conv. & - & .814 & - & .028 & \multirow{2}{*}{$p^{\prime} s>.196$} \\
\hline 4. J-portable & .023 & .037 & .016 & .282 & \\
\hline
\end{tabular}

Performance of the participants of group 1 on insertion time differed significantly across conventional control (setup 1), joystick control with stationary scope (setup 2), and touchpad control with portable scope (setup 5), $\chi 2(\mathrm{~N}=12,2)=9.75, p=.005$. Posthoc analyses indicated that performance on setup 2 was significantly better than performance on setup 1 , $Z=2.76, p=.006$. Participants also performed better on setup 5 than on setup $1, Z=2.67$, $p=.008$. No significant difference in performance was found between both robotic setups, $Z=0.59, p=.556$.

Performance of the participants of group 2 on insertion time differed marginal significantly across conventional control (setup 1), touchpad control with stationary scope (setup 3), and joystick control with portable scope (setup 4), $\chi 2(\mathrm{~N}=12,2)=5.66, p=.060$. Posthoc analysis showed that participants did not performed better on setup 3 than on the conventional setup, $Z=0.24, p=.814$. The difference in insertion time approached significance between setup 4 and the conventional setup, $Z=2.27, p=.023$, suggesting that the robotic setup performed better. Furthermore, the difference in insertion time approached significance between the robotic setups, $Z=2.08, p=.037$, in favor of joystick control with portable scope (setup 4).

The perceived workload of group 1 differed significantly across setup 1, 2, and 5, $\chi 2(\mathrm{~N}=12,2)=6.83, p=.029$. Posthoc analyses indicated that perceived workload on joystick control with stationary scope (setup 2 ) was significantly lower than perceived workload on the conventional setup, $Z=2.54, p=.011$. Participants did not perceive the workload as lower on touchpad control with portable scope (setup 5) than on the conventional setup, $Z=1.51$, $p=.130$, nor was the perceived workload significantly different between both robotic setups, $Z=1.37, p=.169$.

The perceived workload of group 2 differed also significantly across setup 1, 3, and 4, $\chi 2(\mathrm{~N}=12,2)=10.18, p=.004$. Posthoc analyses showed that the difference in perceived workload approached significance between touchpad control with stationary scope (setup 3) and the conventional setup, $Z=2.20, p=.028$, suggesting that the perceived workload was lower for the robotic setup. Participants also perceived the workload as lower on joystick control with portable scope (setup 4) than on the conventional setup, $Z=2.41, p=.016$. The workload between both robotic setups was not perceived as different, $Z=1.08$, $p=$ .282 .

No significant differences in performance across the setups in group 1 was found on detection rate, $\chi 2(\mathrm{~N}=12,2)=0.84, p=.683$. Posthoc comparisons between setups confirmed 
this lack of difference in performance ( $Z$ 's $<1.02$, $p$ 's $>.306$ ). For group 2 the same was concluded, $\chi 2(\mathrm{~N}=12,2)=1.11, p=.599$. Posthoc comparisons between setups confirmed this lack of difference in performance ( $Z$ 's $<1.29$, $p$ 's $>.196)$.

The statistical analyses of the quantitative results indicate that robotic control by novices improves insertion time and workload experience. In comparison with the conventional method, joystick control with stationary scope (setup 2) and touchpad control with portable scope (setup 5) had significantly faster insertion times, while joystick control with portable scope (setup 4) approached significance. Between-subjects analyses using Mann-Whitney tests showed no significant effects on insertion time between setup 2-3, setup 2-4, setup 5-3, and setup 5-4, which is possibly due to the large variation in individual scores.

The workload scoring of all robotic setups, except for touchpad control with portable scope (setup 5), are significantly better than of the conventional method. Between-subjects analyses comparing performance of group 1 and 2 on the different robotic setups showed that the workload of joystick control with portable scope as well as touchpad control with stationary scope are perceived as lower than the workload of touchpad control with portable scope.

No significant differences in performance across the setups was found on the detection rate. Between-subjects analyses comparing performance of group 1 and 2 on the different robotic setups showed no significant effects on detection rate.

In the remainder of this section, the qualitative data (e.g. from the interviews) is discussed in order to explain the quantitative data and to allocate points of improvement for our setup. All participants performed full insertion into the cecum with all experimental setups. Extensive manoeuvring of the endoscope shaft was not required during insertion. For that reason nothing conclusive can be said on the necessity of a portable scope. Future experiments with physicians in a challenging procedure should provide more insight. In the interviews almost all participants complain about the additional weight that needs to be carried in the portable endoscope setup. One might consider free manipulation only in awkward circumstances such as looping of the shaft. During easy parts of the procedure the scope is docked. Despite the additional weight, novices appreciated the ergonomics and work posture of all robotic setups more than of the conventional setup. The user interface shortcomings discussed in Section 3.3 related to holding a traditional endoscope and operating the navigation wheels are confirmed by the participants in this study. The geometry of our remote control and the position of the joystick and touchpad are much more appreciated and do not need any adaptations.

After evaluation of all three setups participants have been asked to rank the different type of input devices. The results are depicted in Table 3.5. The conventional steering method would be the first choice for one participant, and last in 16 of 24 participants. Participants picked the joystick control (portable and stationary) first in 15 of 24 cases. The one participant that preferred conventional control indicated that decoupled up-down and leftright movements of the endoscope is better to understand. Instead of directly moving to the target, he preferred alternately moving in $\mathrm{X}$ and $\mathrm{Y}$-direction. 
Table 3.5 Ranking of input devices

Conventional control
Joystick (portable \& stationary)

15

6

3

Touchpad (portable \& stationary)

\begin{tabular}{lccc}
\hline First & 1 & 15 & 8 \\
Second & 7 & 6 & 11 \\
Third & 16 & 3 & 5 \\
\hline
\end{tabular}

Although participants prefer joystick to touchpad control, quantitative data on performance does not endorse that outcome. Possibly it can be explained by the fact that in contrast to a joystick, the touchpad offers no proprioceptive feedback, i.e. the sense of the relative thumb position and muscle strength. This type of feedback is important in the first phase of learning to control input devices [Zhai, 1993; Zhai and Milgram, 1993]. Presumably, the higher preference scoring for the joystick reflects the appreciation of having this feedback to increase intuitiveness. Additionally, the repetitive movements of the touchpad might explain the lower preference since they increase the workload of the operator. Users also reported unexpected motions and lack of response when using the touchpad. Participants tend to roll the thumb during touchpad control instead of only moving the tip of the thumb over the touch surface. As a consequence, tip movement will not occur as expected, since the contact area with the touched surface is not moved as intended. In the portable setup, rolling the thumb is restricted by the additional weight and the imposed position of the hand with respect to the endoscope, possibly explaining the faster insertion time of the portable compared with the stationary setup. A system that encourages steering with the tip of the thumb will likely lead to improved touchpad control.

Almost all participants thought that motion control of both the joystick and the touchpad were too aggressive, but they valued the intuitiveness of operation. However, about half of the population needed some time to get used to the coupling of thumb movements to camera movements. The exact distribution could not be detected, but three groups were identified:

1. Participants that couple thumb movements to camera movements (bringing the endoscope to the target), as intended in our setup.

2. Participants that couple thumb movements to panning the image (bringing the target to the endoscope), as used in computer applications in case the whole image cannot be displayed.

3. Participants that suggest that up-down should be reversed to copy flight control, as known from joystick interfaces for flight simulator games.

The prevalence of counter directional steering might indicate that there are no general applicable rules on implementing intuitiveness of use. Sensitivity as well as in what way input directions are coupled to output directions could be made adaptable to comply with user preferences. Before the procedure starts the operator first sets its personal settings. Statistical analysis showed that previous experience with game controllers or touch interfaces did not influence performance.

In general participants needed no or limited instruction on steering the robotic setups. In contrast, the conventional setup required instructions with regard to the right way to hold the control handle, how endoscope movements are coupled to navigation wheel manipulation, and in what way the brakes of the navigation wheels could be helpful.

Force feedback information from the navigation wheels was not available in the robotic setup in our experiment. As discussed in Section 3.4 force feedback is helpful in estimating 
the flexion of the tip, interaction forces of the tip with tissue, and shaft loops that need to be straightened. However, the bending diagram that provides feedback on the extent to which the tip is bent, as described in Section 3.5.7, was shown during the experiment. It appeared to be essential even in an easy bowel configuration. Novices appreciated this substitute for haptic feedback very much.

Some participants suggested a 'home' button to steer the endoscope tip automatically to a neutral straight position. The conventional endoscope has this functionality by releasing the two navigation wheels. It is helpful in situations that sight is obstructed or the orientation of the tip is not clear. However, it is an autonomous function that needs critical evaluation with regard to safety.

Although the drive train of antagonistic Bowden cables is pretensioned to prevent backlash and delay in control, it was expected that participants would notice some time-lag in tip response. Particularly when changing to an opposite bending direction, one of the pull-pull cables first needs to be stretched before movement of the drive unit occurs (deadband). However, participants were positive about responsiveness of the system. Possibly the kind of tasks did contribute to this outcome. In the performed long stroke navigational tasks, the deadband is traversed quicker, in comparison with tasks that require fine manipulation.

\subsubsection{Additional experiment}

In addition to the experiment discussed in the previous section, four different types of steering methods in long stroke as well as short stroke targeting tasks have been evaluated [Roozeboom, Ruiter, Franken and Broeders, 2013]. This experiment was conducted to answer the following questions that remained unanswered after the first experiment:

1. How does the robotic endoscope behave in fine manipulation tasks?

2. Results of the first experiment did show a small preference for a rate-controlled joystick compared with a position-controlled touchpad. Could additional research indicate significant differences?

3. Could a non-linear rate control algorithm solve tip response issues?

The four tested steering methods were: conventional with navigation wheels, a touchpad with position control, a joystick with linear rate control, and a joystick with non-linear rate control. The first three methods are known from the previous test. The latter was added to evaluate if a non-linear rate control algorithm could optimize control for short stroke as well as long stroke tasks. It combines a low gain for fine movements and a higher gain with higher velocity changes for large movements. Based on the results of the first experiment the sensitivity of all robotic input devices are lowered.

The test model is depicted in Figure 3.19. To test the navigational functionality, the first task was to touch $3 \mathrm{~mm}$ targets, equally distributed on a circle with a diameter of $200 \mathrm{~mm}$. The second task simulated fine targeting functionality by touching four targets of $1 \mathrm{~mm}$ on a circle with diameter of $50 \mathrm{~mm}$. Targets were placed such that horizontal, vertical and diagonal movements were necessary. 


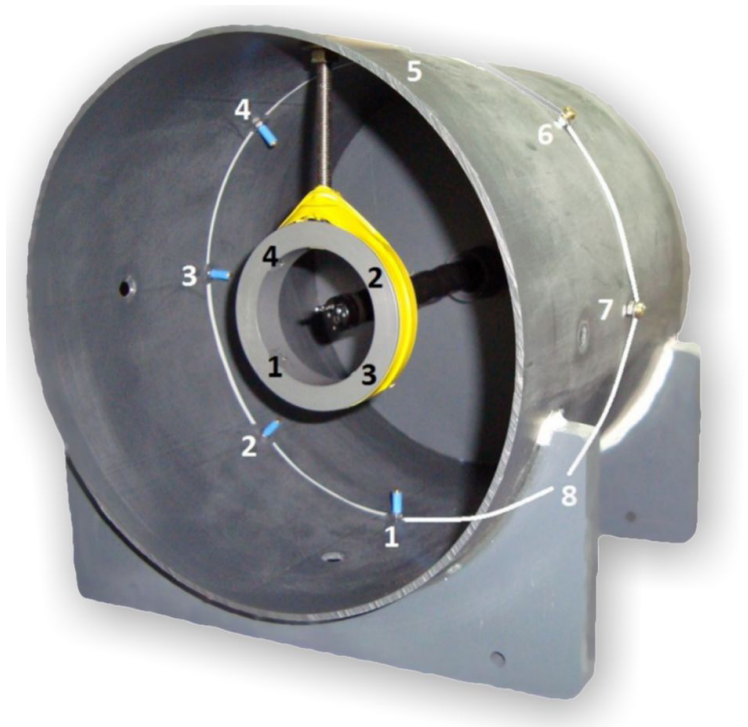

Figure 3.19 Model to test navigational and fine targeting tasks

Fourteen novices in endoscopy were recruited for this study. Efficiency was determined by measuring time and endoscope's tip trajectory.

Except for the joystick with linear rate control in the fine targeting task, participants were significantly faster in steering the endoscope tip with the robotic user interfaces compared to the conventional steering method. The touchpad interface was significantly faster in both tasks compared with the joystick with linear rate control. There were no significant differences between the touchpad and the joystick with non-linear rate control.

It was noticed that participants indeed had difficulties with response delays after changing to an opposite bending direction, especially in the fine targeting tasks. Most participants had difficulty estimating this delay and increased their input. Thereby over-actuating the system which caused the tip to pass the target. The resulting overshoot decreased efficiency in both time and effort. Participants using the joystick with non-linear rate control were able to maintain small tip movements and reduce their overshoot. This setup showed the shortest and smoothest tip trajectory and scored highest in users preference. Despite a longer tip trajectory compared with the joystick interfaces, users appeared fastest using the touchpad interface. The results of this additional experiment are in line with our first experiment and show that a touchpad as well as a joystick could be a suitable user interface for steering a robotic flexible endoscope in diagnosis. What we learned is that a joystick with a non-linear rate control algorithm increases performance in comparison with linear rate control.

A remarkable result from this experiment, and not noticed in our first navigational experiment, is that the conventional system was most popular regarding the perception of control. Although no significant difference was found, 5 out of 14 participants preferred manual actuation while each of the three robotic setups was preferred by 3 out of 14 participants. An explanation can be found in the presence of direct haptic feedback. The users perceive the start and ending of the bending motion because they feel the tension in the navigation wheels when pulling the bending cables. The remote devices do not enable haptic feedback of this bending motion directly, and a visual substitute as discussed in Section 3.4 was not provided. Together with the delay in tip motion, this reduces the perception of control. 


\subsection{Conclusion and recommendations}

A robotic steering module is built that allows ergonomic single person endoscope control while preserving current endoscope qualities. By means of a Bowden cable actuation principle a compact and lightweight portable drive system has been designed that can be coupled to the navigation wheels of a traditional endoscope. Besides actuation of the navigation wheels, all other functionality of a traditional endoscope is integrated in the robotic flexible endoscope and can be controlled with an ergonomic remote control. Breaking the mechanical linkage and integrating computer intelligence between operator and end effector provides opportunities for improved usability. The tests showed that robotic steering by novices increases efficiency and satisfaction. The effectiveness was not significantly affected by robotic steering. A joystick with non-linear rate control or a touchpad with incremental position control were both assessed as being suitable input device-transfer function combinations for robotic steering. If compared to conventional steering 23 out of 24 participants would prefer one of the robotic setups.

The qualitative results showed that robotic steering is easy, intuitive, comfortable, and fun compared with conventional steering. Despite the additional weight in the portable robotic endoscope, novices appreciated the ergonomics and work posture of all robotic setups. Almost all participants felt that motion control of both input devices was too aggressive. In addition, half of the population needed some time to get used to the mapping of thumb movements and camera movements.

Our experiments mainly focused on evaluation of the steering capabilities of different settings of our robotic endoscope. However, as discussed in Section 3.5 a fully functional robotic flexible endoscope for diagnosis is developed in this work. In future experiments all functionality needs to be tested in clinical relevant procedures by experts. These clinical experiments and their preparation are outside the scope of this work and will be performed within the ScopeSupport project by a $\mathrm{PhD}$ candidate of Technical Medicine of the University of Twente. In Section 6.3 some preliminary results are presented. Suggestions for functions that need to be tested and questions that need to be answered in these experiments are listed below.

- Thumb joystick or touchpad?

Our results did not show a clear preference for a touchpad or a joystick and for that reason both alternatives need to be tested by clinical experts in future experiments.

Possibly their performance and preference scores show a significant difference between both input devices.

- Proportional valves for rinsing, insufflation, and suction.

Are the characteristics (flow, time delay) comparable with current practice? Is

proportional actuation of added value? Are the actuation buttons on the remote control suitable?

- Programmable switches.

Are the buttons on the remote control suitable?

- Visual force feedback information of navigation wheels.

Can indication bars that represent force information adequately replace haptic information? Is the depicted data accurate?

- Portability of the robotic flexible endoscope.

Is it required that the robotic endoscope is light so it can be carried and easily maneuvered by the physician? Or is it allowed that the endoscope including the drive unit is docked and the physician only holds the remote control?

- Disinfection. 
Will the current design be accepted in clinical practice with regard to cleanability and logistics?

- Speed, accuracy, response time, range of operation.

Are the current performance specifications sufficient in clinical procedures?

- Is the setup suitable to integrate in an endoscopy room?

- Are there any use limitations of the robotic steering module compared with the conventional setup?

- Are there any safety risks in using the robotic setup?

In addition, from our novices experiments points of improvement are derived that could optimize the robotic endoscope. If it is feasible within the timeline, it is recommended to implement these before the clinical tests with experts. Some improvements are estimated to require a lot of additional research and development and are indicated as future work and should be implemented in a later stage.

- A system that encourages steering with the tip of the thumb could improve touchpad control. A small and round embossing positioned on the thumb of a glove is a possible solution.

- The operator should be able to reverse the mapping of thumb movements to endoscope movements. The graphical user interface could provide this functionality.

- A kind of 'home' button should be implemented to steer the endoscope tip automatically to a neutral straight position. It should be critically evaluated with regard to safety. Possibly haptic guidance, as suggested by Reilink [2011], is a suitable implementation.

- Mechanical induced delay in tip response should be prevented. Possible solutions are a novel actuation principle without Bowden cables or implementation of haptic feedback. (future work)

All additions and adaptations are expected to improve the robotic flexible endoscope. However, they first need to be evaluated in experiments to assess their performance and usability.

This chapter concentrated on the design and evaluation of a robotic steering module to obtain single person endoscope steering for diagnosis. With the addition of instruments in therapy, single person control can only be obtained if a flexible endoscope can be operated with one hand and instruments with the other. In Chapter 4 a robotic shaft manipulation module is introduced that, in conjunction with the robotic steering module of this chapter, allows a single physician to steer, advance, rotate, and maintain the position of an endoscope, while the other hand is able to manipulate instruments. 



\section{4 \\ Robotic shaft manipulation module - existing therapeutic procedures}

In therapeutic flexible endoscopy a team of physician and assistant(s) is required to control all independent translations and rotations of the flexible endoscope and its instruments. Current tools are not suitable to perform therapeutic procedures in an intuitive and user-friendly way by one person. This chapter describes the design and evaluation of a robotic system that interacts with traditional flexible endoscopes to perform therapeutic procedures that require advanced maneuverability. The robotic steering module (Chapter 3) that actuates left-right and up-down of the distal tip is combined with a robotic shaft manipulation module that actuates the axial and rotational movements of the flexible shaft of the endoscope. The physician uses a multidegree-of-freedom input device to control camera steering as well as shaft manipulation of the motorized flexible endoscope with one hand, while the other hand is able to manipulate instruments. Critical use aspects of the current method are identified and addressed in the robotic setup. First a proof-of-principle setup is built and evaluated to assess the usability of the basic functionality. Results show that robotic endoscope control increases efficiency and satisfaction. Subsequently a system is developed that is fully functional and takes safety, cleanability, and easy positioning close to the patient into account.

This chapter is a revised version of the following papers:

J.G. Ruiter, M.C. van der Voort, G.M. Bonnema, I.A.M.J. Broeders, Robotic Control of a Traditional Flexible Endoscope. In Proceedings of Hamlyn Symposium, London, 2012.

J.G. Ruiter, M.C. van der Voort, G.M. Bonnema, I.A.M.J. Broeders, Robotic Control of a Traditional Flexible Endoscope for Therapy. In Journal of Robotic Surgery, accepted for publication 


\subsection{Introduction}

Current commercial available flexible endoscopes and their instruments have limited capacity to execute endoluminal procedures that require advanced maneuverability. As discussed in Chapter 3, traditional endoscope motion control is not intuitive and userfriendly. With the addition of instruments in therapy even more independent translations and rotations of the tools need to be controlled. Various accessories and techniques are available as discussed in Malik et al. [2006] Ellsmere et al. [2006], and Matsui et al. [2012]. A team of physician and assistant(s) is required to perform the procedure, as shown in Figure 1.5. It is expected that existing endoluminal surgery is generally adopted by physicians if the enabling technology is available to perform these procedures efficiently, effectively, safely, and with minimal assistance [Malik et al., 2006; Yeung and Gourlay, 2012].

Chapter 3 concentrated on the redesign of the control section to obtain user-friendly single person endoscope steering for diagnosis. With the addition of instruments in therapy, single person control can be obtained if the flexible endoscope can be operated with one hand and instruments with the other. The robotic steering module (Chapter 3 ) that actuates left-right and up-down of the distal tip is combined with a robotic shaft manipulation module that actuates the axial and rotational movements of the flexible shaft of a traditional endoscope. The physician uses one multi-degree-of-freedom (multi-DOF) input device to steer, advance, rotate, and maintain the position of the motorized flexible endoscope, while the other hand is able to manipulate instruments. In Figure 4.1 the motorized and manual operated degrees of freedom of the robotic flexible endoscope for existing therapeutic procedures are indicated and how displacements of the input device, represented by a pen, could be linked to endoscope movements.

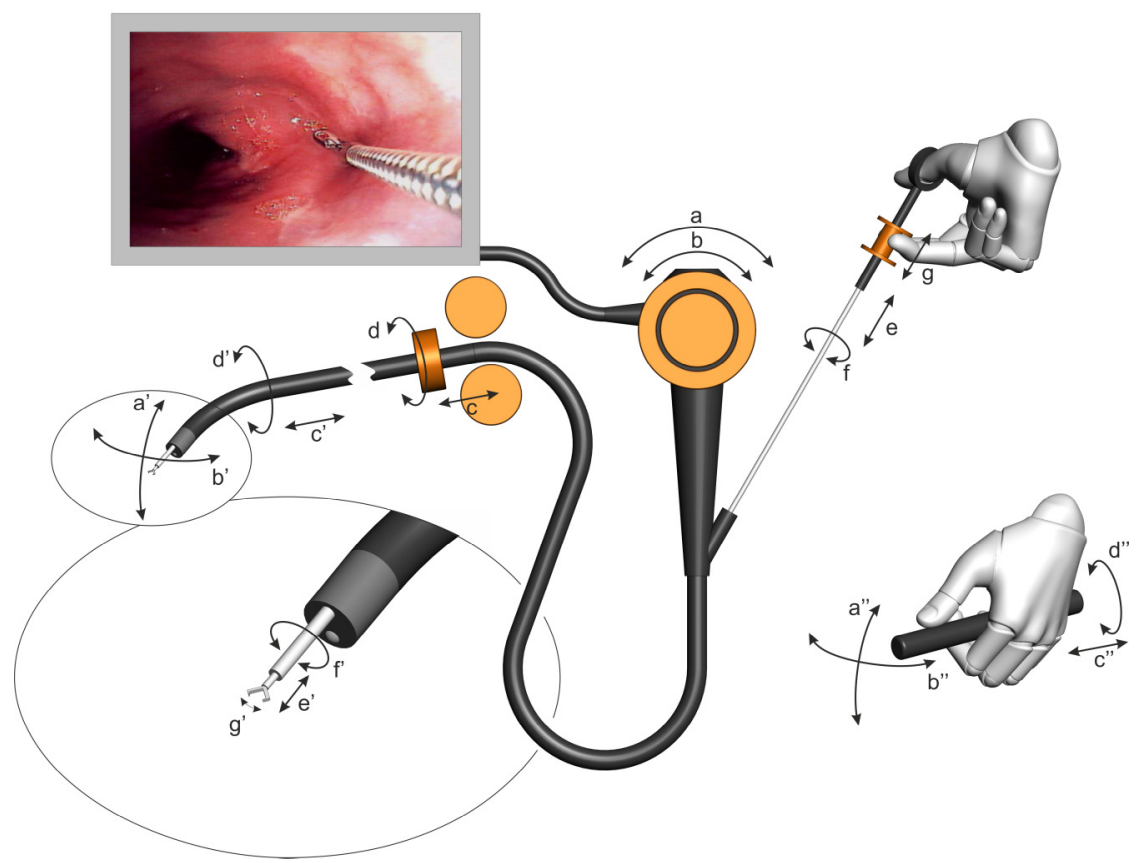

Figure 4.1 DOFs robotic endoscope for therapy and possible mapping to input device: (a) Robotic updown, (b) Robotic left-right, (c) Robotic in-out, (d) Robotic (counter)clockwise rotation, (e) Manual in-out instrument, (f) Manual (counter)clockwise rotation instrument, (g) Manual grasp instrument 
The control handle of the input device resembles the endoscope tip. The operator experiences steering like directly manipulating the distal tip that contains the camera. Movements of the endoscope tip and of the physician's hand should be synchronized to obtain intuitive manipulation [Wentink, 2003].

Robotic shaft control is not intended for endoscope advancement in diagnosis that requires precise interpretation of interaction forces between endoscope and lumen [Williams, 2009]. Diagnosis is performed with the robotic steering module and the robotic shaft manipulation module is only coupled to the endoscope when therapy has to be performed. It enables the physician to intuitively manipulate the tip of the endoscope in the operating area. It creates a stable endoscopic platform without the need of an assistant and it allows for small precise robotic movements of the distal tip when the spatial range of the instruments is too small.

This chapter discusses:

- The development of the robotic shaft manipulation module.

- The integration of the robotic shaft manipulation module, the robotic steering module, a multi-DOF input device and a traditional endoscope into a robotic flexible endoscope for therapy.

- The evaluation of the usability of the robotic endoscope compared with current tools to perform therapeutic tasks.

Section 4.2 starts with the state of the art in robotic shaft manipulation of flexible endoscopes. In Section 4.3 shortcomings of the current user interface are discussed. Section 4.4 describes the design considerations for our system. Section 4.5 presents a proof-ofprinciple setup for testing of critical design aspects. Section 4.6 contains the results of the experiments that are conducted with the proof-of-principle setup. In Section 4.7 the final design is specified and shown. Finally, Section 4.8 concludes and provides directions for future work.

\subsection{Related work}

In this section an overview will be presented of robotic flexible endoscopes with a special focus on electro-mechanical actuation of the shaft.

The Invendoscope (as previously discussed in Section 3.2) consists of a dedicated singleuse flexible endoscope that is actuated by an insertion module equipped with gearwheels, as displayed in Figure 4.2. Tip steering as well as shaft translation is actuated. Rotation of the shaft is not actuated. The endoscope is provided with one working channel to pass instruments for therapy [Groth et al., 2011]. Although not suitable for traditional endoscopes and not (yet) commercially available the Invendoscope is a promising system and is recently approved for clinical introduction.
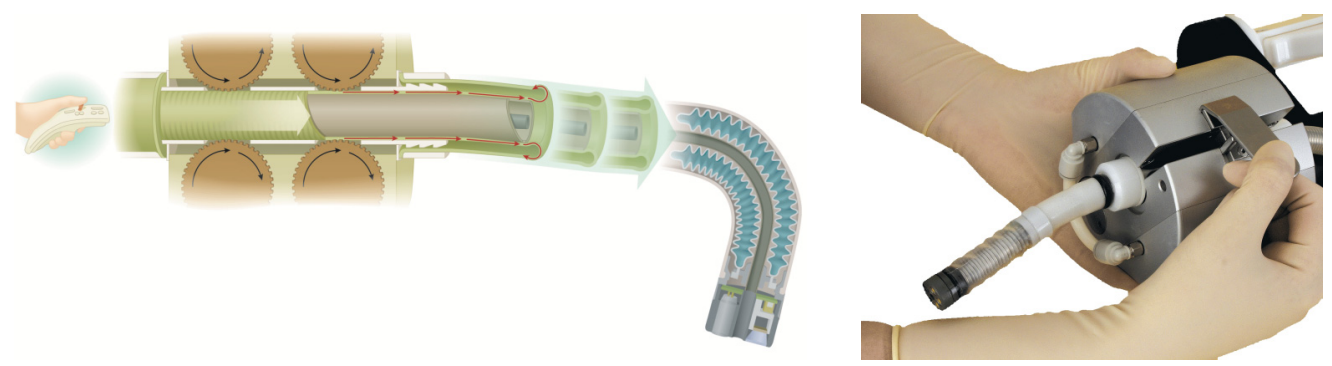

Figure 4.2 Invendoscope ${ }^{\circledR}$ (C2012 Invendo Medical) 
The Endodrive ${ }^{\circledR}$ (ECE Medical Products, Erlangen, Germany, Figure 4.3) is the first and only known commercially available system for electro-mechanical support of shaft manipulation of traditional endoscopes. The system is introduced in 2012 and allows positioning and driving the endoscope shaft forwards and backwards by means of drive rolls and a foot pedal. It assists in inspection and leaves both hands free for operation of the navigation wheels of the endoscope and for instrument manipulation. Rotation of the shaft should be done manually.

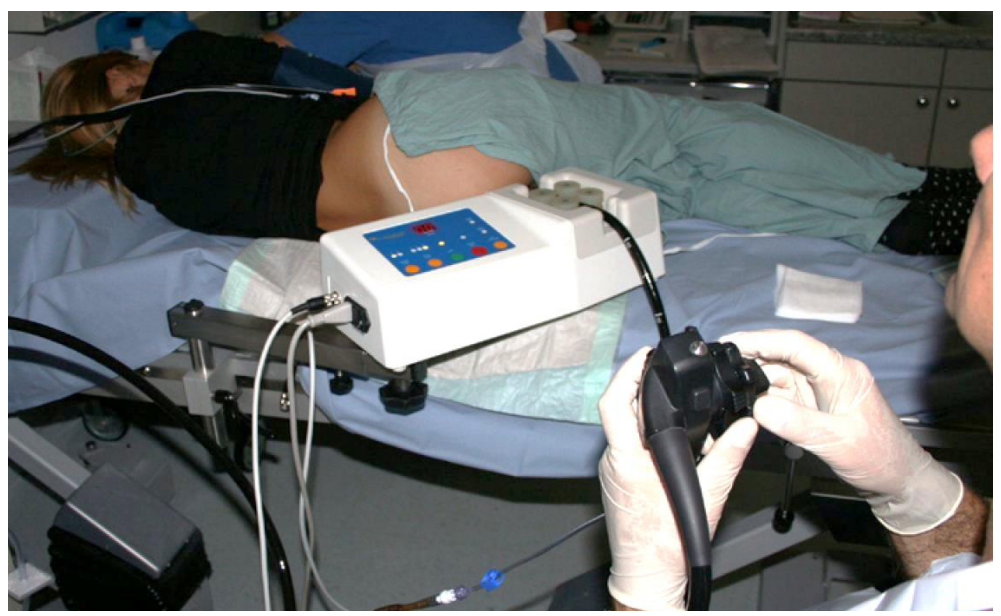

Figure 4.3 Endodrive ${ }^{\circledR}$ (C2012 ECE Medical Products)

Technical details of the Endodrive concept are discussed in its patent application in [Neumann and Bayer, 2006]. Other patents that describe solutions for shaft manipulation are filed by Olympus. One patent shows a device that is positioned over the shaft of a flexible endoscope. It contains a kind of joystick to control camera steering and shaft rotation. Shaft advancement is done manually [Okamoto and Banju, 2009]. In Figure 4.4 a system is depicted that has similarities with the Endodrive system. It contains two rotatable rollers (no.52/53) of which one is actuated for advancement of the endoscope shaft. The gap between actuation unit and patient is bridged with a flexible guide tube (no.40) that is positioned partly in the anus of the patient (no. 101). Endoscope rotation is not actuated [Honda et al., 2011].

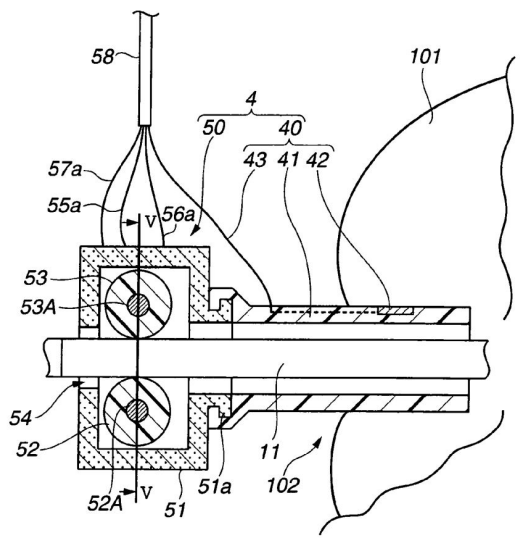

Figure 4.4 Actuation unit of Olympus with two rollers for shaft advancement [Honda et al., 2011] 
Kume et al. have developed an endoscopic operation robot for steering, advancing, rotating, and stabilizing a standard endoscope. The research setup eliminates the need for direct physical contact with the endoscope. It is controlled bimanually by means of two joysticks. The system was tested by measuring the insertion time for total colonoscopy examination. The median insertion time (in minutes) was $22.9 \pm 5.0$ for robotized examination versus $2.60 \pm 1.08$ for manual manipulation in about 50 procedures. Its application in therapeutic procedures has not been tested. Although the authors suggest the possibility of clinical application of the system, it is far from being ready for clinical implementation [Kume et al., 2011].
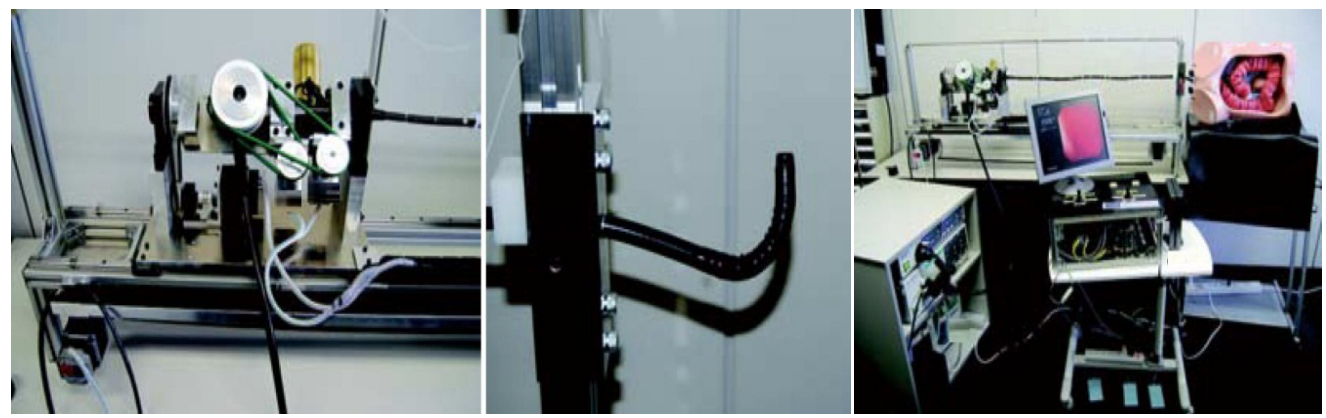

Figure 4.5 The endoscopic operation robot [Kume et al., 2011]

All described systems are mainly developed to assist in navigating the lumen in diagnostic procedures. A system that assists in performing advanced therapeutic procedures by robotizing all degrees of freedom of a flexible endoscope, and that is steered with one hand, does not exist. The remainder of this chapter discusses the development and evaluation of such a robotic flexible endoscope, but first the current problem area is researched.

\subsection{Current user interface shortcomings}

Manipulation of the shaft of a flexible endoscope is associated with awkward wrist, shoulder, and neck postures, and repeated pushing, pulling, and torquing of the shaft. These maneuvers are risk factors for repetitive strain injury (RSI). Most of the injuries are caused by torquing of the flexible endoscope, especially during more difficult therapeutic procedures [Liberman et al., 2005; Pedrosa, 2011; Shergill et al., 2009]. Suggestions in literature to prevent pain include taking rest or having an assistant to apply torque when necessary [Liberman et al., 2005; Kuwabara, 2011]. However, as already discussed in the introduction, except with unusually skilled assistants, two- or three person endoscope manipulation is less dexterous [Williams, 2009; Dykes, 2009]. With the current user interface in flexible endoscopy the procedure is either physically demanding in the single person setup, or requires intensive collaboration with other personnel in the assisted setup.

Besides the physical aspect, single person endoscope control can also be mentally demanding. It requires bimanual action to steer the distal tip of the endoscope and to advance and rotate the shaft. Bimanual coordination of hand movements virtually always requires training. It is a high-level capability that requires intense coupling of the motor areas of both hemispheres of the brain [Swinnen and Wenderoth, 2004; Gerloff and Andress, 2002]. Steering all four degrees of freedom of the endoscope with one hand is, based on [Swinnen and Wenderoth, 2004; Gerloff and Andress, 2002], expected to be more intuitive and less mentally demanding. This assumption is tested in our experiment, as discussed in Section 4.6. 
Current applications of endoluminal surgery are only performed by very technically skilled clinical experts using traditional endoscopes. Most of them are able to perform single-handed (left hand) endoscope tip steering [Williams, 2009]. The right hand alternately controls the shaft of the endoscope and the instrument that protrudes through the working channel. Meanwhile the position of these components is sensitive for change when released by the physician. So even with a very skilled endoscopist all degrees-of-freedom of the endoscope and the applied instruments are not constantly under control.

It can thus be concluded that current endoscope handling is not ergonomic, intuitive, and user-friendly. Robotic technology has the potential to support physicians in easily and safely manipulating flexible instruments. Opportunities and considerations of a robotic flexible endoscope will be highlighted in the next section.

\subsection{Design directions for robotic shaft manipulation}

As discussed in the introduction, the robotic shaft manipulation module will be part of a robotic endoscope for endoluminal therapeutic procedures. Endoscope advancement up to the operating area will be supported by the robotic steering module of Chapter 3 . When the operating area has been reached, the robotic shaft manipulation module will be brought into position and it will be coupled to the endoscope. A lockable swivel arm, that contains a long stroke section for coarse movements and a short stroke section for precise alignment of the robotic module with the endoscope, could be a suitable device. Easy coupling, decoupling and repositioning of the robotic module is needed to switch between robotic and manual operation during a procedure. Not only to optimize usability, but also for safety purposes in case of a system failure or power outage. The complete procedure of coupling or decoupling should not take more than a few seconds.

In current flexible endoscopy the distal tip is manually introduced into the patient by applying axial force on the flexible shaft about $25-30 \mathrm{~cm}$ from the entry point of the patient. In the robotic setup the shaft manipulation module needs to be positioned as close as possible to the patient to minimize loss of shaft length and limit buckling effects of the shaft outside the patient's body. Nevertheless, for safety purposes some distance is required to prevent physical contact between robotic module and patient. A distance of $25-30 \mathrm{~cm}$, as used in manual manipulation and seen in comparable systems (Section 4.2), seems appropriate. Most endoscopists place the patient in the left lateral position. Patient repositioning (to right lateral, supine, or even prone position) may be necessary to optimize visibility and access to the operating area. For instance during endoscopic resection of large colonic mucosal lesions gravity is used to open the incision and to perform dissection under direct vision [Yahagi, 2009]. In order to facilitate robotic shaft manipulation under these conditions the robotic module needs to be small and its position has to be easily adaptable without the need of retracting the endoscope from the patient.

Although not used immediately, the robotic shaft manipulation needs to be prepared by the assistant before the clinical procedure starts. Instead of sterilization or disinfection, usage of disposable parts (including plastic sleeves) that separate the clean from the contaminated world is a known method. Particularly for (electro-) mechanical devices, that are sensitive for heat or moist during cleaning, it is a more suitable solution. The robotic module itself (semicritical part, Section 3.4), the multi-DOF input device (non-critical part), and the swivel arm (non-critical part) are covered with disposables. Additionally, the lay-out of the system has to be suitable for handling a polluted endoscope. The shaft manipulation module should contain a wiper that removes lubrication and/or bodily fluids from the shaft during retraction. This prevents frictional loss between endoscope and actuation mechanism and prevents pollution of the actuation mechanism. After the procedure the robotic shaft 
manipulation module (and the robotic steering module) will be dismantled, disposable parts are discarded and the flexible endoscope has to be disinfected according to the current clinical workflow. Although potentially contaminated parts are covered with disposables they still need to be suitable to be cleaned with a moistened cloth with disinfectants.

In current practice the physician gets force feedback on steering the tip and advancing the shaft into the patient. It helps the physician to estimate the flexion of the tip, to identify interaction forces of the endoscope with tissue, and to detect shaft loops that need to be straightened [Körner and Männer, 2003]. Force feedback is particularly important when advancing the endoscope through the lumen in diagnosis. During interventions endoscope displacements are limited and interaction of the endoscope tip with tissue is avoided. Providing force feedback information is not a must have in robotic manipulation of the shaft in therapy. It is a nice to have, but implementation of force feedback interaction that perfectly reflects endoscope and tissue interaction is a technological challenge [Franken, 2011]. The therapist is mainly interested in force feedback information on interaction of tissue with instruments that protrude from the endoscope tip. If forces reach a critical level, instruments can perforate the intestine wall. The instruments are in the robotic setup manually operated by the physician, so direct force feedback information between instrument and tissue is available.

The instrument channel of a colonoscope is situated at the 5 o'clock position in reference to the visual field. To perform therapy, one of the most important factors is that the point of interest is in a proper position relative to where the instrument protrudes from the endoscope. To capture e.g. a polyp, an attempt should be made to bring it into the 5 o'clock position to facilitate snare placement. This can usually be accomplished by rotation of the shaft of the endoscope [Waye, 2009]. Our robotic setup should be able to initiate (counter)clockwise rotation of $-180^{\circ}$ up to $180^{\circ}$ counted from neutral position.

Despite the limited displacements of the endoscope, safety measures should be taken to prevent excessive forces between endoscope and patient. Occasionally patients will move with respect to the shaft manipulation module. Fortunately the endoscope is flexible and it will bend between patient and robotic module. However if the displacement of the patient is directed to the robotic module and the endoscope would be fixed in it, forces could reach an unacceptable level. The actuation principle should allow movement of the endoscope when axial forces reach a critical level.

High rotational forces are less likely. A possible situation in which forces could increase is when shaft rotations are actuated while the endoscope is in a loop inside the body. However, a good endoscopist will not start the therapeutic intervention before loops are resolved. Advancing and rotating (torquing) the shaft only affects the tip when the shaft is straight. If a loop is present it will enlarge the loop without moving the tip. [Williams, 2009]. Nevertheless, for safety purposes the actuation principle should, besides axial translation, allow rotation of the endoscope when torque forces reach a critical level. Korman et al. [2012] and Appleyard et al. [2000] have studied the applied axial and torque forces of endoscopists during a colonoscopy procedure. In Table 4.1 the results of both experiments are shown. Korman presents mean as well as peak forces, while Appleyard shows only peak forces. Korman's results with regard to the peak forces are of the same magnitude as Appleyard's results. 
Table 4.1 Shaft manipulation forces during colonoscopy [Korman et al., 2012]

\begin{tabular}{lccc}
\hline \multicolumn{1}{c}{ Parameter } & Mean $($ SD) $[$ Korman] & Max. [Korman] & Max. [Appleyard] \\
\hline Push $(\mathrm{N})$ & $18.59(10.56)$ & 56.7 & 44 \\
Pull $(\mathrm{N})$ & $-13.74(8.29)$ & -39.2 & -18 \\
Clockwise torque $(\mathrm{Nm})$ & $0.45(0.21)$ & 1.0 & 1.1 \\
Countercw torque $(\mathrm{Nm})$ & $-0.47(0.24)$ & -1.3 & -0.9 \\
\hline
\end{tabular}

In therapy the applied forces are estimated to be less. However, in literature no data is available on the magnitude of that forces. Therefore the results of Korman [2012] and Appleyard [2000], measured during performing a colonoscopy, are taken as a reference and the robotic module needs to be capable of applying up to $60 \mathrm{~N}$ (in-out translation) and 1.5 $\mathrm{Nm}$ ((counter)clockwise rotation). Since patient pain, instrument damage, and perforation of the lumen are related to the applied forces of the endoscope, these values should not be exceeded and possibly reduced in case experiments indicate that less force is sufficient in endoluminal therapy. With regard to other performance parameters of the actuation mechanism, like speed and accuracy, assumptions were made since no data from literature was available. The most important performance parameters and other important design requirements are summarized in Table 4.2 at the end of this section. All values need to be validated in experiments.

The setup of robotic shaft manipulation is similar to that of robotic steering as described in Chapter 3. The endoscope is positioned in a drive unit and the user interface is decoupled from the endoscope. In case of therapy both robotic modules need to be used simultaneously. The input device can be designed such that the movement of the camera (tip and shaft movements) matches the movement of the physician's hand for optimal eye-hand coordination. A dedicated input device would be the optimal option. All critical characteristics like workspace, accuracy, and affordances [Norman, 2002] can be designed specifically for the application. Many devices, including various instrumented gloves, position trackers, and hand controllers have been developed for manipulating the location and orientation of three dimensional objects with six degrees of freedom [Zhai, 1995]. None of the techniques can be identified as the "best"; their performance is task and environment dependent [Bowman, 2001]. A multi-DOF joystick with a stylus pen could be an appropriate device to enable single-handed control and intuitive coupling between the motion of the input device and the 4-DOF motion (steering and shaft manipulation) of the endoscope. As depicted in Figure 4.6, the stylus pen can be held in a precision grip, in which an object is held with the fingers, or in a power grip, in which an object is held in the palm of the hand. Research of Santos-Carreras et al. [2012] and Zhai et al. [1996] showed that for fine 6 DOF manipulation tasks, a precision grip will result in significantly better performance. However, for manipulations requiring repetitive and large movements, as in our 4 DOF robotic setup, a power grip is preferred. Additionally, if the stylus pen of the input device is held in a power grip, it is expected that the operator experiences steering like directly holding and manipulating the endoscope tip. Integrating buttons with the input device encourages users to adopt a power grip. The stylus pen is clamped in the palm and the thumb and the index finger are able to operate the buttons, as shown in Figure 4.6 [Hinckley, 1997]. 

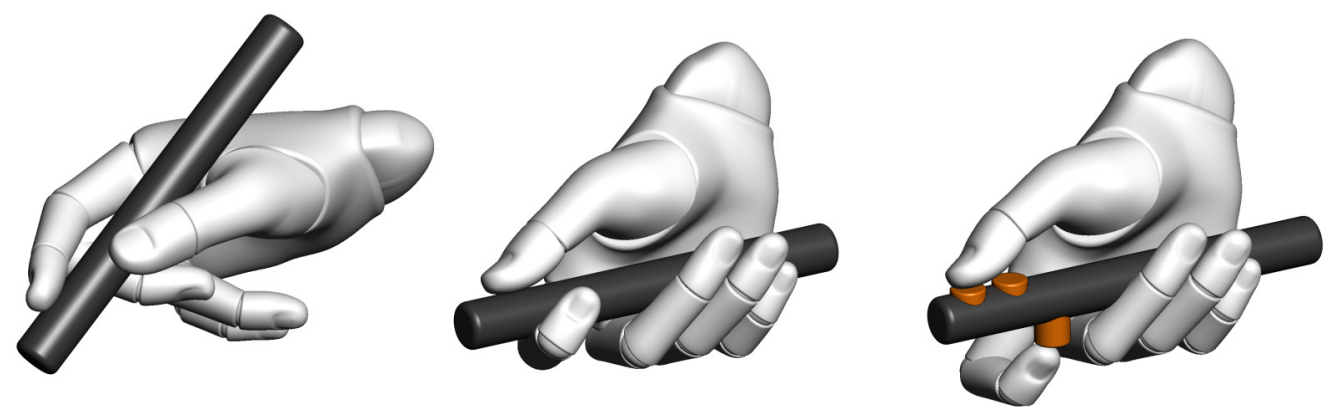

Figure 4.6 Precision grip, power grip, and power grip with buttons

Incremental position control is the most intuitive transfer function in tasks that require accurate manipulation in a limited workspace and should be implemented for tip as well as shaft control in therapy [Zhai, 1995; Kim, 1987]. Hand movement can be coupled to endoscope movement by pressing a hold-to-run button. It prevents unintended movements of the endoscope, allows repositioning of the stylus pen to a comfortable position, and locks the endoscope into position when the input device is (unintentionally) released. It requires that all actuated degrees of freedom are self-locking.

As discussed in the introduction the robotic steering module and the robotic shaft manipulation module are developed to obtain single-handed endoscope control. This allows instrument manipulation with the other hand. However, with the introduction of these robotic modules an assistant is not superfluous. Instruments need to be unpacked, positioned in the working channel, and often more than one degree of freedom needs to be operated during the procedure. These procedural steps cannot be performed with one hand by the physician. Possibly the number of assistants can be reduced. If assistance of the physician is only needed occasionally during the procedure, one assistant should be capable of assisting the physician as well as managing all non-therapeutic actions, like preparation of the room, test equipment, check the availability of accessories, collect specimens obtained during the procedure, and monitor the patient [Dykes, 2009]. This only applies in procedures in which the patients are under moderate sedation. For deep sedation, the assistant performing the patient monitoring should have no other responsibilities [ASGE/SGNA, 2004].

If instruments are used that contain more than one degree of freedom to operate, an additional assistant may be necessary. However, an assistive device that holds the instrument shaft and its control handle into position close to the opening of the working channel could enable single-handed instrument control. Instrument insertion and end effector actuation are alternately performed. The Scope $\operatorname{Doc}^{\circledR}$ (Cook Medical, Bloomington, USA) system that assists in carrying the control section of the flexible endoscope is provided with such an instrument holder, as shown in Figure 4.7. 


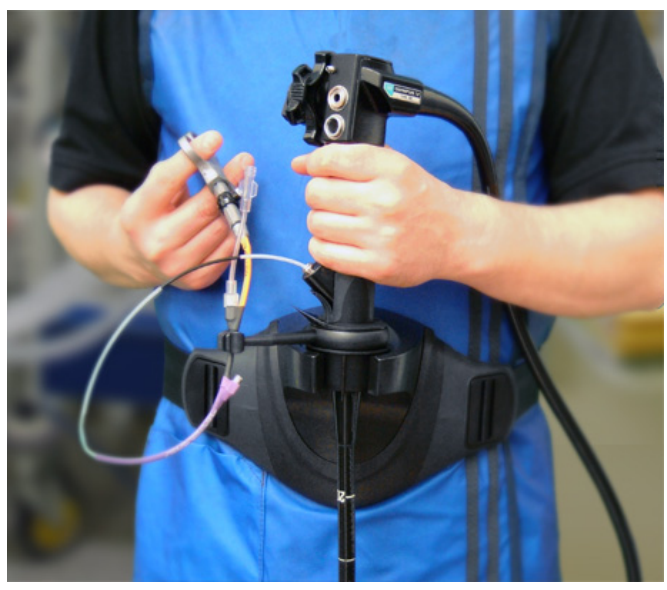

Figure 4.7 The Scope Doc ${ }^{\circledR}$ including an instrument holder (C2012 Cook Medical)

Above considerations are implemented in our design of a robotic shaft manipulation module, as described in Section 4.7. However, first the most critical design aspects are addressed in a basic proof-of-principle setup as discussed in the next section. It has been built to test in an early stage the suitability of our actuation mechanism for shaft manipulation and to test the usability of a standard multi-DOF input device for singlehanded endoscope control.

The most important performance parameters and other important design requirements from this section that are used as input for the proof-of-principle setup are summarized in Table 4.2.

Table 4.2 Important requirements robotic shaft manipulation module

\begin{tabular}{ll}
\hline Decoupling shaft & $<10 \mathrm{sec}$. \\
\hline Degrees of freedom shaft actuation & $\begin{array}{l}\text { 2 DOF: In-out translation, } \\
\text { (Counter)clockwise rotation }\end{array}$ \\
\hline Input device & $\begin{array}{l}\text { Single-handed 4 DOF control of tip } \\
\text { steering and shaft manipulation }\end{array}$ \\
\hline Transfer function & Incremental position control \\
\hline Up-down (a') & Section 3.4 \\
\hline Left right (b') & Section 3.4 \\
\hline In-out force (c') & $60 \mathrm{~N}$ \\
\hline In-out range (c') & $\pm 150 \mathrm{~mm}$ \\
\hline In-out accuracy (c') & $\pm 1 \mathrm{~mm}$ \\
\hline In-out speed (c') & $0-150 \mathrm{~mm} / \mathrm{s}$ \\
\hline (Counter)clockwise torque $\left(d^{\prime}\right)$ & $1.5 \mathrm{Nm}$ \\
\hline (Counter)clockwise range $\left(d^{\prime}\right)$ & $-180^{\circ} /+180^{\circ}$ \\
\hline (Counter)clockwise accuracy $\left(d^{\prime}\right)$ & $\pm 1^{\circ}$ \\
\hline (Counter)clockwise rotational speed & $90^{\circ} / \mathrm{s}$ \\
\hline
\end{tabular}

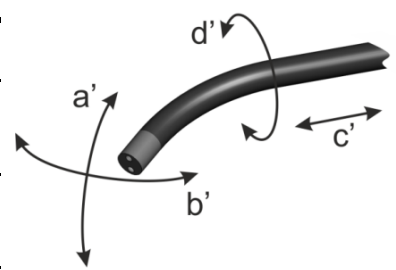




\subsection{Design proof-of-principle}

In Figure 4.8 two pictures are depicted of the actuation mechanism for robotic shaft translation and rotation.

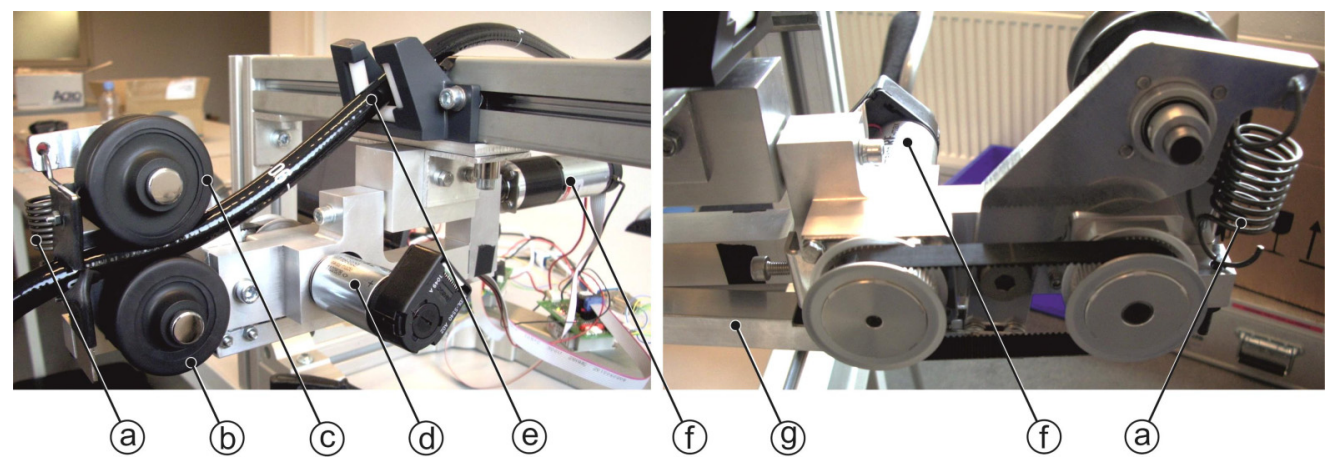

Figure 4.8 Actuation mechanism for shaft manipulation: (a) Spring, (b) Bottom wheel, (c) Upper wheel, (d) Motor translation, (e) Flexible endoscope, (f) Motor rotation, (g) Lever

The endoscope shaft is clamped between two wheels that are pretensioned with a spring. The shaft can be installed and removed at any time during the procedure by pushing a lever down. The lever is linked to the top wheel that moves up to create space. Different sets of wheels allow for different endoscopes with different diameters to be used by the robotic shaft manipulation module. Wheels are preferred above all other solutions due to their superior simplicity. One motor actuates the bottom wheel for translational movements along the shaft axis. The upper wheel is a follower. Another motor rotates the frame on which the wheels are positioned. The axis of rotation is in line with the shaft of the endoscope at the location where it is squeezed between the wheels. In this way pure axial rotation is created without lateral movement. Since the shaft is securely clamped between the wheels, axial rotation is achieved when the frame including the wheels is turned. Two DC servo motors (Maxon, Sachseln, Switzerland) were selected for translational and rotational actuation. The motors are controlled by Elmo Whistle servo amplifiers (Elmo Motion Control, PetachTikva, Israel). The set-points for the two degrees of freedom are generated by a laptop computer (EliteBook 2.4GHz, Hewlett-Packard, Palo Alto, USA) with Windows XP (Microsoft, Redmond, USA) installed. The control software is written in Python (Python Software Foundation).

Except for the rotational range of motion, performance of the actuation mechanism is in accordance with the values indicated in Table 4.2. The range of motion is limited to $-90^{\circ} /+$ $90^{\circ}$, since introducing a larger stroke would require a much more complex proof-ofprinciple design. It has been estimated that a stroke of $-180^{\circ} /+180^{\circ}$ is not needed in our experiment. In the final design, as described in Section 4.7, the full range will be implemented.

A Phantom Omni ${ }^{\circledR}$ haptic device (Sensable Technologies, Woburn, USA) is used as input device to steer shaft manipulation as well as tip movement. It is able to control 6 degrees of freedom (3 translations and 3 rotations) and depicted in Figure 4.9. 


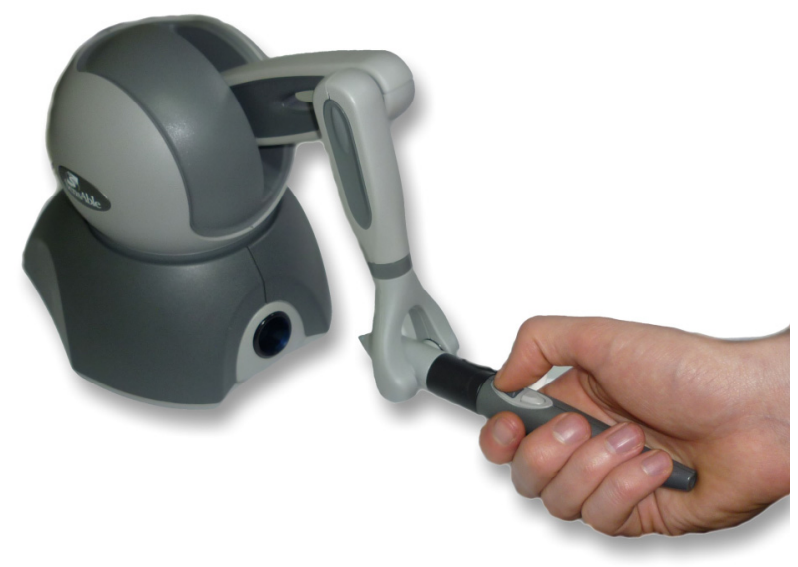

Figure 4.9 Phantom Omni ${ }^{\circledR}$ input device

Figure 4.1 already showed how endoscope movements are linked to stylus displacements in our setup. Two rotational degrees of the freedom of the Phantom Omni are not in use in our setup. Bowman [2001] as well as Hinckley [1994] suggest that redundant degrees of freedom should be constrained. Using haptic restrictions is a known method [Peña, 2008]. However, a Phantom Omni is a cost-effective haptic device with only force feedback on the translational movements not on the rotations. Therefore we were not able to easily restrict the redundant rotational movements. In our experiment, as discussed in Section 4.6, participants have been clearly instructed in how to use the input device. Particular for steering the tip it was emphasized that only the translational movements in XY-direction should be used for steering and that rotational input could induce parasitic movements, like unwanted rotation of the shaft. Future work could focus on improving performance by using a more sophisticated haptic device that provides force feedback on all degrees of freedom, like the sigma. $7^{\circledR}$ or delta. $6^{\circledR}$ of Force Dimension (Nyon, Switzerland). In this way additional forces can be created that restrict haptic device movements to the kinematics of the robotic endoscope. Additionally, dynamic restrictions could also be implemented in future work. As long as the physician cannot move the haptic device faster than the maximum velocity of the robotic endoscope, large position errors between the haptic device and the endoscope are avoided [Peña, 2008]. However, it should be researched if movement are still intuitive with haptic restrictions.

Incremental position control has been implemented as transfer function between user input and end effector displacement. The gain (or scaling factor) of both motors is adaptable to change the accuracy of endoscope manipulation. One of the two buttons of the Phantom Omni stylus (Figure 4.9) is used as hold-to-run button. It allows users to perform movements in a series of grab-release cycles in case manipulation is precise and, as a consequence, the spatial range of motion small.

\subsection{Usability test proof-of-principle}

This section describes the experiment conducted to determine the feasibility of the robotic endoscope in performing existing therapeutic procedures. The usability of conventional control with robotic control is compared in tasks that require advanced endoscope maneuverability. 


\subsubsection{Experimental setup}

In Figure 4.10 the complete setup is depicted that is used in this experiment to assess the intuitiveness and usability of robotic flexible endoscopy in therapy. Besides the robotic shaft manipulation module, the drive unit of the robotic steering module (Chapter 3) is implemented in the setup.

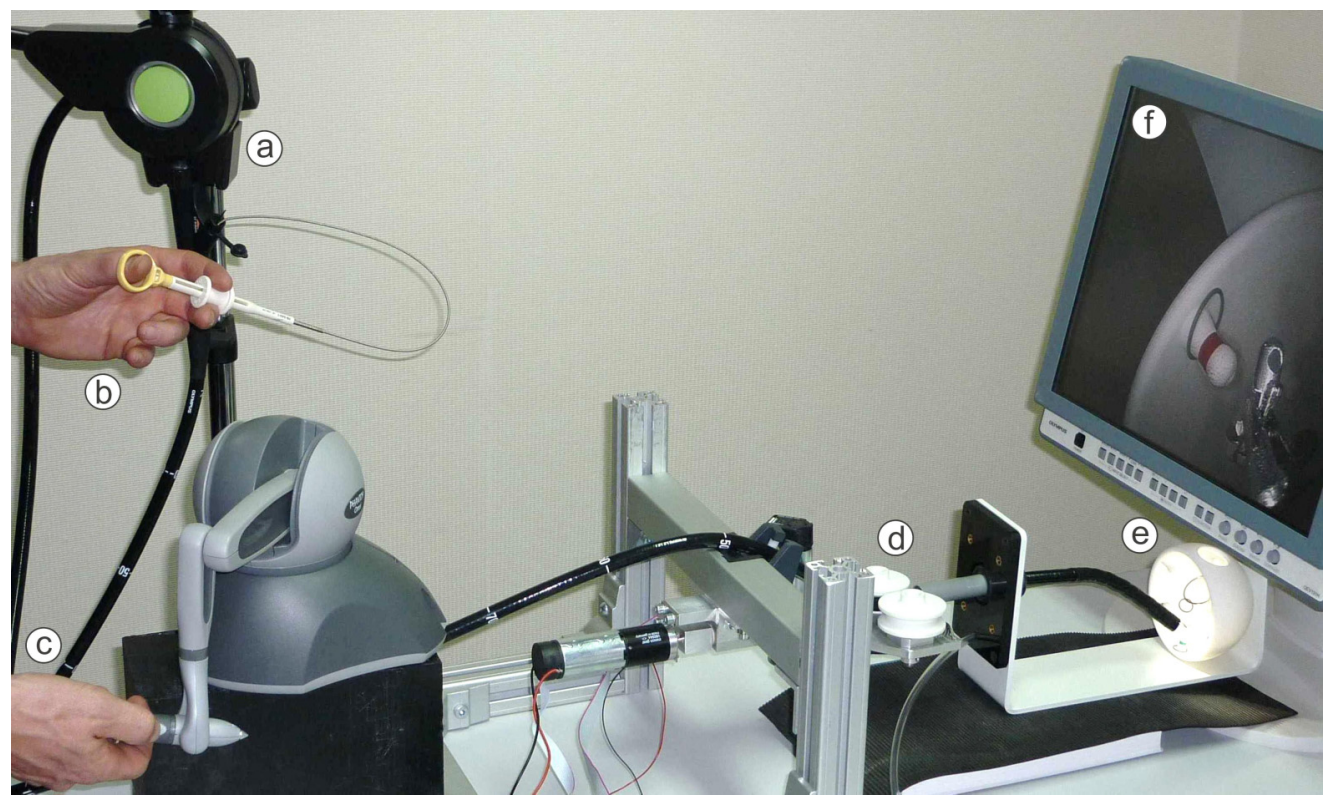

Figure 4.10 Robotic control flexible endoscope: (a) Traditional endoscope with driving means for tip steering, positioned in docking station (Chapter 3), (b) Manual instrument control (c) Multi-DOF input device for tip steering and shaft control, (d) Driving means for shaft actuation, (e) Training model, (f) Monitor.

Three setups have been tested in this experiment, as shown in Table 4.3. In the first setup participants perform conventional endoscope operation while an assistant controls the instrument. This setup is used as a reference for robotic flexible endoscopy. The second setup allows single-handed robotic steering and shaft control (4-DOF) with a Phantom Omni controller and manual instrument control with the other hand (1-DOF, grasping), as shown in Figure 4.10. The third setup consists of the robotic steering module and a Phantom Omni controller to obtain 2-DOF single-handed tip steering. The shaft is manually operated with the other hand (2-DOF translation and rotation) and the instrument by an assistant (1-DOF, grasping). The last setup is added to evaluate the influence of bimanual endoscope control by the physician. A standard flexible colonoscope (Evis Exera II CFH180AL, Olympus, Tokyo, Japan), grasper (FD-410LR, Olympus) and imaging unit (Evis Exera II CLV-180, Olympus) were used for all experimental conditions.

Participants were asked to perform two tasks that required difficult endoscope manoeuvring and that simulated clinical tasks in existing therapy, like performing a polypectomy. First, participants had to pick up an O-ring from a pawn with a grasper and place it on a designated pawn. Second, a ring had to be guided from one end of a tortuous wire loop to the other end. The instrument protruded about $2 \mathrm{~cm}$ from the tip of the endoscope and instrument manipulation was limited to opening and closing the grasper. In Figure 4.11, a close-up of the training model is depicted, which was developed for this 
experiment. The endoscope first passes a $10 \mathrm{~cm}$ long rigid tube (Figure 4.10) just behind the drive wheels, which provides some lateral stability. Thereafter a distance of about $20 \mathrm{~cm}$ has to be bridged by the endoscope to reach the target area. This setup simulates similar situations found in therapeutic endoscopy, like in the stomach.

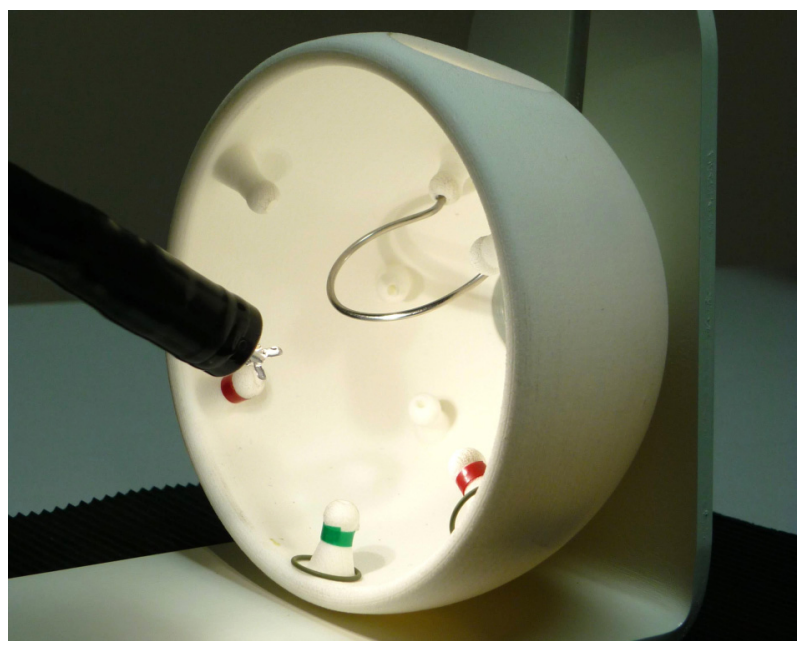

Figure 4.11 Training model experiment

The 12 participants (aged 19-50 years, 2 women and 10 men) were engineers and supporting staff of DEMCON, without medical background, without experience in endoscope handling, and without experience in controlling one of the robotic setups. In this way intuitiveness could be measured. Each of the six possible orders of the three setups was performed equally often to correct for learning effects and fatigue. Each setup was introduced with a short demonstration and the opportunity to ask for advice on usage. Subsequently, the participants were allowed to practice task 1 as well as task 2 once before its evaluation was started.

Our focus was to test the usability of the robotic endoscope by evaluating the effectiveness, efficiency, and satisfaction. The three factors, as discussed in Section 3.6.1, are widely accepted to concern distinct measures. In the current experiment the following dependent variables were measured:

- Tasks completed (effectiveness)

- Time required for tasks (efficiency)

- Subjective workload analysis measuring mental and physical demand, performance, effort and frustration (efficiency). Based on a modified NASA Task Load Index [Hart and Staveland, 1988; NASA TLX, 2011], as shown in Appendix B.1.

- Rank interfaces according to preference (satisfaction).

After testing each setup the participant had to score the workload analysis. The experiment took approximately 1 hour per participant.

\subsubsection{Results and discussion}

The quantitative results and the comments that are made, indicate that robotics enhances the usability of flexible endoscope control by novices in therapeutic tasks. According to participants traditional steering "requires constantly thinking about what to do", "the degrees of freedom 
are not intuitive", and "the navigation wheels for tip control are frustrating". These and other qualitative results are discussed in the remainder of this section. First the quantitative results of the experiment will be discussed. See Table 4.3 for median scores and their ranges on the outcome measures.

Table 4.3 Quantitative results experiment

\begin{tabular}{l}
\hline Setup \\
\hline
\end{tabular}

The low sample size $(n=12)$, the large variation in individual scores, and the absence of normal data distributions on these measures across the three set-ups made us decide to base the analyses on ranked data using non-parametric tests. Separate Friedman's ANOVA's were conducted to compare the three setups. In case of a significant effect, Wilcoxon signed-rank tests were conducted to compare the scores between two setups. A Bonferroni correction was applied to control for chance capitalization, resulting in a .0167 level of significance for the contrast analyses. Overall significance level was $p=.05$. The results are summarized in Table 4.4 and discussed afterwards.

Table 4.4 Summary table statistical results $p$-values

\begin{tabular}{|c|c|c|c|c|c|c|}
\hline & \multicolumn{2}{|c|}{$\begin{array}{c}\text { Task } 1 \\
\chi 2(\mathrm{~N}=12,2)=8.17\end{array}$} & \multicolumn{2}{|c|}{$\begin{array}{c}\text { Task } 2 \\
\chi 2(\mathrm{~N}=12,2)=9.50, \mathrm{p}=.009\end{array}$} & \multicolumn{2}{|c|}{$\begin{array}{c}\text { Workload } \\
\chi^{2}(\mathrm{~N}=12,2)=20.47, \mathrm{p}=.001\end{array}$} \\
\hline & 1. Conv. & 2. Single & 1. Conv. & 2. Single & 1. Conv. & 2. Single \\
\hline 1. Conv. & - & .015 & - & .012 & - & .002 \\
\hline 3. Bimanual & .006 & .666 & .209 & .077 & .002 & .019 \\
\hline
\end{tabular}


Performance of the participants on task 1 differed across the three set-ups, $\chi^{2}(\mathrm{~N}=12$, $2)=8.17, p=.017$. Posthoc analyses indicated that performance on the single-handed robotic setup was significantly better than performance on the conventional setup, $Z=2.43, p=.015$. Participants also performed better on the bimanual setup than on the conventional setup, $Z=2.75, p=.006$. No significant difference in performance was found between both robotic setups, $Z=0.43$, $p=.666$.

Also on task 2 , the performance scores differed significantly across the three setups, $\chi 2(\mathrm{~N}=12,2)=9.50, p=.009$. However, posthoc analyses only showed a significant difference in performance between the single-handed and conventional setups, $Z=2.51, p=.012$. No significant differences were found between the bimanual and conventional setups, $Z=1.26$, $p=.209$, and among the robotic setups, $Z=1.78, p=.077$.

The perceived workload differed significantly among the three setups, $\chi 2(\mathrm{~N}=12$, $2)=20.47, p=.001$. Participants experienced the workload in the single-handed setup as lower than in the conventional setup, $Z=3.06, p=.002$. This was also true for comparing the bimanual setup against the conventional setup, $Z=3.08, p=.002$. In addition, the difference between both robotic setups approached significance, $Z=2.35, p=.019$, suggesting that the perceived workload was lower for the single-hand setup than for the bimanual setup.

The results show that robotic control significantly improves efficiency and satisfaction in simulated clinical tasks performed by novices. Participants were about twice as fast with both robotic setups compared to the conventional setup and the perceived physical and mental workload was significantly lower. All participants were able to complete the tasks with all setups, so improved effectiveness is not demonstrated in this experiment. The task completion times and the workload scoring of the single-handed setup showed no significant differences compared with the bimanual robotic setup.

One participant preferred the bimanual robotic setup, because the rotational range of the single-handed robotic setup is limited to $-90^{\circ} /+90^{\circ}$, whereas in manual shaft rotation the range is limited by human capabilities. All other participants preferred the single-handed setup. Participants valued its intuitiveness, its accuracy, the feeling of being in control, and its single person setup. Additionally, about $50 \%$ of the participants indeed complained about the bimanual robotic setup being more mentally demanding. Some of them constantly switched between tip steering and shaft manipulation during the procedure. One of the participants compared it to driving a car: "In car driving it also takes significant time before simultaneously controlling the steering wheel, foot pedals, and the gear shifter is not mentally demanding anymore". However, in the bimanual robotic setup the degrees of freedom were better decoupled than in the single-handed robotic setup. Although participants were instructed how to realize independent endoscope movements, often intended translations and rotations were leading to small noticeable endoscope movements in other directions. "I like the singlehanded robotic setup very much, but it can be optimized by better decoupled steering of all displacements and rotations" was one of the remarks that indicates that improvements should be made in singlehanded multi-DOF control.

In general participants thought that tip steering by translational movements in XYdirection was intuitive, nevertheless participants tend to move the stylus pen along an arc. One participant suggested that it would be preferred if tip steering would respond on translations as well as rotational movements along an arc without influencing other degrees of freedom of the endoscope. As discussed in Section 4.5. haptic restrictions could enhance dexterity. 
The participants valued the intuitiveness of operation. However, like in robotic steering (Section 3.6.2) about half of the population needed some time to get used to the coupling of pen movements to camera movements. Two groups were identified:

- Participants that couple pen movements to camera movements, as intended in our setup.

- Participants that couple pen movements to panning the image.

In what way input directions are coupled to output directions could be made adaptable to comply with user preferences. Incremental position control and the necessity to perform movements in a series of grab-release cycles to realize large displacements was easily understood and did not lead to reduced usability according to the participants.

What participants missed in all setups was independent axial rotation of the grasper to orient it to grasp a ring. Precise manual rotation of the instrument in the working channel of the endoscope is very difficult due to stick-slip friction effects. Additionally, it is an extra degree of freedom that needs to be operated. Instrument rotation can be realized by rotating the shaft of the endoscope that holds the instrument. However, when the tip is bent, rotating the shaft will result in translational camera movements. As a consequence the target disappears out of sight. Only in the 4-DOF robotic setup this could be automatically compensated for by actuating tip steering in the opposite direction. This control algorithm was not implemented yet, and might be developed in future work. To take advantage of axial rotation of the grasper the rotational range of motion of the shaft (and as a consequence the grasper) should be enlarged from $-90^{\circ} /+90^{\circ}$ to at least $-180^{\circ} /+180^{\circ}$. Additionally, as discussed in Section 4.4, this larger range of rotation will also be helpful in therapy to orient the point of interest in a proper position relative to where the instrument protrudes from the endoscope.

\subsubsection{Conclusion and recommendations}

The positive reviews, the quantitative results of the tests, and the opportunities to implement intelligent algorithms, justify to focus our development on the single-handed robotic setup. The proof-of-principle system demonstrated its usability. However, it is not ready to be implemented in the current clinical workflow. The next section discusses the design of the robotic shaft manipulation module that is fully functional and takes safety, cleanability, and easy positioning close to the patient into account. It addresses the following main design requirements that were discussed in the design directions section (Section 4.4) but not implemented in the proof-of-principle setup:

- Positioning.

The position of the shaft manipulation module needs to be easily adaptable.

- $\quad$ Size.

The robotic module needs to be small to be able to position it close to the patient.

- Disinfection.

All parts that can potentially be touched by the therapist or the patient should be clean to prevent cross contamination. Additionally, the lay-out of the system has to be suitable for handling a polluted endoscope.

- Force limitation.

The actuation principle should allow rotation and translation of the endoscope when forces reach a critical level.

- Rotational range.

The rotational range of the shaft should be $-180^{\circ} /+180^{\circ}$ to be able to rotate the grasper and to be able to bring an instrument into the 5 o'clock position. 
- Input controls for insufflation, suction, and rinsing, and for the programmable switches. The input devices to control insufflation, suction, and rinsing, and for the programmable switches are discussed in Chapter 5.

\subsection{Final design}

\subsubsection{Clinical setting}

In Figure 4.12 the robotic flexible endoscope for existing therapeutic procedures is depicted in its clinic setting. The shaft manipulation module and the multi-DOF input device are supported by two arms which are attached to the main swivel arm of the robotic steering module.

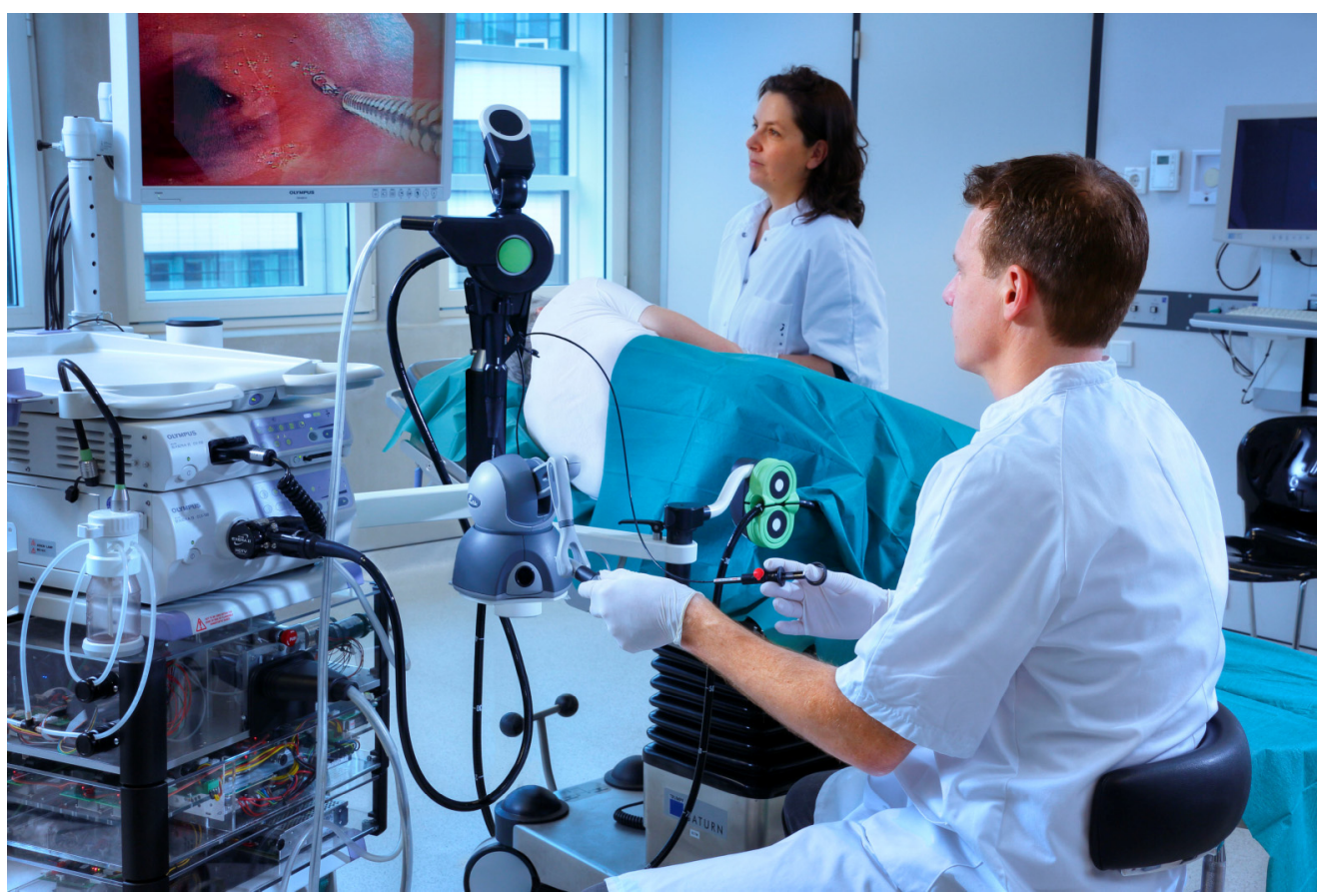

Figure 4.12 Clinical setup of a robotic therapeutic procedure

Robotic endoluminal therapy will in general be performed in an endoscopy room in the polyclinic. However, when the patient needs to be anesthetized, the procedure might be performed in an operating room. As with robotic diagnostic procedures, the gastroenterologist operates all equipment, while the endoscopy assistant monitors the patient at the other side of the bed. Dependent on the type of procedure and the instruments required, assistance might be needed in controlling one of the degrees of freedom of the instruments. If assistance of the physician is only needed occasionally during the procedure, one assistant should be capable of helping the physician as well as managing all non-therapeutic actions. 


\subsubsection{System overview}

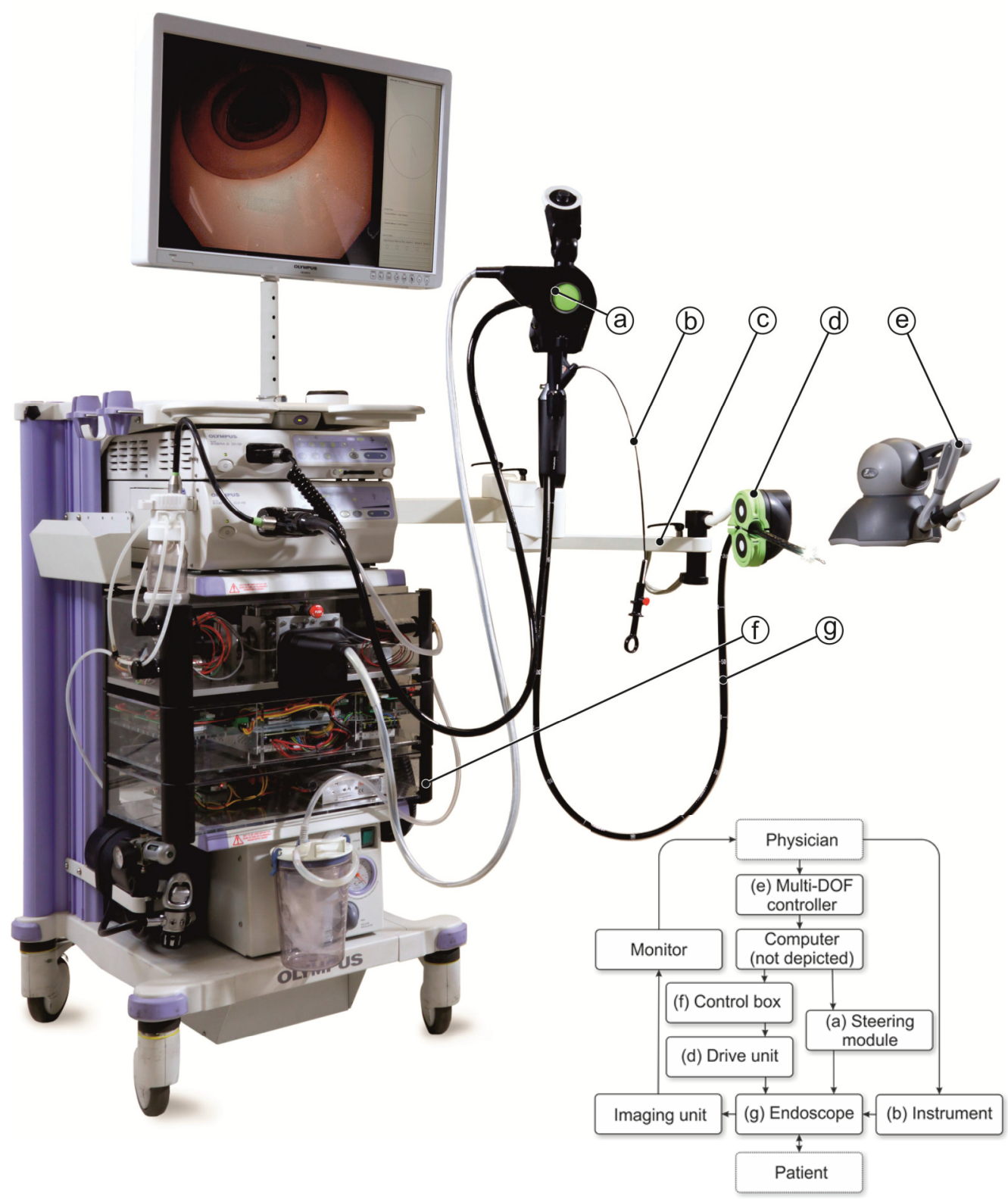

Figure 4.13 System setup robotic therapy of existing procedures (standard equipment in grey): (a) Steering module, (b) Traditional instrument, (c) Swivel arm (part that supports multi-DOF controller not depicted), (d) Drive unit, (e) Multi-DOF controller, (f) Control box, (g) Flexible endoscope

In Figure 4.13 an overview is shown of the setup for robotic endoscope control in existing therapeutic procedures. In Section 3.5 the robotic steering module, that is part of this setup, has been discussed. In this section the design of the robotic shaft manipulation module will be covered. The drive unit that actuates the shaft is designed to be positioned close to the patient. The same actuation principles were adopted as used in the proof-of- 
principle setup (Section 4.7.3), but their configuration is redesigned to obtain an unit that takes safety and cleanability into account (4.7.4), and that can be placed close to the patient (Section 4.7.5). The physician controls the endoscope with a standard multi-DOF input device that is supported by a swivel arm.

\subsubsection{Drive system shaft}

In Figure 4.14 the basic structure (without enclosures and drive wheels) of the final drive system is depicted. On the left the shaft manipulation module is shown, on the right the corresponding control box.

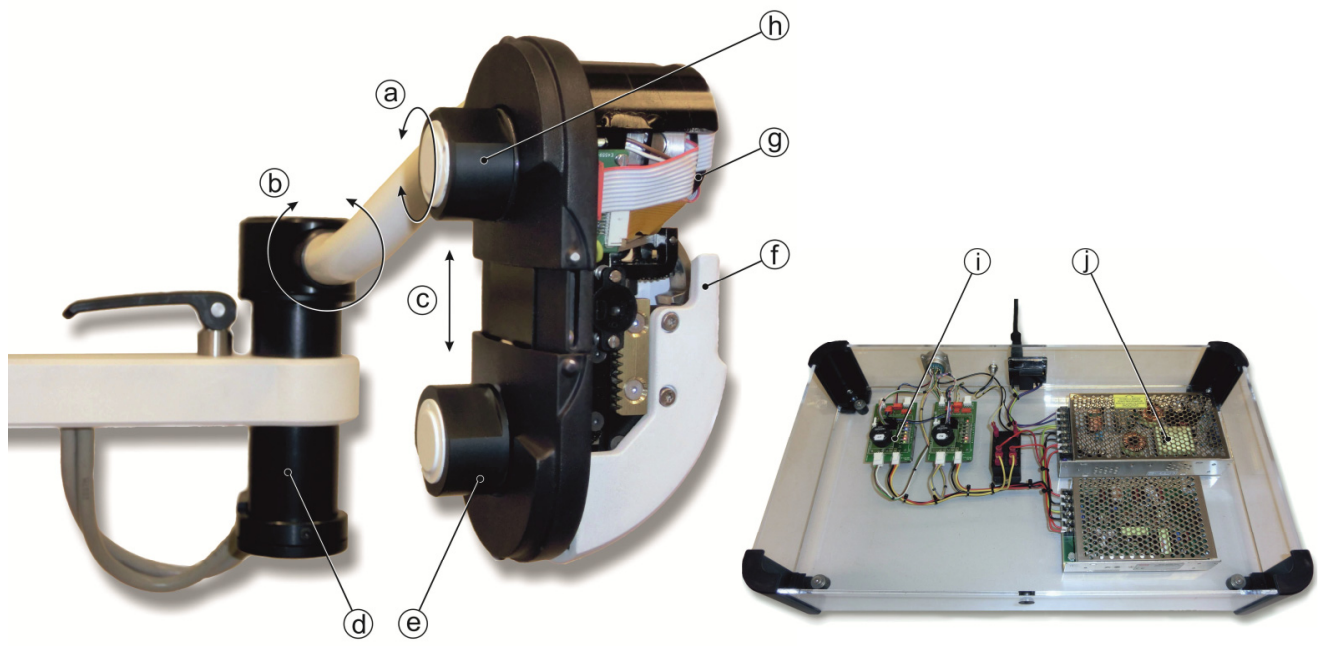

Figure 4.14 Drive system for shaft manipulation: (a) Robotic in-out, (b) Robotic (counter)clockwise rotation, (c) Clamping of shaft, (d) Motor (counter)clockwise rotation (inside the tube), (e) Adapter follow wheel, (f) Closing grip, (g) Motor in-out, (h) Adapter drive wheel, (i) Motor controllers, (j) Power supply.

Two DC servo motors (Maxon, Sachseln, Switzerland) were selected for actuation of the translational motion (powered by Maxon EC32 Flat 15W-24 V) and rotational motion (powered by Maxon EC45 Flat-30W-36V) of the shaft. Incremental encoders provide position feedback. The motors are backdrivable, but the drive system software maintains its position when the input device is not operated. The two motor controllers (Whistle, Elmo motion control, Petach-Tikva, Israel) and the power supplies (24V and 36V) are integrated in the control box that is positioned on the endoscopy cart. Motion commands are received from the main control program through a data link with the steering module. The main program is programmed in Python (Python Software Foundation) and runs on an external laptop computer (EliteBook 2.4GHz, Hewlett-Packard, Palo Alto, USA) with Windows XP (Microsoft, Redmond, USA) installed. The positive results of the usability test with novices with the proof-of -principle setup made us decide to again integrate a Phantom Omni input device in the final design. However, as indicated in Section 4.5, it should be researched if an input device that is restricted to the kinematics of the robotic endoscope, might perform even better. This is allocated as future work.

The motor for in-out movements of the endoscope is placed directly on the axis of the upper wheel ((h) in Figure 4.14). The axis is provided with a dedicated spring loaded friction style torque limiter to prevent excessive forces on the patient. At $60 \mathrm{~N}$ axial push or pull forces on the shaft of the endoscope the unit starts to slip. 
The motor for (counter)clockwise rotation is integrated in one of the tubes of the swivel arm ( $\mathrm{d}$ in Figure 4.14) and via a bevel gear transmission coupled to the (white tube of) the shaft manipulation module. Due to time constraints no torque limiter is integrated in the drive train for shaft rotation. This is allocated as future work.

One of the main conceptual changes with respect to the proof-of-principle is the range of rotational movement from $-90^{\circ} /+90^{\circ}$ to at least $-180^{\circ} /+180^{\circ}$. The original configuration, with an axis of rotation that is in line with the shaft of the endoscope at the location where it is squeezed between the wheels, is maintained. However, the construction is redesigned to obtain a very slim geometry. In the final design the shaft of the endoscope is clamped by the drive wheels and hangs down in the part between the wheels and the control section of the endoscope. Although the shaft will collide with the white tube of the shaft manipulation module after about a half turn, the range of motion is even larger than $-180^{\circ} /$ $+180^{\circ}$, because of the flexibility of the shaft. The range of in-out movement is limited by the length of the endoscope shaft.

The rotational position of the shaft manipulation module needs to be homed in the current system setup. Starting the procedure in a neutral position ensures that the physician is not easily impeded by rotational limitations. In addition, since cables run from the fixed to the rotating world it is important to know the absolute rotational position of the module. If the cables are twisted too much, cable breakage may occur. In the current setup no absolute encoder or end stops are provided yet. The range of motion is software limited to $170^{\circ} /+$ $170^{\circ}$ to be able to see in which direction the module has to be turned to return to the home position. Future work should be directed at the implementation of measures to allow a larger rotational range. The in-out shaft movement does not have to be homed.

The clamping mechanism of the proof-of-principle setup has been redesigned to get a more compact setup. The lever is replaced by a linear slide mechanism. The operator needs to squeeze both wheels together. An internal spring mechanism ensures that the shaft is pretensioned and securely positioned between the wheels. In Figure 4.15 the main parts of the closing mechanism are named.

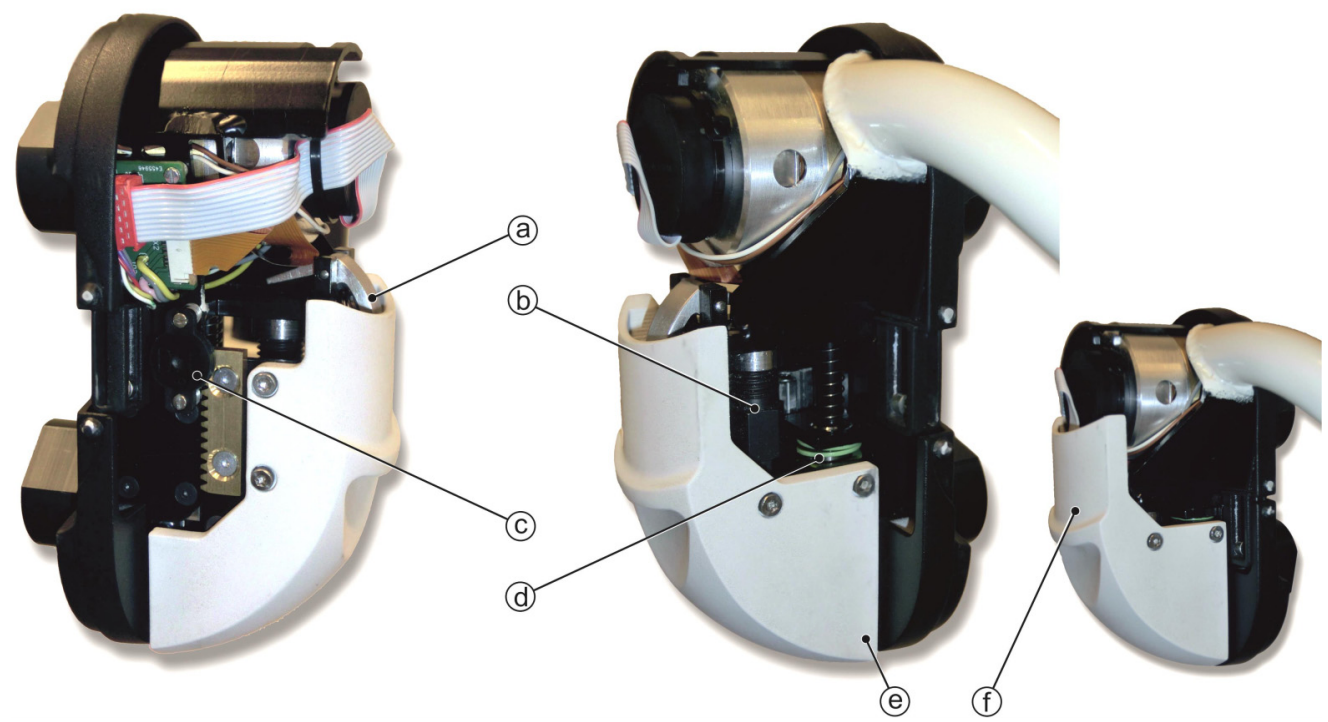

Figure 4.15 Clamping mechanism: (a) Latch, (b) Push-push lock mechanism, (c) Rotary damper, (d) Compression spring, (e) Grip in open configuration, (f) Grip in closed configuration 
The clamping mechanism can be operated with one hand, as shown in step 4 of Figure 4.16. The white grip ((e) in Figure 4.15) is moved upward to bring both wheels together and clamp the shaft of the endoscope. Meanwhile a strong compression spring is pretensioned. In the upper position of the grip, a latch is actuated that secures both wheels with respect to each other. By means of a push-push locking mechanism (like in writing pens) the grip has to be squeezed again to release the clamping mechanism. Since a large amount of energy is stored in the compression spring, for safety purposes a rotary damper controls the speed of opening the mechanism.

\subsubsection{Interfacing with endoscope}

The drive system cannot be sterilized or intensively cleaned. Like for the robotic steering module, the shaft manipulation module and its suspension needs to be enclosed by sterile covers to protect the patient for cross contamination. Additionally, in this way the drive unit will be protected against the accumulation of dirt. In Figure 4.16 an exploded view and an instruction for preparing the shaft manipulation module are depicted.
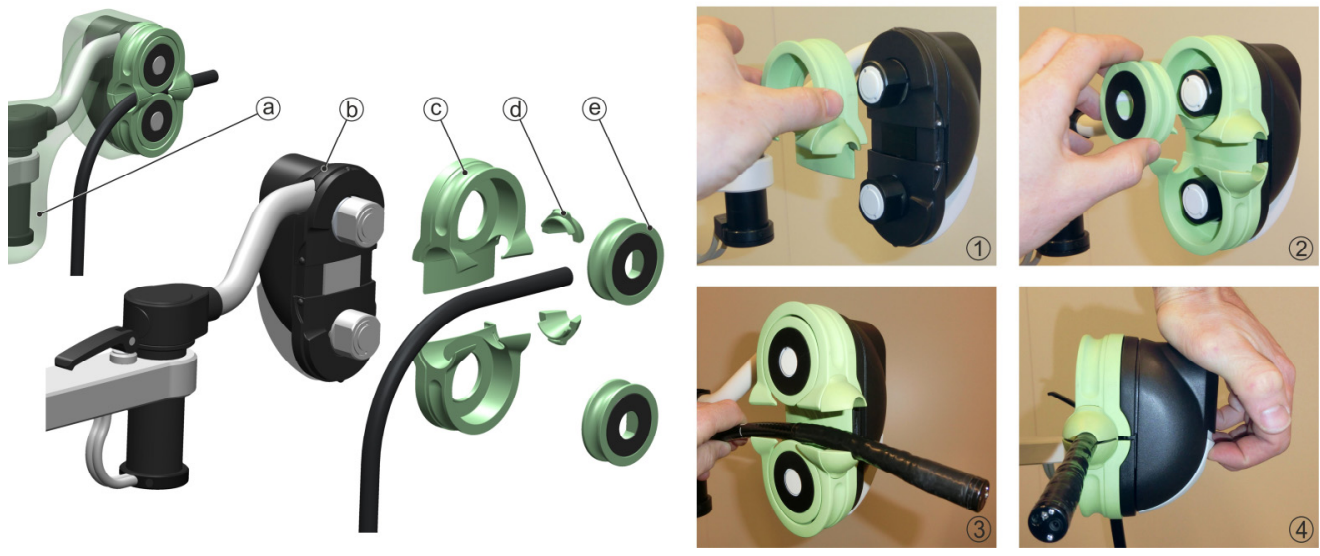

Figure 4.16 Exploded view and installation instruction of the robotic shaft manipulation module: (a) Sterile sleeve, (b) Drive unit, (c) Interface unit, (d) Wiper, (e) Drive wheel, (1-4) Installation instruction

The drive wheels (semi-critical part, Section 3.4) will come in direct contact with the endoscope and need to be absolutely clean. The drive unit could potentially come in contact with the endoscope and is protected by interface parts. A plastic sleeve is connected to the interface parts to cover the swivel arm as well. Two wipers remove lubrication and/or bodily fluids/solids from the shaft during retraction. The wheels, the interface parts, and the wipers are injected moulded parts, that can be discarded or sterilized after the procedure. The Phantom Omni controller should be enclosed by plastic to ensure clean operation. It is not possible to rinse its critical parts.

The interface parts are first connected to the drive unit (step 1 in Figure 4.16). Subsequently, the drive wheels are positioned on the adapters (step 2). The adapters are provided with two flat surfaces on the circumference to transfer the torque from the motor to the wheels. A magnet in the adapter and a steel plate on the drive wheel ensure that the wheels are locked in axial direction. In the third step the endosope can be placed between the wheels (step 3), while the other hand closes the mechanism (step 4).

The shape of the contact surface between the shaft of the endoscope and the drive wheel has been changed with respect to the proof-of-principle setup. First, the shaft ran through a circular groove, which provides a large contact area and prevents the tube from slipping off 
the sides. In the final design the wheels are V-shaped. A V-shape doubles the number of contact points and the frictional forces can be increased by changing the $\mathrm{V}$-angle, having the same effect as a lever. In Figure 4.17 the previous geometry as well as the redesigned geometry has been depicted.
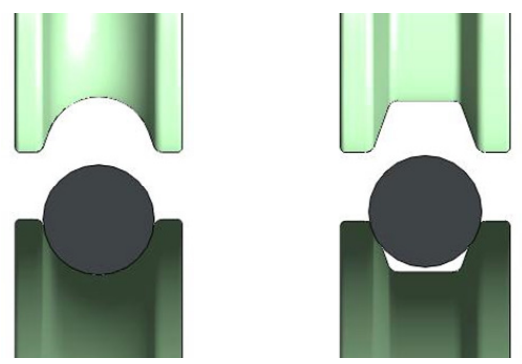

Figure 4.17 Drive wheels: (left) Previous circular groove, (right) New V-shaped wheels

\subsubsection{Suspension and positioning}

The robotic shaft manipulation module will be mounted on a swivel arm. When therapy needs to be performed, the module will be brought into position and it will be coupled to the endoscope. To allow for coarse movements as well as precise alignment of the robotic module with the endoscope, the swivel arm of the robotic steering module (Section 3.5.5) has been expanded with two arms, as shown in Figure 4.18.
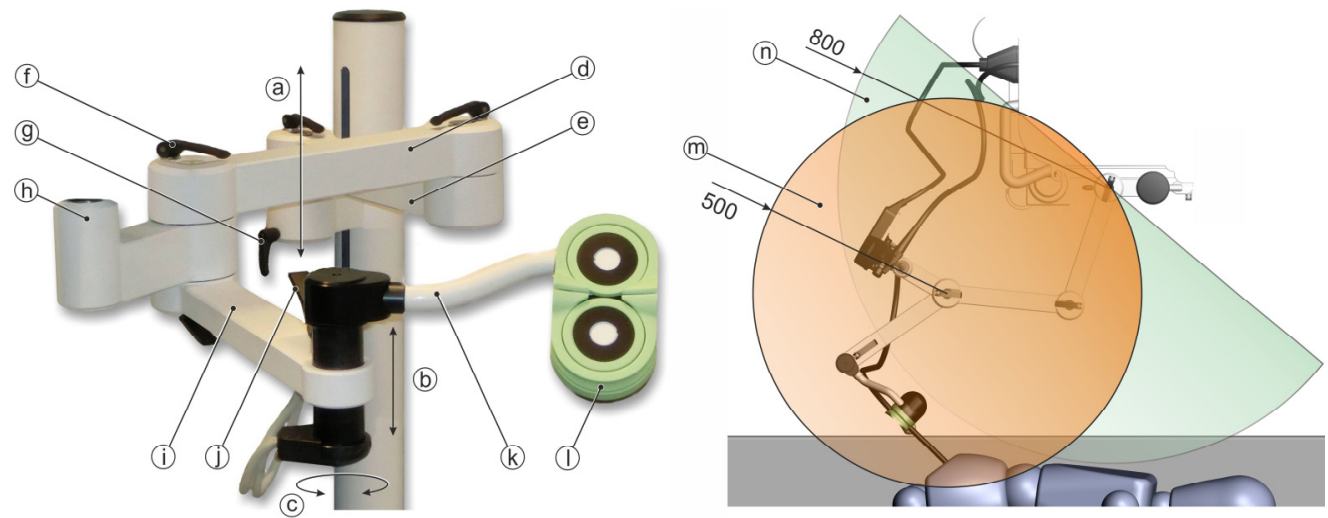

Figure 4.18 Components and range of motion swivel arm: (a) Long stroke height adjustment, (b) Short stroke height adjustment, (c) Adjustment angle with respect to patient, (d) Arm 1 long stroke transverse movements, (e) Arm 2 long stroke transverse movements, (f) Cam lever, (g) Lever height fixation, (h) Support robotic steering module, (i) Arm 1 short stroke transverse movements, (j) Lever for fixation short stroke movements, (k) Arm 2 short stroke transverse movements, (l) Robotic shaft manipulation module

The range of motion of the shaft manipulation module is defined by long stroke movements of the large swivel arm (green area in Figure 4.18), as discussed in Section 3.5.5, and short stroke movements of the small swivel arm (orange area). Likewise, the height of the swivel arm is defined by long stroke height adjustment of the large swivel arm ((a) in Figure 4.18) and short stroke adjustments of the small arm (b). All degrees of freedom can be locked with cam levers.

The patient position might require that the shaft manipulation module is positioned above the bed of the patient. The distance between the bed and the point where the 
endoscope enters the patient is small. Therefore, the height of the mechanical construction of the shaft manipulation module and the swivel arm is minimized.

\subsubsection{Specifications}

The most important performance requirements are estimated based on observations of procedures and on literature study. In Table 4.5 the original requirements as well as the achieved specifications of the robotic flexible endoscope are listed.

Table 4.5 Specifications robotic shaft manipulation

\begin{tabular}{|c|c|c|}
\hline & Requirement & Specification \\
\hline Decoupling shaft & $<10 \mathrm{sec}$ & $\sim 2$ sec. \\
\hline $\begin{array}{l}\text { Degrees of freedom } \\
\text { shaft actuation }\end{array}$ & $\begin{array}{l}2 \text { DOF: In-out } \\
\text { translation, } \\
\text { (Counter)clockwise } \\
\text { rotation }\end{array}$ & $\begin{array}{c}2 \text { DOF: } \\
\text { In-out translation, } \\
\text { (Counter)clockwise } \\
\text { rotation }\end{array}$ \\
\hline Input device & $\begin{array}{l}\text { Single-handed } 4 \mathrm{DOF} \\
\text { control of tip steering } \\
\text { and shaft manipulation }\end{array}$ & $\begin{array}{l}\text { Single-handed } 4 \mathrm{DOF} \\
\text { control of tip steering } \\
\text { and shaft manipulation }\end{array}$ \\
\hline Transfer function & $\begin{array}{l}\text { Incremental position } \\
\text { control }\end{array}$ & $\begin{array}{l}\text { Incremental position } \\
\text { control }\end{array}$ \\
\hline Up-down (a') & Section 3.4 & Section 3.4 \\
\hline Left right (b') & Section 3.4 & Section 3.4 \\
\hline In-out force (c') & $60 \mathrm{~N}$ & $\begin{array}{c}>60 \mathrm{~N} \text { (restricted by } \\
\text { force limiter) }\end{array}$ \\
\hline In-out range (c') & $\pm 150 \mathrm{~mm}$ & $\begin{array}{l}\text { Restricted by length } \\
\text { endoscope }\end{array}$ \\
\hline In-out accuracy (c') & $\pm 1 \mathrm{~mm}$ & Human-in-the-loop \\
\hline In-out speed (c') & $0-50 \mathrm{~mm} / \mathrm{s}$ & $0-75 \mathrm{~mm} / \mathrm{s}$ \\
\hline (Counter)clockwise torque (d') & $1.5 \mathrm{Nm}$ & $\begin{array}{c}1.5 \mathrm{Nm} \\
\text { (calculated) }\end{array}$ \\
\hline (Counter)clockwise range (d') & $-180^{\circ} /+180^{\circ}$ & $\begin{array}{c}-170^{\circ} /+170^{\circ} \text { (restricted } \\
\text { by parameter setting, } \\
\text { otherwise restricted by } \\
\text { flexibility endoscope) }\end{array}$ \\
\hline (Counter)clockwise accuracy & $\pm 1^{\circ}$ & Human-in-the-loop \\
\hline (Counter)clockwise rotational speed & $90^{\circ} / \mathrm{s}$ & $100^{\circ} / \mathrm{s}$ \\
\hline Response delay translation & - & $<0.5 \mathrm{sec}$ \\
\hline Response delay rotation & - & $<0.5 \mathrm{sec}$ \\
\hline
\end{tabular}

The performance of the final design of the robotic setup is verified in usability tests, as described in Section 5.6 (novices) and in Section 6.2 (experts). In these tests the performance specifications are evaluated with regard to intuitive and user-friendly control. 


\subsection{Conclusion and recommendations}

Our proof-of-principle setup, as presented in Section 4.5, demonstrated that robotics enable single-handed flexible endoscope control. Future research should assess the suitability of robotic steering and shaft manipulation for endoluminal surgery. In Section 4.7 a shaft manipulation module is presented that is fully functional and takes safety, cleanability, and easy positioning close to the patient into account. It addresses the main requirements that were discussed in Section 4.6.3, but that were not yet tested in the proof-of-principle setup. In future experiments all functionality needs to be tested by experts in clinical relevant procedures. These clinical experiments and their preparation are outside the scope of this work and will be performed by a PhD candidate of Technical Medicine of the University of Twente. Suggestions for functions that need to be tested and questions that need to be answered in these experiments are listed below.

- $\quad$ Size and positioning.

Is the swivel arm suitable to position the shaft manipulation module at every preferred position? Is the size of the shaft module small enough to position it close to the patient? Are the mechanical characteristics of the swivel arm and the robotic module sufficient to create a stable endoscopic platform?

- Disinfection.

Will the current design be accepted in clinical practice with regard to cleanability and logistics? Is the wiper, that removes lubrication and/or bodily fluids/solids from the shaft during retraction, suitable?

- Force limitation.

Is the current implementation to prevent excessive translational forces on the patient suitable and are the specifications right?

- Speed, accuracy, response time, range of operation.

Are the current performance specifications sufficient in clinical procedures?

- Is the setup suitable to integrate in an endoscopy room?

- Are there any use limitations of the robotic setup compared with the conventional setup?

- Are there any safety risks in using the robotic setup?

In addition, from our novices experiments points of improvement are derived that could optimize the robotic endoscope. If it is feasible within the timeline, it is recommended to implement these before the tests with clinical experts. Some improvements are estimated to require a lot of additional research and development and are indicated as future work and should be implemented in a later stage.

- The operator should be able to reverse the mapping of pen movements to endoscope movements. The graphical user interface could provide this functionality.

- The degrees of freedom of the multi-DOF input device should be restricted to the kinematics of the robotic endoscope. (future work)

- Dynamic restrictions should be implemented to avoid large position errors (future work).

- A torque limiter for shaft rotations needs to be implemented (future work).

- An algorithm that compensates for translational camera movements when shaft rotations are executed should be implemented (future work). 
All additions and adaptations are expected to improve the robotic flexible endoscope. However, they first need to be evaluated in experiments to assess their performance and usability.

In this chapter a robotic shaft manipulation module is introduced that support physicians in performing existing therapy more easily. The introduction of steerable instruments might take endoscopic therapy to the next level. Chapter 5 discusses the robotic instrument manipulation module that enables precise independent coordination of two steerable instruments that can perform advanced tasks. 


\section{Robotic instrument manipulation module - experimental therapeutic procedures}

\footnotetext{
Natural orifice surgery requires a shift from rigid to flexible surgical instruments to reach the operating area without external incisions. Advanced endoscopic intervention platforms with steerable instruments with multiple degrees of freedom enable physicians to perform challenging endoluminal as well as transluminal procedures. The expansion of this new technique is limited by the lack of availability of intuitive and userfriendly tools. This chapter discusses the development and evaluation of a robotic instrument manipulation module that actuates all independent translations and rotations of experimental steerable instruments. If combined with the steering module (Chapter 3) and the shaft manipulation module (Chapter 4) a single physician is able to perform complex natural orifice procedures. The integrated system is controlled with an ergonomic master console, equipped with a monitor and two multi-degree-of-freedom input devices, that intuitively couple hand movements to endoscope and instrument motions. Performance and usability is tested with novice users. The results show that robotic technology improves the usability of advanced endoscopic intervention platforms in existing and experimental therapy.
} 


\subsection{Introduction}

Currently in flexible endoscopy all degrees of freedom are manually controlled. In order to improve the usability, the robotic steering module (Chapter 3) and the robotic shaft manipulation module (Chapter 4) are developed to automate tip steering and shaft manipulation of a traditional flexible endoscope. Driven by the desire to limit the trauma caused to the patient in surgery, new procedures and new instruments are being developed that use the natural body openings as entrance point [Malik et al., 2006; Rattner and Kalloo, 2006]. As stated in Section 1.1 a shift from rigid to flexible endoscopes is a logical step. However, current available flexible endoscopes are not suited to perform complex surgery. Traditionally, complex surgery requires precise independent coordination of two instruments that can perform multiple tasks. Main limitation in flexible endoscopy is related to the number of degrees of freedom available for bimanual manipulation tasks like traction and counter traction of tissue, precise dissection, and suturing. [Spaun et al., March 2009; Swanstrom et al., 2008]. The introduction of steerable instruments facilitates these tasks. A whole new range of challenging endoluminal procedures in tube-shaped organs as well as transluminal procedures in the abdominal and thoracic cavity could become possible with the introduction of advanced endoscopic intervention platforms with steerable instruments, as discussed in Section 1.2. However, the technology is not ready yet for cost effective, safe, and user-friendly use in clinical practice and is up to now only tested in experimental interventions, as discussed in Section 1.3.

In work of Reilink [2013] a robotic intervention platform is presented that allows physicians to control a steerable instrument in an intuitive way using a multi-DOF input device. Performance with the manual control method and the robotic setup are compared in an usability test. Participants are significantly faster in tapping a series of targets using the robotic control method (54 versus $164 \mathrm{sec}$.) This study provides evidence that robotics should be implemented to improve the performance of physicians using steerable instruments of advanced endoscopic intervention platforms.

In this chapter the robotic instrument manipulation module is introduced that enables intuitive and user-friendly control of steerable instruments. If the robotic instrument module is combined with the robotic steering module and the robotic shaft manipulation module an advanced robotic endoscopic intervention platform is created. The development has concentrated on the driving means for actuation of all degrees of freedom and the user interfaces to control them in an intuitive and user-friendly way. The endoscopic platform and the steerable instruments are provided by equipment manufacturers. Despite our key driver that the robotic system is backwards compatible with existing gastro- and colonoscopes (Section 2.2.1), the platform and the steerable instruments were adapted to be integrated in our setup. Given the experimental character of the full robotic setup with steerable instruments and the fact that endoscopic platforms and steerable instruments are not commercially available yet, this is justifiable. The robotic flexible endoscope for experimental therapy consists of:

- An endoscopic platform for instrument guidance and visualization of the operating area. It is a standard flexible endoscope, like the one in Figure 3.6, that is provided by Olympus and modified by us to make it applicable for steerable instruments (Section 5.4 and Section 5.5.5).

- Steerable instruments that are provided by Karl Storz and originally used in the manually operated ANUBIS NOTEScope (Figure 1.8). The instruments are adapted by us to be electro-mechanically actuated and steered with multi-DOF input devices (Section 5.2, Section 5.5.3). 
- The drive units of the steering and shaft manipulation module, and the drive unit of the instrument manipulation module, as presented in this chapter.

- A master console, as presented in this chapter, that provides a comfortable working posture, structured data presentation, and dexterous input devices to control all independent translations and rotations of the instruments as well as the endoscope.

In Figure 5.1 the actuated degrees of freedom of two steerable instruments are indicated. In addition, the figure shows how displacements of the physician's hands, each holding a multi-DOF input device, are linked to instrument movements. Figure 5.2 indicates how the same multi-DOF input devices are used to control the endoscopic platform, as discussed in Chapter 4, and a non-steerable instrument that is, like the steerable instruments, actuated by the instrument manipulation module. By alternately pressing a designated button on one of the pens of the multi-DOF input devices the physician is able to switch between endoscopic platform, traditional instrument, and steerable instruments in order to individually control in total 15 degrees of freedom.

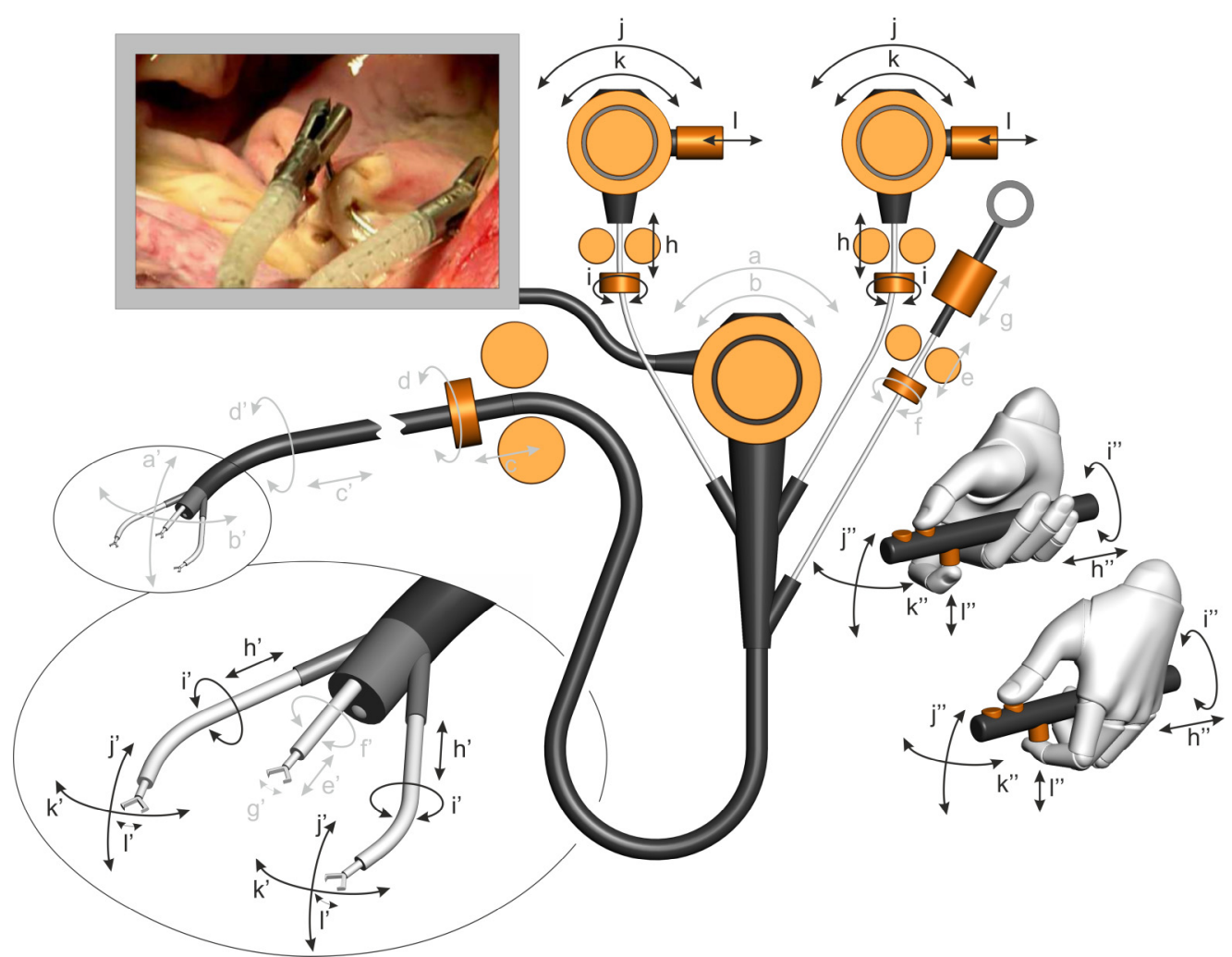

Figure 5.1 Degrees of freedom steerable instruments for experimental therapy: (a-g) in Figure 5.2 (h) In-out, (i) (Counter)clockwise rotation (j) Up-down, (k) Left-right, (l) Grasp instrument 


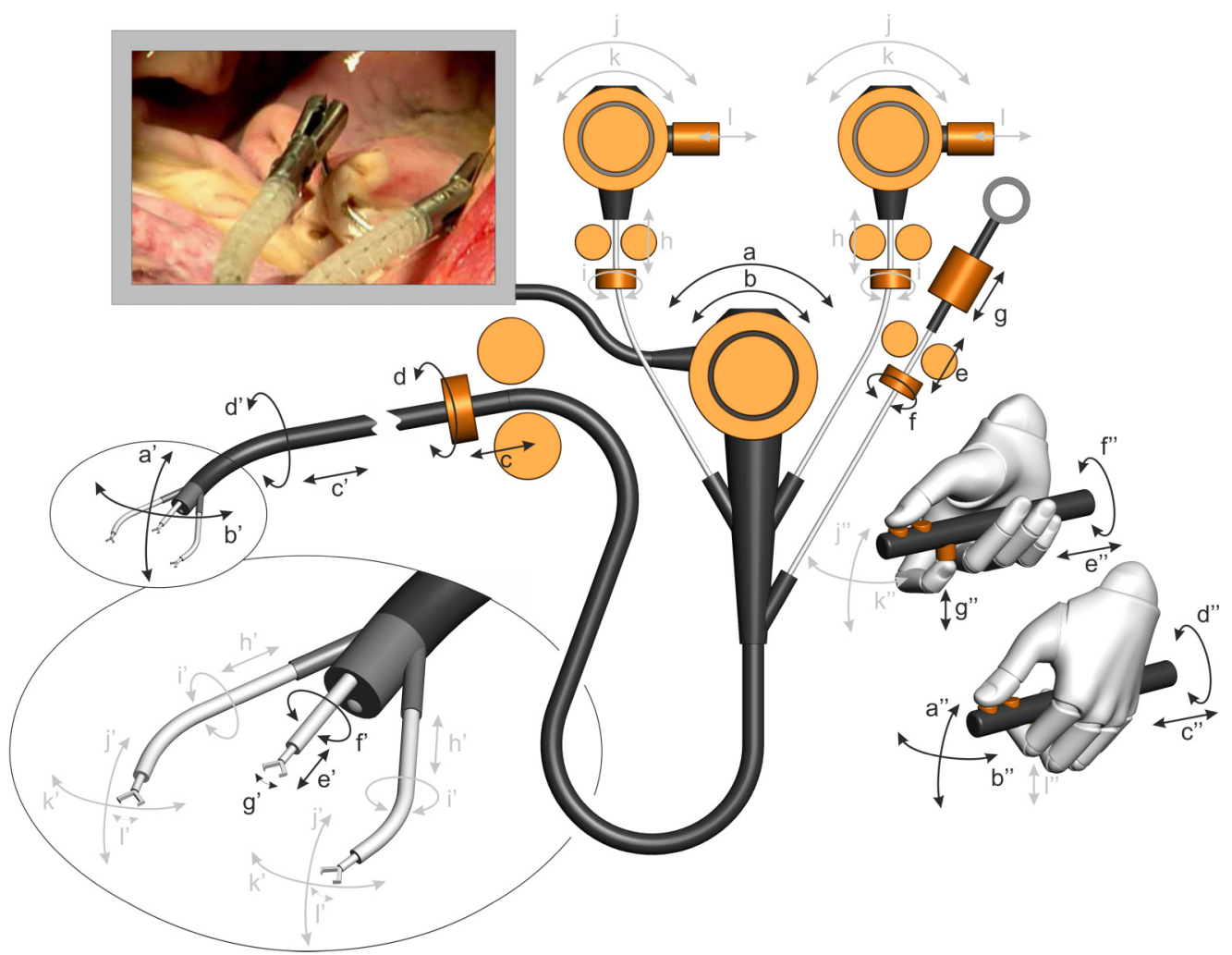

Figure 5.2 Degrees of freedom endoscopic platform and traditional instrument for experimental therapy: (a) Up-down, (b) Left-right, (c) In-out, (d) (Counter)clockwise rotation, (e) In-out instrument, (f) (Counter)clockwise rotation instrument, (g) Grasp instrument, (h-l) in Figure 5.1.

This chapter discusses:

- The development of the robotic instrument manipulation module.

- The integration of the instrument manipulation module, the shaft manipulation module, and the steering module into the robotic flexible endoscope with steerable instruments.

- The development of the user interface to control the robotic flexible endoscope.

- The evaluation of the usability of the robotic endoscope with steerable instruments.

Section 5.2 starts with the state of the art in robotic instrument manipulation of steerable instruments. In Section 5.3 shortcomings of the current user interface are discussed. Section 5.4 describes the design directions for our system. In Section 5.5 the design of the instrument module is specified and shown. In addition the integration of all robotic modules is presented. Section 5.6 contains the results of the experiment that is conducted. Finally, Section 5.7 concludes and provides directions for future work.

\subsection{Related work}

In Section 1.5 a brief overview of advanced endoscopic intervention platforms for endoluminal and transluminal surgery was discussed. In work of Bardou et al. [2009], Karimyan et al. [2009], Swanstrom [4-2011], Yeung and Gourlay [2012], Shaikh and Thompson [2010], and Wilhelm [2011] an extensive overview of mechanical and robotic 
endoscopic platforms is presented. In this section background information is summarized related to (electro-) mechanical concepts, such as instrument guidance, mechanical interfaces for instrument coupling, actuation principles and user interfaces.

\section{Instrument guidance}

The basic design of advanced endoscopic intervention platforms aims at bringing the laparoscopic paradigm to therapeutic flexible endoscopy [Swanstrom, 4-2011]. Triangulation is one of the most essential concepts in laparoscopy [Wang et al., 2012]. The instruments independently reach the operating field from two sides with vision in between. The angle between camera and instruments is about $30^{\circ}$ and their working axes coincide in one point. It improves depth perception and accessibility of tissue and organs. In Table 5.1 some concepts are presented to obtain triangulation.

Table 5.1 Concepts for instrument guidance and triangulation of known intervention platforms

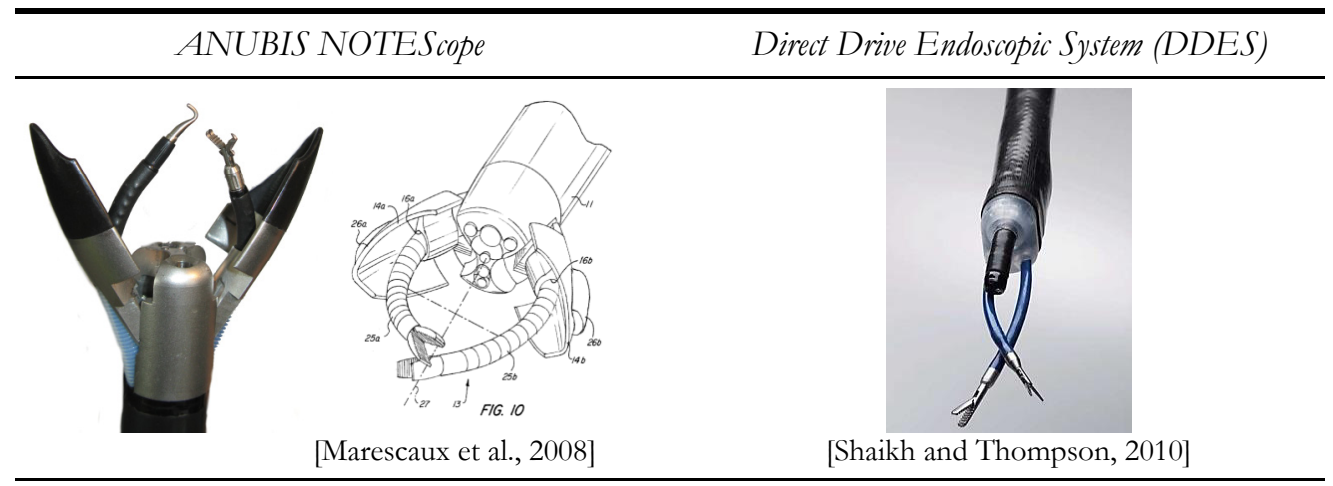

The ANUBIS NOTEScope (see also Section 1.2) is a $16 \mathrm{~mm}$ three-channel endoscope with integrated camera and light. The tip opens in the operating field to expose two instruments both with fourDOF (in-out, rotation, one deflection, grasping). [Bardou, 2009; Marescaux, 2008] Karl Storz, Tuttlingen, Germany
The DDES (see also Section 1.5) is a $16 \times 22 \mathrm{~mm}$ steerable guide sheath that accommodates a pair of five-DOF steerable instruments (in-out, rotation, two perpendicular deflections, grasping) and a 6 $\mathrm{mm}$ standard flexible endoscope for vision and light. [Swanstrom 2009; Thompson et al., 2009] Boston Scientific Corporation, Natick, MA, USA

\begin{tabular}{|c|c|}
\hline Nanyang University endoscopic system & Cobra \\
\hline [Wang and Meng, 2012] & [Wang and Meng, 2012] \\
\hline $\begin{array}{l}\text { The robotic slave of the Nanyang University (see } \\
\text { also Section 1.5) is a cable driven end effector of } \\
\text { round } 22 \mathrm{~mm} \text { that can be mounted on existing } \\
\text { endoscopes. The six-DOF instruments are modeled } \\
\text { after a simplified human arm. The instruments } \\
\text { cannot be exchanged. } \\
\text { [Phee et al., 2008] } \\
\text { Nanyang Technological University, Singapore }\end{array}$ & $\begin{array}{l}\text { The Cobra device consists of the } 16 \mathrm{~mm} \\
\text { TransPort }^{\circledR} \text { overtube with ShapeLock }{ }^{\circledR} \text { technology } \\
\text { (USGI Medical,USA) and three independent arms } \\
\text { for instrumentation and optics. The overtube needs } \\
\text { to be removed from the patient to exchange } \\
\text { instruments. } \\
{[\text { Karimyan, 2009] }} \\
\text { USGI Medical, San Clemente, CA, USA }\end{array}$ \\
\hline
\end{tabular}




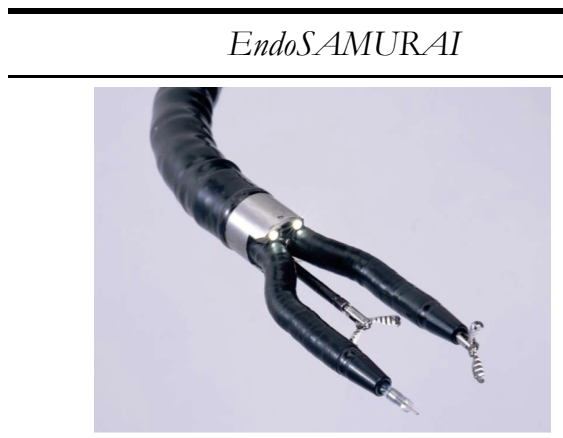

[Shaikh and Thompson, 2010]
EndoLifter ${ }^{\circledR}$

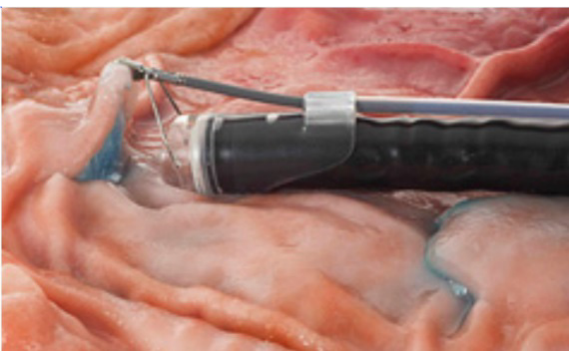

[Matsui, 2012]
The EndoSAMURAI is a $15 \mathrm{~mm}$ three-channel endoscope with two steerable instrument arms, which open in an elbow like fashion to enable triangulation and six-DOF motion of rather standard instruments that protrude through the arms. A third instrument channel is for a standard, straight endoscopic tool, which is primarily used for retraction, suction, or irrigation.

[Fuchs and Breithaupt, 2012; Ikeda et al., 2011]

Olympus Corporation, Tokyo, Japan
The EndoLifter is a distal cap that can be mounted on the tip of the endoscope. An external working channel guides a grasping instrument, which can be used to grasp and lift the mucosa. The system does not provide real triangulation and bimanual instrument manipulation, but shows the potential of add-ons for standard endoscopes.

[Matsui, 2012]

Olympus Corporation, Tokyo, Japan

The endoscopic platforms discussed are comparable to traditional flexible endoscopes and contain the same steering concepts for camera movement. Often two or three working channels are provided that are suitable for steerable instruments. In the ANUBIS NOTEScope and the EndoSAMURAI the optics and the instrument manipulation function are integrated in one device. The DDES and the Cobra rely on the conventional flexible endoscope for visualization. The endoscope and the instruments are protruded through a flexible multi-channel access device, that can be rigidized. The endoscopic system of the Nanyang University and the EndoLifter can be positioned as an add-on device on a standard endoscope. There is limited data regarding comparative performance of various systems. Only the EndoLifter is commercially available.

\section{Mechanical interfaces for instrument coupling}

The ANUBIS NOTEScope of Karl Storz was already shortly introduced in Table 5.1 and shown in Figure 1.8. The steerable instruments have four degrees of freedom that are manually actuated with a pistol like handle. The control handle can be moved forwards and backwards to insert and retract the instrument ((a) in Figure 5.3), and it can be rotated to rotate the instrument around its axis (b). The bending of the instrument is controlled by a lever that is operated by the thumb (c). The grasper is actuated with the index finger (d). 

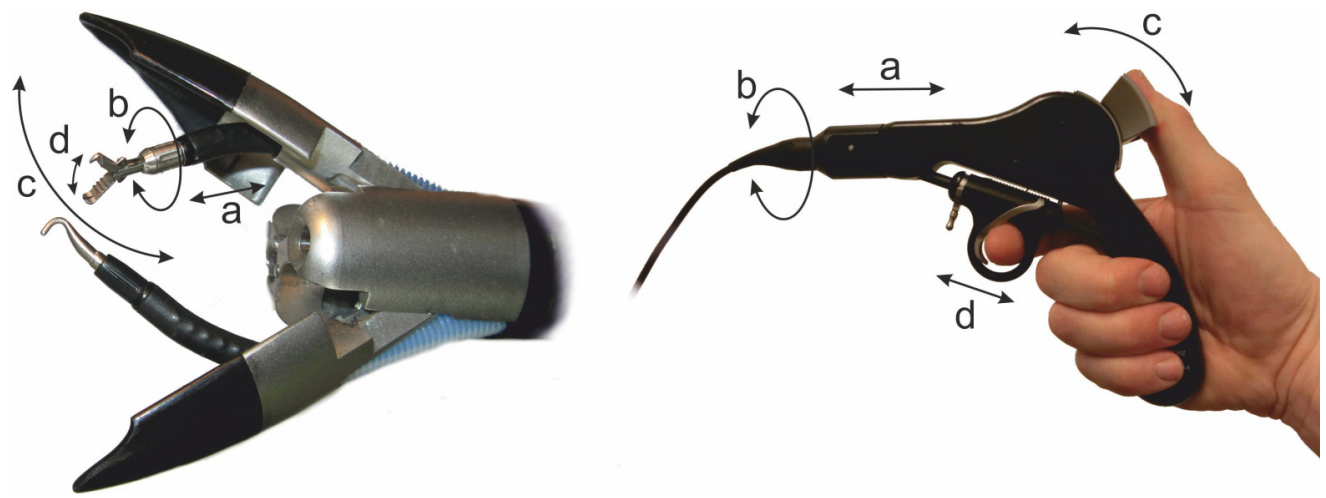

Figure 5.3 Degrees of freedom steerable instruments ANUBIS NOTEScope: (a) In-out, (b) (Counter)clockwise rotation, (c) Bending, (d) Grasp

In our setup all degrees of freedom of the steerable instruments will be electro-mechanically actuated and steered with multi-DOF input devices. In Table 5.2 we discuss instrument coupling concepts.

Table 5.2 Concepts of interfaces between drive unit and instrument.

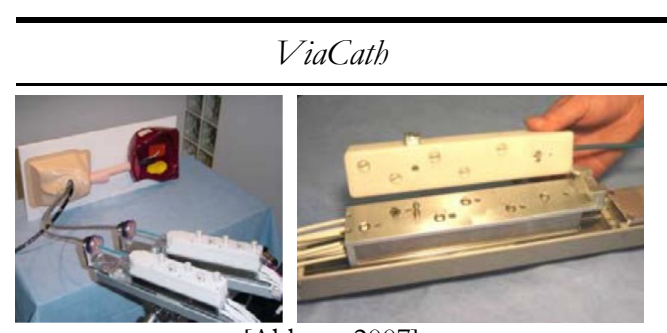

[Abbott, 2007]

The ViaCath system (see also Section 1.5) consists of flexible instruments that run along a standard gastroscope or colonoscope. To simplify the exchange of instruments during a procedure the steerable instruments are connected to the drive unit via a quick connect fitting and rotary couplers. The interface of the drive unit is small and positioned on a mobile stand to be able to position the instruments near the patient and in the right orientation for insertion [Abbott, 2007]. EndoVia Medical, Norwood, MA, USA

\section{US2008/0071288A1 - Intuitive Surgical}

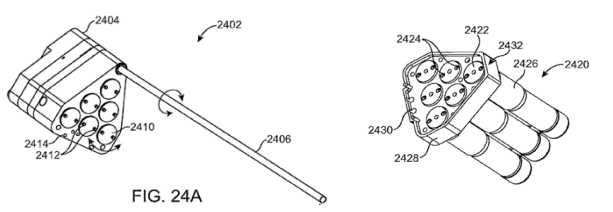

[Larkin and Rosa, 2008]

A patent of Intuitive Surgical describes an actuator assembly (right) that mates with an instrument (left). The transmission mechanism consists of six disks that actuate each of the degrees of freedom available. Torque is transferred via a pin hole connection. The drive unit and the instrument are mutual connected with spring clips.

[Larkin and Rosa, 2008]

Intuitive Surgical, Mountain View, CA, USA

In both described concepts torque between drive unit and instrument is transferred with a pin hole connection. To allow easy exchange of instruments during the procedure the parts are mutually locked with a quick connect fitting. Information regarding the prevention of backlash could not be retrieved.

\section{Actuation principles instruments}

In Table 5.3 known concepts for instrument actuation are presented. Special attention is directed to implementation in the clinical workflow with regard to disinfection. The discussed systems are not commercially available. 


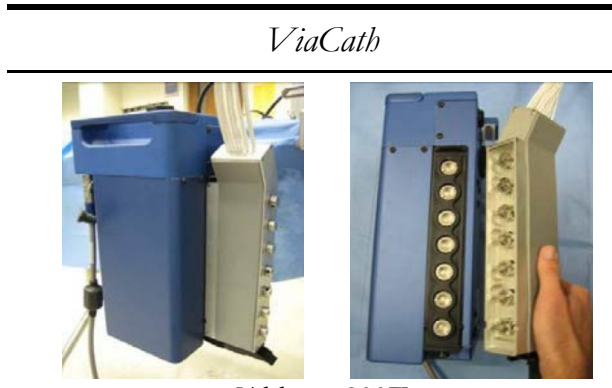

[Abbott, 2007]

The ViaCath system contains two identical drive units that separately actuate the left and the right instrument. The drive units are equipped with seven servo motors and supporting electronics. Via a quick-connect mechanical interface and seven antagonistic cable pairs the rotary motion of the motors is transferred to the base of the instrument in the sterile field near the patient [Abbott, 2007]. EndoVia Medical, Norwood, MA, USA
US2007185377A1 - Olympus

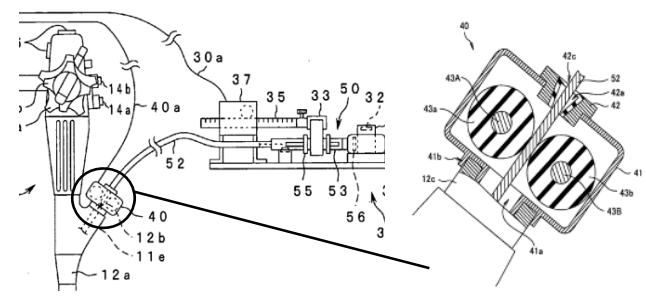

[Murakami et al., 2007]

This Olympus patent describes two drive units for in-out shaft actuation (no. 40) and for grasper actuation (no. 37) of a traditional instrument. The shaft is introduced by two counter-rotating wheels. The instrument handle for grasping is positioned on a linear slide. Axial rotation of the instrument is not actuated. Details on disinfection and positioning close to the patient are not provided [Murakami, 2007]. Olympus, Tokyo, Japan

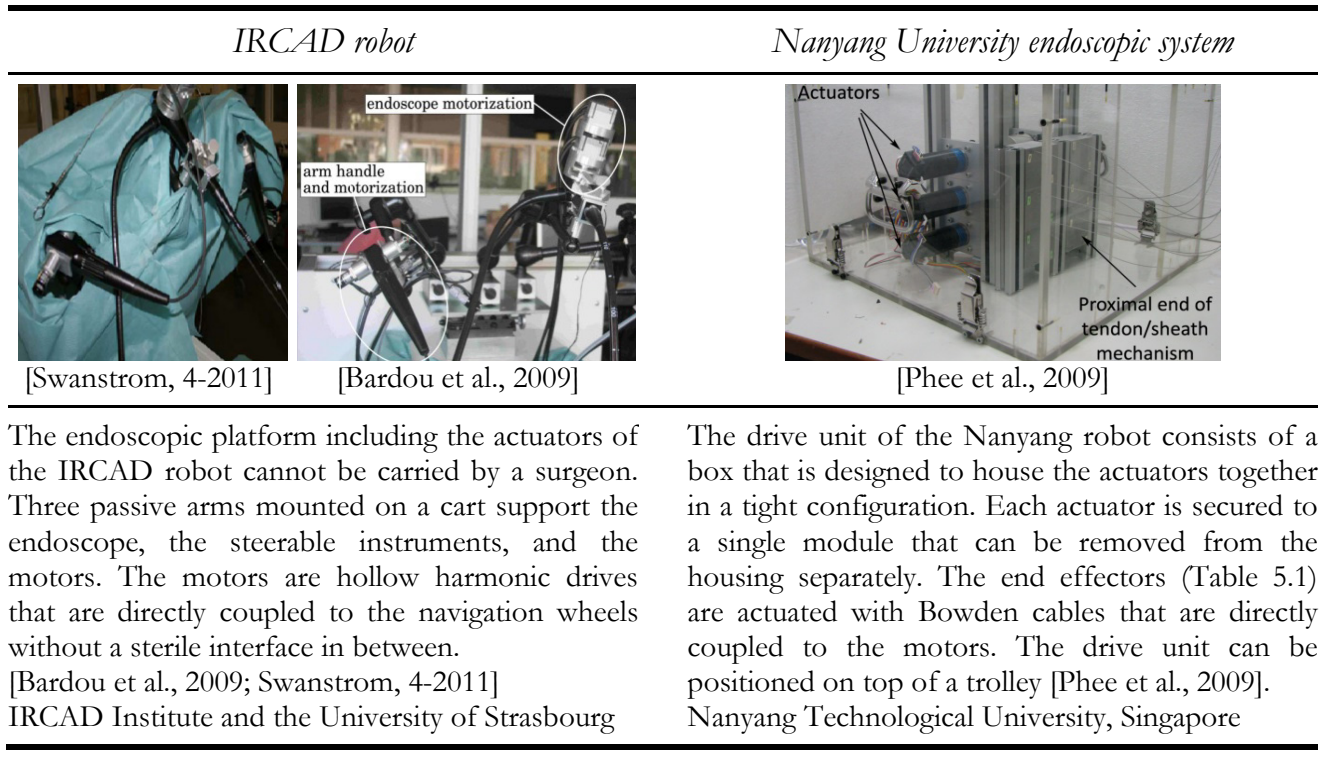

Except for the ViaCath system, measures to fit the system in the current clinical workflow are not implemented. Mainly concepts for disinfection are missing. The ViaCath system as well as the system of the Nanyang University bridge the gap between the non-sterile and the sterile field by using Bowden cable actuation. However, in the Nanyang solution the instruments are permanently coupled to the actuators, so machined disinfection of the instruments is not possible. The antagonistic cable pairs of the ViaCath system can be disconnected from both the drive unit and the instrument and separately disinfected. The main limitation of the ViaCath system is that the instruments could produce only $0.5 \mathrm{~N}$ of lateral force, which is insufficient to manipulate tissue [Abbott, 2007] 


\section{User interfaces}

In Chapter 1 different robotic master consoles are presented. In this section some details regarding the working posture, data presentation, and used input devices are discussed.

Table 5.4 User interface concepts of robotic surgery

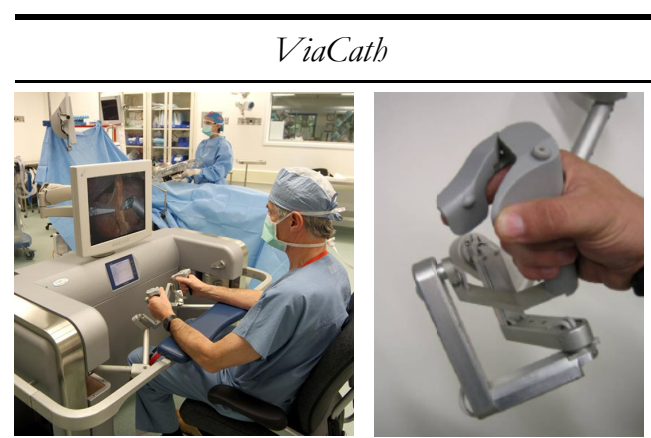

[Abbott, 2007]
Da Vinci Surgical System
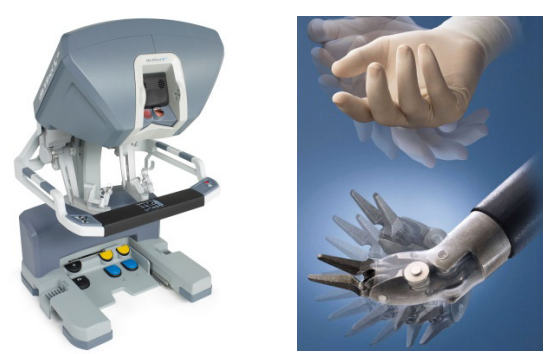

(C2012 Intuitive Surgical)
The master console of the ViaCath allows seated manipulation of two haptic devices with seven actuated DOFs, while the arms are supported by elbow rests for stability and comfort. The haptic input devices counterbalance gravity, prevent master motion when the system is in hold mode, and provide virtual force constraints. The console can be positioned anywhere in the operating room outside of the sterile field. During operation, thumb buttons on the master interface handles are used to change system settings [Abbott et al., 2007]. EndoVia Medical, Norwood, MA, USA
The surgeon sits at the Da Vinci master console (see also Section 1.1) and uses open surgery hand movements which are precisely replicated in the operative field by EndoWrist instruments (sevenDOF) that mimic the dexterity of the human hand and wrist. The stereoscopic display and the input devices are arranged so that it appears to the surgeon that the surgical instruments are in the same position as the hands. The arms are supported by an elbow rest. Auxiliary input controls are operated with the fingers and the feet [Freschi, 2012]. Intuitive Surgical, Mountain View, CA, USA

\section{M.A.S.T.E.R Nanyang University}

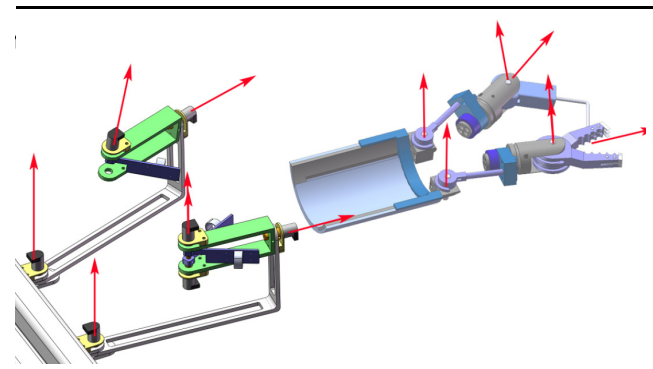

[Phee et al., 2009]

The kinematics of the M.A.S.T.E.R input device (Figure 1.14) copies the human arm in order to give the surgeon better perception in performing the joint-to-joint control of the slave. The length of each link is adjustable to accommodate to the size of different users. Like in the ViaCath system and the Da Vinci system the thumb and index finger of each hand are placed in a gripper interface. The surgeon's fingers are virtually connected to the jaws of the grasper [Phee et al., 2009]. Nanyang Technological University, Singapore
IRCAD robot

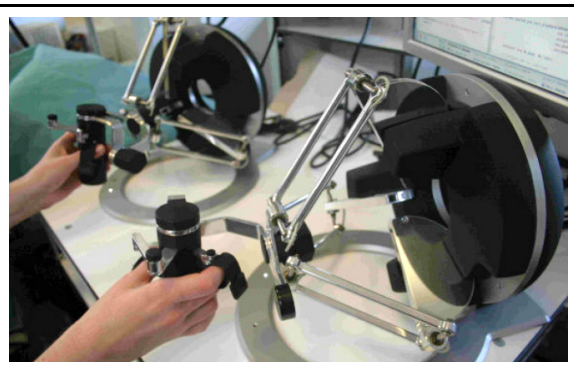

[Bardou et al., 2009]

The surgeon console of the IRCAD robot looks like a desk workstation. It carries two Omega haptic devices with seven-DOFs (Force Dimension, Nyon, Switzerland) and two monitors for displaying the images of the endoscope and other visual information.

[Bardou et al., 2009]

IRCAD Institute and the University of Strasbourg 
Of the discussed systems only the Da Vinci Surgical System is commercially available. It is used for thoracoscopic and laparoscopic procedures with rigid instruments. Ergonomic user interfaces for robotic flexible endoscopes and instruments are not yet implemented in clinical practice.

The presented systems all facilitate seated control. The ViaCath and the Da Vinci are quite bulky, but address all the required functionality for clinical procedures. The M.A.S.T.E.R. and the IRCAD setup are both laboratory setups and far from clinical introduction. The M.A.S.T.E.R. project focuses on providing an intuitive user interface, that uses natural hand and arm movements for instrument control. The IRCAD system is provided with advanced multi-DOF haptic devices that could enhance dexterity by using haptic restrictions. No data is available on how the degrees of freedom of the controllers are linked to endoscope and instrument motions.

\subsection{Current user interface shortcomings}

As discussed in the previous section, several advanced endoscopic operating platforms have been designed to enable independent multi-DOF instrument manipulation. Often these concepts contain mechanical actuation principles that need to be manually operated. Dexterity is limited because of the direct mechanical connection between handle and end effector. Control of all degrees of freedom requires a team of physicians, which is inefficient, creates ergonomic and communication issues, and has potentially higher surgical costs [Santos, 2011; Wilhelm, 2012]. Besides the physical aspect, platform control can also be mentally demanding if steering the device is not intuitive [Swanstrom, 4-2011]. Because of the limited usability and the required large teams the setups are not ready yet for cost effective and safe clinical implementation and are up to now only tested in preliminary laboratory, animal and human studies.

In the previous section some robotic setups were introduced that could take away current usability problems. Although the presented systems indeed allow a single physician to control the steerable instruments, endoscope shaft manipulation and tip steering of the endoscopic platform still needs to be done by an assistant. In addition, all robotic setups are still highly experimental and lack for instance easy positioning close to the patient and disinfection measures. Like the mechanical concepts, the robotic setups do not yet fit in the current clinical workflow.

It should be considered that a single operator with two hands is only able to control a limited number of input controls. Any functions added to the robotic flexible endoscope might lead to practical limitations due to increased complexity [von Renteln et al., 2011]. Adding more degrees of freedom to the instruments does not automatically improve dexterity. Spaun et al. [2009] conclude in their comparative experiment of advanced endoscopic intervention platforms that the added complexity could off-set the advantages of independent instrument motion. In their experiment the best results were obtained when vision and instruments were separated and a stable ergonomic interface was provided. In laparoscopy separation of vision and instrument motion are basic principles to perform procedures safely and efficient [Shaikh, 2010; Spaun et al., 2009; ].

In known mechanical as well as robotic systems the endoscopic platform is comparable to the flexible shaft of traditional flexible endoscopes and contains the same steering concepts for camera movement. The inherent flexibility of current endoscopes, which provides a great advantage for traversing the lumen, is an important limitation for therapeutic tasks like tissue traction and suturing; the endoscope buckles away from its target when force is exerted. [Rattner and Kalloo, 2006]. 
During open surgery the eye-hand coordination is natural, since the surgeon has a direct view on the hands and he controls the instrument tips directly. In flexible endoscopy both the indirect view via a monitor and the kinematics of the instruments significantly change the mapping between action and perception. As a result, eye-hand coordination is disturbed and a relatively long learning curve is required [Wentink, 2003].

Poorly designed user interfaces further contribute to the fact that surgery with flexible instruments is in its infancy and not generally adopted [Swanstrom, 6-2009]. In order for advanced endoscopic procedures to be widely practiced, a novel platform is needed that is ergonomic, intuitive, and user-friendly [Yeung, 2012]. Opportunities and considerations of a robotic flexible endoscope for natural orifice surgery will be highlighted in the next section.

\subsection{Design directions for robotic instrument manipulation}

Since endoluminal interventions are the focus area of the robotic flexible endoscope, the requirements with regard to the advanced endoscopic intervention platform are guided by its esophageal, gastric, and colorectal applications. The simplest platform is the traditional flexible endoscope. A standard gastroscope has been demonstrated to be of benefit, because of its tight bending radius. This allows easy visualization and instrument positioning in narrow spaces, whereas manipulation of a colonoscope would be cumbersome and difficult [Seitz, 2009]. All basic functions that are required for natural orifice surgery, like imaging, tip manipulation, insufflation, rinsing the lens, suction, and cleanability, are available [Miedema, 2008]. However, a standard gastroscope lacks the tip stability needed to perform tissue exposure and retraction. Despite the support of being inside a narrow tract in endoluminal procedures, fixation of the endoscopic platform might be required. In transluminal procedures, that are performed in larger spaces, the flexible endoscopic platform needs to be even stiffer to perform surgery. [Rattner and Kalloo, 2006; Swanstrom, 2008; Wang and Meng, 2012]. A lockable multi-channel overtube, like the commercial available TransPort ${ }^{\circledR}$ of USGI (San Clemente, CA, USA, Figure 5.4), could solve the stability issues.

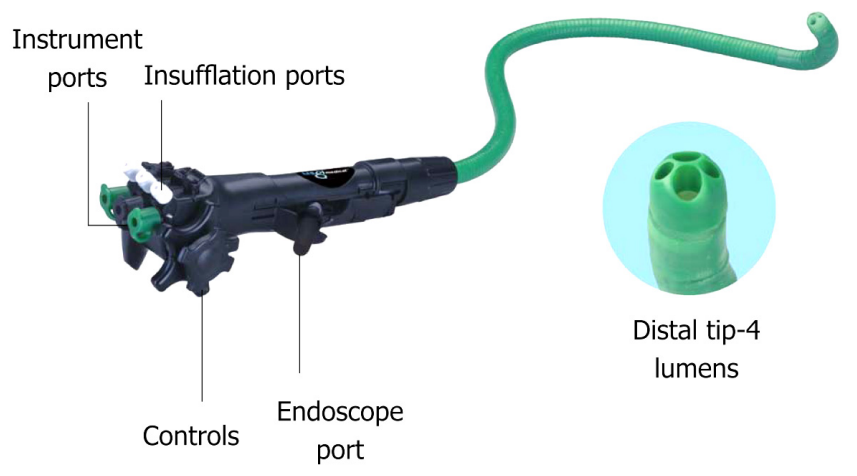

Figure 5.4 TransPort ${ }^{\mathbb{R}}$ (USGI Medical, San Clemente, CA, USA) [Shaikh, 2010]

The TransPort has a steering mechanism similar to a standard flexible endoscope, and a shaft with multiple working channels to accommodate (steerable) endoscopic instruments and a small diameter flexible endoscope to illuminate and visualize the operative site. Once it is in place, it is made rigid, providing a stable platform for surgery [Shaikh, 2010; Swanstrom, 2008]. It is expected that the TransPort with its shaft diameter of $16 \mathrm{~mm}$ is less suitable for endoluminal procedures in tight spaces than a more flexible gastroscope of about $10 \mathrm{~mm}$.

An add-on balloon, the Air Assist (Top Corporation, Tokyo, Japan), is available to stabilize a gastroscope in endoluminal procedures. It is shown in Figure 5.5. The balloon is 
positioned close to the tip of the endoscope and can be inflated to fixate the endoscope within the lumen [Matsui et al., 2012].

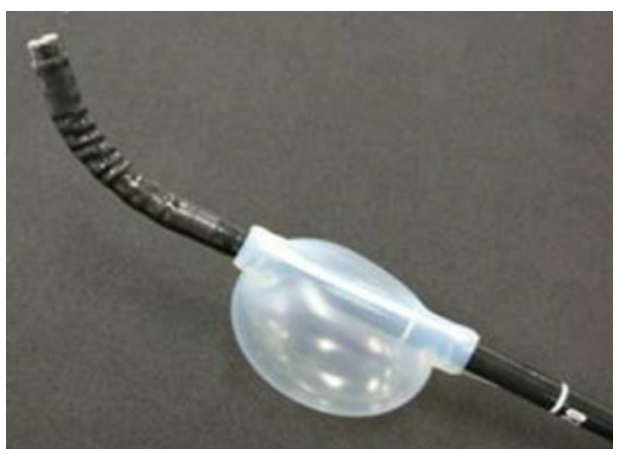

Figure 5.5 Air Assist (Top Corporation, Tokyo, Japan) [Matsui et al., 2012]

Besides maneuverability and stability, triangulation of the endoscopic platform is very important. The added value of triangulation with steerable instruments in natural orifice surgery is that the physician can stabilize the distal tip of the endoscope at the operating area and can concentrate on synergistic bimanual instrument manipulation without moving the optics. Triangulation allows the surgeon to accomplish traction and counter traction of tissue, fine dissection, and suturing and is one of the most essential concepts in laparoscopy [Wang and Meng, 2012]. Triangulation is also essential in natural orifice surgery with flexible tools [Swanstrom, 2009; Rattner and Kalloo, 2006; von Renteln, 2011]. Currently, gastroenterologists manipulate the endoscope tip including the camera and the instrument, that protrudes from the tip, to perform therapy. For endoluminal surgery to be performed with advanced endoscopic intervention platforms by gastroenterologists, improved dexterity of manipulating the steerable instruments in a triangulated configuration is essential. They should get accustomed to working with separated vision and manipulation of multiple instruments, like surgeons do. Currently, the use of advanced endoscopic intervention platforms is for that reason more adopted by surgeons in experimental transluminal surgery. However, gastroenterologists should take advantage of equipment innovations for NOTES to enhance endoluminal procedures. In addition, their competence in flexible instrument manipulation and the management of complications (e.g. closure of perforations) might complement the specific medical knowledge of surgeons in transluminal procedures [Costamagna, 2010; Rattner and Kalloo, 2006].

The TransPort overtube lacks real triangulation, because of its parallel orientation of the working channels at the tip of the endoscope. For that reason, and because of the expected limited maneuverability of the device, the TransPort will not be used in our robotic flexible endoscope. A standard gastroscope seems to be the most suitable endoscopic platform for advanced endoluminal interventions. However, it accommodates only one standard working channel. It will require working channels outside the gastroscope to accommodate the ANUBIS steerable instruments. At least two $4.2 \mathrm{~mm}$ working channels are required, that should not interfere with current endoscope qualities, like imaging and a tight bending radius of the tip. The external working channels should expose the steerable instruments in a triangulated configuration in front of the camera. Bardou et al. [2009] have determined that a deflection angle of $27^{\circ}$ of the working channels with respect to the main endoscope direction results in the largest area in which two ANUBIS steerable instruments can cooperate, as illustrated in Figure 5.6. 


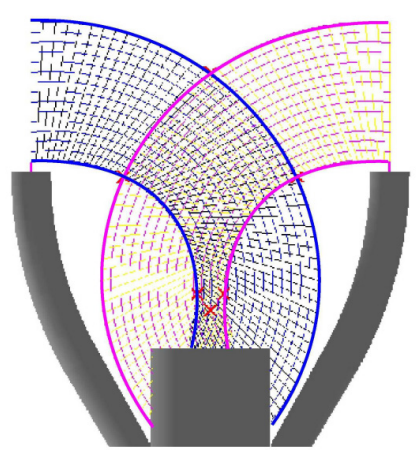

Figure 5.6 Area of operation of two steerable instruments and the resulting area in which both instruments can cooperate [Bardou et al. 2009]

A third (robotic) instrument might be protruded through the standard working channel of the gastroscope. In total three instruments can be coupled simultaneously to the instrument module, two steerable instruments to perform bimanual manipulation tasks and one conventional instrument or 'extra hand' for supportive tasks, like retraction of tissue. It should be possible to exchange all individual instruments during the procedure to perform surgery with different kind of end effectors, like needle holders, electrosurgery instruments, and lasers.

The intervention platforms discussed in Table 5.1 vary in diameter between 15 and 22 $\mathrm{mm}$. It should be targeted to minimize the diameter of the tip and shaft in the robotic setup to allow easy insertion into the patient and to limit the required manoeuvering space in the operating field. Due to the anatomical constrains of the pharynx, systems have to be smaller than $20 \mathrm{~mm}$ to be suitable for esophageal and gastric applications [Yeung, 2012].

Being aware of the spatial orientation of the endoscopic platform in the operating field is not critical in endoluminal interventions in tubular organs, since often there is no point of reference. In transluminal procedures the horizon is important for recognition of the surgical anatomy [Santos, 2011; Rattner and Kalloo, 2006]. Transluminal surgery requires extensive manoeuvring of the endoscope to achieve acceptable positioning and stability. This leads to spatial confusion. Possibly the work of Yi et al. [2007] or the ScopeGuide ${ }^{\circledR}$ system of Olympus (Tokyo, Japan), that both track the orientation and the shape of the tip and the shaft of the flexible endoscope inside the patient, could assist. The spatial orientation of the instruments that protrude from the tip of the endoscope is visualized by the endoscopic image.

The robotic flexible endoscope should try to restore the ergonomics of open surgery by creating a user interface that provides a natural working posture and intuitive control of instruments. A master-slave setup, as discussed in Section 1.4, is a suitable system setup. The master console should contain body supports to provide a stable and comfortable working posture. Sitting as well as standing should be possible in order to adapt the working posture to the type and duration of the task that needs to be performed. The elbow support integrated in the master console of the Da Vinci Surgical System (Figure 1.2), significantly alleviates wrist and shoulder pain typically found in traditional surgery [Santos-Carreras, 2012]. In our robotic setup elbow supports should be integrated as well.

Size matters for surgical robots. Operating rooms and interventional suites are usually small, and, thus, a large robot can occupy too much space. This has been a complaint for many commercially available systems, which are large floor standing robots [Kazanzides, 
2008]. A master console with an open structure, that allows the physician to keep in visual contact with the assistant and the patient, is preferred.

The mutual position of the camera and the working channels of the instruments at the tip is fixed. As a consequence movements of the instruments in relation to the image will never be reversed. The orientation of camera and instruments can be copied at the master console by correct positioning of the monitor and the input controllers. One step further is to align the monitor and the input devices very carefully, so the instruments on the monitor appear to extend from the stylus pen which the physician is holding. This creates a powerful illusion [Madhani, 1997]. Since in current practice the monitor is positioned about one and a half meter from the physician [Rich, 2009], experiments should indicate if positioning of the monitor close to the operator is comfortable and effective.

A master-slave setup can restore a natural kinematic coupling between hand and instrument movements by the decoupling of mechanical actuation principles, the implementation of electro-mechanical actuation, and the integration of computer intelligence. Ideally, a therapist can intuitively move an input device in 3D space and the movements of the instrument correspond exactly [Wentink, 2003]. It should be noted that intuitive movements are limited by the degrees of freedom and the kinematic structure of the end effector. The EndoWrist ${ }^{\mathbb{R}}$ instrument of the Da Vinci system has seven degrees of freedom (including grasping) that mimic the operator's hands. However, the ANUBIS steerable instrument only contains four degrees of freedom (including grasping). One to one mapping of the degrees of freedom of the steerable instrument to the input device might not result in the most intuitive way of steering. Like for endoscope manipulation, as discussed in Section 4.4, it is expected that control is most intuitive if the physician experiences steering as directly holding and manipulating the tip of the steerable instrument. Since the ANUBIS instrument is only able to translate in and out, rotate around its axis and bend in one direction, 3D manipulation is only achieved by joint actuation of these degrees of freedom. In our setup a control algorithm should translate intuitive steering of the operator into intended instrument movements. It should be researched if intuitive four-DOF hand movements (like for endoscope manipulation) are suitable to steer a three-DOF end effector.

Although the limitations of a standard input device are known from our experiment in Section 4.6, a Phantom Omni could also be used for controlling the steerable instruments. At least it allows for low cost single-handed six-DOF control. A dedicated input device, as discussed in Section 4.4, or a standard haptic controller with six actuated DOFs, as discussed in Section 4.5, would be more appropriate. However, at the time of performing our experiments these devices and the required algorithms to implement haptics were not available. Future research should address these potential control improvements, supported by the work of Reilink [2013].

The characteristics of the motions of the steerable instrument are not significantly different compared with the motions of the endoscope. Its range of motions are smaller, but motion scaling enables translation of large input movements by the physician to delicate instrument motions in the surgical field. The same concepts for control, as previously discussed in Section 4.4. are adopted. Like for shaft manipulation incremental position control is expected to be the most intuitive transfer function for steering the instruments. A hold-to-run button couples hand movements to instruments movements, and the stylus pen of the multi-DOF input device should be held in a power grip. Like for the remote control of the robotic steering module (Section 3.5.6), controls to actuate the endoscope valves for insufflation, rinsing, and suction need to be integrated in the stylus pen. In addition an input device is needed to open and close an instrument grasper. While manipulating the 
endoscope and the instruments the physician should be able to operate all these functions. The programmable switches, for functions like taking a picture and switching to narrow band imaging, do not necessarily have to be integrated in the stylus pen and might be controlled on a graphical user interface. Preferably no additional footswitches should be introduced. In current practice the feet are already in use to control electrosurgery during therapeutic flexible endoscopy.

Since in transluminal procedures a sterile area is entered, a system set-up is required that takes sterility during the complete workflow into account. The required setup is not totally different compared with endoluminal procedures, in which also measures should be taken to prevent cross contamination. In the robotic steering module and the shaft manipulation module sterilizable or disposable interface parts are used to separate the clean world (endoscope) from the possibly contaminated world (drive unit). A similar concept can be adopted for the instrument drive unit and the master console. Alternatively, the master console can be placed outside the sterile area. In that case the physician needs to put on a sterile gown and disposable gloves when the sterile zone has to be entered during the procedure.

The most important performance parameters and other important design requirements of instrument manipulation are summarized in Table 5.5. The values are derived from [Abbott et al., 2007], [Bardou et al., 2009], and are sometimes restricted by the degrees of freedom and the kinematics of the ANUBIS steerable instruments. All requirements need to be verified in technical, usability, and clinical tests.

Table 5.5 Important requirements robotic instrument manipulation

\begin{tabular}{|c|c|}
\hline Exchange of instrument & $<30 \mathrm{sec}$ \\
\hline Degrees of freedom steerable instrument & $\begin{array}{l}4 \text { DOF: In-out, rotation, } \\
\text { one deflection, grasping }\end{array}$ \\
\hline Input device & Multi-DOF input device \\
\hline Transfer function & Incr. position control \\
\hline Left-right (k') force & $1 \mathrm{~N}$ \\
\hline Left-right (k') range & $\pm 90^{\circ}$ \\
\hline Left-right ( $\left.k^{\prime}\right)$ accuracy & $\pm 1^{\circ}$ \\
\hline Left-right (k') speed & $90^{\circ} / \mathrm{s}$ \\
\hline In-out force (e' / h') & $5 \mathrm{~N}$ \\
\hline In-out range (e' / h') & $+70 \mathrm{~mm}$ \\
\hline In-out accuracy (e' / b') & $\pm 0.5 \mathrm{~mm}$ \\
\hline In-out max. speed (e' / b') & $70 \mathrm{~mm} / \mathrm{s}$ \\
\hline (Counter)clockwise torque (f' / i') & $0.1 \mathrm{Nm}$ \\
\hline (Counter)clockwise range $\left(f^{\prime} / i^{\prime}\right)$ & $\pm 90^{\circ}$ \\
\hline (Counter)clockwise accuracy (f' / i') & $\pm 1^{\circ}$ \\
\hline (Counter)clockwise rotational speed ( $\left.f^{\prime} / i^{\prime}\right)$ & $90^{\circ} / \mathrm{s}$ \\
\hline Grasp force (proportional) (g'/ l') & $0.5 \mathrm{~N}$ \\
\hline
\end{tabular}

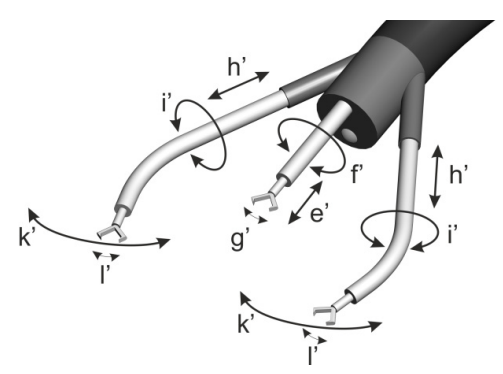




\subsection{Design}

This section discusses the design of the robotic instrument manipulation module and its integration with the robotic steering module and the shaft manipulation module.

\subsubsection{Clinical setting}

In Figure 5.7 the robotic flexible endoscope for advanced therapeutic procedures is depicted in its clinic setting. In case of endoluminal procedures the procedure might be performed in an endoscopy room in the polyclinic, for transluminal procedures a sterile environment is required. The drive unit of the (steerable) instruments is positioned on the same swivel arm as the steering and shaft manipulation module. The ergonomic master console, equipped with a monitor and two multi-DOF input devices, is positioned within or just outside the sterile zone, as discussed in Section 5.4.

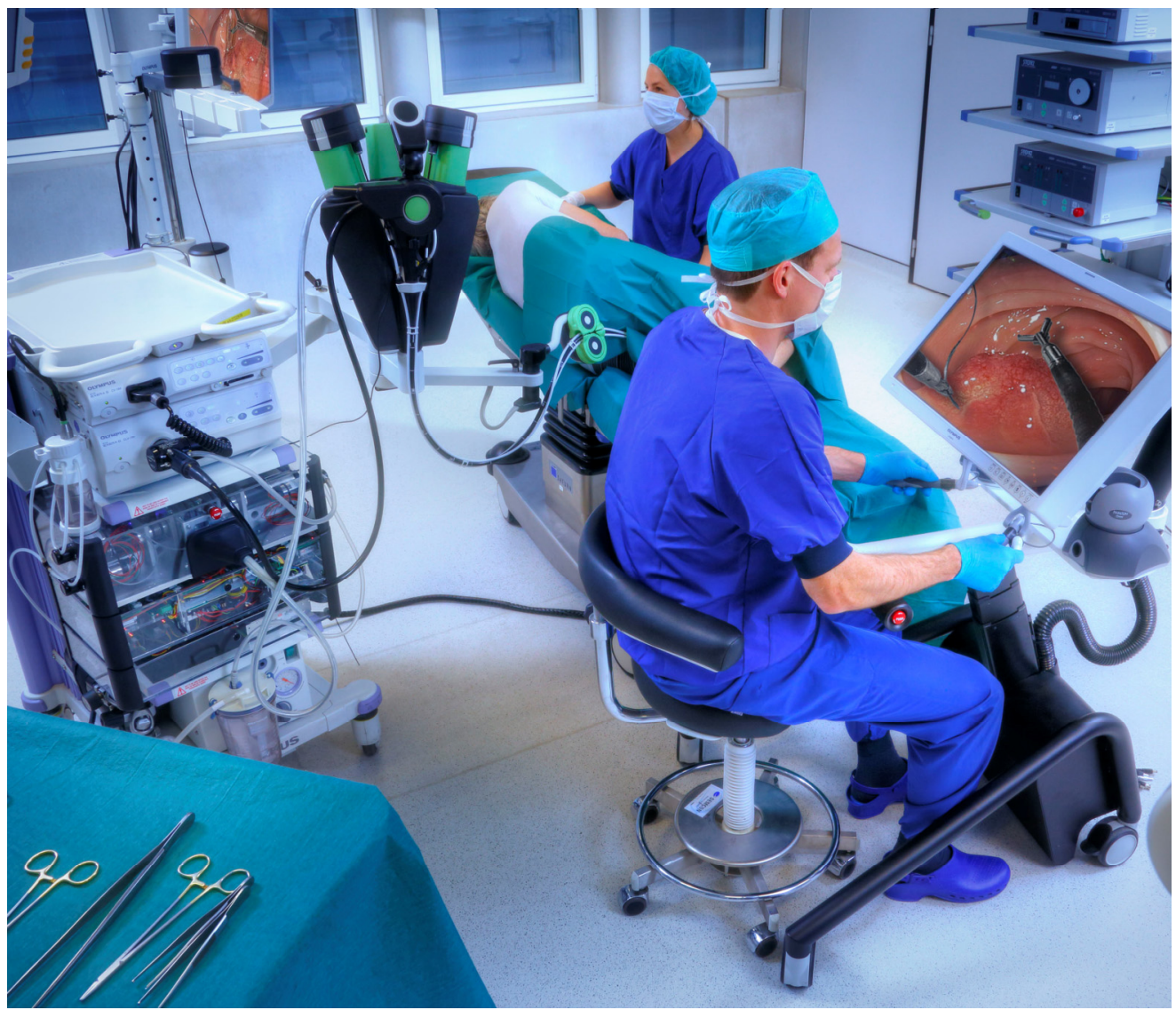

Figure 5.7 Clinical setup for therapeutic procedures with steerable instruments

As in current practice the assistant is responsible for preparing the procedure. The equipment is installed, the robotic endoscope is tested, and the patient is brought into the room. During the procedure the assistant mainly monitors the patient, while the physician operates all equipment. During intubation of the endoscopic platform up to the operating field the physician will only use the robotic steering module, while standing next to the patient. The shaft and instrument manipulation module will be positioned away from the 
patient. When the operating field has been reached, the remote control will be docked, the shaft manipulation module is coupled to the endoscope, and the physician takes place at the master console. The assistant is responsible for preparing, inserting, and exchanging instruments according to instructions of the physician, as shown in Figure 5.8.

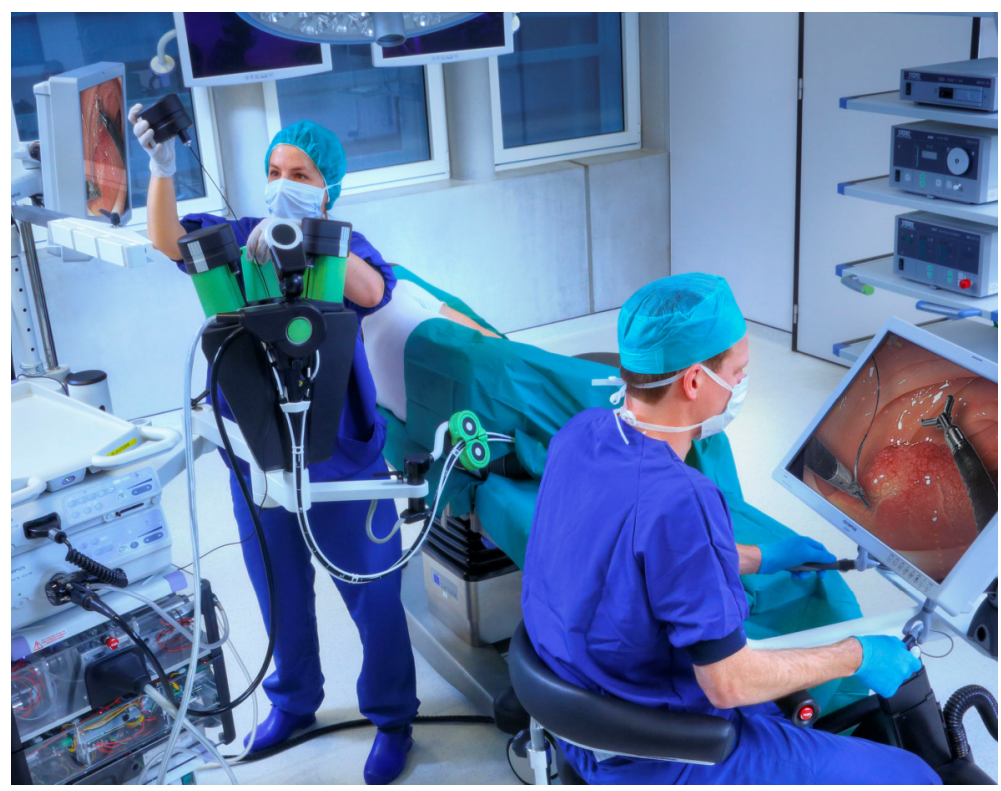

Figure 5.8 Instrument change by assistant

\subsubsection{System overview}

In Figure 5.9 an overview is shown of the setup for robotic control of an advanced endoscopic intervention platform. In Section 3.5 and Section 4.7 respectively the robotic steering and the shaft manipulation module have been discussed. In this section the design of the robotic instrument manipulation module will be covered.

The instrument drive unit is capable of actuating three instruments. Each individual instrument can be easily exchanged to enable usage of different instruments during the procedure (Section 5.5.3). The sterile instruments interface with sterile disposable parts, that are pre-positioned on the drive unit before the procedure starts (Section 5.5.4). One nonsteerable instrument can be inserted in the standard working channel of the endoscopic platform, while the steerable instruments are guided through working channels that are positioned outside the endoscopic platform (Section 5.5.5). All robotic modules are positioned on one swivel arm that is mounted to a standard endoscopy cart (Section 5.5.6). The master console is compact and easy to manoeuvre. The position of input devices, monitor, and body supports can be set to personal preferences (Section 5.5.7). Two multiDOF input devices enable control of all degrees of freedom. A dedicated index finger joystick is added to the stylus pen to operate an instrument grasper and some auxiliary functions (Section 5.5.8). The robotic drive units, the control boxes on the endoscopy cart, the master console, and the standard flexible endoscopy equipment are mechanically, electrically and by software connected, to enable synergetic cooperation (Section 5.5.9). 


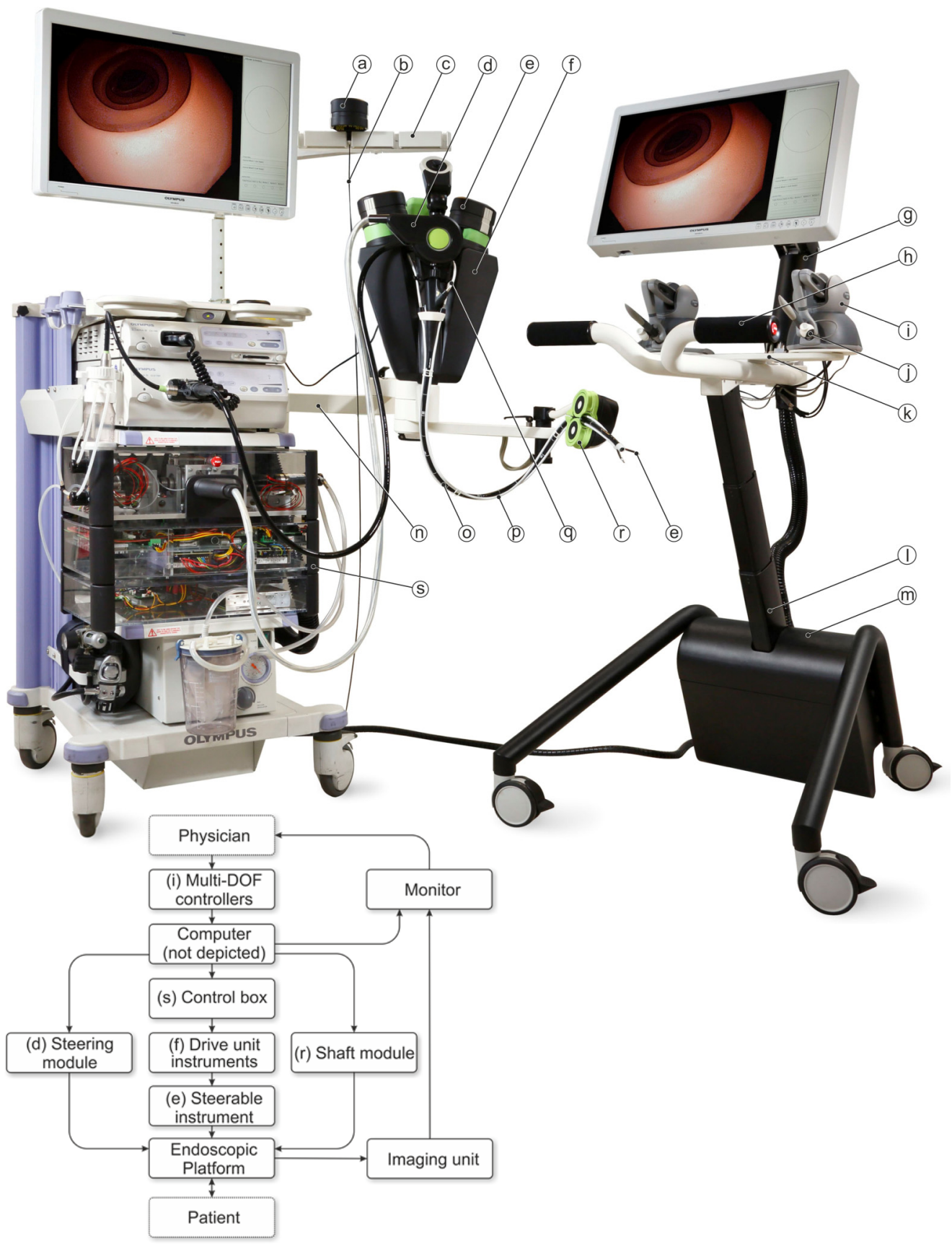

Figure 5.9 System setup robotic therapy with steerable instruments (standard equipment in grey): (a) Robotic interface instrument, (b) ANUBIS steerable instrument, (c) Docking station instruments, (d) Steering module, (e) Steerable instrument, (f) Drive unit instruments, (g) Monitor arm, (h) Elbow support, (i) Multi-DOF input device, (j) Index finger joystick, (k) Adjustable supports input devices, (l) Lifting column, (m) Electro box master console, (n) Swivel arm, (o) Gastroscope, (p) External working channels, (q) Standard working channel, (r) Shaft manipulation module, (s) Control box 


\subsubsection{Drive system instrument}

In Figure 5.10 the main components of the drive unit of the robotic instrument manipulation module are depicted. The drive system consists of three columns that are integrated in one housing. On top of the columns the instruments are coupled (Figure 5.8). The orientation of the columns is in line with the working channels of the endoscopic platform to minimize loss of instrument length outside the endoscopic platform. Additionally, because the instruments are guided in a fairly straight way, friction between instruments and instrument guidance is limited. Friction reduces the dynamic performance and would as a consequence reduce accurate control of the instrument tip.

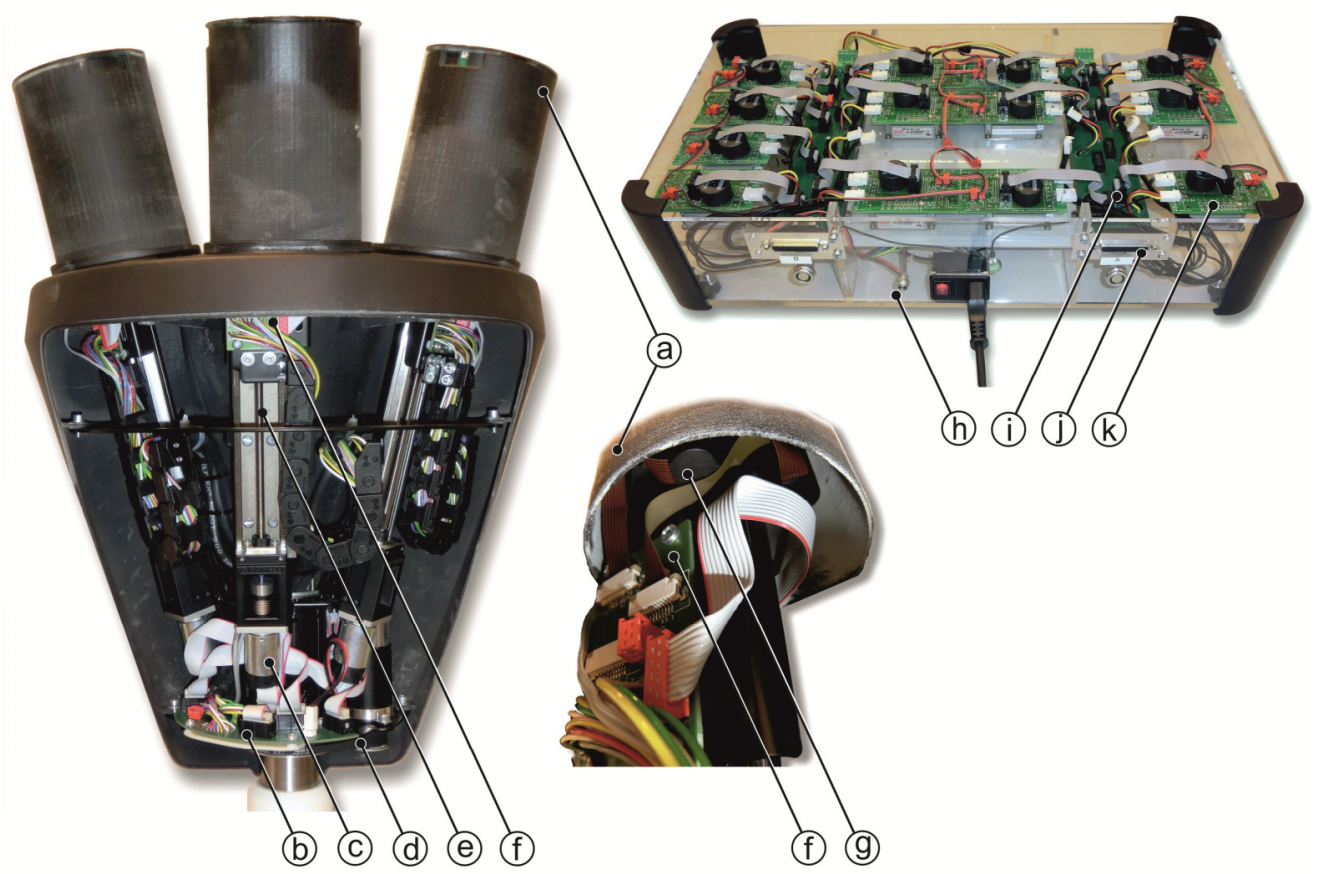

Figure 5.10 Drive unit instrument manipulation module: (a) Instrument actuation column, (b) Interface PCB motors fixed world, (c) Motor in-out, (d) Motor rotation drive unit, (e) Linear slide in-out, (f) Interface PCB motors columns, (g) Motor instrument actuation, (h) Communication interface, (i) Interface PCB motor controllers, (j) Interface motors - motor controllers, (k) Motor controllers

The robotic shaft manipulation module (Chapter 4) is able to rotate the shaft of the endoscope. However, the control section of the endoscope is fixated in the drive unit of the instrument manipulation module. If no specific measures are taken, rotation will put tension on the shaft and will impede operation of the shaft manipulation module and causes possibly problematic swaying motions of the endoscope shaft. A DC servo motor (RE-max 29-22W, Maxon, Sachseln, Switzerland) is integrated in the drive unit to rotate it simultaneously with the shaft manipulation module ((d) in Figure 5.10). The drive unit rotates with respect to the swivel arm.

Each instrument column contains four motors that actuate the degrees of freedom of the instrument. One motor (RE-max 21-6W, Maxon) is positioned on the fixed world and actuates in-out movement of the column and as a consequence the in-out movement of the instrument with respect to the endoscopic platform ((c) in Figure 5.10). In the column itself 
motors can be placed at four positions, as shown in Figure 5.11. Only three are in use in our robotic setup; one for axial instrument rotation (RE-max 13-2W, Maxon), one for actuating the grasper (RE-max 21-6W, Maxon), and one for bending the steerable instrument (RE$\max 13-2 \mathrm{~W}$, Maxon). One position is reserved for a motor that could actuate an additional bending degree of freedom that is moving perpendicular to the current one. Unfortunately, the ANUBIS steerable instruments can only bend in one direction.
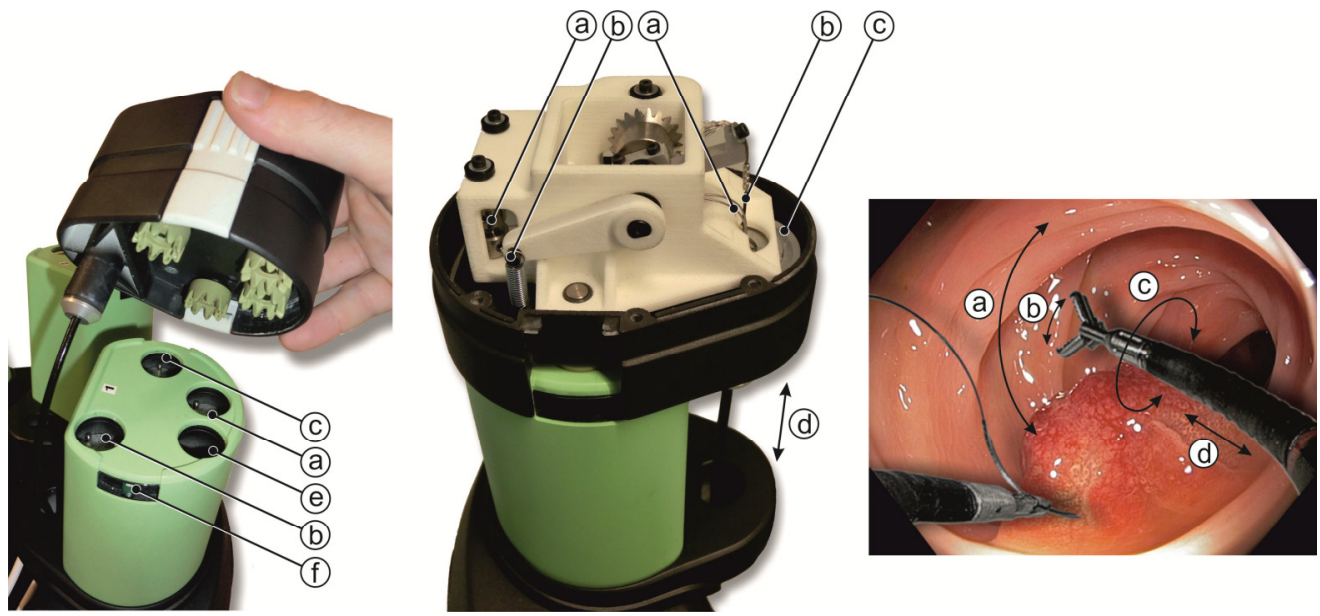

Figure 5.11 Instrument column and its degrees of freedom: (a) Actuation of bending, (b) Actuation of grasper, (c) Actuation of axial rotation, (d) In-out movement, (e) Spare position for bending, (f) Micro switch for instrument detection

The coupling of the degrees of freedom of the instruments to the motors is realized by crown gears that each interface with an adapter with two pins that is mounted on the output shaft of the motor.

Bending of the instrument tip is actuated by an antagonistic Bowden cable pair that runs inside the instrument. Both inner cables run a few times in an opposite direction around a pulley inside the instrument and are then fixated. Rotation of the pulley will unwind one of the inner cables, while the other inner cable is winded on the pulley and pulls the tip of the steerable instrument aside. Rotation of the pulley is limited by two mechanical end stops to prevent excessive bending of the steerable instrument. The drive train for bending the instrument tip does not have to be homed. By inserting the instrument in the working channel the tip is straightened, so the position is known when it is coupled.

The grasper is also actuated by a Bowden cable principle. However, not by an antagonistic pair of cables, but by one push-pull cable. For easy insertion in the working channel it is important that the grasper is closed. For that reason in our setup the grasper is standard closed by means of a tension spring. The motor actuates opening of the grasper and needs to counteract the spring. The grasping force depends on the characteristics of the spring. Tests showed that this solution is non-optimal and should be replaced by a concept in which the operator determines the grasping force. This is allocated as future work.

Axial rotation of the shaft of the instrument is actuated by a timing belt, that drives a pulley that is fixated on the shaft of the instrument. The pulley has a ridge that limits instrument rotation to about $-150^{\circ}$ to $+150^{\circ}$. This prevents damage to the instrument due to internal twisting of the Bowden cables that run inside the steerable instrument. This range is sufficient for dexterous manipulation. The rotational position of the instrument needs to be homed after coupling, so that its position with respect to the input device is known. 
The configuration of a non-steerable instrument is identical to the configuration of a steerable instrument. The only difference is, that no Bowden cables for bending are attached to the pulleys inside the instrument ((a) in Figure 5.11) and actuation of the pulleys will not affect the instrument.

\subsubsection{Interfacing with instrument}

The instruments are inserted in the endoscopic platform close to the drive unit. In case of transluminal procedures the instrument tip enters a sterile zone and needs to be sterile itself. All components of the drive that could be touched by the instrument tip or by personnel should be sterile to prevent contamination. The drive system cannot be sterilized or intensively cleaned and needs to be covered with sterile parts before the procedure starts. In Figure 5.12 the main components are depicted and an visual instruction is provided on how to install these components.
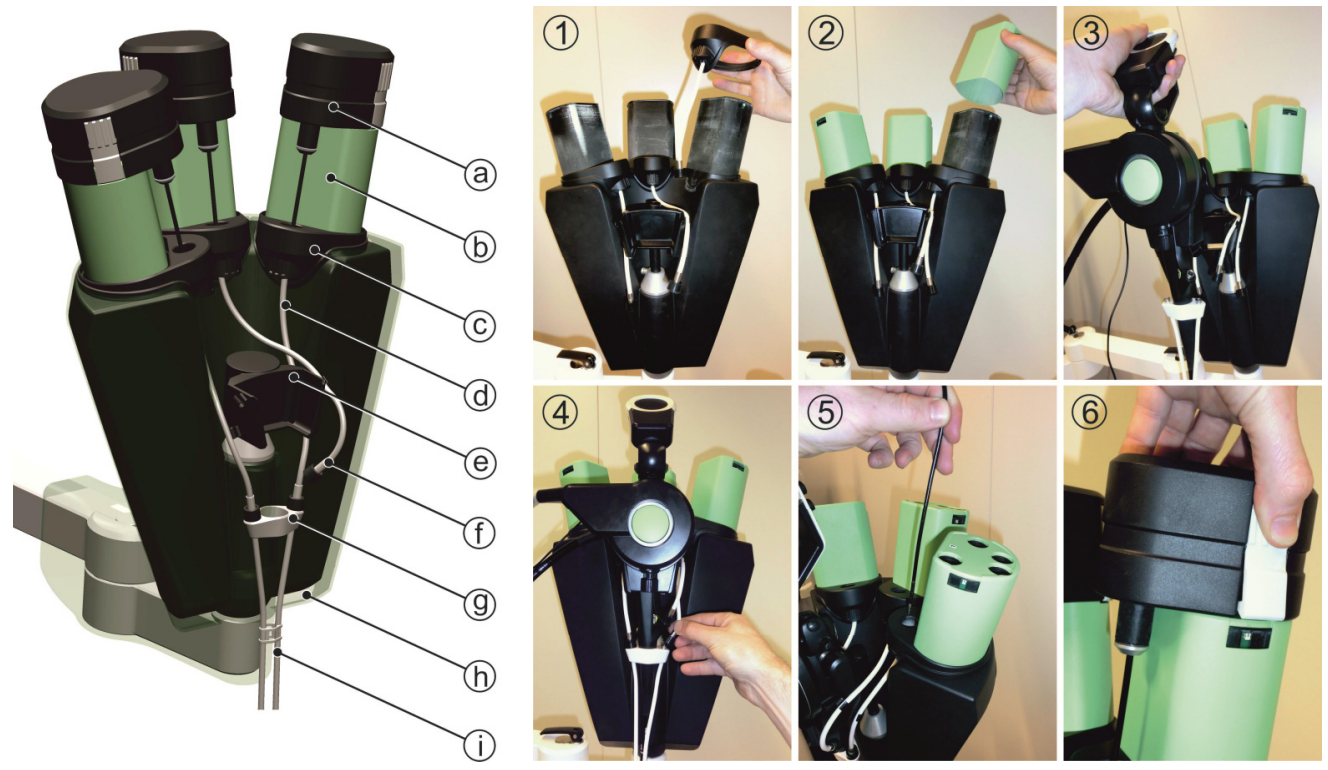

Figure 5.12 Sterile parts and installation instruction of the robotic shaft manipulation module: (a) Instrument, (b) Sterile sleeve column, (c) Sterile adapter working channel drive unit, (d) Working channels drive unit steerable instrument, (e) Docking station, (f) Working channel drive unit non-steerable instrument, (g) Sterile adapter working channel endoscopic platform, (h) Sterile sleeve, (i) Working channel endoscopic platform, (1-6) Installation instruction

In case of sterile interventions the drive unit is positioned in the sterile zone. The endoscopy cart will be outside the sterile zone. The swivel arm connects the components in the sterile zone to the ones in the non-sterile zone.

All components that can be potentially touched by personnel need to be sterile. Like for the robotic steering module and the shaft manipulation module, sterile plastic enclosures and sleeves are used to cover the complete drive unit and part of the swivel arm.

The first step in the installation procedure is to home the drive unit. The columns need to be in the most extended position. Subsequently, sterile adapters are mounted on the enclosure of the drive unit (step 1 in Figure 5.12). Each adapter is provided with a short working channel that guides the instrument to the opening of the working channel on the endoscopic platform. A trunk-like foil sheet is sealed to the adapters that will be simultaneously draped over the drive unit and the swivel arm ((h) in Figure 5.12). This is not 
implemented yet and is not shown in the pictures on the right. Subsequently, sterile enclosures are pushed on the instrument actuation columns (step 2). Thereafter the sterile docking station and the robotic steering module with the endoscopic platform are attached to the drive unit (step 3). Now, the short working channels of the adapters, as discussed in step 1, are connected to the standard working channel of the endoscope and to the working channels for the steerable instruments (step 4). These are all the steps that need to be executed before the therapeutic procedure starts. All above mentioned parts are low cost injected moulded parts, that can be discarded or sterilized after the procedure.

If the master console is positioned within the sterile zone as well, all parts that can potentially be touched by personnel during the procedure, like the elbow supports and the input devices, need to be enclosed by sterile foil.

During the procedure the shaft of the instrument is inserted in the adapter on the drive unit and guided by the working channels to the tip of the endoscope (step 5). Spring clips assure that the instrument stays in position (step 6). A micro switch on the instrument column is actuated by the spring clips to detect if an instrument is present. In addition, it ensures that the instruments can only be operated when coupling has been done correctly.

The neutral position of the instrument column is in its most upper position. When an instrument is coupled by an assistant it is still retracted within the working channel of the endoscopic platform. The short stroke translation into the field of view of the camera is robotized and controlled by the physician. Opening the grasper and steering the instrument is only allowed when the tip protrudes far enough out of the endoscope. Otherwise, the instrument may become damaged. This is software controlled.

\subsubsection{Endoscopic platform}

The endoscopic platform consists of a $10 \mathrm{~mm}$ diameter gastroscope (GIF-H180, Olympus, Tokyo, Japan). The standard gastroscope provides a light source, a camera, channels for insufflation, rinsing, and suction, and one $2.8 \mathrm{~mm}$ diameter instrument channel. A standard instrument (with a robotic interface) can be inserted in the standard working channel. Two $4.2 \mathrm{~mm}$ diameter Teflon working channels are attached to the outside of the shaft of the endoscope. At the control section side of the endoscope, the working channels end in an adapter as shown in Figure 5.12. At the endoscopic tip side, the channels are attached to a specific developed cap that is pushed on the tip of the endoscope and aligned with the front side (Figure 5.13). The steerable instruments are guided through the external working channels and are positioned in a triangulated fashion with respect to the camera. The angle of the working channel with respect to the main direction of the endoscope is $27^{\circ}$ at the position where the steerable instruments protrude from the cap. The frontal size of the cap is $20 \times 13.5 \mathrm{~mm}$, making the system also suitable for esophageal and gastric applications (Section 5.4).
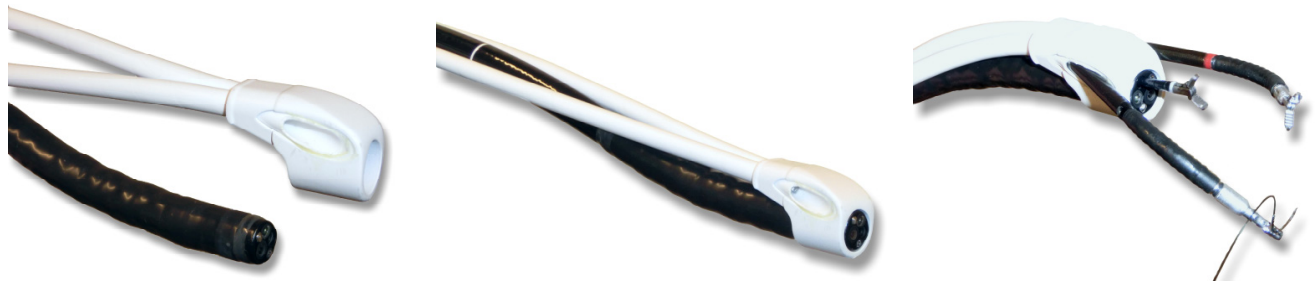

Figure 5.13 Cap for instrument guidance endoscopic platform: (left) Cap with instrument channels attached, (middle) Cap positioned on gastroscope, (right) Two steerable instruments and one non-steerable instrument protrude from the tip. 


\subsubsection{Suspension and positioning}

The endoscopic platform including the robotic steering module is integrated with the robotic instrument manipulation module. This assembly needs to be positioned close to the patient to minimize loss of shaft length. The shaft of the endoscopic platform is controlled by the robotic shaft manipulation module. Therefore all robotic modules should be positioned in close proximity. The swivel arm, as discussed in Section 4.7.5, is suitable to mount all robotic modules. In Figure 5.14 the complete slave setup is shown that is positioned close to the patient. The instrument drive unit is positioned on the same location as the docking station of the robotic steering module (Figure 3.13). The control boxes of all robotic modules are positioned on shelves of the standard endoscopy cart. The power and signal cables that run from the control boxes to the instrument drive unit and the shaft drive unit are guided through the swivel arm. The signal cables of the steering module are integrated with the flexible transmission.

The length of the swivel arm (Figure 4.18) allows an assistant to stand between the endoscopy cart and the patient bed in case an instrument needs to be exchanged. In addition, its large range of motion allows personnel to configure the orientation and the position of the endoscopy cart to personal preferences.

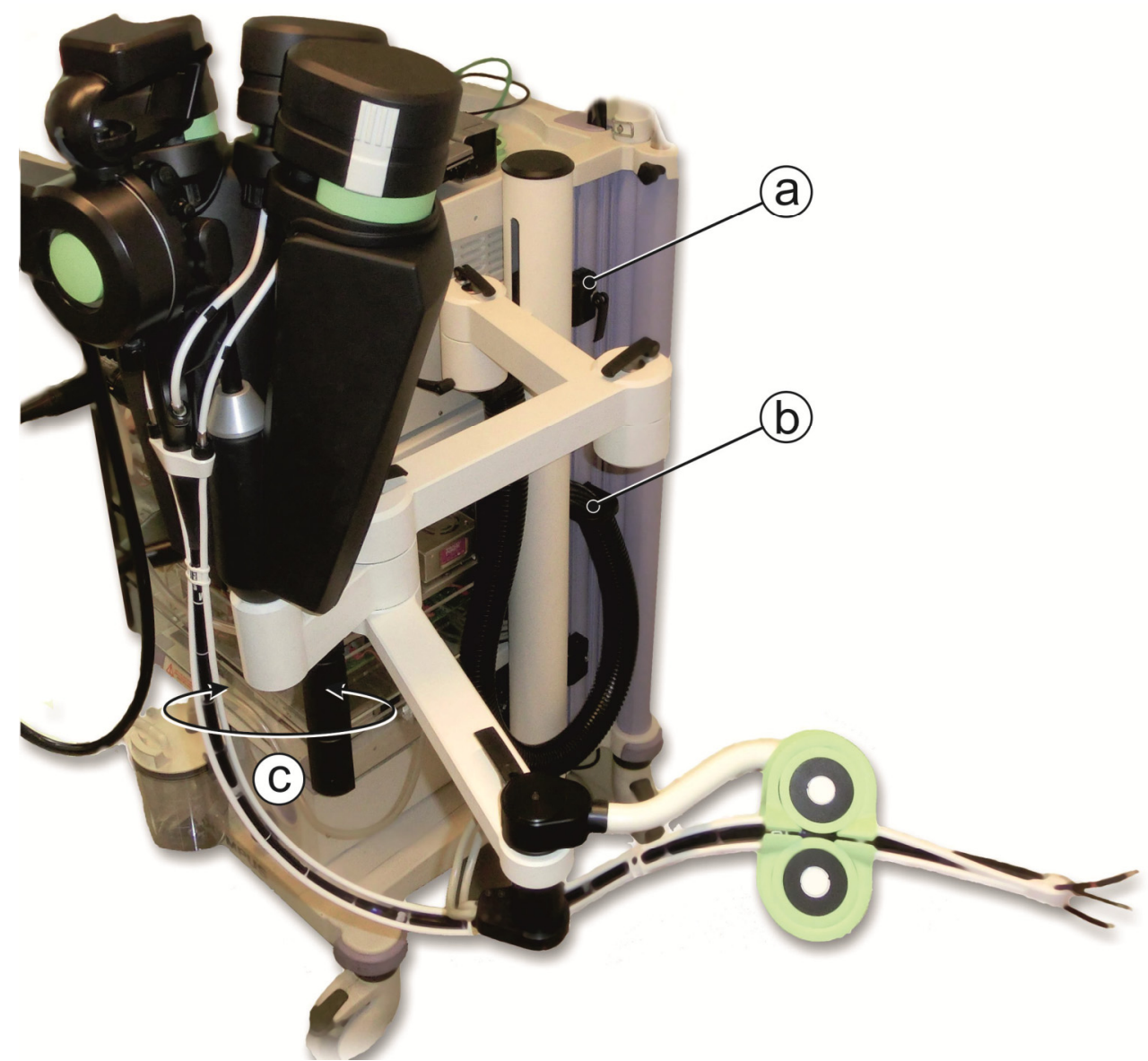

Figure 5.14 Swivel arm instrument module: (a) Mounting bracket on endoscopy cart, (b) Cable sleeve, (c) Robotic rotation drive unit (Section 5.5.3) 


\subsubsection{Master console}

In the full robotic setup with two steerable instruments the physician does not interact directly with the flexible endoscope and the instruments. All degrees of freedom are controlled at the location of the master console. In the setup of Figure 5.7 the physician is seated and his arms are supported by elbow rests to comfortably perform surgery. By lifting the master console with the integrated electric lifting column, the physician is able to stand during the procedure. The elbow supports, the monitor, and the input devices move up together.

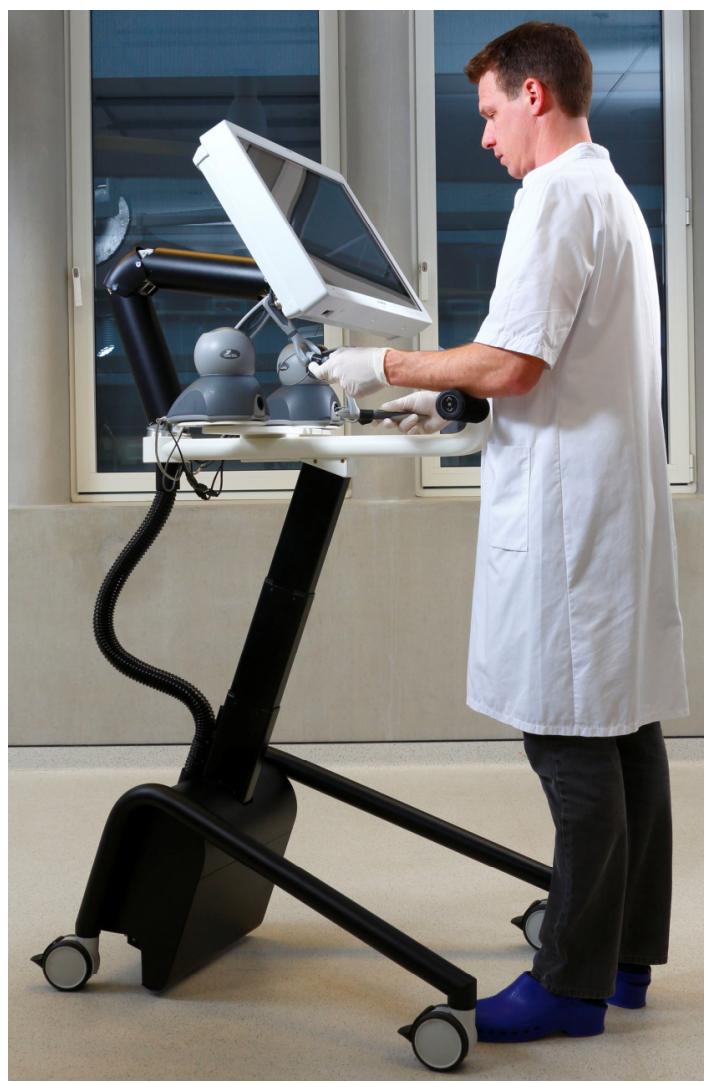

Figure 5.15 Master console operation in standing position

The relative position of the elbow supports, the monitor, and the input devices can also be changed. The position of the high-definition monitor (OEV261H-26 inch, Olympus corporation, Tokyo, Japan) can be set to align the input devices and the instruments that are depicted on the monitor. The monitor arm is self-locking and allows to position the monitor in a vertical as well as a horizontal position. The Phantom Omni input devices are mounted on two sliders. The spacing between the devices ((a) in Figure 5.16) and the distance with respect to the elbow supports ((b) in Figure 5.16) can be changed. All adaptations can be performed without tools and at any time during the procedure. 

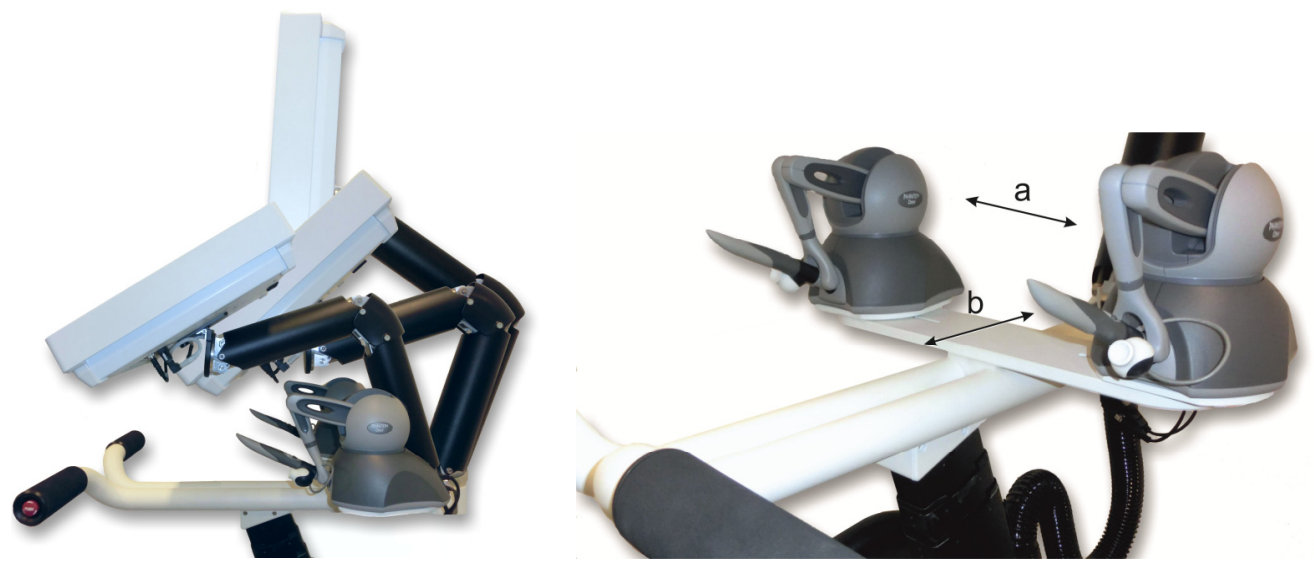

Figure 5.16 Range of motion of the monitor (left), and the setting options of the multi-DOF input devices (right)

Lockable castors allow to move and stabilize the master console anywhere in the room. Because of the small footprint and the open structure, the master console minimally interferes with the existing room layout.

\subsubsection{Input device}

As discussed in Section 5.4 the characteristics required to control an instrument in an intuitive and user-friendly way are comparable to the ones for endoscope control. For that reason the instruments are, like the endoscope, controlled by a Phantom Omni input device. Two devices are integrated in the master console to allow for bimanual instrument manipulation. Incremental position control is used as transfer function between user input and end effector output. However, the implementation of the control algorithm for steering the instruments was not as straightforward as for endoscope control. The tip of an endoscope is able to bend in two perpendicular directions, whereas the ANUBIS steerable instruments can only deflect in one direction. We tried to mimic the behaviour of the endoscope, by mapping the position of the tip of the steerable instruments to the position of the hand of the operator in the XY-plane. This requires combined actuation of the degrees of freedom of the steerable instruments, as discussed in Section 5.4. Our attempt was not very successful due to hysteresis. The instrument position could not be exactly calculated by keeping track of the motor position. As a consequence the mapping of instrument and hand movements deviated in the course of time and control was non-intuitive. Visual servoing could assist in determining the exact position of the steerable instruments in the operating field. It uses the camera image as input instead of the motor position. Reilink [2013] has conducted research on this topic. His work could be helpful in improving the intuitive mapping of hand and instrument movements. Due to time constraints it was not possible to implement his work before the usability tests (Section 5.6 and 6.2) Currently, a control algorithm is implemented that maps input device movements one to one to the kinematic structure of the steerable instrument.

The two standard buttons on the Phantom Omni stylus pens (Figure 5.17) are used as hold-to-run button to prevent unintended movements of the robotic flexible endoscope and the instruments, to allow repositioning of the pen to a comfortable position, and to switch between endoscopic platform, non-steerable instrument, and steerable instruments.

A dedicated index finger joystick is developed within his project and added to the stylus pen to be able to operate a grasper, as shown in Figure 5.17. The hood of the joystick should 
be moved sideways with respect to the stylus pen to open the grasper. The position of the joystick is tracked by potentiometers, so the grasper can be proportionally opened and closed. In addition, the index finger joystick can be moved upwards and downwards to proportionally operate insufflation and suction. If the hood is pressed a micro switch is actuated that controls rinsing of the lens.

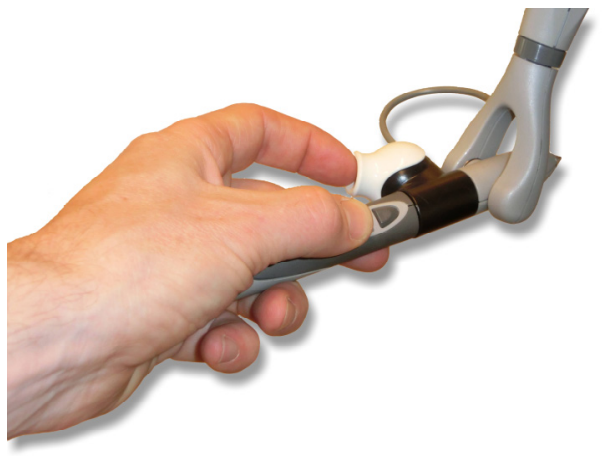

Figure 5.17 Stylus pen of the multi-DOF controller, including the standard buttons and the index finger joystick that is developed within this project

\subsubsection{Electrical and software integration}

In Figure 5.18 a schematic overview is shown of how the robotic modules are connected and according to what protocol they communicate with each other. The control software runs on a laptop (EliteBook 2.4GHz, Hewlett-Packard, Palo Alto, USA) with Windows XP (Microsoft, Redmond, USA) installed. The communication between the laptop and respectively the remote control (USB) and the multi-DOF controller (Firewire) is realized by standard components. The laptop and the microcontroller (mbed NXP LPC1768) communicate via TCP/IP. The CAN communication protocol between the robotic modules allows to add extra components to the system, which guarantees a modular setup. One emergency stop is positioned on the control box of the steering module. Another one is integrated with the elbow support of the master console.

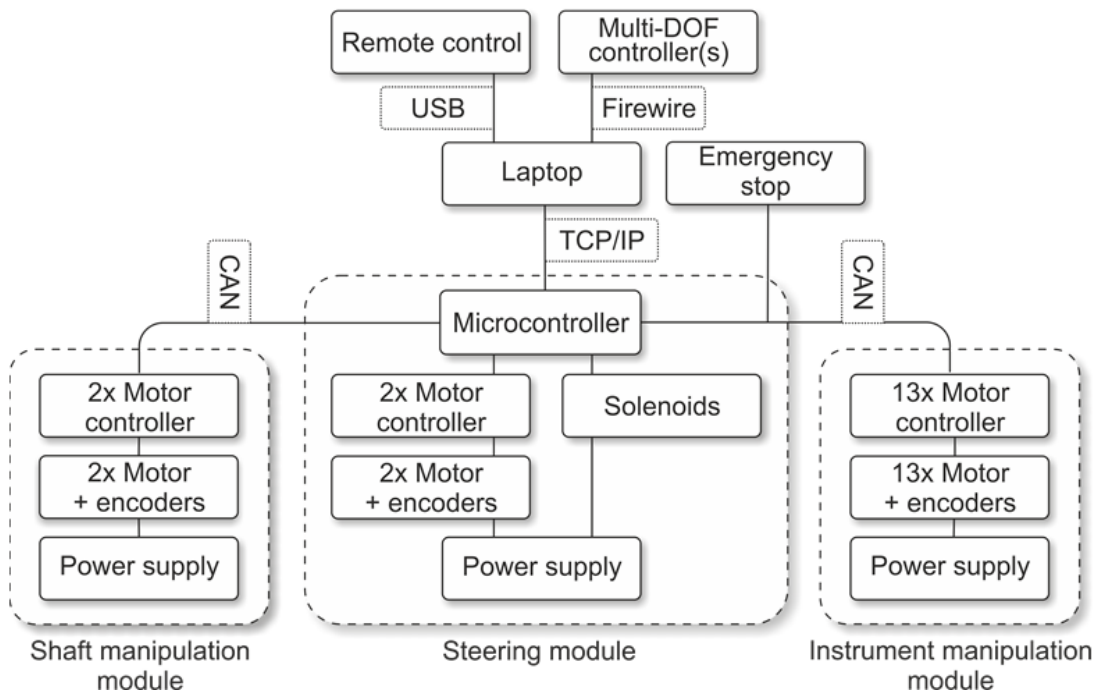

Figure 5.18 Electrical diagram integrated robotic flexible endoscope 


\subsubsection{Specifications}

In Table 5.6 the original requirements as well as the achieved specifications of the robotic instrument manipulation module are listed.

Table 5.6 Specifications robotic instrument manipulation module

\begin{tabular}{|c|c|c|}
\hline & Requirement & Specification \\
\hline Exchange of instrument & $<30$ sec. & $\sim 10 \mathrm{sec}$ \\
\hline $\begin{array}{l}\text { Degrees of freedom steerable } \\
\text { instrument }\end{array}$ & $\begin{array}{l}4 \text { DOF: In-out, } \\
\text { rotation, one } \\
\text { deflection, } \\
\text { grasping }\end{array}$ & $\begin{array}{l}4 \text { DOF: In-out, } \\
\text { rotation, one } \\
\text { deflection, } \\
\text { grasping }\end{array}$ \\
\hline Input device & $\begin{array}{c}\text { Multi-DOF input } \\
\text { device with stylus pen }\end{array}$ & $\begin{array}{c}\text { Multi-DOF input } \\
\text { device with stylus pen }\end{array}$ \\
\hline Transfer function & $\begin{array}{l}\text { Incremental position } \\
\text { control }\end{array}$ & $\begin{array}{l}\text { Incremental position } \\
\text { control }\end{array}$ \\
\hline Left-right (k') force & $1 \mathrm{~N}$ & Not determined \\
\hline Left-right (k') range & $\pm 90^{\circ}$ & $\begin{array}{l} \pm 90^{\circ} \text { (limited by } \\
\text { Anubis) }\end{array}$ \\
\hline Left-right (k') accuracy & $\pm 1^{\circ}$ & Human-in the-loop \\
\hline Left-right (k') speed & $90^{\circ} / \mathrm{s}$ & $90^{\circ} / \mathrm{s}$ \\
\hline In-out force (e' / b') & $5 \mathrm{~N}$ & Not determined \\
\hline In-out range (e' / b') & $+70 \mathrm{~mm}$ & $\begin{array}{l}+85 \mathrm{~mm} \text { (within } \\
\text { operating field } 45 \mathrm{~mm} \text { ) }\end{array}$ \\
\hline In-out accuracy (e' / b') & $\pm 0.5 \mathrm{~mm}$ & Human-in the-loop \\
\hline In-out max. speed (e' / b') & $70 \mathrm{~mm} / \mathrm{s}$ & $80 \mathrm{~mm} / \mathrm{s}$ \\
\hline (Cr)clockwise torque (f' / i') & $0.1 \mathrm{Nm}$ & Not determined \\
\hline (C)clockwise range (f' / i') & $\pm 90^{\circ}$ & $\pm 150^{\circ}$ \\
\hline (C)clockwise accuracy (f' / i') & $\pm 1^{\circ}$ & Human-in the-loop \\
\hline (C)clockwise rotational speed & $90 \% \mathrm{~s}$ & $130 \% / \mathrm{s}$ \\
\hline Grasp force (g' / l') & $0.5 \mathrm{~N}$ & $\begin{array}{c}<0.5 \mathrm{~N}, \text { could not be } \\
\text { measured but is } \\
\text { probably too small }\end{array}$ \\
\hline
\end{tabular}

The forces that can be applied by the instruments are mainly determined by their stiffness. The drive train exerts sufficient force. Within this work no further research has been performed on this topic. Future work could address the opportunity to increase the forces by improving the instrument stiffness.

As discussed before in Section 3.5.8, the accuracy of the robotic system is impeded by the presence of hysteresis. The instruments are actuated by Bowden cables that are difficult to control due to friction and compliance. For that reason the initially defined required accuracy is not achieved. However, since a human operator is in the control loop, the 
instruments can be accurately positioned. This requires some training. In the next section and in Section 6.2 the performance of the robotic setup is verified in usability tests.

\subsection{Usability test}

This section describes the experiment conducted to determine the intuitiveness, the usability, and the optimal settings of our robotic flexible endoscope with steerable instruments for natural orifice surgery. In Figure 5.19 our complete system setup is depicted as used in the experiment.
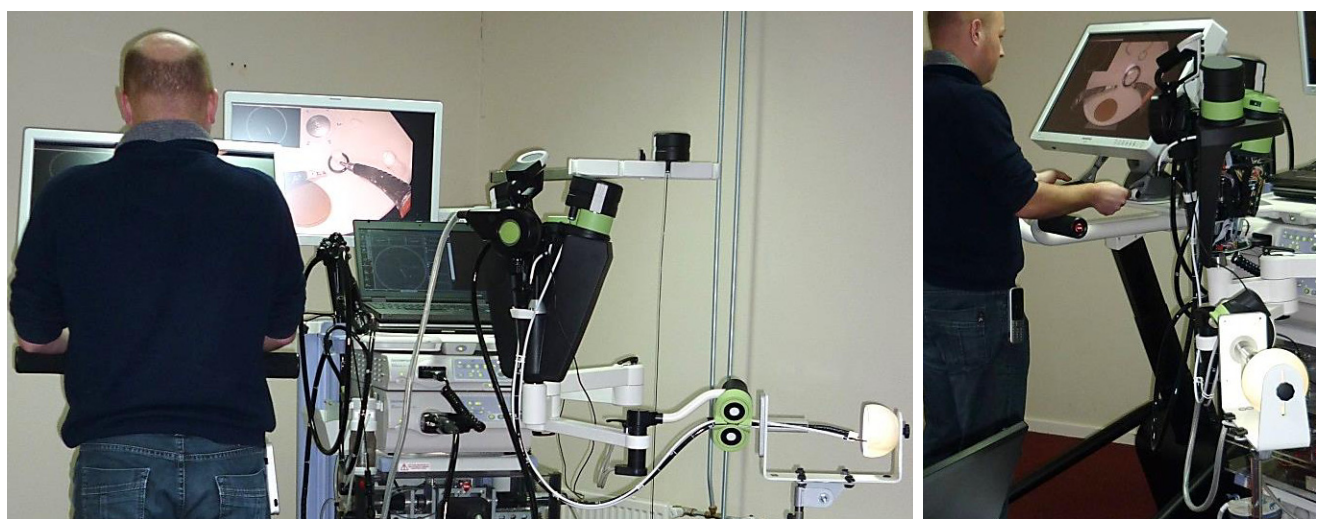

Figure 5.19 Experimental setup robotic flexible endoscope for experimental therapy

\subsubsection{Experimental setup}

The full robotic setup, as described in this chapter, is compared with the conventional setup and to the robotic setup as described in Chapter 4, which consists of robotic control of the endoscope and manual operation of the instrument. Besides our goal to assess our full robotic setup for complex bimanual tasks, this experiment allowed us to evaluate our final design of the shaft manipulation module (Section 4.7) and to evaluate if steerable instruments can enhance not only experimental therapy but also existing therapy.

The first two tasks in this experiment are executed to be able to compare all experimental setups. These tasks are comparable with the ones performed in the experiment as described in Section 4.6. The same training model (Figure 5.20) has been used. First, participants had to perform a pick-and-place task by transferring an O-ring from one pawn to another (Task 1). Second, they were asked to guide a ring along a tortuous wire loop (Task 2). Task 1 was slightly different compared with the one in Section 4.6 as the inner pawns are used instead of the ones on the outer ring. Rationale for this change is that in the previous experiment a colonoscope was used in all experimental settings, whereas in this experiment a gastroscope is used for all setups that has a smaller bending section and is not able to reach the outer ring. 

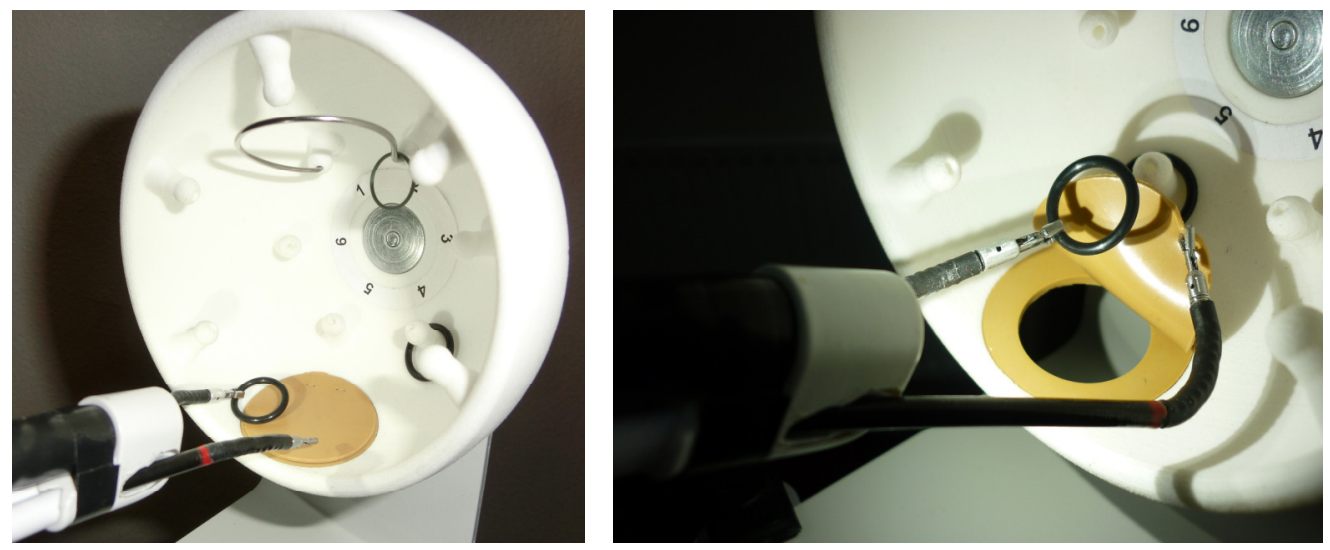

Figure 5.20 Training model for experimental tasks

Task 1 and task 2 have been performed with the following three setups, as depicted in Table

5.7 in the next section:

1. Conventional steering.

Left hand control of navigation wheels and right hand control of the shaft. An assistant controls the grasper of a traditional instrument. We used this method as a reference for the robotic setups.

2. Robotic endoscope for existing therapy.

Single-handed robotic steering and shaft control (4-DOF) with a Phantom Omni controller and manual control with the other hand of a traditional instrument.

3. Robotic endoscope for experimental therapy.

Single-handed robotic steering and shaft control (4-DOF) with a Phantom Omni

controller and robotic control of one steerable instrument with the other hand (4-DOF) with another Phantom Omni controller.

A setup could have been added that allows robotic steering and shaft control (4-DOF) with a Phantom Omni controller with one hand (like setup 2 and 3) and manual control of an ANUBIS steerable instrument (Figure 1.8) with the other hand. However, research of Reilink et al. [2013] already showed that robotic control is preferred if compared with manual control of a steerable instrument.

After completion of task 1 and 2 with setup 1, 2 and 3, participants had to perform two tasks that were only performed with the robotic endoscope for experimental therapy with two steerable instruments (setup 4, see Table 5.7). These tasks required advanced bimanual manipulation:

- $\quad$ Task 3 - bimanual transfer task

Pick up an O-ring from a pawn with the right instrument, pass it to the left instrument, and place it with the left instrument on a designated pawn (Figure 5.20, left).

- $\quad$ Task 4 - bimanual pick-and-place task

Pick up an O-ring from a pawn with the left instrument, lift with the right instrument a rubber sheet that simulates tissue, position the O-ring with the left instrument in the opening underneath the rubber sheet (Figure 5.20, right).

These tasks were added to obtain knowledge about the ability of participants to control in total 12 degrees of freedom, and to assess the added value and the limitations of our robotic 
flexible endoscope with steerable instruments. The robotic traditional (non-steerable) instrument (Figure 5.2) is not used in setup 4.

In all experimental conditions a modified (Section 5.5.5) flexible gastroscope (Evis Exera II GIF-H180, Olympus, Tokyo, Japan) and a standard imaging unit (Evis Exera II CLV-180, Olympus) were used. In setup 1 and 2 a standard grasper (FD-410LR, Olympus) protruded about $2 \mathrm{~cm}$ from the tip of the endoscope. Instrument manipulation was limited to opening and closing the grasper. In setup 3 one steerable instrument and in setup 4 two steerable instruments were available that are robotically controlled. In all tasks if the ring was dropped, it was penalized by placing the ring back by the examiner on the last pawn it was positioned on.

Participants were engineers and supporting staff of DEMCON, without medical background, without experience in endoscope handling, without experience in controlling one of the robotic setups, and who did not participate in one of the previous experiments. In this way intuitiveness could be measured. Each setup was introduced with a short demonstration and the opportunity to ask for advice on usage. Subsequently, the nine participants (aged 24-69 years, 2 women and 7 men) were allowed to practice task 1 as well as task 2 once before its evaluation was started. Participants had not the opportunity to practice task 3 and 4, since it would take a lot of time. It did not matter how fast the bimanual tasks were executed, but whether the participants managed to accomplish the tasks. For practical reasons the available time for task 1 and 2 was restricted to five minutes, and for task 3 and 4 to ten minutes. All participants were allowed to adapt the height of the elbow rests of the master console, and to reposition the monitor and the Phantom Omni input controllers.

After completion of our pilot experiment it appeared that manipulation of setup 3 and 4 required a lot of instruction because of the many degrees of freedom that needed to be operated. Data overload was prevented by confronting the participant first with the other setups. In this way they could get accustomed to the type of tasks and the training model. Half of the population started the experiment with the conventional setup (setup 1), the other half with the robotic endoscope for existing therapy (setup 2). Thereafter setup 3 was used and at last the bimanual tasks were performed with setup 4.

Our focus in task 1 and 2 was to compare the usability of setup 1,2, and 3 by evaluating the effectiveness, efficiency, and satisfaction. These three factors were also evaluated in the experiments discussed in Section 3.6.1 and 4.6. In this experiment the following dependent variables were measured:

- Tasks completed (effectiveness)

- Time required for tasks (efficiency)

- Subjective workload analysis measuring mental and physical demand, performance, effort and frustration (efficiency). Based on a modified NASA Task Load Index [Hart and Staveland, 1988; NASA TLX, 2011], as shown in Appendix B.1.

- Rank interfaces according to preference (satisfaction)

- Questionnaire by interview related to intuitiveness, ease of use, and ergonomics (satisfaction), as indicated in Appendix B.3.

After testing of each condition the participant was interviewed and the scoring of the workload was documented. The experiment took approximately 1,5 hour per participant. 


\subsubsection{Results and discussion}

The quantitative results and the comments that are made, indicate that robotics enhances the usability of flexible endoscope control by novices in therapeutic tasks. First the quantitative results of the experiment, that are depicted in Table 5.7, will be discussed.

Table 5.7 Quantitative results experiment

\begin{tabular}{lcccc}
\hline Setup & 1. Conventional & 2. Robotic single-handed & 3. Robotic \\
1steer. instrument & 4. Robotic \\
2 steer. instruments
\end{tabular}

The low sample size $(n=9)$, the large variation in individual scores on task performance and perceived workload measures, and the absence of normal data distributions on these measures across the three set-ups made us decide to base the analyses on ranked data using non-parametric tests. Separate Friedman's ANOVA's were conducted to compare the three setups on respectively task 1 , task 2 , and perceived workload. In case of a significant effect, Wilcoxon signed-rank tests were conducted to compare the scores between two set-ups. A Bonferroni correction was applied to control for chance capitalization, resulting in a .0167 level of significance for the contrast analyses. Overall significance level was $p=.05$. The results are summarized in Table 5.8 and discussed afterwards.

Table 5.8 Summary table statistical results $p$-values

\begin{tabular}{|c|c|c|c|c|c|c|}
\hline & \multicolumn{2}{|c|}{$\begin{array}{c}\text { Task } 1 \\
\chi 2(\mathrm{~N}=7,2)=2.57, p=.31\end{array}$} & \multicolumn{2}{|c|}{$\begin{array}{c}\text { Task. } 2 \\
\chi 2(\mathrm{~N}=9,2)=6.23, p=.046\end{array}$} & \multicolumn{2}{|c|}{$\begin{array}{c}\text { Workeload } \\
\chi 2(\mathrm{~N}=9,2)=3.56, p=.187\end{array}$} \\
\hline & 1. Conv. & 2. Single & 1. Conv. & 2. Single & 1. Conv. & 2. Single \\
\hline 1. Conv. & - & .859 & - & .050 & - & .032 \\
\hline 3. Steerable & .237 & .128 & .050 & .624 & .405 & .191 \\
\hline
\end{tabular}


Performance of the participants on task 1 did not differ significantly across the three setups, $\chi 2(\mathrm{~N}=7,2)=2.57, p=.31$. Posthoc analyses indicated that performance of single-handed robotic control (setup 2) was not significantly better than performance on the conventional setup (setup 1), $Z=0.18, p=.859$. Participants also did not perform better on the robotic setup with one steerable instrument (setup 3) than on the conventional setup, $Z=1.18$, $p=.237$. No significant difference in performance was also found between both robotic setups, $Z=1.52, p=.128$.

On task 2 , the performance scores differed significantly across the three setups, $\chi 2(\mathrm{~N}=9$, $2)=6.23, p=.046$. Posthoc analyses showed that the difference in performance approaches significance between setup 2 and the conventional setup, $Z=1.96, p=.050$, and between setup 3 and the conventional setups, $Z=1.96, p=.050$. It suggests that both robotic setups are more efficient than the conventional setup. No significant difference was found between the robotic setups, $Z=0.49, p=.624$.

The perceived workload did not differ significantly among the three setups, $\chi 2(\mathrm{~N}=9$, $2)=3.56, p=.187$. Posthoc analysis showed that the difference in workload approached significance between setup 2 and the conventional setup, $Z=2.14, p=.032$, suggesting that the perceived workload was lower for the single-handed robotic setup. There was no significant difference between setup 3 and the conventional setup, $Z=0.83, p=.405$. The difference between both robotic setups was also not significant, $Z=1.31, p=.191$.

All participants successfully completed task 1 and 2 with setup 1 and 2 . Two participants did not finish task 1 within 5 minutes with setup 3 , so effectiveness is negatively affected by setup 3 in our experiment with novices.

If traditional endoscope control (setup 1) is compared with single-handed robotic control (setup 2) the results are in line with the results of the experiment described in Section 4.6. However, the difference in scoring of the dependent variables is smaller. In task 1 no significant difference is found in efficiency. For task 2 robotic setup 2 is still faster. It is, like in the previous experiment, about twice as fast as the conventional setup. The workload scoring of the robotic setup is also better than the conventional setup, but less evident. Probably the deviation in the results are caused by the changes that are made in task 1 , as described in 5.6.1. Participants had more control with the conventional setup in task 1, because of the smaller angulation required of the tip and as a consequence the smaller angulation movements and forces required by the operator.

If the quantitative results of the robotic setup with one steerable instrument (setup 3) are compared with the results of the conventional setup, it may be concluded that robotics with a steerable instrument enhances flexible endoscope control by novices in therapeutic tasks. However, only for task 2 a significant difference was achieved in the outcome measures. The differences between both robotic setups with regard to task 1, task 2, and perceived workload did not show any significant differences.

After evaluation of setup 1,2, and 3, participants have been asked to rank them to preference (Table 5.7). The scorings underpin the conclusions as discussed above. None of the participants preferred the conventional setup. In general the participants felt that "the conventional setup is not intuitive; it is a trial and error process". Small movements with the navigation wheels have to be made to experimentally determine the coupling to the endoscope tip. Additionally, accuracy is limited because of the pretensioned cables that make the tip move back in an angulated position. The angulation lock can be helpful, but the drawback is that additional torque has to be applied to actuate the navigation wheels. The ranking of setup 2 and 3 was about equally divided. Setup 2 was valued because it was easy to understand and easy to handle, whereas setup 3 required more mental effort and some time to get enough manipulation skills to perform the tasks. Nevertheless, setup 3 was 
appreciated because of its freedom of movement and its potential to perform advanced procedures. Both robotic setups are valued for their single person setup. The need of an assistant in the conventional setup is a disadvantage.

Task 3 and 4, that required manipulation of two steerable instruments, were only executed with setup 4. In total seven out of nine participants performed the tasks. One participant stopped very quickly performing these tasks, because it was too demanding for him and he did already not succeed in finishing task 1 . The other participant had to leave because of time constraints. The other seven participants successfully completed task 3 and 4. Although time was not critical, it was recorded to be able to compare performance of task 3 and task 4. Task 4 was estimated to be more difficult than task 3 and for that reason always performed last. Although task 4 was estimated to be more difficult, the procedure time was shorter compared with task 3. Possibly due to a steep learning curve. This assumption was confirmed by the fact that first participants were grumbling when they used a steerable instrument in setup 3 with task 1 and 2, whereas in the end in performing task 4 people were enthusiastic about being successful in difficult bimanual manoeuvring.

In the remainder of this section, the qualitative data as obtained from the experiment is discussed to allocate the added value of our setups and the points of improvement.

In addition to the remarks made during the previous experiment, as discussed in Section 4.6.2, in this experiment suggestions were provided by the participants to improve shaft control. One of the participants suggested that like for tip steering, coupling between input direction and shaft rotation could be made adaptable to comply with user preferences. For him current mapping was not intuitive. Another participant suggested that the rotational position of the shaft should be fed back, like the bending position of the tip of the endoscope (Section 3.5.7). In the current setup the operator has to look to the shaft manipulation module to see if the end position already has been reached. Preferably a diagram is added to the graphical user interface to provide the operator with visual feedback without having to look away from the monitor.

The speed of steering, rotating and translating the endoscope is fine according to most participants. One participant suggested to implement an user set gain to adapt speed to personal preferences. Another one proposed precision enhanced positioning by implementing an algorithm in which the displacement range of the endoscope is dependent on the input speed of the pen of the multi-DOF input device, like in mouse pointer acceleration. It is comparable to the non-linear rate control algorithm as discussed in Section 3.6.3, that combines a low gain for fine movements and a higher gain with higher velocity changes for large movements. Casiez et al. [2007] have evaluated pointer acceleration and conclude that it slightly improves performance time in position control, because of reduced clutching. Nothing was concluded with respect to accuracy. Future experiments have to be executed to assess if the concept of pointer acceleration is beneficial for our robotic endoscope.

As already noticed in the previous experiment with the robotic endoscope for existing therapy (Chapter 4) a rotatable grasper would allow the operator to grasp the ring at any position. In none of the setups in this experiment this functionality was available. The orientation of the grasper of the steerable instruments is determined by the position of the steerable instrument in space. A second articulation of the steerable instrument, perpendicular to the current one, would enable a user controlled grasper orientation. Additionally it would allow a better coupling of hand movements to instrument movements. In the current setup the user has to perform decoupled bending and axial rotation of the steerable instrument to bring the grasper to another position in the XY-plane. Preferable it should be copied from endoscope control (Chapter 4) in which the control handle of the 
input device resembles the endoscope tip and movements of the endoscope tip and of the physician's hand are matched to obtain intuitive manipulation. On one hand the current 12 degrees of freedom in the full robotic setup are already hard to handle, on the other hand with the addition of one degree of freedom per steerable instrument manipulation will be more intuitive. One of the participants confirmed the need of an extra degree of freedom by remarking: "System is magisterial if a second articulation for the steerable instruments would be added". Another noticed that we need "an endoscope in an endoscope system". Unfortunately we were restricted to the degrees of freedom that were provided by the steerable instruments of the ANUBIS NOTEScope of Karl Storz.

Performance of the participants might be related to the ability to adapt to the dynamic limitations of the robotic flexible endoscope. Response time, backlash, hysteresis, and stiffness are components that influence the feeling of being in control. The dynamic characteristics of the shaft manipulation module, in terms of speed, accuracy and response time, are in general judged by the participants as being fine. One participants complained about movements being a little bit jerky. It appeared that stiffness of the swivel arm as used in the experiment is low and that vibrations are initiated by translational and rotational movements of the shaft manipulation module.

Although the majority of the participants thought the dynamic characteristics of shaft manipulation were fine, it should be noted that the addition of working channels to the endoscopic platform stiffens the endoscope tip, especially when instruments are inserted. The range of motion is badly influenced. It did not limit the performance in this experiment, but further developments with regard to the endoscopic platform should address this problem.

The dynamic performance of the steerable instruments was judged as being insufficient by most participants. Remarks that support that conclusion are: "It feels like moving something that is heavy which subsequently has overshoot", "It feels like a car with backlash in its steering wheel", and "Fine sense of knowing when the instrument starts to move is missing". Like already discussed in Section 4.5 force feedback via the multi-DOF input device, to imitate the kinematic and dynamic limitations of the steerable instrument, could enhance the feeling of being in control. Additionally, improvements can be made to the mechanical characteristics of the current setup. Friction between steerable instrument and the working channel is the main cause for reduced user control. Friction causes hysteresis that leads to response delay and limited accuracy. Understanding the dynamic behaviour of the instrument inside the working channel might assist in improved control, as discussed by Khatait [2013]. Reilink [2013] proposes visual servoing by estimating the instrument position from the endoscopic images. The latter method is advantageous because it can adapt to variations in the hysteresis parameters that may occur during the intervention.

As discussed in the previous paragraph steerable instrument control is non-optimal. On one hand because of the dynamic characteristics, on the other hand because of the missing articulation. In this paragraph the input device is discussed as another point of improvement. By alternately pressing one of the two hold-to-run buttons on the pens the participant is able to switch between endoscopic platform, traditional instrument, and the left and right steerable instrument. Finding out which button to press to couple particular degrees of freedom to the multi-DOF input devices is sometimes difficult. Additionally, often the left and the right hand are both in use and coupled to different degrees of freedom. As discussed in Section 4.3 bimanual coordination of hand movements virtually always requires training. One participant compared controlling our setup with playing the piano. No suggestions for improvement were proposed during the experiment. Future 
experiments should evaluate how fast participants get used to the multi-DOF robotic setups by determining the learning curve.

Holding the pen in a power grasp was fine. The hold-to-run buttons could easily be actuated with the thumb. However, most participants had problems with operation of the index finger joystick for opening and closing the grasper. The need to press the hold-to-run button while operating the grasper is cumbersome. Additionally, the thumb joystick was positioned too close to the buttons, so it was difficult to actuate it with the index finger, as shown in Figure 5.21.

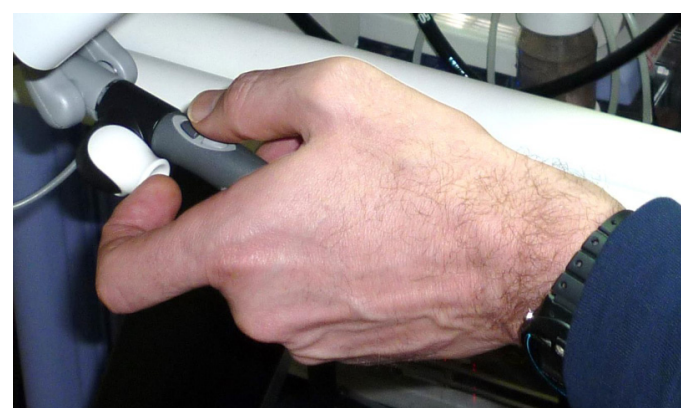

Figure 5.21 Operation thumb joystick with index finger

One suggested to position the buttons on the bottom side and actuate them with the index finger, while the thumb is used to actuate the joystick for grasping. Other participants suggested alternative input devices, like a trackball, mouse wheel, or a pistol trigger.

Visual cues on the instruments might assist in improved dexterity. The operator is better able to estimate the current pose of a steerable instrument and knows in which direction the pen has to be moved to initiate displacement. Currently, two problems were faced in steering. First, if the steerable instrument was in a straight position, participants could not estimate in which direction it would bend if it was operated. Second, participants did not know exactly when the steerable instrument protruded far enough from the endoscope tip to be able to actuate grasping and bending, as discussed in Section 5.5.4. Both problems will probably be eliminated if clear markers will be added to the instrument. A marker (e.g. a red spot) could be added to the bending section of the steerable instrument at a position in the plane of bending. Another marker (e.g. a red ring) could indicate when grasping and bending is available whenever the red ring is in view. Although some visual cues were available and instructions were provided how to use them, some participants still got lost. An alternative solution might be to add position feedback of the steerable instruments to the graphical user interface. As confirmed by one participant this might increase the workload because of data overload. In future work alternative modalities may be researched for providing feedback.

In our experiment the participants did not notice any obvious benefits of one of the camera setups, moving (setup 1 and 2) or stabilized (setup 3 and 4), as discussed in Section 5.3. Maybe the outcome would have been different if the participants did not have to adapt the position of the endoscope (camera) during the procedure because of the limited range of the steerable instruments. Some of the participants remarked that $3 \mathrm{D}$ vision would be very helpful. This is supported by the fact that participants were often not able to grasp the Oring in one time. The relative position between grasper and O-ring was often estimated incorrectly, especially during the first attempts. After some time participants performed better by using alternative cues, like dropshadows on the training model and relative size of the grasper compared with the O-ring. 
All participants were unanimous in their opinion that the master console positively contributed to a good working posture. Despite the fact that in the experiment participants had to stand, our participant of 69 claimed: "the master console is very comfortable and I could perform these tasks for a whole day, if required". The elbow rests were used by all of the participants, particularly in instrument manipulation. During shaft advancement the arm was lifted to allow translational movements of the forearm. One participant proposed rotatable elbow rests. Drawback of this solution might be its instability in fine manipulation tasks. The participants were positive about the position of the monitor, only one positioned it more straight up. The distance between the eyes and the monitor was fine according to the participants. Possibly this is related to the task that is performed. As indicated by some participants in navigational tasks the operator probably prefers a larger distance to have a better overview.

As discussed in Section 5.5.7 the multi-DOF input devices are positioned behind the monitor. The positions of the stylus pens and the steerable instruments are matched to suggest that the steerable instruments are an extension of the arm. Participants did not experience that particular feeling from the start, but indicated that during performance of the tasks dexterity was rising. As previously discussed, dexterity will probably further improve if an extra bending degree of freedom is implemented in each steerable instrument. It will allow a better coupling of hand movements to instrument movements.

\subsection{Conclusion and recommendations}

The results of the usability tests with novices show that robotic technology improves usability of flexible endoscope control. In existing therapeutic tasks single-handed robotic endoscope control with manual instrument control (setup 2) is superior compared with conventional manipulation (setup 1) and full robotic manipulation with a steerable instrument (setup 3). Setup 1 as well as setup 3 require constantly thinking about what to do. Additionally the mechanical and control characteristics of both setups negatively influence results. However, participants did not indicate having a clear preference for setup 2 . According to them, setup 3 has a lot of potential.

Setup 4 supports performing complex bimanual surgical tasks, because of the extra degrees of freedom available, and the ergonomic user interface. Some improvements are needed in our advanced endoscopic intervention platform, but in its current embodiment difficult tasks can already be completed that are not feasible with existing flexible tools. If the recommendations, as discussed in the remainder of this section, are implemented the enabling technology for performing advanced natural orifice surgery becomes available. However, first all functionality needs to be tested by clinical experts to complement the current list of recommendations. The next chapter discusses the evaluation of our robotic flexible endoscope by clinical experts, who had to perform the same experiment as the novices in this chapter. It is a first step in assessing the clinical added value of our system. Future experiments have to address all clinical aspects. These clinical experiments are outside the scope of this work. Suggestions for functions that need to be tested and questions that need to be answered in these experiments are however discussed in Section 6.2.3.

From our novices experiment, as described in this chapter, points of improvement are derived that could optimize our robotic flexible endoscope. These are listed below. It was unfortunately not feasible to implement (some of) the improvements before our experiment with clinicians (Chapter 6), because the experiments with novices and experts were executed right after each other. If feasible within the timeline, it is recommended to implement these improvements before future tests with clinical experts. Some improvements are however 
estimated to require a lot of additional research and development and are indicated therefore as future work. Points of improvement are:

- The coupling direction between shaft rotation and pen rotation should become a user setting.

- The scaling factor (gain) between input and output speed of endoscope control should become a user setting.

- Pointer acceleration should be implemented in incremental position control to reduce clutching.

- Besides feedback on direction and flexion of the tip of the endoscope, feedback on the degree of rotation of the shaft with respect to the centre position should be implemented.

- The instrument should have a better indication with regard to the minimum protrusion length from the endoscope tip to be able to bend the steerable instrument and open the grasper.

- The steerable instrument should have an indication of the orientation in space. It supports the operator in predicting the bending direction if the steerable instrument is in a straight position.

- The coupling of pen movements to endoscope movements should be adaptable by the operator. The graphical user interface could provide this functionality.

- Visual servoing should be implemented to improve the dynamic performance of the steerable instruments.

- The stiffness of the swing arm should be enlarged to prevent vibrations initiated by translational and rotational movements of the shaft manipulation module.

- The suitability of a rotatable elbow rests for navigational as well as fine manipulation tasks should be researched.

- The thumb joystick on the stylus pen for operation of the grasper needs to be revised. Its position should be changed or a new principle has to be designed.

- An additional bending degree of freedom should be added to the steerable instrument. (future work)

- The working channels should be integrated in the endoscopic platform in a way that it does not stiffen the bending section. (future work)

All additions and adaptations are expected to improve the robotic flexible endoscope. However, they first need to be evaluated in experiments to assess their performance and usability. 



\section{Evaluation by clinical experts}

This chapter discusses the results of the usability tests performed by clinical experts with the integrated robotic flexible endoscope. The quantitative results show that physicians perform significantly better with a standard flexible endoscope than with a robotic flexible endoscope with regard to efficiency, effectiveness, and satisfaction on basic tasks that simulate current clinical practice. The dynamic performance of the robotic setup impedes the feeling of being in control and should be improved to be of real added value and to be accepted in clinical practice. However, physicians expect that their dexterity with the robotic systems will rapidly increase by practicing. Additionally, the suggested improvements and the opportunities for computer enhanced control are expected to significantly improve current performance and will further expand the clinical capabilities of the robotic flexible endoscope. Because of the extra degrees of freedom available and the ergonomic user interface, difficult surgical tasks can be performed with the robotic flexible endoscope that are not feasible with existing flexible tools. 


\subsection{Introduction}

The experiments conducted in Chapter 3, 4, and 5 were performed with participants without medical background, without experience in endoscope handling, and without experience in controlling one of the robotic setups. Until now we were mainly interested in evaluation of the intuitiveness and usability of manipulating the robotic flexible endoscope. Novices have well contributed to acquiring knowledge in that area. This chapter discusses the current status of the evaluation of the clinical added value. All functionality of the robotic flexible endoscope needs to be tested in clinical relevant procedures by experts. This will be a stepwise approach:

1. Usability tests in tasks that replicate clinical tasks, like the experiments performed with novices.

2. Experiments on training models and virtual reality simulators to test usability, performance, and learning curves in clinical procedures.

3. In vivo animal tests to evaluate usability and performance in clinical procedures.

4. In vivo human subject tests to evaluate usability and performance in clinical procedures.

In this work the robotic setups for existing and experimental therapy have been evaluated by gastroenterologists in usability tests, as described in Section 6.2. The usability tests with experts of the robotic steering module for diagnosis are currently performed by a $\mathrm{PhD}$ candidate of Technical Medicine of the University of Twente. In addition she will perform with this setup also evaluation step 2, 3, and 4. In Section 6.3 some preliminary results and an outlook to future work will be presented.

Further experiments (evaluation step 2, 3, and 4) with the robotic flexible endoscope for existing and for experimental therapy need to be executed but are not planned yet. Probably these will also be performed by a $\mathrm{PhD}$ candidate of Technical Medicine in collaboration with clinical experts from academic hospitals.

\subsection{Evaluation robotic flexible endoscope for existing and experimental therapy}

This section describes the experiments conducted to determine the clinical feasibility of our robotic endoscope in performing therapeutic procedures. To judge if robotics can enhance existing therapy, conventional control is compared with two different robotic setups in tasks that require advanced endoscope maneuverability. Additionally, some bimanual tasks are performed to assess our full robotic system with steerable instruments in experimental therapy. In Figure 6.1 a picture is shown of a gastroenterologist performing an experiment with the full robotic flexible endoscope. 


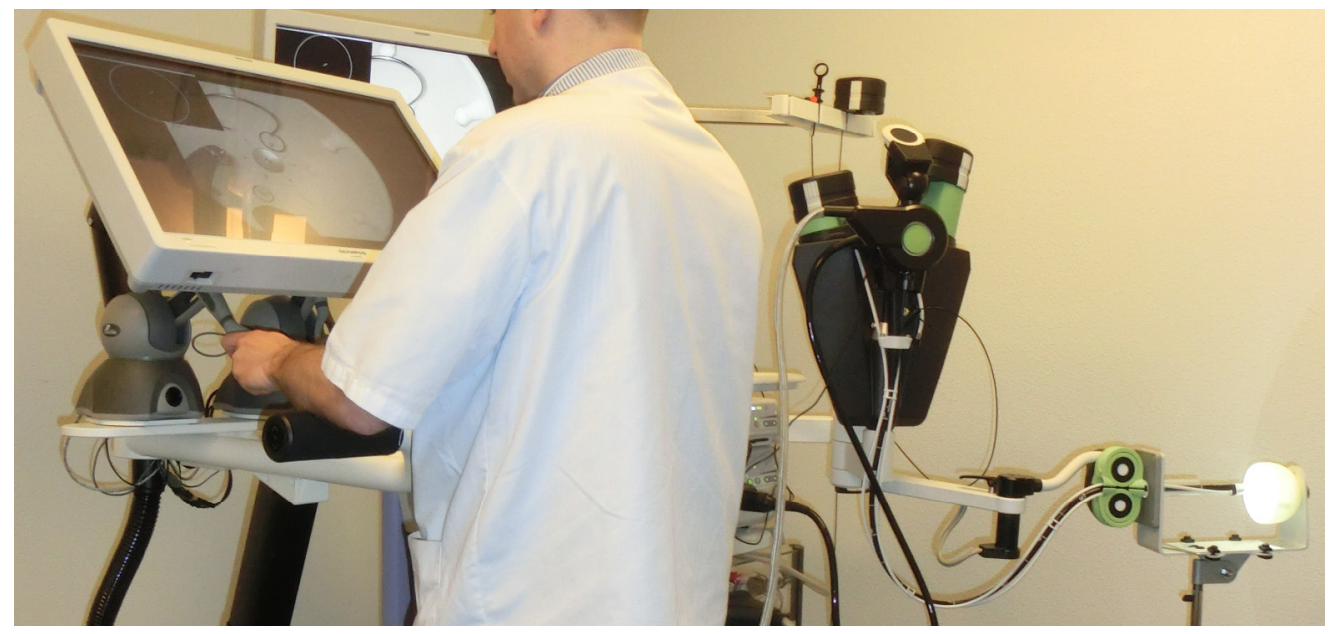

Figure 6.1 Experimental setup for clinical experts to test the full robotic flexible endoscope

\subsubsection{Experimental setup}

The experimental setup for evaluation of our integrated system by physicians was almost identical to the one for novices that was discussed in Section 5.6.1. Only some questions related to clinical practice were added to the interview, as indicated in Appendix B.4, and the time for performing the tasks was not restricted.

Participants were recruited from the University Medical Centre Utrecht (UMCU). In total 9 gastroenterologists (aged 29-58 years, 1 woman and 8 men) tested the system. Their experience level ranged from 3 to 29 years of patient experience, while performing 300 to 1000 scopies each year. Except for one, all participants perform gastro- and colonoscopies about equally often. One participant mainly performs gastroscopies.

\subsubsection{Results and discussion}

The quantitative results(Table 6.1) in our experiments with experienced physicians show that usability of conventional flexible endoscopy, in terms of efficiency and satisfaction, is significantly better compared with the robotic setups. This conclusion is confirmed in the interviews.

Despite the fact that the results favour the conventional setup, the potential benefits of our robotic systems in advanced complex procedures are recognized by the participants. This conclusion is supported by remarks that "for us it was a feast, to get acquainted with this exciting development", and "the transition from fiber- to videoscope late 90 s also required some adaptability, it is just a matter of getting used to the new technology". Additionally participants expect that their dexterity with the robotic systems will rapidly increase by practicing. "During performing the tasks my skills improved. I expect that after a while controlling the robotic devices will not require any mental effort anymore". These and other qualitative results are discussed in the remainder of this section. We limit ourselves to the additions with respect to the novices experiment. First the quantitative results of the experiment will be further discussed. 
Table 6.1 Quantitative results experiment

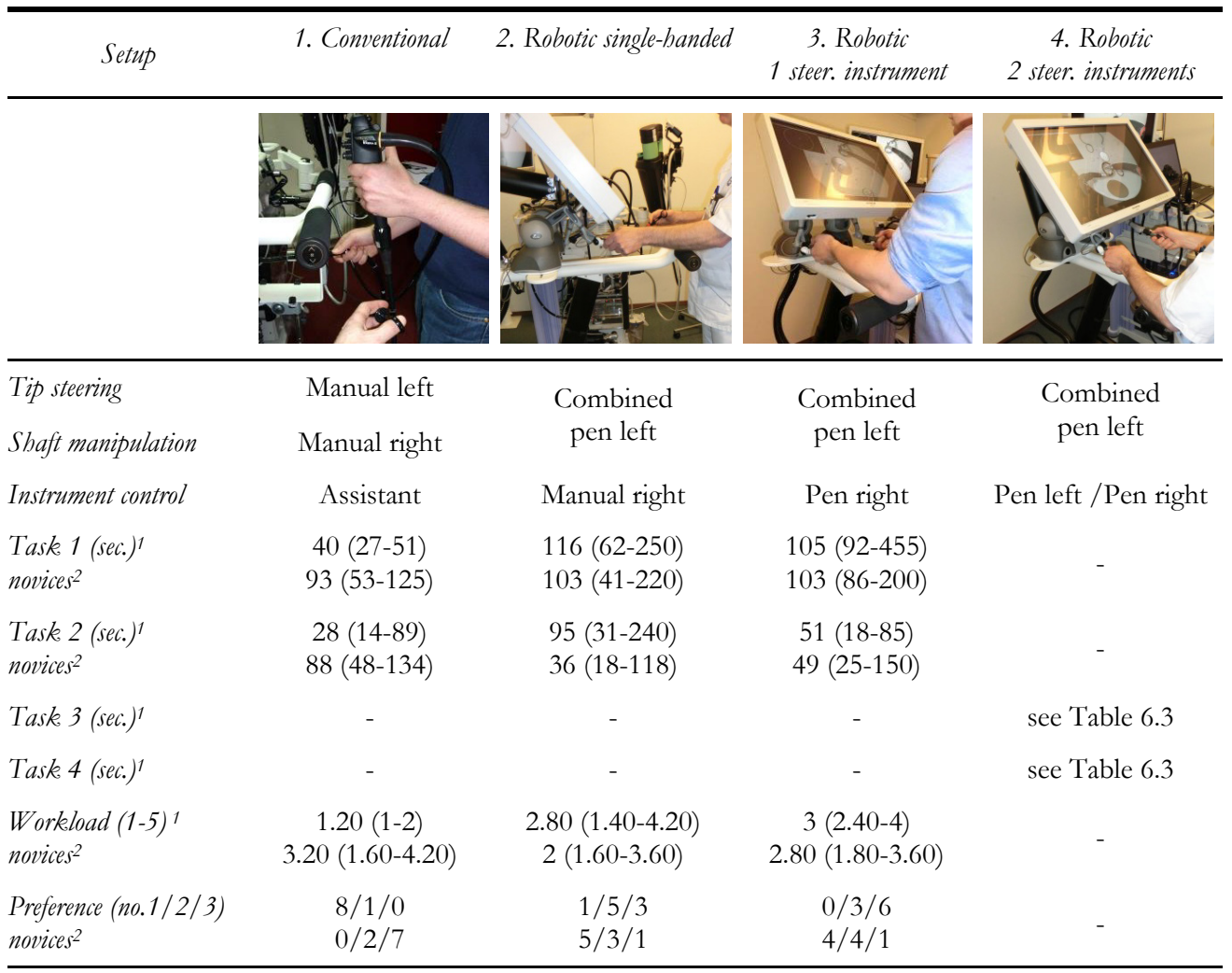

${ }^{1}$ V alues are represented as median (range), ${ }^{2} V$ alues are copied from Table 5.7

The low sample size $(n=9)$, the large variation in individual scores on task performance and perceived workload measures, and the absence of normal data distributions on these measures across the three set-ups made us decide to base the analyses on ranked data using non-parametric tests. Separate Friedman's ANOVA's were conducted to compare the three setups on respectively task 1 , task 2 , and perceived workload. In case of a significant effect, Wilcoxon signed-rank tests were conducted to compare the scores between two set-ups. A Bonferroni correction was applied to control for chance capitalization, resulting in a .0167 level of significance for the contrast analyses. Overall significance level was $p=.05$. The results are summarized in Table 6.2 and discussed afterwards.

Table 6.2 Summary table statistical results $p$-values

\begin{tabular}{|c|c|c|c|c|c|c|}
\hline & \multicolumn{2}{|c|}{$\begin{array}{c}\text { Task } 1 \\
\chi 2(\mathrm{~N}=8,2)=12.25, p=.001\end{array}$} & \multicolumn{2}{|c|}{$\begin{array}{c}\text { Task } 2 \\
\chi 2(\mathrm{~N}=8,2)=8.97, p=.007\end{array}$} & \multicolumn{2}{|c|}{$\begin{array}{c}\text { Workload } \\
\chi 2(\mathrm{~N}=8,2)=12.25, p=.001\end{array}$} \\
\hline & 1. Conv. & 2. Single & 1. Conv. & 2. Single & 1. Conv. & 2. Single \\
\hline 1. Conv. & - & .018 & - & .018 & - & .007 \\
\hline 3. Steerable & .012 & .401 & .107 & .018 & .012 & .123 \\
\hline
\end{tabular}


Performance of the participants on task 1 differed across the three set-ups, $\chi^{2}(\mathrm{~N}=8$, $2)=12.25, p=.001$. Posthoc analyses indicated that performance on the single-handed robotic setup (setup 2) was significantly worse than performance on the conventional setup (setup 1), $Z=2.67, p=.008$. Participants also performed worse on the robotic setup with one steerable instrument (setup 3) than on the conventional setup, $Z=2.52, p=.012$. No significant difference in performance was found between both robotic setups, $Z=0.84$, $p=.401$.

Also on task 2, the performance scores differed significantly across the three setups, $\chi 2(\mathrm{~N}=8,2)=8.97, p=.007$. Posthoc analyses indicated that performance on setup 2 was significantly worse than performance on setup $1, Z=2.37, p=.018$. However, no significant difference was found between setup 3 and the conventional setup, $Z=1.61, p=.107$, whereas setup 3 scored significant better than setup $2, Z=2.37, p=.018$.

The perceived workload differed significantly among the three setups, $\chi 2(\mathrm{~N}=8,2)=12.25$, $p=.001$. Participants experienced the workload in setup 2 as significantly higher than in the conventional setup, $Z=2.68, p=.007$. This was also true for comparing setup 3 against the conventional setup, $Z=2.53, p=.012$. No significant difference was found between both robotic setups, $Z=1.54, p=.123$, suggesting that the perceived workload was similar for both robotic setups.

If we compare the efficiency, represented by procedure time and workload, the conventional setup performs significantly better than the robotic setups (setup 2 and 3). Possibly the tasks were too easy, as reflected in the short completion times. Our system is expected to be beneficial in tasks that require multi-DOF manipulation skills in advanced procedures. Experts were about 2.5 times faster with the conventional setup in task 1 as well as task 2, whereas novices in the previous experiment (Table 6.1 - small font) performed equivalent in task 1 and about twice as fast in task 2 with the robotic setups compared with the conventional setup. These results are confirmed by the significant lower workload scoring of experts in the conventional setup, whereas novices preferred the robotic setups. As one physician explained: "conventional control is in my spine and does not require any mental effort anymore".

If we compare robotic setup 2 with setup 3 it is remarkable that the robotic setup with a steerable instrument (setup 3) is significantly faster in task 2 than setup 2. The outcome might be influenced by learning effects, since setup 3 was always tested last as explained in Section 5.6.1. In task 1 and in the workload scoring no significant differences were found.

All participants successfully completed task 1 and 2 with setup 1 and 2. One participants did not start task 1 and 2 with setup 3, since finishing task 2 already took almost five minutes. The participant expected not be able to complete the tasks with setup 3, so effectiveness is negatively affected by setup 3 in our experiment with experts.

After evaluation of setup 1,2, and 3, participants have been asked to rank them to preference (Table 6.1) with regard to performing task 1 and 2. Except for one, all physicians prefer the current way of endoscope steering, because they are most familiar with that method. One participant preferred the single-handed robotic setup with the simple argument: "I like it and see the opportunities'. Other participants remarked that "for these tasks I would pick the conventional endoscope, however the learning curve is steep and for more difficult tasks I might have preferred one of the robotic setups" and "the robotic setups require another coordination and that is purely a matter of getting used to it". When comparing the robotic setups there was a small preference for the single-handed setup (setup 2). Participants indicated that this setup was more simple to control, although that has not been confirmed in the time scores.

As stated by Spaun in an experiment with a similar setup [March 2009], it should be noted that the results with the robotic setups are at the beginning of the learning curve. All participants were all very experienced with conventional flexible endoscopy. Additionally, 
our participants were educated to use torque steering and applied this in the conventional setup as well as in the robotic setups. In the robotic setups tip steering without rotating the shaft would probably have improved performance. These confounding factors probably have biased the results against the robotic setups, although the differences were large even so.

The learning curve of single-handed endoscope control was estimated by the physicians to be steep. The time available to get acquainted to full robotic control with steerable instruments was insufficient. The type of actions was not difficult according to the participants, but the number of actions that could be performed simultaneously appeared problematic. Often the degrees of freedom were actuated sequentially. In future research the learning curve steepness of robotic as well as conventional control should be determined. First, the expert level should be determined by the average performance from experts with the conventional steering method. Next, the learning curve to reach this expert level is determined for novice endoscopists with the robotic as well as the conventional setup. In this way, it is determined whether robot control leads to a shorter learning curve for novice users. In addition the final competence level and the workload score should be assessed and compared with conventional control.

Not all participants were able to perform task 3 and 4, that required manipulation of two steerable instruments with setup 4. Some of the participants had to leave because of time constraints, others did not expect to finish the task and did not try. Additionally, we faced technical problems with opening and closing the grasper of one of the steerable instruments. In total six out of nine participants experienced bimanual instrument handling in one or both of the tasks. In Table 6.3 an overview is shown.

Table 6.3 Participation and results of task 3 and 4

\begin{tabular}{lcccccccccc}
\hline Participant & 1 & 2 & 3 & 4 & 5 & 6 & 7 & 8 & 9 & Novices1 $^{2}$ \\
\hline Task.3 (sec.) & 210 & TC & TP & NT & DNF & TP & TP & TP & TP & $152(90-395)$ \\
Task 4 (sec.) & DNF & TC & TP & NT & NT & 220 & 650 & 450 & 480 & $144(105-300)$ \\
\hline
\end{tabular}

${ }^{1} \mathrm{~V}$ alues are copied from Table 5.7 and represented as median (range)

$D N F=$ did not finish, $T C=$ time constraint, $T P=$ technical problem, $N T=$ not tried

Although only a limited number of outcome measures were recorded, it is obvious that experts had trouble in handling the robotic flexible endoscope with two steerable instruments. When we compare it with the results of novices (Table 6.3), it might be concluded that experts are less able to adapt to the dynamic limitations of the robotic setup. Or to put in another way, experts tried to control the robotic endoscope in the same way as they control the conventional setup. In general, instrument movements were more aggressive compared with novices. In clinical practice the target is approached quickly and often corrections are needed to anticipate on movements of the intestines. Because of hysteresis, that leads to response delay and limited accuracy, physicians were limited in this ability with the robotic setup. Furthermore, the poorer outcomes of physicians in task 4 compared with novices can be explained by the fact that the grasper of the right steerable instrument did not function. Participants had to lift the sheet by pushing it aside instead of grasping it (Figure 5.20). This probably negatively influenced the outcome results.

The experiment was conducted with experienced gastroenterologists. The participants were very well capable in performing task 1 and task 2 of this experiment, since these tasks simulated clinical procedures in existing therapy with flexible endoscopes, like performing a 
polypectomy. However, task 3 and task 4, that required bimanual handling as faced in minimal invasive surgery, required much more effort. As also suggested by one of the participants, surgeons might perform better on these tasks. The concept of natural orifice transluminal endoscopic surgery that requires triangulation and independent manipulation of instruments is indeed more adopted by surgeons than by gastrointestinal endoscopists [Costamagna, 2010]. Gastrointestinal endoscopists are accustomed to working in line with their camera and light source because all instruments pass through working channels of the endoscope, whereas surgeons are accustomed to work with separated vision and acting, in larger spaces, and with multiple instruments and access ports [Rattner and Kalloo, 2006]. One of the participants mentioned that although he is used to coupled movements of endoscope and instruments, he liked the idea of a stabilized image at the operating site with decoupled instrument movements to have a better overview. An additional experiment to compare performance of surgeons with gastroenterologists would be highly relevant. Possibly, our user group of medical specialists in general surgery, cardiothoracic surgery, and urology, as formed in the beginning of this project, is a suitable reference. This experiment is allocated as future work.

According to the participants the master console contributes to improved ergonomics in therapeutic procedures. One of the participants said: "I can work much more relaxed". The opportunity to sit down in lengthy procedures is attractive. The position of the monitor close to the operator is fine and might even support in getting more focus in therapeutic tasks.

The clinical opportunities were discussed with the participants in the interview. In general the robotic systems could assist in tasks that require fine and difficult manipulation. To anticipate on patient movements, the robot should have no delay in response and high movement speeds must be achieved. For the robotic steering and shaft manipulation module these performance requirements are met. Dynamic performance of the steerable instruments should be improved to be clinically applicable. Participants had difficulties with position overshoot due to response delays, especially in the fine targeting tasks. Participants increased their input, thereby over-actuating the system which caused the instrument to pass the target.

For all robotic modules currently the parasitic movements are limiting the feeling of being in control. System movements do not exactly replicate the movements of the hand. To be accepted in clinical practice and to be of added value, the robotic systems should be characterized by reliability, predictability, accuracy, and dynamic performance. Current limitations should be taken away by improving the mechanical characteristics, like reduction of backlash and hysteresis, and by improving the control software, possibly by introducing intelligent (vision) algorithms in the feedback loop. Further research is required. According to the physicians no safety hazards are related to use of the robotic flexible endoscope. Very important is that the robotic modules can be decoupled within a few seconds. Positioning of the robotic modules close to the patient does not imply that the patient needs to be anesthetized.

Physicians were asked for clinical interventions that could benefit from robotic control. These are listed below. It should be noted that these procedures are suggestions and that the robotic system might need adaptation to be able to perform them. Future clinical evaluation of the robotic flexible endoscope should further address the limitations and opportunities.

- Polypectomy of large polyps.

These procedures are characterized by shortage of hands because of all combined movements of the endoscope, of the instrument within the endoscope, and the snare within the instrument. The single-handed robotic system (setup 2) could assist in 
controlling these degrees of freedom by the physician. Possibly a dedicated robotic polypectomy snare that is actuated by the robotic instrument manipulation module (setup 3) would further reduce required manipulation skills.

- Biopsy and polypectomy in areas that are difficult to approach.

Currently in therapy keeping the endoscope in position requires constant attention. According to one participant the big difference between the conventional and the robotic setups is that "keeping position is part of the job in conventional control, whereas in robotic control the effort is limited to getting into position". In case of difficult polypectomy, it is very helpful if the scope is stabilized in the right position and that from this position precise endoscope movements are still possible. Single-handed endoscope control (setup 2) fulfills that requirement. Additionally, being able to rotate the instrument independently from the endoscope would be very handy. Currently, the endoscope shaft has to be turned and as a consequence the image will rotate, and sometimes even the endoscope position is lost. A system that allows to rotate the instrument independently, like in setup 3, does not change the approach of the operating area.

- Endoscopic Retrograde Cholangiopancreatography (ERCP).

Easy three dimensional manipulation of a cannula catheter simplifies cannulation of the common bile duct. The robotic steering and shaft manipulation module (setup 2) could assist in positioning the endoscope in the right position (long stroke manipulation), and the instrument manipulation module (setup 3) could assist in fine manipulation of a dedicated steerable cannula catheter (short stroke manipulation).

- Argon plasma coagulation.

Our single-handed robotic system could assist in intuitive steering along a trajectory and maintaining the right distance between the coagulation probe and tissue. Dexterity can be further improved by implementation of vision based algorithms and haptic guidance.

- Endoscopic Mucosal Resection (EMR).

Piecemeal resection of large lesions requires dexterity. Our setup for single-handed robotic control of the endoscope (setup 2) could assist in these procedures, while the instrument is manipulated manually by the physician.

Procedures that were suggested by physicians that could benefit from dexterous bimanual instrument manipulation (setup 4) are listed below. In general these are tasks in which tissue blocks the approach to the surgical site. One instrument is used to expose the operating field, while the other instrument performs e.g. dissection or clipping.

- Treatment of bleeding ulcers.

One steerable instrument is used to lift the ulcer, while the other instrument treats the bleeding.

- Endoscopic Submucosal Resection (ESD).

En bloc resection of malignant tissue in ESD procedures allows a safer pathologic assessment compared with piecemeal resection in EMR. It is easier to assess whether a free resection margin has been achieved. However, ESD can only be recommended to be performed by experts with extensive experience. In the Netherlands only about 5 physicians are performing the procedure and about 10 physicians are in training. A high risk of perforation has to be expected, particularly in the initial period of the learning curve [Seitz, 2009]. With a conventional setup it is difficult to resect along a straight line parallel to the muscle layer. Robotic endoscope manipulation (setup 2) could assist in these operations. It is essential that the system acts as expected and that the ideal resection line can be achieved. Ideally dexterous bimanual instrument manipulation 
(setup 4) is available in which one steerable instrument is used to expose the muscle layer, while the other one precisely dissects. The endoscope is stabilized in position and will only be repositioned when the range of the steerable instruments falls short.

In addition to the suggested clinical procedures, suggestions for robotic features were provided.

- Distance controller.

The robotic system automatically controls the distance between tissue and instrument.

- Autopilot.

Start and endpoint of a trajectory are indicated by the physician and the path is autonomously travelled according to predefined preferences.

The forces that can be applied by the robotic endoscope and its instruments are being estimated by the physicians as being sufficient in existing therapy. Probably it will be insufficient to perform suturing. As a consequence the system is not ready for transluminal surgery in which suturing is a basic task. However, feedback of the physicians in this experiment already indicated that transluminal procedures will most probably not be adopted in the clinic on a large scale in the near future. Apart from the difficulty in closing the internal incision afterwards, in their opinion the benefits of reducing the trauma to the patient does not outweigh the drawback of precautious infection prevention with antibiotics. Laparoscopic surgery is currently the preferred alternative. This opinion should be verified by (laparoscopic) surgeons.

\subsubsection{Conclusion and recommendations}

The quantitative results from the experiment show that physicians perform significantly better with a standard flexible endoscope than with a robotic flexible endoscope with regard to efficiency, effectiveness, and satisfaction on basic tasks that simulate current clinical practice. The qualitative results show that robotic flexible endoscopy allows physicians to perform instrument operations that could enhance current practice. Additionally, the introduction of robotics expands the range of surgical applications of flexible instruments.

Although the outcome measures of the experiment did not show immediate gain of the robotic setups, the potential benefits are subscribed by the participants. According to gastroenterologists, the single-handed robotic endoscope with manual instrument manipulation might contribute to enhanced dexterity in current clinical practice, like in performing an EMR. The robotic setup with one steerable instruments is beneficial in tasks that require precise short stroke 3D manipulation, like in cannulation of the common bile duct in an ERCP procedure. The full robotic flexible endoscope with steerable instruments could be advantageous in tasks that are currently really difficult and that need bimanual coordination, like performing an ESD. To summarize, these are all endoluminal interventions that require advanced manipulation in a limited space, being the focus clinical area of our robotic flexible endoscope. The added value of robotic flexible endoscopy as envisioned by the development team and the user group of medical specialists at the start of the project, matches with the added value as experienced by physicians at the end of the project. An important design goal has been achieved. The created technology needs improvement, but it provides the functionality required to perform the focus interventions.

The dynamic performance of the robotic setups should be improved to be of real added value and to be accepted in clinical practice. Hysteresis is the main cause for reduced perception of control especially in fine manipulation tasks. System movements do not exactly replicate the movements of the hand. However, it should be noted that participants 
were at the beginning of their learning curve of robotic control and indicated that more time is required to get familiar with the systems. Additionally, having experience in conventional control might have negatively influenced the outcome measures, since manipulation techniques that are currently performed might have an adverse effect when used in robotic control, like rotating the endoscope shaft. Future research should address the learning curve of novice endoscopists to reach expert level in performing conventional as well as singlehanded robotic control. Additionally, surgeons need to be involved in further assessing and improving the full robotic flexible endoscope with steerable instruments. They are accustomed to separation of vision and acting, and might be the target group for performing natural orifice surgery.

The interviews contributed significantly in assessing the limitations and added value of our robotic systems and provided input for improvements, as already discussed in Section 6.2.2. In Section 5.7 points of improvement were discussed as obtained from the experiment with novices. Below some additional points are summarized as obtained from the experiment with experts. These are all estimated to require a lot of additional research and development and are allocated as future work.

- Dedicated robotic instruments for polypectomy and ERCP (Section 6.2.2).

A robotic polypectomy snare that is actuated by the robotic instrument manipulation module might assist in performing single person and easy polypectomy.

A robotic steerable catheter for ERCP might assist in easy cannulation.

- Intelligent algorithms (Section6.2.2).

With vision based algorithms and haptic guidance our robotic systems might significantly improve dexterity in current clinical practice. The input device directs the physician in performing intuitive and precise motions based on camera input. A distance controller and an autopilot function were suggested by participants.

The experiment as conducted with gastroenterologists focused on evaluation of the usability of steering all degrees of freedom of the endoscope and the instruments. Nevertheless, the robotic setups as used in the experiment were equipped with most of the functionality as required in clinical practice. Because of time constraints we could not evaluate all functionality with the physicians and ask them for the clinical suitability of our solutions. Future experiments have to address all clinical aspects. Suggestions for functions that need to be tested and questions that need to be answered in these experiments are discussed below.

- $\quad$ Size and positioning.

Is the swivel arm suitable to securely stabilize all robotic modules in the right position?

Are the robotic modules with regard to size suitable to position close to the patient?

- Disinfection.

Will the current design be accepted in the operating room with regard to cleanability and logistics?

- Speed, accuracy, response time, range of operation, forces.

Are the current performance specifications sufficient in clinical procedures? Which manipulation tasks can be performed with the steerable instruments if looked at the forces that can be applied? Is suturing possible with the steerable instruments?

- Proportional valves for rinsing, insufflation, and suction.

Are the actuation buttons on the input device suitable?

- Programmable switches.

Are touch buttons on the graphical user interface suitable as input controls? 
- Endoscopic platform.

Currently the working channels are positioned along the flexible endoscope. Is the current size and geometry acceptable or should the working channels be integrated in the flexible endoscope?

- Robotic non-steerable grasper

Are the current performance specifications sufficient in clinical procedures? Which manipulation tasks can be performed with the non-steerable instrument?

- Is the setup suitable to integrate in an endoscopy/operating room?

- Are there any use limitations of the robotic setup compared with the conventional setup?

- Are there any safety risks in using the robotic setup?

In the next section the first results and an outlook to future work will be discussed of the evaluation of the robotic steering module for diagnosis, as currently performed by a $\mathrm{PhD}$ candidate of Technical Medicine.

\subsection{Evaluation robotic steering for diagnostic procedures}

Recently expert testing has started with endoscopists to assess whether robotic steering (Chapter 3) increases usability of a flexible endoscope in a clinical setting. The following evaluation steps are and will be taken:

- Quick scan (finished).

The robotic steering module is tested on a virtual reality simulator by three experienced gastroenterologists. Subsequently a questionnaire by interview is conducted related to usability, clinical added value, and safety.

- Learning curve evaluation (current work).

First, the expert level is determined by the average performance from experts with the conventional steering method on a virtual reality simulator. Next, the learning curve to reach this expert level is determined for experts with the robotic steering module and for novices with the robotic as well as the conventional setup.

- Evaluation of effectiveness in patients (future work).

An experienced endoscopist performs diagnostic colonoscopy on about 20 patients.

The main outcome parameters are intubation time and experienced pain, and data with regard to the use environment, the use and the user.

The quick scan has been performed and the learning curve evaluation is currently executed. The scientific results will be published within the ScopeSupport project by Esther Rozeboom (MIRA - Institute for Biomedical Technology and Technical medicine, University of Twente). From the interviews the most interesting remarks, and the ones that were not already suggested by novices (Section 3.6), are discussed beneath. The remarks are not validated.

Currently there is large variation in steering techniques. An endoscopist with average competence can benefit from robotic steering. In current practice the big challenge is in simultaneous tip steering and shaft manipulation (bimanual manipulation). One physician claimed that currently about 30\% of the gastroenterologists in peripheral hospitals use an assistant for shaft advancement.

Steering with a remote control is comfortable, logic and intuitive. The geometry, size, and weight of the remote control are fine. One participant claimed after experiencing 15 minutes of robotic steering that "the steering is now very relaxed ". On the other hand another participant 
mentioned that "I need more practice time, before I would prefer the robotic system". All participants were unanimous in their opinion that haptic feedback of conventional navigation wheel control is missing and precise manipulation is more difficult in robotic control. Proprioceptive feedback in controlling the input device for tip steering is important. The thumb joystick seems to perform better on that requirement, but with the current results it is not possible to choose already between the touchpad and the thumb joystick. Both input devices need better evaluation on all characteristics, like accuracy and reliability. Possibly, if the currently tested devices do not satisfy, alternative input devices like a track ball need to be researched.

The speed of tip steering is fine and the physicians that tested the system in diagnostic procedures experienced no response delay or restrictions in manipulation ranges. In current practice omnidirectional steering to inspect the inner lining of the gastrointestinal tract is impeded by the ergonomics of the navigation wheels. Robotic steering might result in better detection of suspicious tissue because of easy inspection in all directions. A 'home' button to steer the endoscope tip automatically to a neutral straight position is required in clinical practice.

Rotational movements of the shaft are important to pass difficult parts of the lumen. If the docking station allows axial rotation of the endoscope, it is not required to have a portable endoscope to rotate the shaft. The shaft can directly be torqued by the right hand and the robotic flexible endoscope that is docked will rotate likewise. Physicians remarked that a docking station on a swivel arm is easier to fit in the endoscopy room than a pole cart.

Proportional actuation of insufflation, rinsing and suction is not needed. It is not missed in current practice. Insufflation and rinsing should be combined in one button, like it is in a traditional endoscope. Possibly it is handy if the water jet can be actuated with a button on the remote control. In current practice the foot pedal for actuation is often not immediately within reach.

Easy decoupling of the traditional endoscope from the robotic system is important to revert to conventional steering. Probably it will not happen often, but it is recommended for safety purposes. According to the participants, using the robotic steering module implies no significant safety risks. This is underpinned by a remark of one of them: "I feel comfortable to test the device on patients".

The clinical evaluation of the robotic steering module has recently started and the presented results in this section are based on a low sample size. However, the tests provided already a lot of valuable feedback. Future research has to show the real clinical added value of robotic steering. 


\section{7 \\ Reflection}

\subsection{Introduction}

This chapter reflects on the present research project by discussing to what extent the originally stated goals are achieved by applying our design approach and realizing the robotic modules and the integrated proof-of-principle setup. Section 7.2 provides an overview of the original design goals. Section 7.3 reflects on the design approach that is used to realize all goals. Section 7.4 summarizes the outcome of the design process, that is the resulting designs as well as the test results. Section 7.5 addresses the overall conclusion of this work. Finally, in Section 7.6 the main directions for future work are provided.

\subsection{Design goals}

Despite the expected increase in the number of flexible endoscopy procedures performed, at this time no equipment is available that allows a single physician to perform diagnostic and therapeutic endoscopy procedures in an intuitive and user-friendly way. Several research groups and companies are working on solving the current problems, by designing completely new concepts. These efforts have not yet resulted in a successful product that is put on the market, mainly due to the difficult integration in the current clinical workflow and the large investment costs related to the replacement of existing flexible endoscopy equipment. By contrast, the aim of the present research is to develop robotic modules that interact with standard equipment to enhance manipulation of traditional flexible endoscopes and instruments. The main design requirements for our robotic flexible endoscope are captured in three key drivers representing the essence of the objectives of the end-user (i.e. the physician):

- Intuitive and user friendly control.

- Single person control.

- Backwards compatibility with existing gastro- and colonoscopes.

The use of the robotic flexible endoscope was initially targeted on endoluminal therapeutic interventions that require advanced manipulation in a limited space. From analyzing, documenting, and reviewing the current workflow it appeared that physicians often need assistance in controlling the endoscope and the instruments in both diagnostic and therapeutic procedures. This is mainly caused by the many degrees of freedom that need to be manipulated and the non-ergonomic and non-intuitive user interfaces of traditional flexible endoscopes and instruments. Currently, advanced endoscopic intervention platforms are developed that are even more problematic to operate. These platforms potentially take endoscopic therapy to the next level by introducing steerable instruments that allow physicians to perform bimanual manipulation tasks as known from surgery. However, even more degrees of freedom are introduced that are difficult to manipulate. A team of physicians is required to control these experimental platforms.

It was concluded that by breaking the mechanical linkage between the user interfaces and the end effectors and by introducing motors, computer intelligence, and user-friendly interfaces, physicians could potentially be supported in performing diagnosis, existing therapy with existing equipment, and experimental therapy with advanced endoscopic 
intervention platforms. Familiar eye-hand coordination as used in direct manipulation of instruments can be restored and the user interface is ergonomically optimized for the physician.

The main focus has been directed to the development of robotics modules that fit to existing endoscopes and instruments, that actuate all degrees of freedom, that are steered with user friendly user interfaces, and that fit in the current clinical workflow. By adopting a modular system setup, end-users are enabled to customize the robotic endoscope to their clinical requirements.

\subsection{Methodology}

Development of a robotic system is a complex process. Development of a robotic system with critical user interaction is even more challenging. It requires balancing between what is technically possible and what end-users need. Due to the exploring character and the many unknown parameters of the robotic flexible endoscope, the development process is subdivided into the proof-of-principle, the prototype, and the pre-production phase. The present research projects limits itself to the proof-of-principle phase, in which critical aspects of the design are analyzed, and the feasibility of concepts are tested in laboratory setups. However since use, user, and use environment are paramount in this work the proofof principle setups are suitable for evaluation in a clinical setting as well.

As a final step within this research project an integrated proof-of-principle of a full robotic flexible endoscope is created that has been tested in different usability tests with novices and physicians. Currently, the medical added value is tested with physicians in (simulated) clinical procedures within a successive research project. Within that project, more elaborate end-user feedback is gathered to obtain further knowledge about the feasibility, limitations, and opportunities of the robotic flexible endoscope in clinical practice. The sequential prototype phase will focus on the detailed design and certification of the product, while taking factors like robustness and cost-effectiveness into account. Finally, in the pre-production phase the prototype will be prepared for mass production. The proofof-principle phase, the focus of the present research, was subdivided into four steps:

1. Definition.

- Definition of the clinical procedures that can be enhanced by robotics.

- Definition of the functional overview

- Definition of the system requirements, i.e. clinical, technical and user requirements

- Definition of the system architecture that defines the needed robotic modules and their interfaces

2. Concept design.

- Conceptual system design

- Conceptual module design

3. Realization.

- Realization of proof-of-principle setups

- Realization of integrated system

4. Evaluation.

- Evaluation of proof-of-principle setups

- Evaluation of integrated system

In the first two steps, in which the system is defined and concepts are created, our usercentred system design approach (Chapter 2) is used to streamline this part of the development process. The definition of the system architecture has supported in translating an abstract system development assignment into concrete concepts. The created system 
architecture consists of schemes, flow charts, documents, and 3D rendered views that were obtained by executing the seven steps of our approach. The main contribution of system architecting has been the structured way in which knowledge of key stakeholders, like physicians, nurses, and equipment suppliers, was made explicit and used to generate viable concepts.

To ensure a structured as well as user-centred approach in the realization and evaluation phase as well, the $\mathrm{V}$-model has been adopted to structure the complete user-centred design process. In the realization and evaluation phase the conceptual designs are translated into three proof-of-principle setups. The subdivision of the system in three separate robotic modules has been directed by the clinical procedures that are targeted. The robotic modules operate stand-alone. In this way, technical and usability tests could be conducted in an early stage of the development process and the risk of being confronted with major issues in the integration step was limited. The tests were split in a verification step, i.e. technical test, that evaluated whether the robotic module complies with the technical requirements, and a validation step, i.e. usability test, to assess if the robotic module meets the needs of the stakeholders, as documented in the clinical and user requirements. The final integration of the mechanical design, the electronic design, and the control software into an integrated robotic flexible endoscope proceeded without problems. The following conditions and strategic choices have contributed to the straightforward integration:

- Under supervision of the author, a small team was involved in the development process, allowing direct communication. Knowledge could be easily shared and problems were quickly identified.

- The lead engineers were involved during the entire development process.

- The fit between the separate modules, both in geometry and functionality was checked constantly during the development process.

- Use of the system architecture overviews and 3D rendered views streamlined internal communication.

As stated in the beginning of this section, development of a robotic system with critical user interaction is a challenging process. Selection of a ready-made system development method that perfectly fits the system development assignment would speed up the process. However as stated by Hoolhorst [2012] available methods are developed to be generic and only give guidance with respect to the main process steps. Our approach has been specified based on experience of the author and by consulting experts on user-centred design approaches and system architecting methods. The main contribution has been to consciously think about a structured approach in acquiring knowledge about the use and user of the system. By executing the development steps the author was able to define, design, and test robotic modules that are finally integrated in a full robotic flexible endoscope that is suitable for clinical implementation, being the main design goal. It may therefore be concluded that our design approach was successful in this project.

\subsection{Summary of results}

In this section the designs resulting from the application of the new design approach are discussed. Specifically, it is addressed to what extent the designs succeeded in fulfilling all stakeholders' needs and desires, being an important indicator of the added value of the design approach. First, in Table 7.1 the main performance specifications, the usability test results, and the clinical contribution of the present research project are summarized. Subsequently, the results are discussed in detail in the following sections 
Table 7.1 Summary table of achievements

\begin{tabular}{|c|c|c|c|c|c|}
\hline & Diagnosis & Existing & therapy & \multicolumn{2}{|c|}{ Experimental therapy } \\
\hline \multicolumn{6}{|c|}{ Technical specifications } \\
\hline Robotic DOFs & 2 & \multicolumn{2}{|c|}{4} & \multicolumn{2}{|c|}{15} \\
\hline Input device & $\begin{array}{c}\text { Thumb joystick / } \\
\text { touchpad }\end{array}$ & \multicolumn{2}{|c|}{ Multi-DOF input device } & \multicolumn{2}{|c|}{$\begin{array}{l}2 \text { Multi-DOF input } \\
\text { devices }\end{array}$} \\
\hline Transfer function & $\begin{array}{l}\text { Non-linear rate control / } \\
\text { increm. position control }\end{array}$ & \multicolumn{2}{|c|}{$\begin{array}{l}\text { Incremental } \\
\text { position control }\end{array}$} & \multicolumn{2}{|c|}{$\begin{array}{l}\text { Incremental } \\
\text { position control }\end{array}$} \\
\hline Tip steering & Remote control left & \multirow{2}{*}{\multicolumn{2}{|c|}{$\begin{array}{c}\text { Combined } \\
\text { stylus pen left }\end{array}$}} & \multirow{2}{*}{\multicolumn{2}{|c|}{$\begin{array}{l}\text { Combined } \\
\text { stylus pen left }\end{array}$}} \\
\hline Shaft manipulation & Manual right & & & & \\
\hline Instrument control & Assistant & & \multicolumn{2}{|c|}{ Pen left / Pen right } \\
\hline $\begin{array}{l}\text { Operation of valves / } \\
\text { Programmable switches }\end{array}$ & Remote control & \multicolumn{2}{|c|}{$\begin{array}{c}\text { Index finger joystick / } \\
\text { GUI }\end{array}$} & \multicolumn{2}{|c|}{$\begin{array}{c}\text { Index finger joystick / } \\
\text { GUI }\end{array}$} \\
\hline Installation time & $<60 \mathrm{sec}$ & \multicolumn{2}{|c|}{$<30 \mathrm{sec}$} & \multicolumn{2}{|c|}{$<90 \mathrm{sec}$} \\
\hline Performance specifications & Table 3.2 & \multicolumn{2}{|c|}{ Table 4.5} & \multicolumn{2}{|c|}{ Table 5.6} \\
\hline Single person control & $\checkmark$ & \multicolumn{2}{|c|}{$\checkmark$} & \multicolumn{2}{|c|}{$\checkmark$} \\
\hline Backwards compatible & $\checkmark$ & \multicolumn{2}{|c|}{$\checkmark$} & \multicolumn{2}{|c|}{$x$} \\
\hline Usability & Experts & Novices & Experts & Novices* & Experts* \\
\hline Efficiency & $>$ & $>$ & $<$ & $>$ & $<$ \\
\hline Effectiveness & $=$ & $=$ & $=$ & $=$ & $=$ \\
\hline Workload (rob. / conv.) & $>2.30 / 3.40$ & $>2.10 / 3.40$ & $<2.80 / 1.20$ & $=2.80 / 3.20$ & $<3 / 1.20$ \\
\hline Preference (no. 1) & $>(23$ of 24$)$ & $>(9$ of 9$)$ & $<(1$ of 9$)$ & $>$ & $<(0$ of 9$)$ \\
\hline
\end{tabular}

\section{Clinical added value}

\begin{tabular}{lccc}
\hline Diagnosis & $\checkmark$ & $x$ & $x$ \\
Simple polypectomy & $\checkmark$ (assisted) & $\checkmark$ & $x$ \\
Difficult polypectomy & $x$ & $\checkmark$ & $\checkmark$ \\
ESD & $x$ & $\checkmark$ & $\checkmark$ \\
Transluminal surgery & $x$ & $x$ & $x$ \\
Clinical tests performed & $x$ & $x$ & $x$ \\
\hline
\end{tabular}

$\checkmark$ achieved, $x$ future work, $x$ no goal, $>$ significantly better, $<$ significantly worse, $=$ no difference, *one steerable instrument 


\subsubsection{Robotic steering module - diagnostic procedures}

The robotic steering module assists physicians in steering the tip of a flexible endoscope. In the new design the physician uses a remote control that steers a drive system that is coupled to the endoscope. The main design effort has been directed to motorized actuation of the navigation wheels for up-down and left-right movements of the tip and user friendly control of these degrees of freedom. Critical use aspects in traditional steering are identified and addressed in the robotic setup. It was targeted that the problem area was solved without impeding other functionality.

A big challenge was to drive the endoscope without degrading the portability of the endoscope, because of the size and weight of the coupled robotic module. By means of a Bowden cable actuation principle, a compact and light portable drive system has been designed with stationary positioned motors. Although the robotic module adds to the weight, the improved ergonomics of holding the endoscope contributes to improved comfort. Additionally, the docking station allows physicians to position the motorized endoscope on a swivel arm and position it anywhere during the procedure. In that configuration only the remote control that steers the endoscope tip needs to be carried.

An important requirement is that the robotic system provides feedback of the actuation forces that are required to turn the navigation wheels. It provides valuable feedback on the shape of the tip and the shaft inside the patient's body. The flexion of the endoscope tip is derived from the motor positions and shown in a bending diagram on the monitor. In addition, bar indicators are shown that depict the torque required to turn the navigation wheels. The forces are measured with load cells. Due to time constraints, within this work it was not possible to depict accurate torque forces that could be easily interpreted. In future work an algorithm needs to be developed that filters the input data and represents it in a meaningful way.

A joystick with rate control or a touchpad with incremental position control were judged as being the most suitable input device-transfer function combinations for robotic steering. Since literature is not decisive on which setup is more suitable, both options were evaluated.

Next to actuation and steering of the navigation wheels, all other functionality of a traditional endoscope is integrated in the robotic flexible endoscope. Insufflation of CO2, rinsing the camera lens, and suction is controlled by electro-mechanical valves on the stationary unit that are operated with proportional buttons on the dedicated remote control. The programmable switches are in the robotic setup controlled with the remote control as well.

Prevention of cross contamination between patients is essential for market acceptance. A dedicated interface unit couples and simultaneously separates the clean endoscope from the possibly contaminated drive unit.

To conclude, a fully functional robotic flexible endoscope for diagnosis is realized that could be implemented in clinical practice. In the next subsections we reflect on the tests that are performed to assess the usability of the system.

\section{Usability tests with novices (Section 3.6)}

Test 1

The focus of this experiment was to test the usability of steering the endoscope in colonoscopy tasks. Efficiency, effectiveness, and satisfaction have been measured of the 
conventional and of four robotic setups (joystick-stationary endoscope, joystick-portable scope, touchpad-stationary scope, touchpad-portable scope).

The quantitative results showed that both a touchpad and a thumb joystick increase efficiency and satisfaction in navigational tasks when compared with conventional navigation wheel control. The effectiveness was not significantly affected by robotic steering. The results did not show a clear preference for a joystick or a touchpad input device. Usability of the portable compared with the stationary robotic endoscopes did also show no significant differences. The added value of the robotic setups are best expressed by the perceived lower physical and mental workloads in comparison with the conventional setup. On a scale of $1-5$, the median score of conventional control is 3.40 whereas the robotic setups score between 2.30 and 3.00. In addition, conventional steering would be the first choice of only one participant, and last in 16 of 24 participants.

Despite the additional weight in the portable robotic endoscope, novices appreciated the ergonomics and work posture of all robotic setups. Critical observations were related to the implementation of the control transfer function. Almost all participants felt that motion control of both input devices was too aggressive. In addition, half of the population needed some time to get used to the mapping of thumb movements and camera movements. Both settings should be adjustable by the operator. Nevertheless, in general the qualitative results from the interview showed that robotic steering is easy, intuitive, comfortable, and fun compared with conventional steering.

\section{Test 2 (Section 3.6.3)}

An additional experiment was performed to compare conventional navigation wheel control, a touchpad with position control, a joystick with linear rate control, and a joystick with non-linear rate control in long stroke as well as short stroke targeting tasks. Non-linear rate control was introduced and appeared to increase performance in comparison with linear rate control. The results of this additional experiment were in line with our first experiment and showed that a touchpad as well as a joystick could be a suitable user interface for steering a robotic flexible endoscope in diagnosis.

\section{Usability tests with clinical experts (Section 6.3)}

The usability tests with clinical experts are currently performed within the ScopeSupport project by a $\mathrm{PhD}$ candidate of Technical Medicine. A quick scan of the robotic steering module is performed on a virtual reality simulator and currently the learning curve is determined. Here some preliminary qualitative results are discussed that were obtained from interviews. Haptic feedback of conventional control is missing and precise manipulation is more difficult in robotic control. For diagnostic procedures the speed of movements is fine, and no motion delay or restrictions in manipulation ranges were experienced. A 'home' button to steer the endoscope tip automatically to a neutral straight position is required in clinical practice. There is no need for a portable endoscope, it only needs to be lifted occasionally to resolve severe shaft loops. Proportional insufflation, rinsing, and suction is not a must have. Easy decoupling of the traditional endoscope from the robotic system is important to revert to conventional steering. However, no significant safety risks are expected, and the interviewed physicians feel comfortable to test the device on patients.

\subsubsection{Robotic shaft manipulation module - existing therapeutic procedures}

The robotic shaft manipulation module actuates shaft rotation and translation. Its added value shows when this module is combined with the robotic steering module and both modules are operated single-handedly with one multi-DOF controller to control all degrees 
of freedom of the flexible endoscope. Meanwhile the instrument can be manually operated with the other hand. The main design effort has been directed to the actuation mechanism that needs to be small, reliable (also in handling a slippery endoscope), and that can be quickly (de)coupled to the endoscope at any time during the procedure. First, the most critical design aspects are addressed in a basic proof-of-principle to test the suitability of our actuation mechanism and to test the usability of a standard multi-DOF input device for single-handed endoscope control. Second, the final design is realized that is fully functional and also addresses issues, like disinfection and positioning close to the patient.

The endoscope shaft is clamped between two V-shaped wheels. The closing mechanism, that is manually operated by the physician, ensures that the shaft is pretensioned and securely positioned between the wheels. One of the wheels is actuated for translational movement, while the frame on which both wheels are mounted can rotate for rotating the shaft. The required rotational range of in total $360^{\circ}$ enforced us to make a very slim design that allows the shaft to move freely at the front and back of the robotic module.

A standard multi-DOF controller with position control was implemented to steer the tip and to manipulate the shaft. It was an excellent device for the usability tests, but its clinical application is doubtful. It is not suitable for disinfection and its reliability and safety measures are not approved for clinical use. Additionally, the multi DOF-controller contains degrees of freedom that are not in use. This reduces intuitiveness during operation. The accuracy of the multi-DOF controller is sufficient and movements of the stylus pen are smooth. Alternative standard controllers are available, but it should be determined in future work whether one of these meets the requirements. Otherwise a dedicated input device needs to be developed.

The robotic shaft manipulation module is placed on a swivel arm that can be easily positioned close to the patient. Sterility measures are taken by using disposable wheels, interfaces, and sleeves for covering the robotic module and the swivel arm. All measures were not completely implemented, but the basic functionality of our concepts could be demonstrated to stakeholders.

With the completion of the shaft manipulation module, a robotic flexible endoscope is created that assists in all procedural steps of existing therapy and fits into the current clinic workflow. In the next subsections usability test are discussed that are performed.

\section{Usability tests with novices}

Test1 (Section 4.6)

The usability tests are performed with a basic proof-of-principle setup to test the suitability of a standard multi-DOF input device for single-handed endoscope control. Efficiency, effectiveness, and satisfaction have been measured among conventional endoscope operation with assisted instrument control (1), the single person setup with single-handed robotic endoscope manipulation and manual instrument control with the other hand (2), and bimanual robotic endoscope manipulation with assisted instrument control (3). Participants had to perform two tasks that required difficult endoscope manoeuvring and that simulated clinical tasks in existing therapy, like performing a polypectomy.

The results show that robotic control significantly improves efficiency and satisfaction in simulated clinical tasks performed by novices. Participants were about twice as fast with both robotic setups compared to the conventional setup and the perceived physical and mental workload was much lower. On a scale of 1-5, the median score of conventional control is 3.40 whereas the single person setup (2) and the bimanual setup (3) score 
respectively 2.10 and 2.40. The task completion times and the workload scoring of the single-handed setup showed no significant differences compared with the bimanual robotic setup. All participants were able to complete the tasks with all setups, so improved effectiveness is not demonstrated in this experiment. One participant preferred the bimanual robotic setup (3), whereas for 11 out of 12 participants the single person setup (2) is the first choice. Participants valued its intuitiveness, its accuracy, the feeling of being in control, and its single person setup.

\section{Test 2 (Section 3.6.3)}

In the usability tests of the robotic instrument manipulation module, as summarized in Section 7.4.3, the shaft manipulation module was also tested. The same kind of experimental setup was used as in test 1 , only now the final design of the shaft manipulation module has been used. The actuation principle and the implementation of the multi-DOF input device were the same. Two tasked were performed that are comparable with the ones in test 1 . Again efficiency, effectiveness, and satisfaction have been measured. Traditional endoscope control is compared with single-handed robotic control and the results confirm the findings of test 1 .

\section{Usability tests with clinical experts (Section 6.2)}

The setup of the usability tests with clinical experts was equal to test 2 as performed with novices. If we compare the efficiency, represented by procedure time and workload, the conventional setup performs significantly better than single-handed robotic control. Physicians were about 2.5 times faster with the conventional setup and the workload scoring was much lower, 1.20 versus 2.80 on a scale of $1-5$. The effectiveness of the setups did not show a significant difference. Except for one, all physicians prefer the current way of endoscope tip and shaft steering, because they are most familiar with that method.

Currently, the parasitic endoscope movements, due to non-optimal decoupling of input device motions, reduce performance. In addition, like in robotic steering about half of the population preferred reversed mapping of pen movements to camera movements.

Despite the non-optimal experimental setup, physicians were enthusiastic about the potential benefits of the robotic system in clinical procedures. In general the single-handed robotic endoscope could assist in tasks that require fine and difficult manipulation. Possibly the tasks in this experiment were too easy, as reflected in the short completion times, and would tasks that require dexterous multi-DOF manipulation skills be more suitable to show the added value of the robotic endoscope. In addition, experts are in the beginning of the learning curve of robotic control, whereas the experience level in traditional endoscopy was very high. Future work should verify these findings.

\subsubsection{Robotic instrument manipulation module - experimental therapeutic procedures}

The robotic instrument manipulation module is capable of actuating in total three instruments. In our setup one conventional grasper and two steerable graspers are available that can be coupled to the drive unit. In total 11 motors are in use to independently actuate axial translation, axial rotation, grasping, and bending of the instruments. The steerable instruments are guided along a standard flexible gastroscope through prepositioned working channels, whereas the conventional grasper is guided through the standard available working channel. The robotic steering module and the shaft manipulation module are coupled to the gastroscope to obtain a full robotic flexible endoscope with three instruments, of which two 
are steerable. The drive units are telemanipulated from a master console that contains multiDOF input devices, a monitor, and elbow supports. The master console has an electric lifting column to allow physicians to either sit or stand, while operating the system.

The big challenge was to create a robotic module that contains in total 16 motors, that allows easy coupling of interchangeable instruments, that can be positioned close to the patient, and that is suitable for sterile use in case of transluminal procedures. Realizing such a design has been achieved. The only dependency is related to the steerable instruments that are not commercially available yet and are retrieved from a project partner. The interface of the steerable instrument was adapted to allow coupling to our robot.

The master console is also successfully developed. It enables physicians to work in their preferred working posture, since the position of all components can be individually adapted. Eye-hand coordination is optimized by matching movements of the hand and the instruments and by positioning the monitor in front of the input devices (hands) to suggest that the instrument is an extension of the hand. Currently, because of parasitic movements and response delays, system movements do not exactly replicate the movements of the hand. Use of another multi-DOF input device, without redundant degrees of freedom, and the implementation of vision-based control algorithms are expected to considerably improve performance.

With the completion of the instrument manipulation module, a robotic flexible endoscope is created that assists in all procedural steps of advanced bimanual therapy. It allows to perform surgical tasks that are not possible with existing equipment in clinical practice. In the next subsections we reflect on the tests that are performed to assess the usability of the system.

\section{Usability tests with novices (Section 5.6)}

Our goal in this experiment was twofold. On the one hand, we wanted to compare the usability of conventional endoscope operation with assisted instrument control (1) with the single-handed robotic endoscope with manual instrument control (2) and with the robotic flexible endoscope with one steerable instrument (3). On the other hand we wanted to assess the bimanual manipulation capabilities of the robotic flexible endoscope with two steerable instruments.

In the previous section we already discussed the results of single-handed endoscope control compared with conventional control (Section 7.4.2 - test 2). The robotic setup with one steerable instrument performed on one task faster than the conventional setup, whereas in the other task and on workload scoring no significant differences were found. The differences in outcome measures were not as evident as between the single-handed robotic endoscope and conventional control, but it may be concluded that robotics with a steerable instrument enhances flexible endoscope control by novices in therapeutic tasks. The outcome measures of both robotic setups did not show any significant differences.

None of the participants preferred the conventional setup. The ranking of the robotic setups was about equally divided. The single-handed robotic endoscope was valued because it was easy to understand and easy to handle, whereas the setup with one steerable instrument was appreciated because of its freedom of movement and its potential to perform advanced procedures. Both robotic setups are valued for their single person setup.

To assess the bimanual manipulation capabilities, two tasks were performed that required coordinated manipulation of in total 12 degrees of freedom of the endoscope and two steerable instruments. The dynamic performance of the steerable instruments was judged by most participants as being insufficient at this time. In addition, a second articulation of the 
steerable instrument, perpendicular to the current one, would enable a user controlled grasper orientation and better coupling of hand movements to instrument movements. In general participants indicated that more practice time is required to perform dexterous bimanual coordination of hand movements in manipulating all degrees of freedom.

Despite the limitations of the current setup and the lack of experience of participants, eight out of nine participants successfully completed both complex tasks. This indicates that our system has added value, since with current available flexible endoscopy equipment these tasks cannot be performed.

\section{Usability tests with clinical experts (Section 6.2)}

The experimental setup of the usability tests with physicians was the same as the one for novices that is discussed above. The quantitative results show that usability of conventional flexible endoscopy, in terms of efficiency and satisfaction, is significantly better compared with the robotic setup with one steerable instrument. Participants performed about twice as fast on the conventional setup and the workload was much lower (1.20 versus 3). One participant did not manage to complete the tasks, so effectiveness might be negatively affected by robotic control. Except for one, all physicians prefer the current way of endoscope control, because they are most familiar with that method. One participant preferred the single-handed robotic setup. In general participants indicated that for the tested tasks they prefer the conventional endoscope, however for more difficult tasks they might have preferred one of the robotic setups. In addition, the learning curve of robotic control was estimated by the physicians to be steep.

The potential benefits of our robotic system with one steerable instrument in therapy is recognized by physicians. Robotic control enhances the manipulation skills of the physician and reduces the number of hands needed. It is for instance helpful in performing procedures in which the scope needs to be stabilized in a difficult position and that from this position precise endoscope and instrument movements need to be performed, like for instance in difficult polypectomies and in ERCP procedures. In addition physicians suggested to develop intelligent control algorithms that assist in tasks like distance control in argon plasma coagulation and precise steering along a trajectory in ESD procedures.

Experts had trouble in handling the robotic flexible endoscope with two steerable instruments. To be accepted in clinical practice and to be of added value, the robotic systems should be characterized by reliability, predictability, accuracy, and dynamic performance. However, participants expect that their dexterity with the robotic systems will rapidly increase by practicing. Although the outcome measures of the experiment did not show immediate gain of the robotic setups, the potential benefits are subscribed by the participants. The added value of steerable instruments is expected in tasks in which one instrument is used to expose the operating field, while the other instrument performs the intervention, like in ESD procedures.

Although not tested, it was estimated by physicians that the current forces that can be applied by the robotic endoscope and its instruments are insufficient in transluminal therapy in which organs need to be repositioned and suturing is a basic task. In addition, it was noted that the potential benefit for the patient of reduced trauma will not outweigh the infection risks related to these procedures. Surgeons should be consulted to ask their opinion. In addition, since surgeons might perform better on bimanual tasks, future experiments should assess their performance to compare it with the results of gastroenterologists. 


\subsection{Conclusion}

A robotic flexible endoscope is created that has been tested in different usability tests with novices and physicians and that is suitable for future evaluation in a clinical setting. Since physicians have very strong expectations about usability, a user-centred system design approach is developed that has been combined with the $\mathrm{V}$-model for system design. By executing the development steps the author was able to define, design, and test robotic modules that are finally integrated in a full robotic flexible endoscope. In general, the robotic setups are highly appreciated by participants in usability experiments. It is expected that our design approach is also useful when developing other (non-medical) complex systems in which user interaction is critical.

The technical designs are the main results of this doctoral research. However, not only the physical results but also this thesis with the documentation and scientific justification of the results contributes to future improvements in flexible endoscopy. It is a reference document that contains detailed information about robotic flexible endoscopy and provides guidance for future work.

At the start of this project we had a wide spectrum of solution directions to solve the problems faced in flexible endoscopy. Initially the focus of this project was to develop robotic technology to improve the usability and expand the clinical opportunities in endoluminal interventions that require advanced manipulation in a limited space. However, being able to perform simpler diagnostic as well as more complex transluminal procedures with the robotic system, and to solve problems in these kind of procedures was also desired. A top-down design approach was adopted in the analysis phase in which we started with the definition of the big picture: a robotic flexible endoscope with steerable instruments that is suitable for sterile transluminal surgery. Subsequently, the overall system design was decomposed in independently working robotic modules for diagnosis, basic therapy, and advanced therapy. In the synthesis phase a bottom-up approach was used. It started with the realization of the robotic steering module for diagnosis, as defined in the analysis phase, and ended with the fully functional setup for transluminal surgery (the big picture) by subsequently adding modules. In this way a wide spectrum of modular technical designs have been realized that can be arranged by end-users to their clinical needs. The created technology needs further improvements and the clinical validation needs to be continued, but a robotic flexible endoscope is designed that can be applied in clinical practice and that enhances intuitiveness and usability of both existing endoscopy equipment and advanced intervention platforms with steerable instruments. In addition, it expands the range of surgical applications of flexible instruments. The added value of robotic flexible endoscopy as envisioned by the development team and the user group of medical specialists at the start of the project, matches with the added value as experienced by physicians at the end of the project. A supportive tool for diagnosis has been realized. It is uncertain if transluminal procedures can be performed, because of the limited manipulation forces of the endoscope and the instruments, but the main goal, the development of robotic technology for endoluminal interventions that require advanced manipulation in a limited space, has been achieved.

Special attention in the present research and development project has been on incorporating human factors into the robotic flexible endoscope to optimize usability. The main focus has been directed to improving the usability of controlling all degrees of freedom 
of the endoscope and the instruments. However, all other functions that are currently in use in flexible endoscopy are identified as well and addressed in the robotic flexible endoscope.

A lot of insights are gained by performing usability tests with novices. Although the preliminary tests with medical experts are providing more reliable feedback, the input of novices proved to be very important in the development process. Usability tests with novices allowed an iterative design approach that revealed already in an early stage of the development process the majority of limitations and opportunities of the robotic systems. In general the feedback we got on our experimental setups indicate that the robotic flexible endoscope in all of its configurations is highly appreciated by participants. Novices were enthusiastic about the ease with which the degrees of freedom are operated, whereas experts value the clinical opportunities that robotic control provide. Experts were critical about the dynamic performance of the robotic endoscope and instruments with regard to accuracy and response delay. These factors currently impede the feeling of being in control. However, clinicians expect that their dexterity with the robotic systems will rapidly increase by practicing. Additionally, the suggested improvements and the opportunities for computer enhanced control are expected to significantly improve current performance and will further expand the clinical capabilities of the robotic flexible endoscope.

The ultimate robotic flexible endoscope has not yet been designed. However, this work contributes to further developments of the enabling technology for performing easy diagnosis and advanced endoluminal as well as transluminal therapy in the future. Equipment manufacturers have shown their interest in commercializing the product ideas, being an important indicator of the added value of the present work. As confirmed by these manufacturers, the main value of the robotic system lies in its ability to couple standard flexible endoscopy equipment. Customers are able to integrate the new technology in current practice without the need of replacing existing equipment.

To conclude, a robotic flexible endoscope system is developed that enhances diagnostic and therapeutic endoscopy and that fulfills the key drivers of this project:

- Intuitive and user friendly control.

- Single person control.

- Backwards compatibility with existing gastro- and colonoscopes.

A robotic steering module is built that allows ergonomic single person flexible endoscope control while preserving current endoscope qualities. Diagnostic procedures become less skill dependent and the required mental and physical workload is reduced.

The robotic shaft manipulation module demonstrates that robotics enable user-friendly flexible endoscope control with one hand and instrument control with the other hand. The improved dexterity of endoscope manipulation potentially increases the confidence and capabilities of physicians. Advanced endoluminal therapeutic procedures might become generally adopted with the introduction of the robotic system.

Finally, the robotic instrument manipulation module supports performing complex bimanual surgical tasks, because of the extra degrees of freedom available, and the ergonomic user interface. Difficult surgical tasks can be performed that are not feasible with existing flexible tools. The setup is suitable for single person control and prepared for introduction in both the polyclinic and the operating room. 


\subsection{Directions for future work}

Clinical acceptance of our robotic flexible endoscope is the ultimate goal. However, clinical acceptance is also the ultimate challenge. Medical experts only accept a system that does exactly what they expect (that is intuitive), and that in addition is reliable, accurate, efficient, and (cost) effective. For all robotic modules mainly the parasitic movements and the response delays are currently limiting the feeling of being in control. System movements do not exactly replicate the movements of the hand. To be accepted in clinical practice and to be of added value, the input device characteristics and the dynamic performance of the end effectors should be improved. To realize the envisioned enhanced performance, a multidisciplinary approach is required with a team of user interface, mechanical, and control software specialists. Research into the following issues can further improve the performance of the robotic flexible endoscope.

\section{Robotic steering module - diagnostic procedures}

In the robotic steering module the Bowden cable actuation mechanism of the drive unit suffers from hysteresis. It is inherent to this kind of actuation principle. However, other actuation principles are expected to add more weight to the endoscope and therefore impede portability. Currently, clinical tests address the need of a portable robotic flexible endoscope. If the Bowden cable actuation needs to be maintained, the solution may possibly be found in vision-based control algorithms. These algorithms compare the user input with the actual displacement and compensate for response delay and backlash.

The perception of control is improved if operators experience the start and ending of the bending motion and the corresponding forces that are required to turn the navigation wheels. In the current robotic setup visual feedback is provided, but haptic feedback is the preferred way. It should be researched if a 2DOF haptic input device, that can be integrated with a small remote control, is available or can be developed. Possibly, tactile feedback (vibration) is a promising alternative.

Robotic proportional valve control of insufflation, rinsing, and suction allows to implement advanced vision algorithms that anticipate on changing conditions. For instance when during inspection the intestine is collapsing and vision is disturbed, automatic dosed insufflation of air or CO2 into the lumen is possible.

\section{Robotic shaft manipulation module - existing therapeutic procedures}

A standard multi-DOF input device with position control was implemented to steer the tip and to manipulate the shaft. It impeded intuitiveness of endoscope manipulation, since there were more input degrees of freedom available than could be steered. It should be researched if a standard input device is available that allows better mapping of endoscope and hand movements. Possibly, a dedicated multi-DOF input device needs to be developed.

\section{Robotic instrument manipulation module - experimental therapeutic procedures}

The working channels for the steerable instruments are now easily added to an existing gastroscope. However, because of disinfection, space, and flexibility issues, the working channels might better be integrated within the shaft of the endoscope. If these findings are confirmed in the clinical tests, a dedicated endoscopic platform needs to be developed. Current available platforms do not conform, because of lack of maneuverability, stability, or triangulation.

A second articulation of the steerable instrument, perpendicular to the current one, would enable a user controlled grasper orientation and better coupling of hand movements to 
instrument movements. Research into the availability of steerable instruments with two bendable degrees of freedom should be conducted. Alternatively, it might be developed independently from current manufacturers.

Currently, only robotic grasper instruments are available in the setup. The implementation of other instruments for specific procedures might expand the range of applications of the robotic instrument manipulation module. For instance a robotic polypectomy snare could allow single person and easy polypectomy, and a robotic steerable catheter for ERCP might assist in easy cannulation of the common bile duct. The implementation of vision algorithms with for instance a target lock, that compensates for physiological patient motions, may further improve current practice.

When vision based robotic control is coupled to haptic guidance, dexterity of the robotic flexible endoscope might be further improved. In this setup, the input device directs the physician in performing intuitive and precise motions based on camera input. Two applications were suggested by physicians. A 'distance controller' could assist the physician in maintaining the right distance between instrument and tissue. For instance in argon plasma coagulation, the haptic input device guides the physician in maintaining the probe at a fixed distance with regard to the tissue while treating the target area. An 'autopilot function' steers the end effector semi-autonomous from A to B. The physician is guided along a trajectory by the input device that provides force feedback. The physician is still in control and is able to overrule the system. For instance in an ESD procedure the system could assist in performing an incision along the circumference of a tumor.

This overview of directions for future work shows that the potential of robotics is enormous. The created technology in this work is a solid base for future developments that will result in a robotic flexible endoscope for clinical use that benefits both the physician and the patient. 


\section{Bibliography}

Abbott D.J. et al., Design of an Endoluminal NOTES Robotic System. In Proceedings of the IEEE/RSJ International Conference on Intelligent Robots and Systems, San Diego, USA, 2007.

Adachi H., Motor-Driven Bending Endoscope. European Patent Application, EP 1992272 A1, Nov. 19, 2008.

Albayrak A., Ergonomics in the Operating Room: Transition from Open to Image-based Surgery. PhD Thesis, Delft University of Technology, the Netherlands, 2008.

Allemann P. et al., Joystick Interfaces are not Suitable for Robotized Endoscope Applied to NOTES. Surgical Innovation, Volume 16, pp. 111-116, 2009.

Appleyard M. N. et al., The Measurement of Forces Exerted during Colonoscopy. In Gastrointestinal Endoscopy, Volume 52, No. 2, pp. 237-240, 2000.

ASGE/SGNA, Role of GI Registered Nurses in the Management of Patients Undergoing Sedated Procedures. American Society for Gastrointestinal Endoscopy, 2004.

Auyang E.D. et al., Natural Orifice Translumenal Endoscopic Surgery (NOTES): a Technical Review. In Surgical Endoscopy, Volume 25, No. 10, pp. 3135-3148, 2011.

Banerjee S. et al., Infection Control during GI Endoscopy. In Gastrointestinal Endoscopy, Volume 67, No. 6, pp. 781-790, 2008.

Bardou B. et al., Design of a Telemanipulated System for Transluminal surgery. In Proceedings of 31st Annual International Conference of the IEEE EMBS, Minnesota, USA, 2009.

Barlow D.E., The Video Colonoscope. Colonoscopy: Principles and Practice, 2nd ed., J.D. Waye, D.K. Rex, and C.B. Williams, 2nd edition, Chichester: Wiley-Blackwell, pp. 269-291, 2009.

Bar-Meir S., New Colonoscopes and Assist Devices. Colonoscopy: Principles and Practice, 2nd ed., J. D. Waye, D. K. Rex, and C.B. Williams, 2nd edition, Chichester: Wiley-Blackwell, pp. 777-783, 2009.

Blanchard B.S. and Fabrycky W.J., Systems Engineering and Analysis. Prentice Hall, Upper saddle river, New Jersey, $3^{\text {rd }}$ edn., 1998.

Bonnema G.M., FunKey Architecting - an Integrated Approach to System Architecting Using Functions, Key Drivers and System Budgets. Ph.D. Thesis, University of Twente, Enschede, The Netherlands, 2008.

Borches P.D. and Bonnema G.M., 'Living' Architecture Overviews - Supporting the Design of Evolutionary Complex Systems. In Proceedings of the CIRP Design Conference, Enschede, the Netherlands, 2008.

Bowman D. et al., An Introduction to 3-D User Interface Design. In Presence, Volume 10, No. 1, pp. $96-108,2001$.

Bretthauer M. et al., Air and Carbon Dioxide Volumes Insufflated During Colonoscopy. Gastrointestinal Endoscopy, Volume 58, pp. 203-206, 2003. 
Canes D. et al., The Future of Notes Instrumentation: Flexible Robotics and In Vivo Minirobots. In Journal of Endourology, Volume 23, No. 5, pp. 787-792, 2009.

Chamberlain R.S., S.V. Sakpal, A Comprehensive Review of Single-Incision Laparoscopic Surgery (SILS) and Natural Orifice Transluminal Endoscopic Surgery (NOTES) Techniques for Cholecystectomy. In Journal of Gastrointestinal Surgery, Volume 13, No. 9, pp. 17331740, 2009.

Cohen D. et al., The Perception of Gastroenterology Fellows Towards the Relationship Between Hand Size and Endoscopic Training. Digestive Diseases and Sciences, Volume 53, pp. 1902-1909, 2008.

Costamagna G. et al., EURO-NOTES: Advanced Interventional Endoscopic Procedures and NOTES. In Endoscopy, Volume 42, No. 4, p. 691, 2010.

Cuschieri A., Whither Minimal Access Surgery: Tribulations and Expectations, In American Journal of Surgery, Volume 169, No. 1, pp. 9-19, 1995.

Dunkin B. et al., Position Statement on Endoluminal Therapies for Gastrointestinal Diseases. Society of American Gastrointestinal and Endoscopic Surgeons (SAGES), 2009.

Dupont P.E., Extending the Reach and Stability of Manually Steerable Neuroendoscopes Through Robotics. In Proceedings of Hamlyn Symposium, London, 2012.

Dykes C.A., The Gastrointestinal Assistant during Colonoscopy. Colonoscopy: Principles and Practice, 2nd ed., J. D. Waye, D. K. Rex, and C.B. Williams, 2nd edition, Chichester: Wiley-Blackwell, pp. 59-60, 2009.

Ellsmere J. et al., Endoluminal Instrumentation is Changing Gastrointestinal Surgery. In Surgical Innovation, Volume 13, No. 2, pp. 145-151, 2006.

Ergonomic Requirements for Office Work With Visual Display Terminals (VDTs) - Part 11: Guidance on Usability, ISO 9241-11:1998(E).

Fang C. et al., A Motorized Hand-Held Flexible Rhino Endoscope in ENT- Diagnosis and its Clinical Experience. In Proceedings of International Conference on Biomedical Robotics and Biomechatronics, Rome, 2012.

Ferlay J. et al., GLOBOCAN 2008 v2.0, Cancer Incidence and Mortality Worldwide: IARC CancerBase No. 10 [Internet]. Lyon, France: International Agency for Research on Cancer; 2010. Available from: http://globocan.iarc.fr, accessed on 15/12/2012.

Franken M.C.J, Control of Haptic Interaction: An Energy-Based Approach. PhD Thesis, University of Twente, the Netherlands, 2011.

Freschi C. et al., Technical Review of the Da Vinci Surgical Telemanipulator. In International Journal of Medical Robotics and Computer Assisted Surgery, early view online version, 2012.

Fuchs K. and Breithaupt W., Transgastric Small Bowel Resection with the New Multitasking Platform EndoSAMURAI for Natural Orifice Transluminal Endoscopic Surgery. In Surgical Endoscopy, Volume 26, No. 8, pp. 2281-2287, 2012.

Gaglia A. et al., New Endoscopy Devices to Improve Population Adherence to Colorectal Cancer Prevention Programs. World Journal of Gastrointestinal Endoscopy, Volume 2, pp. 244-251, 2010. 
Gerloff C. and Andres F.G., Bimanual Coordination and Interhemispheric Interaction. In Acta Phsychologica, Volume 110, No. 2-3, pp. 161-186, 2002.

Groth S. et al., High Cecal Intubation Rates with a New Computer-Assisted Colonoscope: A Feasibility Study. In the American Journal of Gastroenterology, Volume 106, No. 6, pp. 1075-1080, 2011.

Gulliksen J. et al., Key Principles for User-Centred Systems Design. Behaviour \& Information Technology, Volume . 22, No. 6, 2003.

Guthart G.S., Salisbury J.K., The Intuitive ${ }^{\mathrm{TM}}$ Telesurgery System: Overview and Application. In Proceedings of the IEEE International Conference on Robotics \& Automation, San Francisco, 2000.

Hager G.D. et al., Surgical and Interventional Robotics: Surgical Assistance Systems. IEEE Robotics and Automation Magazine, Volume 15, pp. 84-93, 2008.

Hansel S.L. et al., Prevalence and Impact of Musculoskeletal Injury Among Endoscopists: a Controlled Pilot Study. Journal of Clinical Gastroenterology, Volume 43, pp. 399-404, 2009.

Hardyck C. and Petrinovich L.F., Left Handedness. Psychological Bulletin, Volume 84, pp. 385-404, 1977.

Harewood G.C., Relationship of Colonoscopy Completion Rates and Endoscopist Features. Digestive Diseases and Sciences, Volume 50, pp. 47-51, 2005.

Hart S.G. and Staveland L. E., Development of NASA-TLX (Task Load Index): Results of Empirical and Theoretical Research. In Human Mental Workload, P. A. Hancock and N. Meshkati, Amsterdam: North Holland Press, pp. 239-250, 1988.

Hinkley K. et al., A Survey of Design Issues in Spatial Input. In Proceedings of Symposium on User Interface Software and Technology, Marina del Rey, pp. 213-222, 1994.

Hinckley K., Usability Analysis of 3D Rotation Techniques. In Proceedings of Symposium on User Interface Software \& Technology, Alberta, 1997.

Honda K. et al., Medical Treatment System. European Patent Application, EP 2332459 A1, June 15, 2011.

Hoolhorst F., Structuring User-Centred Product Development Processes. Ph.D. thesis, University of Twente, The Netherlands, 2012.

Hornbæk K., Current Practice in Measuring Usability: Challenges to Usability Studies and Research. International Journal of Human-Computer Studies, Volume 64, pp. 79-102, 2006.

Ikeda et al., Evaluation of a New Multitasking Platform for Endoscopic Full-Thickness Resection. In Gastrointestinal Endoscopy, Volume 73, No. 1, pp. 117-122, 2011.

ISO 9241-11(E), Ergonomic Requirements for Office Work with Visual Display Terminals (VDTs) - Part 11: Guidance on usability, 1998.

ISO 9241-210, Ergonomics of human-system interaction - Part 210: Human-centred design for interactive systems, 2010.

ISO/IEC/IEEE 42010, Systems and software engineering - Architecture description, 2011. 
Karimyan V. et al., Navigation Systems and Platforms in Natural Orifice Translumenal Endoscopic Surgery (NOTES). In International Journal of Surgery, Volume 7, No. 4, pp. 297-304, 2009.

Kazanzides P. et al, Surgical and Interventional Robotics: Core concepts, Technology, and Design. In IEEE Robotics and Automation Magazine, Volume 15, No. 2, pp. 122-130, 2008.

Khatait J.P., Motion and Force Transmission of a Flexible Instrument Inside a Curved Endoscope, PhD Thesis, University of Twente, the Netherlands, 2013, draft in-preparation.

Kim W.S., A Comparison of Position and Rate Control for Telemanipulations with Consideration of Manipulator System Dynamics. In Journal of Robotics and Automation, Volume 3, No. 5, pp. 426-436, 1987.

Kim E.Y. et al., Chicken Soup for Teaching and Learning ESD. In In World Journal of Gastrointestinal Endoscopy, Volume 17, No. 4, pp. 123-136, 2012.

Kim W. H. et al., Factors Affecting Insertion Time and Patient Discomfort during Colonoscopy. Gastrointestinal Endoscopy, Volume 52, pp. 600-605, 2000.

Korman L.Y. et al., Segmental Increases in Force Application during Colonoscope Insertion: Quantitative Analysis using Force Monitoring Technology. In Gastrointestinal Endoscopy, Volume 76, No. 4, pp. 867-872, 2012.

Körner O. and Männer R., Implementation of a Haptic Interface for a Virtual Reality Simulator for Flexible Endoscopy. In Proceedings of 11th International Symposium on Haptic Interfaces for Virtual Environment and Teleoperator Systems, Los Angeles, USA, pp. 278-284, 2003.

Kume K. et al., Development of a Novel Endoscopic Manipulation System: The Endoscopic Operation Robot. In World Journal of Gastrointestinal Endoscopy, Volume 3, No. 7, pp. 145-150, 2011.

Kuwabara T. et al., Prevalence and Impact of Musculoskeletal Pain in Japanese Gastrointestinal Endoscopists: A Controlled Study. In World Journal of Gastroenterology, Volume 17, No. 11, pp. 1488-1493, 2011.

Larkin D.Q. and Rosa D.J., Minimally Invasive Surgery Guide Tube. United States Patent Application, US2008/0071288A1, Mar. 20, 2008.

Liberman A. S. et al., Injuries Sustained by Colorectal Surgeons Performing Colonoscopy. Surgical Endoscopy, Volume 19, pp. 1606-1609, 2005.

Madhani A., Design of Teleoperated Surgical Instruments for Minimally Invasive Surgery. $\mathrm{PhD}$ Thesis, Massachusetts Institute of Technology, USA, 1997.

Maier M.W. and Rechtin E., The Art of Systems Architecting. Second Edition, CRC Press, Boca Raton, Florida, 2000.

Makris K.I. et al., Natural Orifice Trans-Luminal Endoscopic Surgery (NOTES) in Thoracic Surgery. In Seminars in Thoracic and Cardiovascular Surgery, Volume 22, No. 4, pp. 302309, 2010.

Malik A. et al., Endoluminal and Transluminal Surgery: Current Status and Future Possibilities. In Journal of Surgical Endoscopy, Volume 20, No. 8, pp. 1179-1192, 2006. 
Marescaux J. et al., Surgery Without Scars. In Archives of Surgery, Volume 142, No. 9, pp. 823-827, 2007.

Marescaux J. et al., Endoscopy System with Pivotable Arms. United States Patent Application, US2008/0269562A1, Oct. 30, 2008.

Matsui N. et al., Endoscopic Submucosal Dissection for Removal of Superficial Gastrointestinal Neoplasms: A Technical Review. In World Journal of Gastroenterology, Volume 17, No. 21, pp. 2618-2622, 2012.

Miedema B.W. et al., NOTES Techniques: Present and Future. In European Surgery, Volume 40, No. 3, pp. 103-110, 2008.

Militello L.G. et al., The Role of Cognitive Systems Engineering in the Systems Engineering Design Process. In Journal of Systems Engineering, Volume 13, No. 3, pp. 261-273, 2010.

Muller G.J., How to Create an Architecture Overview, 2011.

http://www.gaudisite.nl/OverviewHowToPaper.pdf, accessed on Sep. 28, 2012.

Muller G.J., CAFCR: A Multi-view Method for Embedded Systems Architecting: Balancing Genericity and Specificity. Ph.D. thesis, Delft University of Technology, The Netherlands, 2004.

Murakami K. et al., Endoscopy System. United States Patent Application, US2007/185377A1, Aug. 9, 2007.

NASA TLX: Task Load Index.

http://humansystems.arc.nasa.gov/groups/TLX/index.html, viewed 2011.

Neumann M. and Bayer K.H., Drive for an Endoscope. United States Patent Application, US2006/161043 A1, Jul. 20, 2006.

Niwa H. and Williams C.B., History of Endoscopy in the Rectum and Colon. Colonoscopy: Principles and Practice, 2nd ed., J. D. Waye, D. K. Rex, and C.B. Williams, 2nd edition, Chichester: Wiley-Blackwell, pp. 3-18, 2009.

Norman D.A. and Draper S.W., User Centered System Design. Lawrence Erlbaum Associates, Hillsdale, New Jersey, 1986.

Norman D.A., The Design of Everyday Things, The Perseus Books Group, New York, 2002.

North O.J. et al., Design and Evaluation of Endoscope Remote Actuator for MRI-Guided Endoscopic Retrograde Cholangio-Pancreatography (ERCP). In Proceedings of International Conference on Biomedical Robotics and Biomechatronics, Rome, 2012.

Okamoto Y. and Banju K., Electrical Bending Operation Device and Medical treatment System Including Electric Bending Operation Device. United States Patent Application, US2009/0287055 A1, Nov. 19, 2009.

Ott L. et al., Physiological Motion Rejection in Flexible Endoscopy using Visual Servoing. In Proceedings of IEEE International Conference on Robotics and Automation, Pasadena, USA, 2008.

Pedrosa M.C. et al., Minimizing Occupational Hazards in Endoscopy: Personal Protective Equipment, Radiation Safety, and Ergonomics. In Gastrointestinal Endoscopy, Volume 72, No. 2, pp. 227-235, 2010. 
Peña C. et al., Teleoperation of a Robot Using a Haptic Device with Different Kinematics. In Proceedings of EuroHaptics, p. 181-186, 2008.

Pew R.W. and Mavor A.S., Human-System Integration in the System Development Process: A New Look. Report of the Committee on Human-System Design Support Changing Technology, National Academies Press, 2007.

Phee S.J.. et al., Robotic System for No-Scar Gastrointestinal Surgery. In International Journal of Medical Robotics and Computer Assisted Surgery, Volume 4, No. 1, pp. 15-22, 2008.

Phee S.J. et al., Master And Slave Transluminal Endoscopic Robot (MASTER) for Natural Orifice Transluminal Endoscopic Surgery (NOTES). In Proceedings of International Conference of the IEEE EMBS, Minnesota, USA, 2009.

Rattner D. and Kalloo A., ASGE/SAGES Working Group on Natural Orifice Transluminal Endoscopic Surgery, White paper. In Surgical Endoscopy, Volume 20, No. 9, pp. 329-333, 2006.

Reilink R. et al., Evaluation of Flexible Endoscope Steering Using Haptic Guidance. In International Journal of Medical Robotics and Computer Assisted Surgery, Volume 7, pp. 178-186, 2011.

Reilink R., Image-Based Robotic Steering of Advanced Flexible Endoscopes and Instruments. PhD Thesis, University of Twente, the Netherlands, 2013.

Rentschler M.E. et al., Natural Orifice Surgery with an Endoluminal Mobile Robot. In Surgical Endoscopy, Volume 21, No. 7, pp. 1212-1215, 2007.

Rich M.E., The Colonoscopy Suite. In Colonoscopy: Principles and Practice, 2nd ed., J. D. Waye, D. K. Rex, and C.B. Williams, 2nd edition, Chichester: Wiley-Blackwell, pp. 19-40, 2009.

Roberts-Thomson I.C. and Teo E., Colonoscopy: Art or Science?. Journal of Gastroenterology and Hepatology, Volume 24, pp. 800-804, 2009.

Roozenburg N.F.M. and Eekels J., Product Design: Fundamentals and Methods. John Wiley \& Sons Ltd, UK, 1995.

Rosen M., Ponsky J., Minimally Invasive Surgery. In Endoscopy, Volume 33, No. 4, pp. 358366, 2001.

Rozeboom E.D., Ruiter J.G., Franken M., Broeders I.A.M.J., Demonstrating that Intuitive User Interfaces Increase Efficiency in Endoscope Tip Control. In Endoscopy, Under review.

Santos-Carreras L. et al., Survey on Surgical Instrument Handle Design: Ergonomics and Acceptance. In Surgical Innovation, Volume 19. No. 1, pp. 50-59, 2012.

Santos B.F. and Hungness E.S., Natural Orifice Translumenal Endoscopic Surgery: Progress in Humans Since White Paper. In World Journal of Gastroenterology, Volume 17, No. 13, pp. 1655-1665, 2011.

Seitz U. et al., Difficult Polypectomy. Colonoscopy: Principles and Practice, 2nd ed., J. D. Waye, D. K. Rex, and C.B. Williams, 2nd edition, Chichester: Wiley-Blackwell, pp. 582-602, 2009. 
Shaikh S.N. and Thompson C.C., Natural Orifice Translumenal Surgery: Flexible Platform Review. In World Journal of Gastrointestinal Surgery, Volume 2, No. 6, pp. 201-216, 2010.

Shergill A.K. et al., Ergonomics and GI endoscopy. Gastrointestinal Endoscopy, Volume 70, pp. 145-153, 2009.

Shergill A.K. et al., Pinch Force and Forearm-Muscle Load During Routine Colonoscopy: a Pilot Study. In Gastrointestinal Endoscopy, Volume 69, No. 1, pp. 142-146, 2009.

Spaun G. et al., A Multitasking Platform for Natural Orifice Transluminal Endoscopic Surgery (NOTES): A Benchtop Comparison of a New Device for Flexible Endoscopic Surgery and a Standard Dual-Channel Endoscope. In Surgical Endoscopy, Volume 23, No. 17, pp. 2720-2727, April 2009.

Spaun G. et al., Bimanual Coordination in Natural Orifice Transluminal Endoscopic Surgery: Comparing the Conventional Dual-Channel Endoscope, the R-Scope, and a Novel Direct-Drive System. In Gastrointestinal Endoscopy, Volume 69, No. 6, pp 39-45, May 2009.

Swanstrom L.L. et al., Developing Essential Tools to Enable Transgastric Surgery. In Surgical Endoscopy, Volume 22, No. 3, pp. 600-604, 2008.

Swanstrom L.L., Development and Validation of a New Generation of Flexible Endoscope for NOTES. In Surgical Innovation, Volume 16, No. 2, pp. 104-110, 2009.

Swanstrom L.L., NOTES: Platform Development for a Paradigm Shift in Flexible Endoscopy. In Gastroenterology, Volume 140, No. 4, pp. 1150-1154, April 2011.

Swanstrom L.L., Novel Endoscopic Platforms for Endoluminal and NOTES Surgery. In Proceedings of the Hamlyn Symposium on Medical Robotics, pp. 5-6, London, June 2011.

Swinnen S. and Wenderoth N., Two Hands, One Brain: Cognitive Neuroscience of Bimanual Skill. Journal of Trends in Cognitive Sciences, Volume 8, No. 1, pp. 18-25, 2004.

Tassios P.S. et al., Acquisition of Competence in Colonoscopy: the Learning Curve of Trainees. Endoscopy, Volume 31, pp. 702-706, 1999.

Thompson C.C. et al., Evaluation of a Manually Driven, Multitasking Platform for Complex Endoluminal and Natural Orifice Transluminal Endoscopic Surgery Applications. In Gastrointestinal Endoscopy, Volume 70 , No. 1, pp. 121-135, 2009.

Torry-Smith J.M. et al., Mechatronic Design - Still a Considerable Challenge. In Proceedings of International Design Engineering Technical Conferences \& Computers and Information in Engineering Conference, Washington, USA, 2011.

van den Bedem L.J.M, Realization of a Demonstrator Slave for Robotic Minimally Invasive Surgery. PhD Thesis, Eindhoven University of Technology, the Netherlands, 2010.

van der Voort M.C. and Tideman M., Combining Scenarios and Virtual Reality into a New Approach to Including Users in Product Design Processes. In Journal of Design Research, Volume 7, No. 4, pp. 393-410, 2008.

van Veldhuizen-Eshuis $\mathrm{H}$. et al., Feasibility study into population screening for bowel cancer. Report 225082001/2012,National Institute for Public Health and the Environment, 2012. 
von Renteln D. et al., Triangulation: the Holy Grail of Endoscopic Surgery? In Surgical Endoscopy, Volume 5, No. 25, pp. 1355-1357, 2011.

Wang X. and Meng M., Robotics for Natural Orifice Transluminal Endoscopic Surgery: A Review. In Journal of Robotics, 2012. doi:10.1155/2012/512616

Waye J.D., Polypectomy: Basic principles. Colonoscopy: Principles and Practice, 2nd ed., J. D. Waye, D. K. Rex, and C.B. Williams, 2nd edition, Chichester: Wiley-Blackwell, pp. 572581, 2009.

Wentink M., Hand-Eye Coordination in Minimally Invasive Surgery: Theory, Surgical Practice and Training. PhD Thesis, Delft University of Technology, the Netherlands, 2003.

Wilhelm D., Multitasking-Plattformen: Revolution in der interventionellen Endoskopie? In Gastroenterologe, Volume 7, pp. 44-48, 2012.

Williams C., Insertion technique. In Waye et al., Colonoscopy: Principles and Practice, 2nd edition, Chichester, UK, pages 537-559, 2009.

Yahagi N., Endoscopic Submucosal Dissection in the Colon. Colonoscopy: Principles and Practice, 2nd ed., J. D. Waye, D. K. Rex, and C.B. Williams, 2nd edition, Chichester: WileyBlackwell, pp. 603-612, 2009.

Yeung B.P.M. and Gourlay T., A Technical Review of Flexible Endoscopic Multitasking Platforms. In International Journal of Surgery, Volume 10, No. 7 , pp. 345-354, 2012.

Yi X. et al., An Innovative 3D Colonoscope Shape Sensing Sensor Based on FBG Sensor Array. In Proceedings of the International Conference on Information Acquisition, pp. 227232, Jeju City, Korea, 2007.

Zhai S., Investigation of Feel for 6DOF Inputs: Isometric and Elastic Rate Control for Manipulation in 3D Environments. In Proceedings of Human Factors and Ergonomics Society 37th Annual Meeting, 1993.

Zhai S. and Milgram P., Human Performance Evaluation of Manipulation Schemes in Virtual Environments. In Proceedings of IEEE Virtual Reality Annual International Symposium, Seattle, 1993.

Zhai S., Human Performance in Six Degree of Freedom Input Control. Ph.D. thesis, Department of Industrial Engineering, University of Toronto, Canada, 1995.

Zhai S. et al., The Influence of Muscle Groups on Performance of Multiple Degree-ofFreedom Input. In Proceedings of Conference on Human Factors in Computing Systems, pp. 308-315, Vancouver, 1996.

Zhang S.H. et al., The Human Machine Interface implementation for the Robot Assisted Endoscopic Surgery System. In Proceedings of the International Workshop on Robot and Human Interactive Communication, Berlin, Germany, pp. 442-447, 2002. 


\section{Appendix A Workflow colonoscopy}

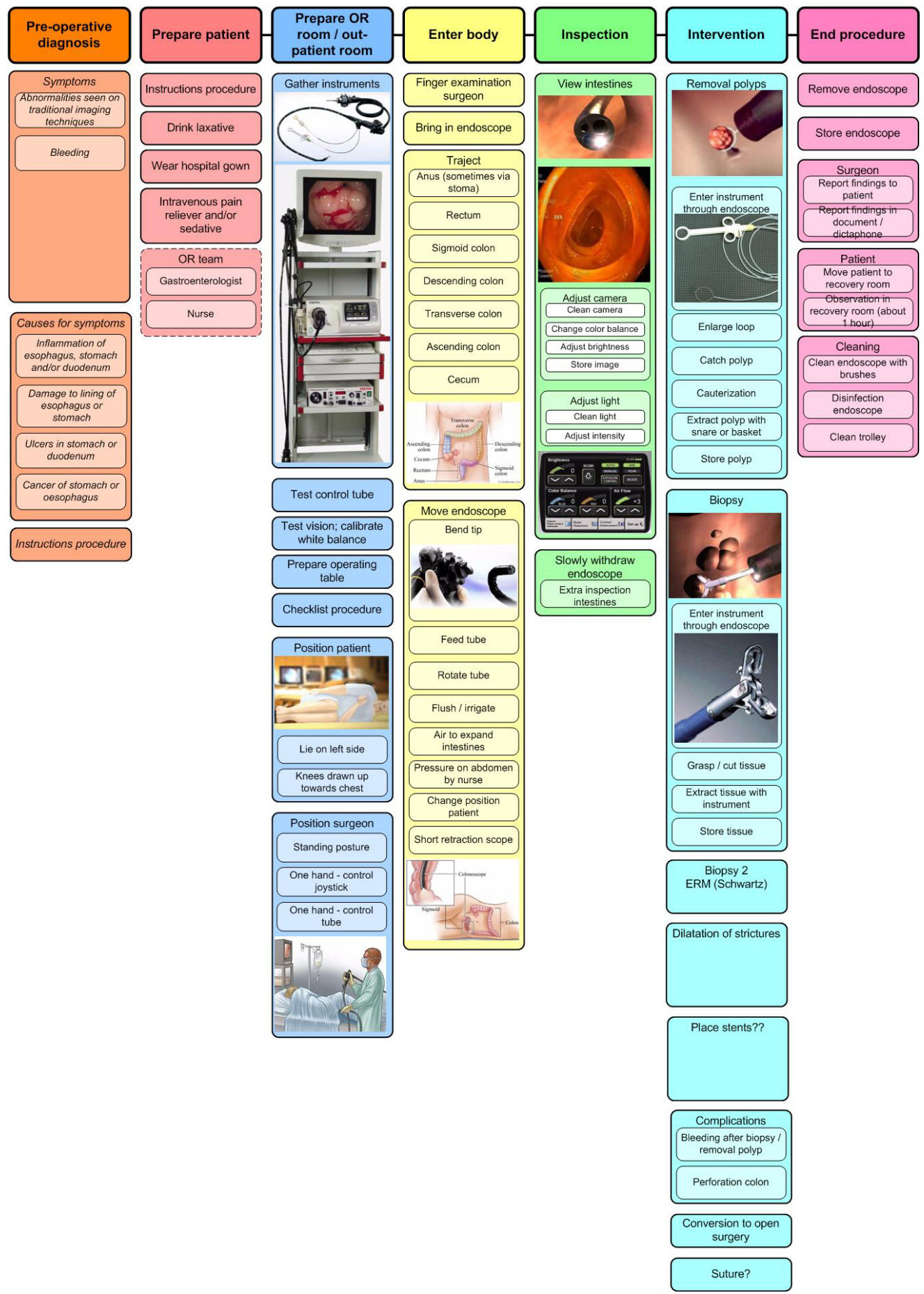





\section{Appendix B Experiments}

\section{B.1 Modified NASA Task Load Index}

Scoor de volgende uitspraken? Op een schaal van 1 tot 5 , met; $1=$ eens; $2=$ niet geheel eens; 3 = niet eens $/$ niet oneens; $4=$ niet geheel oneens; $5=$ oneens. Licht ook toe?

1. Ik moest veel nadenken tijdens de procedure.

122345

2. Ik vond het lichamelijk zwaar werk.

$\begin{array}{lllll}1 & 2 & 3 & 4 & 5\end{array}$

3. Ik was gespannen tijdens de procedure.

122345

4. Ik vond het een moeilijke procedure.

$\begin{array}{lllll}1 & 2 & 3 & 4 & 5\end{array}$

5. Ik vond het uitvoeren van de taken frustrerend.

123345

\section{B.2 Questionnaire experiment steering module}

Datum:

Naam:

Functie:

Leeftijd:

Geslacht:

\# Scopiën:
Spelletjes ervaring:

Links/rechtshandig:

Smartphone met touchpad:

Gebruikersinterface:

Onderzoeker:

Locatie:

\section{Resultaten tabel}

Foto insertie (sec.)

Tot flexura lienalis?

Foto caecum (sec.)

Tot flexura hepatica?

Foto lesies (sec.)

Tot caecum?

Foto einde (sec.)

\# Laesies?

Taak 1 - inbrengen:

1. Welke handelingen zijn het moeilijkst met deze gebruikers interface?

Taak 2 - terugtrekken en inspectie:

2. Welke handelingen zijn het moeilijkst met deze gebruikers interface?

\section{Algemeen}

3. Heeft u veel uitleg nodig over de werking van de gebruikersinterface?

4. In hoeverre ondervindt $u$ hinder van het dragen van de endoscoop bij de taken/ hinder van het eenzijdig vastzitten van de endoscoop bij de taken?

5. Heeft $\mathrm{u}$ altijd het gevoel in controle te zijn? Voldoende feedback / feed forward over status systeem en resultaat van acties?

\section{Ergonomie}

6. Wat vond $U$ van de draagbaarheid van de user interface (bijv. vorm, positie en gewicht)? 
7. Wat vond u van de lichaamshouding? Kon u ontspannen staan?

\section{Sturen}

8. Is de bewegingsrichting van de camera logisch/intuïtief bij het sturen met de interface?

9. Is de interface geschikt voor kleine nauwkeurige verplaatsingen?

10. Is de interface geschikt voor grote snelle verplaatsingen?

11. Reageert de camera beweging voldoende snel op het sturen?

12. Geeft de opstelling voldoende informatie over de positie van de tip?

\section{Na testen van alle condities}

13. Rangschik de geteste gebruikersinterfaces naar gebruiksvriendelijkheid en licht toe?

14. Wat vind u van de systemen?

\section{B.3 Questionnaire experiment instrument manipulation module - novices}

Datum:

Naam:

Functie:

Leeftijd:

Geslacht:
\# Scopiën:

Links/rechtshandig:

Robotisch setup:

Onderzoeker:

Locatie:

1. Voor welke procedures is deze (robotische) opstelling geschikt?

2. Welke handelingen zijn het moeilijkst?

3. Heeft $\mathrm{u}$ altijd het gevoel in controle te zijn over de bewegingen?

4. Voldoende feedback ten aanzien van de positie van de endoscoop en de instrumenten?

5. Is de koppeling tussen user interface en bewegingsrichtingen endoscoop en instrumenten intuïtief?

6. Wat vond $U$ van de ergonomie van de pen van de joystick?

7. Wat vond u van de snelheid van bewegen van de endoscoop en de instrumenten?

8. Wat vond u van de nauwkeurigheid van de endoscoop en de instrumenten?

9. Wat vond u van de reactietijd van de endoscoop en de instrumenten?

10. a) Wat vond $u$ van het feit dat het camerabeeld meebeweegt met instrument / endoscoop verplaatsingen?

b) Wat vond u van het feit dat het camerabeeld (de endoscoop) soms stilstond en alleen de instrumenten bewegen?

11. Wat vond u van de werkhouding?

12. Wat vond $u$ van de positie van het beeldscherm?

13. Had $\mathrm{u}$ het gevoel dat instrumentmanipulatie een verlengstuk van de hand is?

14. Rangschik de geteste gebruikersinterfaces naar gebruiksvriendelijkheid en licht toe?

15. Heeft robotica toegevoegde waarde?

16. Heeft de geavanceerde endoscoop met stuurbare instrumenten meerwaarde? 


\section{B.4 Questionnaire experiment instrument manipulation module - experts}

Datum:

Naam:

Functie:

Leeftijd:

Geslacht:

Links/rechtshandig:
\# Jaren ervaring:

\# Scopiën / jaar:

Robotisch setup:

Onderzoeker:

Locatie:

1. Voor welke procedures is deze (robotische) opstelling geschikt? Waarom? Hoeveel van deze procedures worden er landelijk per jaar uitgevoerd?

2. Welke handelingen zijn het moeilijkst?

3. Heeft $\mathrm{u}$ altijd het gevoel in controle te zijn over de bewegingen?

4. Voldoende feedback ten aanzien van de positie van de endoscoop en de instrumenten?

5. Is de koppeling tussen user interface en bewegingsrichtingen endoscoop en instrumenten intuitief?

6. Wat vond U van de ergonomie van de pen van de joystick?

7. Wat vond u van de snelheid van bewegen van de endoscoop en de instrumenten?

8. Wat vond u van de nauwkeurigheid van de endoscoop en de instrumenten?

9. Wat vond u van de reactietijd van de endoscoop en de instrumenten?

10. a) Wat vond u van het feit dat het camerabeeld meebeweegt met instrument / endoscoop verplaatsingen?

b) Wat vond $u$ van het feit dat het camerabeeld (de endoscoop) soms stilstond en alleen de instrumenten bewegen?

11. Wat vond u van de werkhouding?

12. Wat vond $u$ van de positie van het beeldscherm?

13. Had $\mathrm{u}$ het gevoel dat instrumentmanipulatie een verlengstuk van de hand is?

14. Wat zijn de gebruiksbeperkingen van de robotische setup t.o.v. de conventionele setup?

15. Wat zijn eventuele risico's voor de patiënt?

16. Rangschik de geteste gebruikersinterfaces naar gebruiksvriendelijkheid en licht toe?

17. Heeft robotica toegevoegde waarde?

18. Heeft de geavanceerde endoscoop met stuurbare instrumenten meerwaarde? 



\section{About the author}

Jeroen Ruiter was born on November 24, 1974, in Enschede, The Netherlands. After completing his secondary education at De Bouwmeester in Haaksbergen in 1993, he started his study of Industrial Design Engineering at the Delft University of Technology. In 1998 he did his internship for six months at MMID in Delft and the same year he and two fellow students spent two months in a rural village in Sri Lanka to develop simple techniques for helping villagers produce bricks and roof tiles. In 2000 he graduated, having worked on a measurement chair that generates data for adapting wheelchairs to user specific anthropometrics. This graduation project took place at Idéon Twente in Oldenzaal where he was subsequently hired as industrial design engineer. In 2002 Idéon Twente was integrated as industrial design department within the Demcon group. Up until the end of 2008 he had been working full time as industrial design engineer at Demcon. In that year he accepted a part time position as $\mathrm{PhD}$ candidate within the TeleFLEX project at the department of Design, Production, and Management at the University of Twente, in cooperation with Demcon. His focus was on improving the usability of flexible endoscopes and instruments by implementing robotics. After receiving his doctorate, he continued working full time at Demcon. 
In flexible endoscopy a flexible tube with a steerable camera is used to inspect the internal patient tracts and to perform small surgical interventions. In current practice the physician is faced with usability problems. Often assistance is required to manipulate the flexible endoscope and the instruments. In addition, current attempts to perform more advanced therapeutic procedures by using steerable instruments are limited by the lack of availability of intuitive and user-friendly tools.

This thesis describes the development and evaluation of a robotic flexible endoscope that allows a single physician to perform diagnostic and therapeutic procedures in an intuitive and user-friendly way. The robotic modules interact with standard available endoscopy equipment and the setup can be customized to the clinical requirements of a specific procedure. The robotic flexible endoscope improves current practice and expands the clinical capabilities of flexible endoscopy.

ISBN 978-90-365-0291-7 